\title{
Emprego da Madeira do Gênero Pinus na Construção de Estruturas de Cobertura
}

\section{ROBERTO VASCONCELOS PINHEIRO}

Dissertação apresentada à Escola de Engenharia de São Carlos, da Universidade de São Paulo, como parte dos requisitos para obtenção do Título de Mestre em Engenharia de Estruturas.

ORIENTADOR: Prof. Titular Francisco A. Rocco Lahr 
Pinheiro, Roberto Vasconcelos

P722e Emprego da madeira do gênero Pinus na construção de estruturas de cobertura / Roberto Vasconcelos Pinheiro. -- São Carlos, 1996. $163 p$.

Dissertação (Mestrado) -- Escola de Engenharia de São CarlosUniversidade de São Paulo, 1996.

Orientador: Prof. Dr. Francisco A. Rocco Lahr

1. Estruturas de cobertura (Madeira). 2. Madeira de Pinus. I. Titulo. 
Aos meus pais Rubens e Neuza, que me ensinaram o que há de mais importante, os primeiros passos. 
Ao meu grande e único "AMOR", Ana Lúcia. 


\section{AGRADECIMENTOS}

Ao professor e amigo Francisco Antonio Rocco Lahr pelo companheirismo e compreensão desprendida durante todo o desenvolvimento deste trabalho.

Ao professor Carlito Calil Júnior pela colaboração profissional e amiga.

À amizade conquistada dos professores Márcio Corrêa e Márcio Ramalho.

Aos professores de maneira geral, que de alguma maneira contribuíram para o desenvolvimento deste trabalho.

Aos amigos Tarcísio, Lívio, Dino que efetivamente auxiliaram e contribuíram no desenvolvimento da pesquisa.

Aos demais amigos que puderam contribuir com a simpatia e generosidade.

Ao desenhista Roberto Galindo pela grande ajuda prestada.

Às secretárias Silvana e Tânia pela paciência e amizade.

A todos os funcionários e colegas do LaMEM pela colaboração direta e indireta, bem como a amizade e a agradável convivência.

À Fundação de Amparo à Pesquisa do Estado de São Paulo - FAPESP, pelo apoio financeiro sempre pontual, sem o qual, não seria possível desenvolver tal pesquisa. 


\section{SUMÁRIO}

LISTA DE FIGURAS

i

LISTA DE TABELAS

iii

LISTA DE ABREVIATURAS E SIGLAS

$\mathbf{v}$

LISTA DE SÍMBOLOS vi

RESUMO X

ABSTRACT

1 INTRODUÇÃO 1

1.1 Contextualização 1

$\begin{array}{ll}1.2 \text { Justificativa } & 2\end{array}$

1.3 Objetivo 3

2 REVISÃO BIBLIOGRÁFICA 4

2.1 Aspectos histórico do emprego das estruturas de madeira para cobertura 4

2.1.1 Introdução 4

2.1.2 Generalidades 5

2.1.3 Resumo histórico da aplicação da madeira em estruturas para cobertura em $\begin{array}{ll}\text { edificações } & 8\end{array}$

2.1.3.1 De 3000 a 500 a.C. no ocidente 8

2.1.3.2 De 1000 a 500 a.C. no oriente 9

$\begin{array}{ll}\text { 2.1.3.3 Arquitetura grega e romana } & 10\end{array}$

$\begin{array}{ll}\text { 2.1.3.4 Arquitetura a partir do século IV d.C. } & 12\end{array}$ 
2.1.4 O material madeira

2.2 Generalidades do gênero Pinus

2.2.1 Aspectos gerais a respeito do Gênero Pinus

2.2.2 Algumas considerações sobre espécies de Pinus crescidas no Estado de São Paulo

2.2.2.1 Pinus caribaea var. caribaea

2.2.2.2 Pinus caribaea var. bahamensis

2.2.2.3 Pinus caribaea var. hondurensis

2.2.2.4 Pinus oocarpa

2.2.2.5 Pinus taeda

2.2.2.6 Pinus elliottii

2.2.3 Propriedades Físicas, de Resistência e de Elasticidade de espécies de Pinus 24

2.2.3.1 Características Físicas

2.2.3.2 Características de Resistência e de Elasticidade

2.2.4 Durabilidade natural

2.3 Aspectos gerais da durabilidade natural da madeira e da demanda biológica 30

2.3.1 Introdução

2.3.2 Deterioração da madeira

2.3.2.1 Defeitos naturais

2.3.2.2 Agentes deterioradores

2.3.2.2.1 Agentes abióticos

2.3.2.2.2 Agentes bióticos

2.3.2.2.2.a Microorganismos

2.3.2.2.2.b Isóptera

2.3.2.2.2.c Coleóptera

2.3.3 Secagem da madeira

2.3.4 Preservação da madeira

2.3.4.1 Os tratamentos preservativos

2.3.4.1.1 Tratamento preventivo

2.3.4.1.1.a Processo à vácuo e pressão 
2.3.4.1.2 Tratamento curativo

2.3.4.2 Classificação dos preservativos 46

2.3.4.3 - Especificação do tratamento de uma estrutura 47

2.3.4.4 - Controle de qualidade do tratamento de uma estrutura 48

2.4 Classificação da Madeira 49

2.4.1 Introdução 49

2.5 Sistemas construtivos $\quad 52$

2.5.1 Introdução $\quad 52$

2.5.2 Sistema construtivo convencional (artesanal) 52

2.5.3 Sistema construtivo industrializado (pré-fabricação) 54

3 METODOLOGIA $\quad 58$

3.1 Introdução $\quad 58$

3.2 Dispositivos de ligação $\quad 61$

$\begin{array}{ll}3.2 .1 \text { Introdução } & 61\end{array}$

$\begin{array}{ll}\text { 3.2.2 Parafusos de aço } & 61\end{array}$

3.2.3 Chapas com dentes estampados (CDE) 61

3.3 Sistemas estruturais $\quad 62$

3.3.1 Estrutura secundária (terça): viga maciça $\quad 62$

3.3.2 Estrutura principal (treliça): viga treliçada 63

3.3.2.1 Treliça tipo "Howe" 64

3.3.2.2 Treliça tipo "Pratt" 65

3.3.2.3 Treliça tipo "Fink" 65

$\begin{array}{ll}\text { 3.3.3 Estrutura de Contraventamento } & 66\end{array}$

4 DIMENSIONAMENTO DOS ELEMENTOS ESTRUTURAIS 69

4.1 Introdução $\quad 69$

$\begin{array}{ll}4.2 \text { Estrutura secundária (terça) } & 71\end{array}$

$\begin{array}{ll}4.2 .1 \text { Introdução } & 71\end{array}$

4.2.2 Dimensionamento 72

$\begin{array}{ll}\text { 4.2.2.1 Cálculo das grandezas geométricas } & 73\end{array}$ 
4.2.2.2 Determinação das ações

$\begin{array}{ll}\text { 4.2.2.2.1 Permanente } & 74\end{array}$

4.2.2.2.2 Variável (acidental) 74

4.2.2.3 Verificação dos deslocamentos e cálculo dos esforços internos $\quad 74$

4.2.2.3.1 Verificação dos deslocamentos 76

4.2.2.3.2 Cálculo dos esforços Internos $\quad 77$

4.2.2.3.2.a Cálculo do momento fletor máximo 78

4.2.2.3.2.b Cálculo do esforço cortante máximo 79

$\begin{array}{ll}\text { 4.2.2.4 Cálculo das tensões } & 79\end{array}$

4.2.2.4.1 Tensão Normal $\quad 79$

4.2.2.4.2 Tensão tangencial $\quad 80$

$\begin{array}{ll}\text { 4.2.2.5 Verificação da estabilidade lateral } & 81\end{array}$

4.3 Estrutura principal (treliça) 82

4.3.1 Ações, carregamentos e esforços internos $\quad 82$

4.3.1.1 Ação variável $\quad 82$

4.3.1.1.1 Vento $\quad 82$

4.3.1.2 Ação permanente $\quad 84$

4.3.1.2.1 Estrutural $\quad 84$

4.3.1.2.2 Não-estrutural $\quad 84$

$\begin{array}{ll}\text { 4.3.2 Dimensionamento } & 87\end{array}$

4.3.2.1 Cálculo das grandezas geométricas $\quad 88$

4.3.2.1.1 Referentes ao banzo superior e inferior $\quad 88$

4.3.2.1.2 Referentes às diagonais $\quad 88$

4.3.2.1.3 Referentes ao montante central $\quad 89$

4.3.2.1.4 Referentes aos demais montantes $\quad 89$

4.3.2.2 Verificação das tensões normais $\quad 89$

4.3.2.2.1 Tração paralela às fibras 90

4.3.2.2.1.a Verificação para o banzo inferior 90

4.3.2.2.1.b Verificação para o banzo superior 90

4.3.2.2.1.c Verificação para as diagonais 91

4.3.2.2.1.d Verificação para o montante central 91 
4.3.2.2.1.e Verificação para os demais montantes

4.3.2.2.2 Compressão paralela às fibras e estabilidade local 91

4.3.2.2.2.a Verificação para o banzo superior 91

4.3.2.2.2.b Verificação para o banzo inferior 93

4.3.2.2.2.c Verificação para as diagonais 94

4.3.2.2.2.d Verificação para o montante central 94

4.3.2.2.2.e Verificação para os demais montantes 96

4.3.2.3 Estabilidade global 96

4.3.2.4 Verificação do deslocamento 97

4.3.2.5 Dimensionamento das ligações 97

4.3.2.5.1 Resistência de cálculo de um pino 97

4.3.2.5.1.a Embutimento na madeira 97

4.3.2.5.1.b Flexão no pino 98

4.3.2.5.2 Cálculo do número de parafusos 99

4.3.2.5.2. a Ligação entre banzo superior e inferior 99

4.3.2.5.2.b Ligação do nó central (banzo inferior) 100

4.3.2.5.2.c Ligação do montante e diagonal com o banzo inferior 101

4.3.2.5.2.d Ligação do montante e diagonal com o banzo superior 102

4.3.2.5.2.e Ligação do nó central (banzo superior) 103

$\begin{array}{ll}4.3 .2 .5 .2 . f \text { Emendas } & 105\end{array}$

$\begin{array}{ll}\text { 4.3.2.5.3 Espaçamentos dos parafusos } & 106\end{array}$

5 RESULTADOS E DISCUSSÕES 108

5.1 Dimensões finais das estruturas principais (treliças) 108

5.2 Dimensões finais das estruturas de contraventamento e de travamento 108

5.3 Dimensões finais das estruturas secundárias (terças) 108

$\begin{array}{ll}5.4 \text { Consumo final de material } & 111\end{array}$

5.4.1 Consumo de material das estruturas principais e secundárias. 112

5.4.2 Consumo de material das estruturas de contraventamento e de travamento 125

5.5 Relação entre o peso próprio de parafusos e o peso total da estrutura $\quad 129$ 
6 CONCLUSÕES E SUGESTÕES

ANEXO "A"

REFERÊNCIAS BIBLIOGRÁFICA

OBRAS CONSULTADAS 


\section{LISTA DE FIGURAS}

Figura 1 - Habitação com cobertura em troncos de madeira ................................... 08

Figura 2 - Habitação com cobertura em pranchas de madeira ................................ 09

Figura 3 - Habitações com coberturas côncavas....................................................... 09

Figura 4 - Seções transversais compostas de madeira......................................... 10

Figura 5 - Estrutura de cobertura com barras encaixadas ...................................... 11

Figura 6 - Estrutura de cobertura com barras inclinadas........................................ 11

Figura 7 - Estrutura de cobertura posterior ao século IV d.C................................ 12

Figura 8 - Esquema geral da estrutura de contraventamento do banzo inferior ....... 67

Figura 9 - Esquema geral da estrutura de contraventamento do banzo superior....... 68

Figura 10- Esquema da elevação da edificação...................................................... 70

Figura 11 - Esquema da planta da edificação........................................................... 70

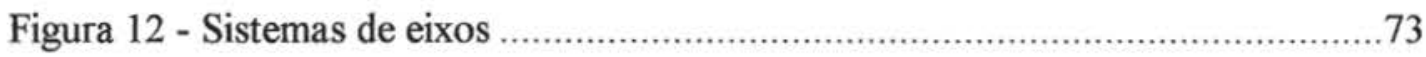

Figura 13 - Vão teórico em relação ao eixo " $z$ " ........................................................73

Figura 14- Vão teórico em relação ao eixo "y"

Figura 15 - Esquema estático e diagrama de momento fletor em relação ao eixo "z" 78

Figura 16- Esquema estático e diagrama de momento fletor em relação ao eixo "y"..78

Figura 17 - Esquema estático e diag. de esforço cortante em relação ao eixo “z"..... 79

Figura 18 - Seção transversal das barras do banzo superior e inferior........................87

Figura 19 - Seção transversal das barras das diagonais .............................................87

Figura 20 - Seção transversal da barra do montante central................................. 87

Figura 21 - Seção transversal das barras dos demais montantes............................. 88

Figura 22 - Elevação da estrutura principal (treliça) ............................................. 88

Figura 23- Consumo de madeira x Área coberta (Telha de Fibro-cimento)............ 114 
Figura 24 - Consumo de madeira x Área coberta (Telha de Aço). 117

Figura 25 - Consumo de parafuso x Volume de madeira (Telha de Fibro-cimento..120

Figura 26 - Consumo de parafuso x Volume de madeira (Telha de Aço). 122

Figura 27 - Consumo de CDE x Volume de madeira. 125 


\section{LISTA DE TABELAS}

Tabela 1 - Classificação das madeiras segundo sua durabilidade natural................ 29

Tabela 2 - Resistência natural e permeabilidade em espécies de Pinus..................... 29

Tabela 3 - Teor de umidade final recomendado para certos produtos de madeira..... 39

Tabela 4 - Esforços internos - dimensionamento dos elementos estruturais............... 89

Tabela 5 - Esforços internos - dimensionamento dps parafusos.............................. 99

Tabela A1 - MTA - Estrutura tipo "Howe" - parafusos passantes......................... 113

Tabela A2 - MTA - Estrutura tipo "Fink" - parafusos passantes.......................... 113

Tabela A3 - MTA - Estrutura tipo "Fink" - CDE .............................................. 113

Tabela A4 - MTA - Estrutura tipo "Pratt" - CDE …....................................... 114

Tabela A5 - MEL - Estrutura tipo "Howe" - parafusos passantes...................... 114

Tabela A6 - MEL - Estrutura tipo "Fink" - parafusos passantes........................ 114

Tabela A7 - MTA - Estrutura tipo "Howe" - parafusos passantes.......................... 116

Tabela A8 - MTA - Estrutura tipo "Fink” -parafusos passantes............................ 116

Tabela A9 - MTA - Estrutura tipo "Fink” - CDE ................................................ 116

Tabela A10 - MTA - Estrutura tipo "Pratt" - CDE ........................................... 117

Tabela A11 - MEL - Estrutura tipo "Howe" - parafusos passantes...................... 117

Tabela A12 - MEL - Estrutura tipo "Fink” - parafusos passantes...................... 117

Tabela B1- MTA - Estrutura tipo "Howe"........................................................... 119

Tabela B2- MTA - Estrutura tipo "Fink" .......................................................... 119

Tabela B3 - MEL - Estrutura tipo "Howe" ....................................................... 119

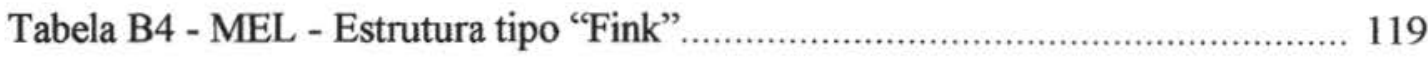

Tabela B5 - MTA - Estrutura tipo "Howe" ................................................... 121

Tabela B6 - MTA - Estrutura tipo "Fink" .................................................. 121 
Tabela B7 - MEL - Estrutura tipo ‘Howe …................................................ 122

Tabela B8 - MEL - Estrutura tipo "Fink".................................................... 122

Tabela C1 - MTA - Estrutura tipo "Fink", telha de fibro-cimento........................ 124

Tabela C2 - MTA - Estrutura tipo "Pratt", telha de fibro-cimento......................... 124

Tabela C3 - MTA - Estrutura tipo "Fink", telha de aço ..................................... 124

Tabela C4 - Estrutura tipo "Pratt", telha de aço................................................ 124

Tabela D1 - MTA - Estrutura tipo "Howe" - Parafusos passantes ...................... 125

Tabela D2 - MTA - Estrutura tipo "Fink” - Parafusos passantes........................... 126

Tabela D3 - MTA - Estrutura tipo "Fink" - CDE ............................................... 126

Tabela D4 - MTA - Estrutura tipo "Pratt" - CDE.............................................. 126

Tabela D5 - MEL - Estrutura tipo "Howe" - Parafusos passantes.......................... 126

Tabela D6 - MEL - Estrutura tipo "Fink" - Parafusos passantes....................... 127

Tabela D7 - MTA - Estrutura tipo "Howe" - Parafusos passantes....................... 127

Tabela D8 - MTA - Estrutura tipo "Fink" - Parafusos passantes........................... 127

Tabela D9 - MTA - Estrutura tipo "Fink" - CDE ............................................ 127

Tabela D10 - MTA - Estrutura tipo "Pratt" - CDE ................................................ 128

Tabela D11 - MEL - Estrutura tipo "Howe" - Parafusos passantes....................... 128

Tabela D12 - MEL - Estrutura tipo "Fink" - Parafusos passantes......................... 128

Tabela 6 - MEL - Estrutura tipo "Howe", telha de fibro-cimento .......................... 129

Tabela 7 - MEL - Estrutura tipo "Fink", telha de fibro-cimento............................ 129

Tabela 8 - MEL - Estrutura tipo "Howe", telha de aço........................................... 130

Tabela 9 - MEL - Estrutura tipo "Fink", telha de aço......................................... 130 


\section{LISTA DE ABREVIATURAS E SIGLAS}

CDE - Chapas com Dentes Estampados

MEL - Método dos Estados Limites

MTA - Método das Tensões Admissíveis

NBR 7190/82 - "Cálculo e Execução de Estruturas de Madeira"

NBR 6120/82 - "Cargas para o Cálculo de Estruturas de Edificações"

NBR 8681/84 "Ações e Segurança nas Estruturas"

NBR 8800/86 - "Projeto e Execução de Estruturas de Aço de Edificios"

NBR 6123/88 - "Forças Devidas ao Vento em Edificações".

NBR 7190/96 - "Projetos de Estruturas de Madeira"

SAP90 - Software Structural Analysis Program by Finite Element 


\section{LISTA DE SÍMBOLOS}

$a_{1} \quad$ - definido conforme Ítem 6.8.2 - PNBR 7190/96, cm

A - área da seção transversal da peça de madeira, $\mathrm{cm}^{2}$

$\mathrm{A}_{1} \quad$ - área da seção transversal da peça de madeira, (definido conforme Ítem 6.8.2 - PNBR 7190/96), $\mathrm{cm}^{2}$

$\mathrm{A}^{\mathrm{inf} .} \quad$ - área de influência da ação do vento, $\mathrm{m}^{2}$

$\mathrm{A}^{\text {útil. }} \quad$ - área útil da seção transversal da peça de madeira, $\mathrm{cm}^{2}$

b - largura, cm

B $\quad$ - definido conforme Ítem 7.3.4 - PNBR 7190/96

$\beta_{\lim } \quad$ - definido conforme Ítem 7.3.4 - PNBR 7190/96

$\beta_{\mathrm{M}} \quad$ - coeficiente de correção

$\mathrm{C}_{\mathrm{p}}$ - coeficiente de pressão

d - diâmeto do pino metálico, $\mathrm{cm}$

$\mathrm{e}_{\mathrm{a}} \quad$ - excentricidade acidental, $\mathrm{cm}$

$\mathrm{e}_{\mathrm{c}} \quad$ - excentricidade suplementar de $1^{\mathrm{a}}$ ordem, $\mathrm{cm}$

$\mathrm{e}_{\mathrm{i}} \quad$ - excentricidade de $1^{\mathrm{a}}$ ordem, $\mathrm{cm}$

$\mathrm{e}_{1} \quad$ - soma entre " $\mathrm{e}_{\mathrm{a}}$ " $\mathrm{e}$ " $\mathrm{e}_{\mathrm{i}}$ ", cm

$\mathrm{e}_{1, \mathrm{ef}} \quad$ - excentricidade efetiva de $1^{\mathrm{a}}$ ordem, $\mathrm{cm}$

$\mathrm{e}_{\mathrm{d}} \quad$ - excentricidade de cálculo, $\mathrm{cm}$

$\mathrm{E}_{\mathrm{c} 0, \mathrm{~m}}$ - valor médio do módulo de elasticidade na compressão paralela às fibras, $\mathrm{daN} / \mathrm{cm}^{2}$

$\mathrm{E}_{\mathrm{c} 0 \text {,ef }}$ - valor efetivo do módulo de elasticidade na compressão paralela às fibras, $\mathrm{daN} / \mathrm{cm}^{2}$

F - força estática devida ao vento, daN

$\mathrm{F}_{\mathrm{E}} \quad$ - força de Euler, daN

$\mathrm{F}_{\mathrm{td}} \quad$ - valor de cálculo da força máxima de tração, daN

$\mathrm{f}_{\mathrm{c} 0 \mathrm{~d}, \mathrm{~d}} \quad$ - valor de cálculo da resistência ao embutimento paralelo às fibras, daN $/ \mathrm{cm}^{2}$

$\mathrm{f}_{\mathrm{e} 90, \mathrm{~d}}$. - valor de cálculo da resistência ao embutimento nnormal às fibras, daN $/ \mathrm{cm}^{2}$

$\mathrm{f}_{\mathrm{c} 0, \mathrm{~d}}$ - valor de cálculo da resistência à compressão paralela às fibras, daN/cm² 
$\mathrm{f}_{\mathrm{t} 0 \mathrm{~d} \text {. }} \quad$ - valor de cálculo da resistência à tração paralela às fibras, daN $/ \mathrm{cm}^{2}$

$\mathrm{f}_{\mathrm{v} 0, \mathrm{~d} \text {. }} \quad$ - valor de cálculo da resistência ao cisalhamento paralelo às fibras, daN $/ \mathrm{cm}^{2}$

$\mathrm{f}_{\mathrm{yd} \text {. }} \quad$ - valor de cálculo da resistência de escoamento do aço, daN $/ \mathrm{cm}^{2}$

$f_{\text {yk. }} \quad$ - valor da resistência nominal característica de escoamento do aço, daN $/ \mathrm{cm}^{2}$

$\mathrm{f}_{\mathrm{wd}}$. - valor de cálculo da resistência da madeira, daN $/ \mathrm{cm}^{2}$

$\phi \quad$-coeficiente de fluência

g - peso próprio da terça, daN/m

$\mathrm{g}_{\mathrm{t}} \quad$ - carga permanente distribuída da telha(peso específico), daN $/ \mathrm{m}^{2}$

$\mathrm{g}_{\mathrm{c}}$ - carga permanente distribuída do sistema de contraventamento (peso específico), $\mathrm{daN} / \mathrm{m}^{2}$

$\gamma_{\mathrm{G}} \quad$ - coeficiente de ponderação das ações permanentes (Estado Limite Último)

$\gamma_{\mathrm{Q}} \quad$ - coeficiente de ponderação das ações variáveis (Estado Limite Último)

$\gamma_{\mathrm{f}} \quad$ - coeficiente de ponderação das ações variáveis (Estado Limite de Utilização)

$\gamma_{\mathrm{s}} \quad$ - coeficiente de ponderação da resistência de escoamento do aço

$\gamma_{\mathrm{wt}} \quad$ - coeficiente de ponderação da resistência à tração paralela às fibras(Estado Limite Último)

$\gamma_{\mathrm{wc}} \quad$ - coeficiente de ponderação da resistência à compressão paralela às fibras (Estado Limite Último)

$\gamma_{\mathrm{m}}$ - coeficiente de ponderação da resistência ao cisalhamento paralela às fibras (Estado Limite Último)

$\gamma_{\mathrm{w}}$ - coeficiente de ponderação das resistências (Estado Limite de Utilização)

$\mathrm{i}_{\min }$ - raio de giração mínimo, $\mathrm{cm}$

h - altura, cm

$\mathrm{I}_{2}$ - momento de inércia (definido conforme Ítem 6.8.2 - PNBR 7190/96), $\mathrm{cm}^{4}$

Iy - momento de inércia em relação ao eixo " $y$ ", $\mathrm{cm}^{4}$

$I_{y, \text { ef }}$ - momento de inércia (definido conforme Ítem 6.8.2 - PNBR 7190/96), $\mathrm{cm}^{4}$

$\mathrm{I}_{\mathrm{z}} \quad$ - momento de inércia em relação ao eixo " $\mathrm{z}$ ", $\mathrm{cm}^{4}$

$\mathrm{K}_{\bmod }$ - coeficiente de modificação total

$\mathrm{K}_{\text {modi }}$ - coeficiente de modificação parcial

$\mathrm{K}_{\mathrm{M}}$ - coeficiente de correção

L - vão, cm 
$\mathrm{L}_{0} \quad$ - comprimento teórico de referência, $\mathrm{cm}$

$\mathrm{L}_{1}$ - vão entre espaçadores, $\mathrm{cm}$

$\lambda \quad$ - índice de esbeltez

$\mathrm{M}_{\mathrm{y}, \mathrm{d}}$ - valor de cálculo do momento máximo de flexão em relação ao eixo "y", $\mathrm{daN}^{*} \mathrm{~cm}$

$\mathrm{M}_{\mathrm{z}, \mathrm{d}}$ - valor de cálculo do momento máximo de flexão em relação ao eixo " $\mathrm{z}$ ", $\mathrm{daN} * \mathrm{~cm}$

$\mathrm{M}_{\mathrm{d}} \quad$ - valor de cálculo do momento fletor devido a excentricidade " $\mathrm{e}_{\mathrm{d}}$ ", daN* $\mathrm{cm}$

$\mathrm{M}_{1 \mathrm{~d}}$ - valor de cálculo do momento fletor na excentricidade do elemento estrutural da treliça, daN*cm

$\mathrm{N}_{\mathrm{d}} \quad$ - valor de cálculo da força normal de compressão, daN

$\mathrm{N}_{\mathrm{gk}}$ - valor característico da força normal de compressão devido às ações permanentes, daN

$\mathrm{N}_{\mathrm{p}}$ - número de parafusos

$\mathrm{N}_{\mathrm{qk}}$ - valor característico da força normal de compressão devido às ações variáveis, $\mathrm{daN}$

n - definido conforme Ítem 6.8.2 - PNBR 7190/96

$\Psi_{0}$ - fator de combinação (Estado Limite Último)

$\Psi_{1}$ - fator de utilização (Estado Limite de Utilização)

$\Psi_{2}$ - fator de utilização (Estado Limite de Utilização)

$\mathrm{P}_{\mathrm{e}} \quad$ - pressão estática devida à ação permanente estrutural, daN $/ \mathrm{m}^{2}$

$\mathrm{P}_{\mathrm{ne}} \quad$ - pressão estática devida à ação permanente não-estrutural, daN $/ \mathrm{m}^{2}$

$\mathrm{P}_{\mathrm{p}}$ - pressão estática devida à ação permanente total, daN $/ \mathrm{m}^{2}$

$\mathrm{P}_{\mathrm{v}} \quad$ - pressão estática devida ao vento, $\mathrm{daN} / \mathrm{m}^{2}$

q - pressão dinâmica devida ao vento, daN $/ \mathrm{m}^{2}$

Q - ação acidental (variável), daN

$\mathbf{R}_{\mathrm{vd}, 1}$ - valor de cálculo da resistência de um pino metálico, referente a uma seção de corte, daN

$\sigma_{\mathrm{cd}}$ - valor de cálculo da tensão normal máxima na compressão paralela às fibras, $\mathrm{daN} / \mathrm{cm}^{2}$ 
$\sigma_{\mathrm{cld}} \quad$ - valor de cálculo da tensão máxima de flexão na borda mais comprimida, em relação ao eixo " $y$ ", daN/ $\mathrm{cm}^{2}$

$\sigma_{\mathrm{My}, \mathrm{d}}^{\text {máx. }}$ - valor de cálculo da tensão máxima de flexão, em relação ao eixo "y", $\mathrm{daN} / \mathrm{cm}^{2}$

$\sigma_{\mathrm{Mz}, \mathrm{d}}{ }^{\text {máx. }}$ - valor de cálculo da tensão máxima de flexão, em relação ao eixo " $\mathrm{z}$ ", $\mathrm{daN} / \mathrm{cm}^{2}$

$\sigma_{\text {nd }}$ - valor de cálculo da tensão de compressão devida a força de compressão paralela às fibras, daN $/ \mathrm{cm}^{2}$

$\sigma_{\mathrm{Md}}$ - valor de cálculo da tensão de compressão devida ao momento fletor " $\mathrm{M}_{\mathrm{d}}$ ", $\mathrm{daN} / \mathrm{cm}^{2}$

$\sigma_{\mathrm{td}} \quad$ - valor de cálculo da tensão normal máxima na tração paralela às fibras, $\mathrm{daN} / \mathrm{cm}^{2}$

$\theta \quad$ - ângulo entre barras da treliça, graus

$\mathrm{t}$ - espessura convencional da madeira, $\mathrm{cm}$

$\tau_{\mathrm{d}} \quad$ - valor de cálculo da tensão máxima de cisalhamento, daN $/ \mathrm{cm}^{2}$

$\mathrm{V}_{\mathrm{zd}}$ - valor de cálculo do esforço cortante máximo em relação ao eixo " $\mathrm{z}$ ", daN

$\mathrm{v}_{\mathrm{y}}$ uti - flecha máxima atuante em relação ao eixo " $\mathrm{y}$ ", $\mathrm{cm}$

$\mathrm{v}_{\mathrm{z}}{ }^{\text {uti }}$ - flecha máxima atuante em relação ao eixo " $\mathrm{z}$ ", $\mathrm{cm}$

$\mathrm{v}_{\mathbf{y}}{ }^{\text {lim }}$ - flecha máxima permitida em relação ao eixo " $\mathrm{y}$ ", $\mathrm{cm}$

$v_{z}{ }^{\lim }$ - flecha máxima permitida em relação ao eixo " $\mathrm{z}$ ", $\mathrm{cm}$ 


\section{RESUMO}

PINHEIRO, R. V. Emprego da madeira do gênero Pinus na construção de estruturas de cobertura. São Carlos, 1996. 163p. Dissertação (Mestrado) - Escola de Engenharia de São Carlos, Universidade de São Paulo.

A redução e escassez das matas nativas nas regiões Sul/Sudeste se deu principalmente em virtude da contínua e descontrolada exploração das mesmas. Em vista disto e do incentivo fiscal, houve o aparecimento de grandes áreas de reflorestamento. Diante das circunstâncias, tomaram-se algumas espécies de Pinus como fonte alternativa para a obtenção de peças estruturais de madeira, com a recomendação do tratamento adequado para a preservação e classificação. $\mathrm{O}$ trabalho em questão tem como objetivo principal evidenciar a viabilidade técnica do emprego da madeira de Pinus na construção de estruturas treliçadas para cobertura. Como produto final da pesquisa, determinou-se também o consumo de madeira por metro quadrado de área coberta e o consumo de dispositivos de ligação. A utilização da madeira serrada de Pinus na construção civil, uma vez demonstrada sua viabilidade técnica, deverá se constituir em importante alternativa, considerando a implantação, a exploração e a possibilidade de manejo sustentados destas florestas artificiais, mantendo equilibrada a capacidade de oferta que, aliada à proximidade dos grandes centros consumidores, conduz a um custo final mais acessível. Finalmente, a plena utilização das florestas artificiais promove a desejada diminuição da pressão sobre as florestas nativas brasileiras.

Palavras-chaves : Madeira, Pinus, Estruturas de Cobertura 


\section{ABSTRACT}

PINHEIRO, R. V. Using Pinus timber in construction roof structures. São Carlos, 1996. 163p. Dissertação (Mestrado) - Escola de Engenharia de São Carlos, Universidade de São Paulo.

The reduction and shortage of natives forests in south and south-east regions in Brasil happened specially because their continuous and incontrolled exploration. This fact and the governamental incentives provided large areas of planted forest. So, several Pinus species were taken as alternatives source for obtaining wooden structural pieces previously classified and preserved against biological attack. This work aims to demonstrate the technical viability of using Pinus timber in trussed roof structures. As final conclusion of the work, comparative tables related to wood comsuption per unit covered area and the joints comsuption are presented. The utilization of Pinus lumber in civil construction, demonstrated its technical and viability, will constitute na expressive alternative, taking in account the implantation, the exploration of these planted forest. So, it will keep equilibrated the wood deal that, in addition to the short distance related to the consumer centers, will conduct to a accessible final cost. At last, the full utilization of the planted forest permits desinable reduction of the extensive exploration of the brazilian native forests.

Key-words: Wood, Pinus, Roof Structures. 


\section{INTRODUÇÃO}

\subsection{Contextualização}

$\mathrm{O}$ atendimento dos requisitos do mercado de madeira serrada destinadas à construção de estruturas, principalmente nas regiões Sul e Sudeste do Brasil, dado ao extrativismo contínuo e descontrolado das suas florestas nativas, tem sido através do fornecimento de matéria-prima proveniente das florestas localizadas nas regiões Centro-Oeste e Norte do país. Entretanto, aspectos técnicos e econômicos relacionados à exploração e ao transporte, fazem com que a madeira acabe chegando aos grandes centros consumidores a um elevado custo final.

Diante destas dificuldades, como fonte alternativa para obtenção de madeira serrada, têm sido consideradas as florestas artificiais (não nativas) plantadas em áreas de significativa extensão, em especial no próprio Estado de São Paulo. Tratam-se de florestas de Eucalipto e de Pinus. Gradativamente, observa-se o crescimento do emprego estrutural de peças de madeira serrada provenientes das áreas de reflorestamento, principalmente nos cimbramentos de edificios de concreto armado.

Mesmo assim, deve ser reconhecido que a utilização da madeira de Pinus na construção de estruturas ainda é percentualmente pequena, e vem sendo limitada em parte pela resistência do mercado consumidor, às vezes exageradamente conservador e refratário a novos materiais, e pela carência de informações tecnológicas provenientes de pesquisas adequadamente conduzidas, que incentive o uso para a finalidade mencionada. 
Neste contexto é feita a presente proposta de trabalho, com vistas à geração de informações que possam dar suporte para a difusão do emprego da madeira do gênero Pinus na construção de estruturas de cobertura.

\subsection{Justificativa}

As florestas artificiais de Pinus têm sido fornecedoras de matérias-primas para o atendimento de diversas necessidades. Podem ser citadas a fabricação de diferentes tipos de resinas e de produtos delas derivados, a produção de celulose de fibra longa e de papel, desde algum tempo consagradas. Mais recentemente, mencionam-se a indústria moveleira para abastecimento interno e para exportação, a produção de variados tipos de chapas aglomeradas, compensadas, sarrafeadas, laminado-colado, entre outras. Constantemente aumenta o número de alternativas para utilização da matéria-prima oriunda dos reflorestamentos. Com a necessidade de crescimento e desenvolvimento do país, o mesmo vem ocorrendo com relação à construção civil.

Há um certo consenso entre os pesquisadores ligados à engenharia florestal que, na produção de celulose, pasta e chapa de madeira aglomerada, devem ser aproveitados os resíduos das serrarias, das laminadoras e dos desbastes florestais, em geral com diâmetro reduzido. Desta forma, as madeiras com melhores propriedades intrínsicas (físico-mecânicas) seriam utilizadas na construção civil e, dentro dela, na construção de estruturas. Esta posição é perfeitamente compatível com idéia de uso múltiplo dos produtos florestais, garantindo maior rentabilidade através da adoção de técnicas silviculturais e de manejo adequado.

A utilização da madeira serrada de Pinus na construção de estruturas e, mais especificamente, na construção de coberturas, uma vez demonstrada sua viabilidade técnica, deverá se constituir em importante alternativa, considerando a economicidade dos custos de implantação, exploração e a possibilidade de manejo sustentados destas florestas artificiais, mantendo equilibrada a capacidade de oferta que, aliada à 
proximidade dos grandes centros consumidores, conduz a um custo final mais acessível.

Finalmente, a plena utilização das florestas artificiais promove a desejada diminuição da pressão sobre as florestas nativas brasileiras.

\subsection{Objetivo}

O desenvolvimento das atividades de pesquisa constantes deste plano tem como objetivo primordial evidenciar a viabilidade técnica de se empregar a madeira de Pinus na construção de estruturas de cobertura com vão livre entre seis e doze metros, considerando-se geometrias consagradas no meio técnico, como por exemplo, treliças de duas águas tipo "Howe", "Pratt" e "Fink".

Entre os sub-produtos da pesquisa, podem ser mencionados a determinação do consumo de madeira por metro quadrado de área coberta em diferentes condições de projetos (tipo de telha, tipo de dispositivo de ligação entre peças estruturais, forma geométrica, etc), a avaliação de espaçamentos entre estruturas sob a citadas condições e o consumo de dispositivo de ligação entre peças estruturais. 


\section{REVISÃo BIBLIOGRÁFICA}

\subsection{Aspectos históricos do emprego das estruturas de madeira para cobertura}

\subsubsection{Introdução}

Ao longo do desenvolvimento histórico, foi constatado que a madeira, por ser um recurso natural, sempre esteve presente no cotidiano do ser humano, tornando-se um material pioneiro na engenharia estrutural. A diversidade de suas características possibilita o seu emprego para as mais distintas finalidades, tais como estruturas (pontes, cimbramentos, coberturas, silos), móveis, brinquedos, pisos e lambris, instrumentos musicais, embalagens (caixas), implementos agrícolas, divisórias, produção de papel, chapas (compensado e aglomerado) e outros. Todavia, a tecnologia da utilização da madeira atinge os mais variados níveis de desenvolvimento, tendo como bom exemplo, as indústrias de chapas (aglomeradas e compensadas). Em contrapartida, há enormes deficiências nos setores relacionados com a construção civil, principalmente, no que diz respeito à utilização da madeira como elemento estrutural.

A respeito da madeira voltada ao uso em estrutura de cobertura, pode-se dizer que, dentre todos os sistemas estruturais, as vigas treliçadas são as mais difundidas e utilizadas.

Evidentemente, este fato está relacionado com os aspectos históricos, onde, toda a tradição do emprego da madeira se reflete em inúmeros tópicos, isto é, das 
formas geométricas até as técnicas construtivas comumente adotadas pelos carpinteiros (artesões). Além disto, não se pode ignorar que ainda falta muito para se alcançar o pleno conhecimento do comportamento e das características intrínsicas do material.

Com base nos problemas até aqui abordados, parece oportuna a realização de um resumo histórico do emprego da madeira em estruturas de cobertura, para que, desta forma, se possa ter um efetivo apoio bibliográfico e, conseqüentemente, registrar elementos que contribuam com a realização do trabalho.

\subsubsection{Generalidades}

Desde as mais remotas civilizações e, ao decorrer milhares de anos, o ser humano vem gradativamente desenvolvendo formas de suprir suas próprias necessidades e, com isto, melhorando as condições de sua existência. Diante destas preocupações e necessidades a serem ultrapassadas, a mais importante a ser vencida, seria conseguir para si mesmo e para sua família, um ambiente onde pudesse ter resguardo dos agentes da natureza, proteção das intempéries, além de abrigo contra possíveis inimigos, para exercer suas atividades com tranqüilidade.

Esta iniciativa levou ao surgimento das primeiras edificações, construídas com os materiais então disponíveis, ou seja, a pedra, a argila e a madeira. De início, as edificações propriamente ditas eram constituídas de pedra e argila, ficando a madeira destinada à construção de paliçadas, elementos de defesa e, posteriormente, das aldeias.

Com o passar do tempo, surgiram novas aplicações para os materiais existentes, bem como, a descoberta de novos materiais. A priori, estas descobertas estavam voltadas para a melhoria das habitações. Depois, houve a necessidade de se preocupar com a edificação em si, isto é, com a estrutura e sua durabilidade. 
Ao mesmo tempo, foi necessário se pensar em um melhor aproveitamento dos espaços, ou seja, otimizar as formas e os contornos, criando estilos e padrões. Isto propiciou o surgimento de edificações mais amplas, mais altas e esbeltas.

$\mathrm{Da}$ interação Engenharia-Arquitetura, os problemas da construção de edificações em geral foram analisados e resolvidos, para isso, estão sendo utilizados materiais de melhor qualidade, configurações estético-funcionais mais desenvolvidas e técnicas construtivas sempre mais aperfeiçoadas.

Em resumo, nas edificações de um modo em geral, a importância de cada um dos elementos arquitetônicos e estruturais envolvidos é significativa, pois a construção deve se apresentar como um todo, completo e homogêneo em si mesmo. Para se alcançar esta homogeneidade, cada elemento deve ser cuidadosamente projetado e construído, sob todos os pontos de vista.

$\mathrm{Na}$ atualidade, os critérios de utilização das estruturas de madeira estão passando por um intenso processo de reformulação, objetivando o resgate de sua importância no contexto da Engenharia. Dentre tantas peculiaridade, pode-se salientar que a madeira é o único material estrutural renovável e cuja produção requer baixo consumo energético.

Segundo FUSCO (1989), a previsível crise energética do século XXI certamente levará ao emprego intensivo das estruturas de madeira. Desta forma, é conveniente se fazerem algumas comparações entre a madeira e os demais materiais comumente empregados na construção civil, ou seja, o concreto armado e o aço.

De acordo com o mesmo autor, pode-se citar algumas vantagens da madeira:

$\Rightarrow$ geralmente, como material estrutural, as madeiras consideradas "duras" têm resistências superiores e rigidez equivalentes a um bom concreto;

$\Rightarrow$ a massa específica aparente da madeira é equivalente a aproximadamente 1/3 em relação ao concreto e 1/8 se comparado com o aço; 
$\Rightarrow$ ainda como material construtivo, a usinagem da madeira é mais simples, por esta razão, os investimentos industriais necessários e a mão-de-obra a ser empregada são menos onerosos.

O mesmo autor, sugere algumas desvantagens da madeira:

$\Rightarrow$ a heterogeneidade deste material pode variar de árvore a árvore em uma mesma espécie e, até mesmo dentro da mesma árvore, sendo este um fenômeno natural inerente ao material;

$\Rightarrow$ a anisotropia da madeira, dada origem biológica, faz com que suas características mecânicas e elásticas sejam distintas em relação às três direções principais;

$\Rightarrow$ este material pode sofrer variações de suas características causadas por defeitos naturais devidos ao crescimento, como por exemplo, regiões cristalinas e amorfas, madeira de reação, nós, bolsões de resinas, etc.;

$\Rightarrow$ a natureza biológica da madeira torna-a susceptível a ataques de organismos xilófagos, tais como microorganismos (principalmente os fungos apodrecedores), insetos (principalmente os cupins). Contra a demanda biológica, geralmente adotam-se a preservação e a secagem como métodos preventivos, tornando as estruturas de madeira tão duráveis quanto as de concreto e de aço.

Desta forma, observa-se que, ao ser estudada e adequadamente empregada, poderá conduzi-la a um emprego racionalizado e, conseqüentemente, obter-se-á um melhor desempenho do material. 


\subsubsection{Resumo histórico da aplicação da madeira em estruturas para coberturas em edificações}

ROCCO LAHR (1983) apresenta um breve histórico referente à utilização da madeira em estruturas de cobertura, considerando habitações, edificios voltadas à práticas esportivas, reuniões sociais, entre outras.

\subsubsection{De 3000 a 500 a.C. no ocidente}

No período neolítico, verificou-se amplo uso da madeira e argila, materiais de fácil trabalhabilidade. Por volta do ano 3000 a.C., os egípcios já usavam a madeira em estruturas treliçadas, fazendo a sustentação de palafitas às margens do Rio Nilo. Além disto usavam as pedras como elementos de fundação e a argila como parede, na função de vedar. Com o passar do tempo, a madeira - na forma de troncos - começa a ser utilizada em cobertura de edificações. Este processo foi difundido por volta de 1000 a.C. na Mesopotâmia, como mostrado a seguir:
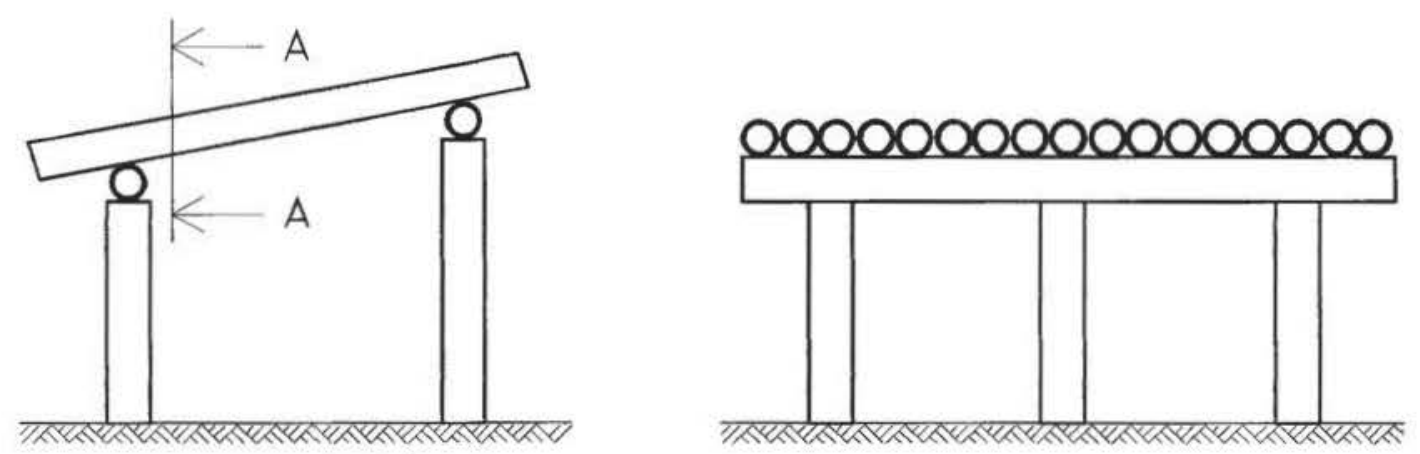

FIGURA 1 - Habitação com cobertura em troncos de madeira

No que diz respeito as ligações entre os troncos, não se têm referências. $\mathrm{Na}$ Pérsia, século VII a.C., desenvolveram-se estruturas de coberturas planas (Figura 2), mas o grande obstáculo a ser vencido era a falta de ferramentas adequadas para facilitar o corte da madeira. 


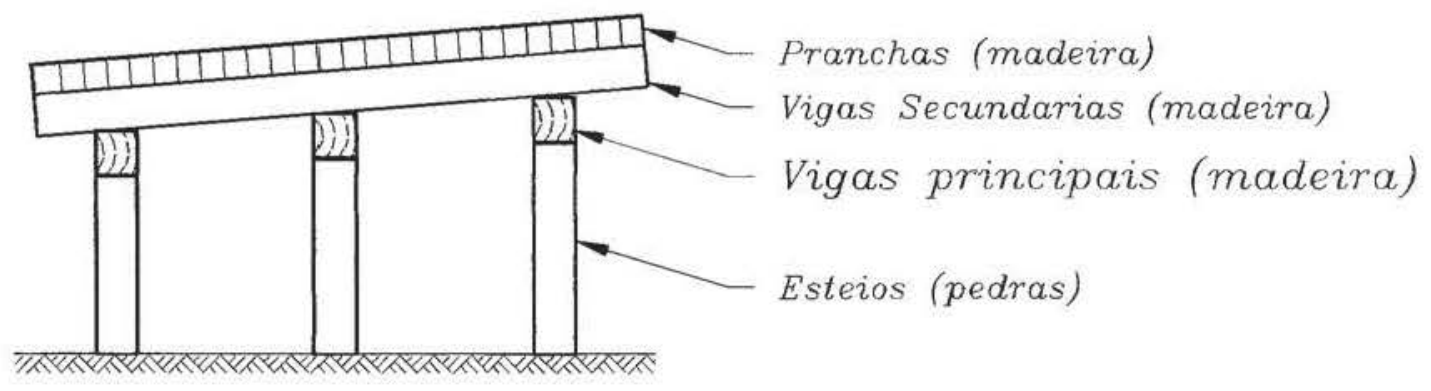

FIGURA 2 - Habitação com cobertura em pranchas de madeira

\subsubsection{De 1000 a 500 a.C. no oriente}

Considerada nestas regiões, a existência de amplas áreas de florestas nativas, o emprego da madeira ocorreu em grande escala se comparada ao Ocidente.

A arquitetura da Índia, desde esta época já incluía abóbadas e arcos, assim como coberturas de forma piramidal.

$\mathrm{Na}$ China, o emprego da madeira em estruturas de cobertura sempre foi mais comum, com formato de retângulos rígidos superpostos. Para as regiões com alto índice pluviométrico, foi desenvolvido um telhado não mais plano com apenas uma inclinação, mas na forma côncova (Figura 3) para facilitar o escoamento das águas da chuva, e com grandes beirais para proteção das paredes.
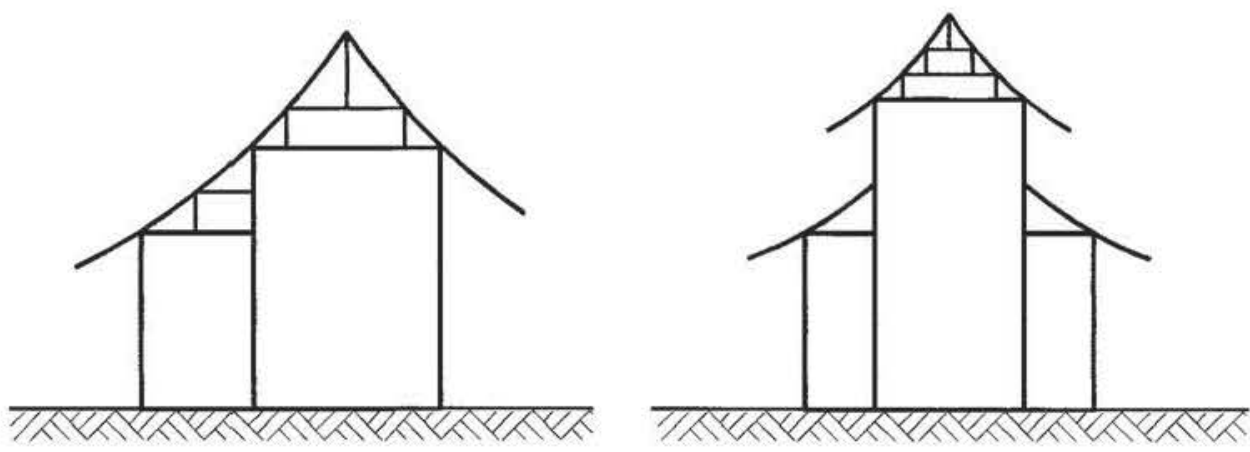

FIGURA 3 - Habitações com coberturas côncavas 
A evolução das ferramentas, possibilitou também o avanço nas estruturas de cobertura, no sentido de vencer vãos maiores, de se inovar nas configurações geométricas.

A geometria das estruturas japonesas eram bem mais simples em comparação às utilizadas pelos chineses. A grande inovação foi aplicar a madeira como elemento de vedação, pintada como tinta especial para aumentar sua durabilidade.

\subsubsection{Arquitetura grega e romana}

A arquitetura grega se baseou em técnicas mais desenvolvidas. Seus arquitetos e construtores souberam aproveitar o máximo dos materiais fornecidos pela natureza, tais como o cobre e depois o ferro. Com estes em mãos, souberam desenvolver ferramentas que facilitassem o manuseio da madeira, e com isso puderam desenvolver, aperfeiçoar ainda mais as estruturas de cobertura.

Conseguiram desenvolver métodos de construção empregando seções transversais compostas (Figura 4) quando sentiam a ineficiência de apenas um tronco para suportar vãos maiores.

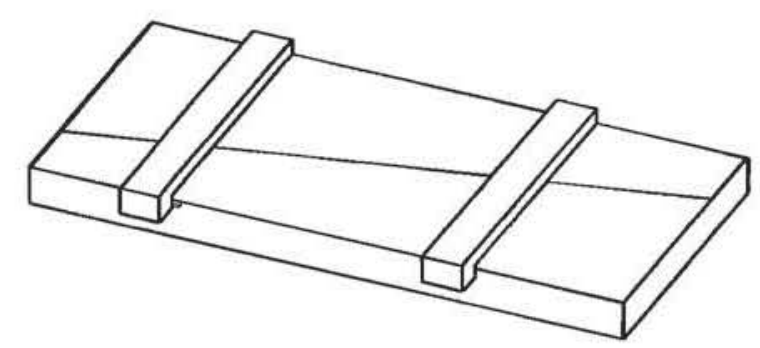

FIGURA 4 - Seções transversais compostas de madeira

Um exemplo de estruturas de cobertura está mostrada na Figura 5, onde se tem todas as peças de madeira, inclusive a cobertura. $\mathrm{O}$ telhado é constituído de uma barra horizontal e duas inclinadas, cuja ligação se dá em um esteio central localizado no ponto médio da barra horizontal. Estes elementos eram apenas encaixados ou 
simplesmente apoiados. Desta maneira, existe apenas esforços de compressão paralela às fibras e flexão. Pelo fato de se ter barras horizontais, o efeito da flexão começou a limitar os vãos devido às deformações excessivas.

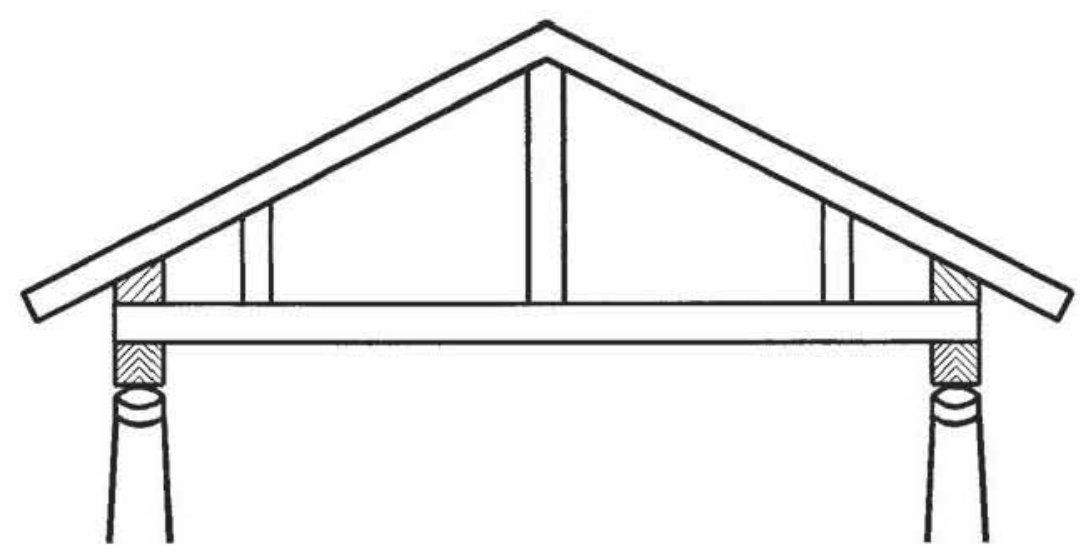

FIGURA 5 - Estrutura de cobertura com barras encaixadas

Para suprir estas deficiências, criou-se uma nova geometria, isto é, barras dos banzos superior e inferior inclinadas, como mostra a Figura 6. Com esta configuração passou-se a ter apenas esforços axiais de tração e compressão em relação às fibras. Estas novas configurações só foram possíveis com o advento de novas ferramentas; ferramentas estas criadas pelos Romanos. A arquitetura Romana foi precursora no que diz respeito à seções compostas dos banzos superior e inferior, e entre eles se encaixavam as diagonais e os montantes.

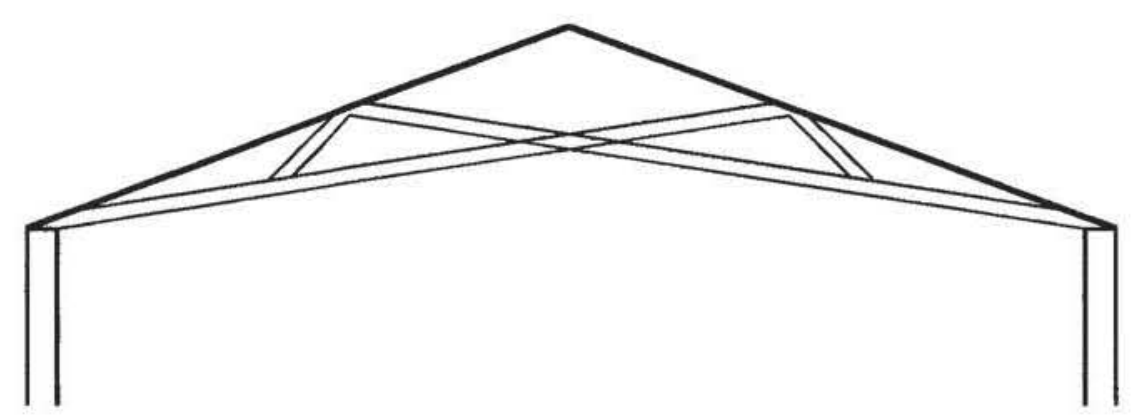

FIGURA 6 - Estrutura de cobertura com barras inclinadas 


\subsubsection{Arquitetura a partir do século IV d.C.}

Ainda com os Romanos e a partir do século IV d.C. com os Bizantinos, foram construídas treliças com aspectos geométricos muito parecidos com as atuais. Mais uma vez, a evolução das ferramentas tornou a trabalhabilidade com a madeira muito melhor, facilitando o uso em estruturas de cobertura. Neste período prevalecia ainda o uso de telhados de duas águas, para residências, igrejas, edificios públicos, palácios e outros, (Figura 7).
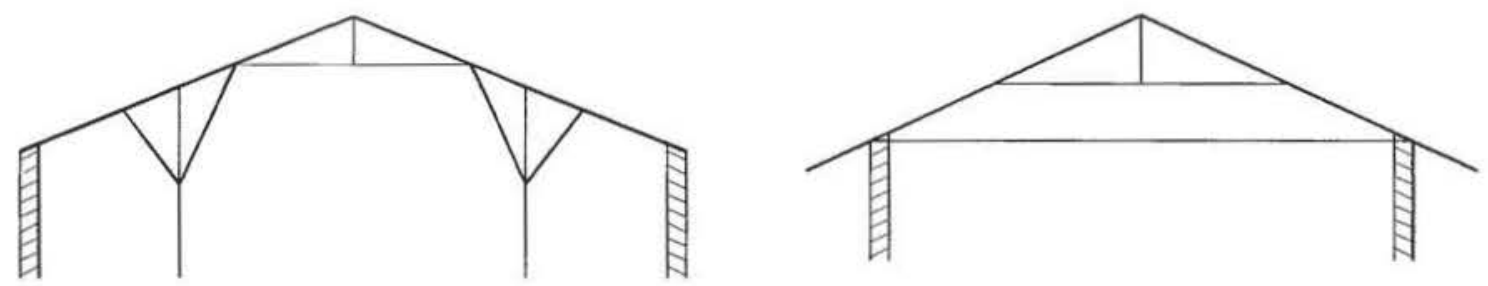

FIGURA 7 - Estrutura de cobertura posterior ao século IV d.C.

Devido à grande incidência de incêndios passou-se a empregar coberturas com folhas metálicas convenientemente combinadas com a madeira.

Com o passar dos séculos, fins do século X d.C., a Arquitetura Mulçumana se fez notar pelas novas características de coberturas; características estas adaptadas às condições do clima. A cobertura das edificações se faziam por meio de pranchas sobrepostas apoiadas em vigas de madeira, com uma capa de material isolante e impermeabilizante, e finalmente com um revestimento de placas cerâmicas. Em torno do século XV d. C., a Arquitetura Românica reviveu os telhados com duas águas, largamente utilizados pelos Bizantinos, mas também, introduziu os telhados de uma água, com aplicação em igrejas.

Este formato apresenta duas grandes vantagens:

$\Rightarrow$ fácil execução;

$\Rightarrow$ o escoamento pluvial fica facilitado devido à ausência da intersecção dos banzos superiores. 
Nesta mesma época surgiu uma das maiores inovações da história, quanto ao sistema estrutural, isto é, alguns pontos contraventados. Apareceram também novas disposições geométricas no sentido de melhorar o comportamento do sistema estrutural, de modo a diminuir as deformações, melhorando o aspecto estético do conjunto.

A Arquitetura Gótica foi marcada pela utilização das treliças de madeira para as grandes obras, caracterizadas pelas acentuadas inclinações dos panos, o que acarreta problemas nas ligações, estas feitas por cavilhas e encaixes. Somente no final do século XVI e início do século XVII apareceram os parafusos e chapas metálicas.

Por falta de conhecimento mais aprofundado dos dispositivos de ligações, estava impossibilitada a construção em estrutura de madeira com mais de 25 metros de vão livre.

\subsubsection{O material madeira}

Tomando como referência o relato histórico até aqui apresentado, pode-se afirmar que as estruturas treliçadas na forma de tesouras foram as primeiras a serem utilizadas com a finalidade específica de sustentação de coberturas.

Apesar da grande incidência de estruturas de madeira até as primeiras décadas do século XIX, pouco se conhecia a respeito das características físicas, de resistência e de elasticidade da madeira. Além disso, havia apenas aplicações baseadas nas obras anteriores. Portanto, não haveria possibilidades de obter projetos estruturais mais elaborado.

Com o objetivo de tornar o emprego da madeira mais racional, houve na metade do século XIX a iniciativa por parte de alguns pesquisadores, no que diz respeito à caracterização de algumas espécies. Desde então, muitas trabalhos já foram 
concluídos e, gradativamente, vêm sendo dado andamento a outros trabalhos tanto no que diz respeito à caracterização de novas espécies, quanto às demais áreas inerentes ao uso da madeira, isto é, emprego de espécies de reflorestamento em estruturas, tipos de uniões entre elementos estruturais, habitação, conforto térmico e acústico e outros.

Sabendo-se que as aplicações do material são inúmeras e, visando a busca do emprego racional da madeira, alguma sistematização deve ser feita. A partir desta idéia, são consideradas quatro formas distintas da aplicação da madeira:

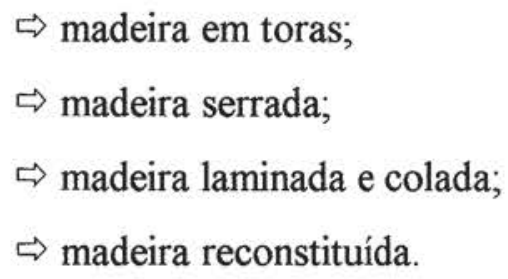

O emprego da madeira em tronco é a forma que mais se assemelha ao estado natural da matéria-prima, proporcionando menor transformação ao material. Esta aplicação está voltada às estruturas e habitações, principalmente para edificações executadas no meio rural. Quanto ao emprego estrutural, podem ser citados alguns exemplos, tais como, postes de eletrificação rural, infraestrutura (estaqueamento) de obras portuárias fluviais, infra e superestruturas de pontes, estruturas de sustentação de telhados, pilares, vigas e outros. Como elemento de vedação destinado a habitações, foi altamente utilizado na Europa Central, países escandinavos e Rússia e, mais recentemente, na América do Norte, principalmente nas áreas rurais. No Brasil, não se tem dados precisos quanto ao seu emprego.

A madeira serrada pode ser direcionada às construções de habitações, na forma estrutural ou como vedação. Emprega-se também em caixilhos, portas, pisos, etc. A madeira serrada na forma de vigas maciças com seções transversais retangulares não é a maneira mais eficiente de aproveitamento, pois, a forma geométrica se confronta com as características naturais do material. Como 
conseqüência, podem advir problemas devidos à instabilidade dimensional, principalmente decorrente do processo de secagem. Tais problemas, associados às dificuldades de realização das emendas e uniões entre elementos estruturais, acabaram por reduzir o emprego das estruturas de madeira.

À vista do exposto, os usuários podem concluir precipitada e errôneamente, que, para grandes estruturas, obrigatoriamente há necessidade de grandes peças estruturais. Como conseqüência, há um aumento no consumo de madeira, onerando o custo da estrutura. Isto provoca a redução da sua competitividade em relação às estruturas compostas por outros materiais.

Do ponto de vista estrutural, a madeira serrada é de grande utilidade se usada de forma correta, isto é, com peças de pequena espessura, associadas quando necessário, e a adequada execução da união entre elementos estruturais. Desta maneira, as estruturas de madeira serão tão versáteis quanto às demais estruturas correntes.

O emprego da madeira laminada e colada tem como grande vantagem a capacidade de construção de peças estruturais de quaisquer dimensões e com enorme variabilidade na concepção da forma geométrica. Esta forma de utilização permite a redução da heterogeneidade aleatória natural existente no material. A possibilidade de se empregar quaisquer procedimentos para classificação de peças, viabiliza o emprego do material mais resistente nas regiões mais solicitadas das estruturas.

No âmbito estrutural, este sistema inovador no Brasil permite um melhor aproveitamento das espécies de reflorestamento, já que estas, geralmente, estão disponíveis a partir de árvores com diâmetros inferiores àquelas de florestas nativas.

A madeira reconstituída, ou seja, os compensados, os aglomerados e as chapas de fibras, não possuem obrigatoriamente as características iniciais encontradas no material natural, mas sim, as propriedades dos materiais que as compõem. A grande 
vantagem do processo de reconstituição, é a capacidade de controlar a heterogeneidade, a anisotropia e a assimetria, podendo aumentá-las, diminuí-las ou eliminá-las, conforme a necessidade de utilização do fabricante.

As quatro formas de emprego da madeira são viáveis, uma vez conhecidas as particularidades do material em cada uma delas. Deste modo é possível fazer exigências compatíveis. Este é o melhor caminho para se prosseguir o processo de racionalização deste nobre material: a madeira.

Apesar dos problemas citados, atualmente, a madeira continua sendo muito empregada como estruturas de coberturas destinadas a residências, barracões industriais e comerciais, depósitos, instalações sociais e esportivas, além da utilização em edificações rurais. 


\subsection{Generalidades do gênero Pinus}

\subsubsection{Aspectos gerais a respeito do gênero Pinus}

$\mathrm{O}$ gênero Pinus provavelmente teve sua origem no norte da Eurásia ou no norte da América, há cerca de duzentos e cinqüenta milhões de anos. A partir daí, o gênero vem se dispersando, descendo pelos continentes europeu e asiático, bem como pelo americano, chegando até a América Central e Caribe, onde se formou um centro secundário de evolução, do qual surgiram as incursões para a América do Sul, BORTOLETTO Jr. (1993).

Informações interessantes a respeito da introdução de espécies exóticas no país encontram-se reunidas no trabalho "Introdução de Coníferas no Brasil: Um Esboço Histórico", PEREIRA apud BORTOLETTO Jr. (1993) ${ }^{1}$. O autor reúne os dados das primeiras introduções de coníferas feitas no Brasil, a princípio para fins ornamentais e, em seguida, para fins silviculturais. Posteriormente, foram destinadas para suprir a redução de oferta de matéria-prima causada pelo intenso extrativismo nas reservas de Araucária angustifolia, o Pinho-do-Paraná, única fonte no país de "madeira mole" e fibra longa, e para reduzir a dependência nacional de importação de celulose e resina, produtos obtidos a partir das coníferas.

No Brasil, a introdução de espécies exóticas de coníferas, principalmente do gênero Pinus, deu-se na década de 40 e no início dos anos 50. O mencionado autor destaca e separa a participação do setor privado e do setor público no processo de introdução de coníferas para fins silviculturais no Brasil, relatando sua importância e a alternância de seu período de atuação até o advento da lei $\mathrm{n}^{0}$ 5106, de 1966, a respeito de incentivos fiscais para reflorestamento, que deu origem ao zoneamento ecológico proposto por GOLFARI et al. (1978), contribuindo para que as

\footnotetext{
1 PEREIRA, B. A. Introduçāo de coniferas no Brasil: um esboço histórico. Piracicaba, 1987. $34 p$. Monografia (Trabalho de Pós-graduação) - Escola Superior de Agricultura "Luiz de Queiróz", Universidade de São Paulo apud BORTOLETTO Jr., G. Indicações para a utilização da madeira de seis espécies $e$ variedades de Pinus aplicada na construção civil. São Carlos, 1993. 119p. Dissertação (Mestrado) Escola de Engenharia de São Carlos - Universidade de São Paulo
} 
introduções de sementes de coníferas se restringissem às espécies com procedências recomendadas. A partir deste período, a iniciativa privada passa a preponderar sobre a do governo, e os reflorestamentos ganham impulso expressivo, alcançando ainda na mesma década 6,2 milhões de hectares, sendo mais da metade em Eucalipto e cerca de $30 \%$ com Pinus.

De acordo com FLORESTAR ESTATíSTICO (1994/95), o Estado de São Paulo possue áreas reflorestadas de aproximadamente 935 mil hectares, sendo 220 mil de Pinus e o restante de Eucalipto. Segundo dados da Duratex - Agudos/S.P., a área plantada de Pinus, tem potencial para fornecer aproximadamente 45 milhões de metros cúbicos apenas para uso no âmbito estrutural.

\section{Segundo SOCIEDADE BRASILEIRA DE SILVICULTURA apud} BENEVENTE (1995) ${ }^{2}$, no âmbito nacional, a distribuição de madeira nativa e de reflorestamento é dada da seguinte forma:

$$
\begin{aligned}
& \Rightarrow \text { madeira nativa: } 69 \% \\
& \Rightarrow \text { madeira de reflorestamento (Eucalipto): } 24 \% \\
& \Rightarrow \text { madeira de reflorestamento (Pinus): } 7 \%
\end{aligned}
$$

PINHEIRO et al. (1993) desenvolveu um trabalho tomando-se as estruturas de cobertura com referência. $\mathrm{O}$ objetivo principal era verificar o consumo de madeira por metro quadrado de área coberta relativo à algumas espécies nativas, tais como:

$$
\begin{aligned}
& \Rightarrow \text { Peroba-Rosa (Aspidosperma polyneurum); } \\
& \Rightarrow \text { Cambará (Erisma uncinatum); } \\
& \Rightarrow \text { Canafistula (Cassia ferruginea). }
\end{aligned}
$$

\footnotetext{
${ }^{2}$ SOCIEDADE BRASILEIRA DE SLVICULTURA. A sociedade brasileira e seu patrimônio florestal. São Paulo: SBS, 1987. apud BENEVENTE, V. A. Durabilidade em construções de madeira - uma questão de projeto. Sä́b Carlos, 1995. 231p. Dissertação (Mestrado) Escola de Engenharia de São Carlos - Universidade de São Paulo.
} 
Para estruturas com telhas de fibro-cimento e vãos teóricos variando entre 6 e 12 metros, obteve-se valores de consumo de madeira (metros cúbicos) por área coberta (metros quadrados) entre 0,018 a 0,020 .

\subsubsection{Algumas considerações sobre espécies de Pinus crescidas no Estado de São Paulo}

Segundo BERTOLANI (1978), normalmente os Pinus tropicais necessitam de temperatura média ao redor de $23^{\circ} \mathrm{C}$, período de seca bem determinado e precipitação pluviométrica acima de $900 \mathrm{~mm}$ anuais.

ARRUDA VEIGA (1981), registra que atualmente é possível definir, com grande probabilidade de acerto, as regiões paulistas mais adequadas para os Pinus tropicais e sub-tropicais. Os sub-tropicais, como o Pinus elliottii e Pinus taeda, podem ser plantados na maior parte do Estado, cujo clima abrange invernos frios, chuvas bem distribuídas ao longo do ano e altitude entre 600 e 1100 metros. Com relação aos tropicais, Pinus oocarpa e algumas variedades do Pinus caribaea, sua adaptação se verifica em regiões com invernos secos e deficiências hídricas.

De acordo com BERTOLANI (1978), os Pinus, de um modo geral, não necessitam de solos férteis, desenvolvendo-se bem em solos ácidos e com pouca matéria orgânica. Preferem solos arenosos e profundos, próprios dos cerrados e dos campos.

A seguir são registrados alguns aspectos das espécies de pinus mais difundidos no Estado de São Paulo: 


\subsubsection{Pinus caribaea var. caribaea}

É nativo da província de Pinar del Rio e Ilha de Pinus, Cuba, onde cresce em planícies suavemente onduladas e colinas baixas a uma altitude entre 30 e 35 metros. O clima desta área é tropical com uma temperatura média anual entre 24,5 e $25^{\circ} \mathrm{C}$ e precipitação entre 1200 e 1600 mm anuais, de tipo periódico e com estação seca que dura de quatro a cinco meses, GOLFARI et al. (1978).

Entre as variedades de Pinus caribaea, é a que melhor se adapta a regiões com déficit hídrico reduzido. Os solos da região de origem são geralmente ácidos, com textura variando de média a leve e com drenagem livre.

Entre as três variedades de Pinus caribaea é a que apresenta menor incremento, porém melhor forma com fustes retos e galhos finos e curtos GOLFARI et al. (1978).

A madeira, cuja densidade varia de 0,35 a $0,50 \mathrm{~g} / \mathrm{cm}^{3}$, a $12 \%$ de umidade, é usada em contruções leves e pesadas, construção de barcos, laminação, compensados, chapas de fibras e fabricação de polpa de fibras longas, CARPANEZZI et al., (1986).

\subsubsection{Pinus caribaea var. bahamensis}

Ocorre nas Ilhas Bahamas, entre as latitudes 24 e $27^{\circ} \mathrm{N}$ e altitudes compreendidas entre 0 e 1000 metros. A precipitação na região de origem varia entre 1000 e $1500 \mathrm{~mm}$ e a temperutura média anual, de 22 a $26^{\circ} \mathrm{C}$. O regime de chuvas é periódico, com estações secas de dois a cinco meses. Ocorre naturalmente em solos bem drenados, de textura leve, alcalinos e neutros, e tolera solos rasos. Entre as variedades de Pinus caribaea, é a mais indicada para solos de baixada, onde a drenagem é lenta. A madeira, cuja densidade varia de 0,35 a $0,50 \mathrm{~g} / \mathrm{cm}^{3}$, a $12 \%$ de utridade, pode ser utilizada para construções leves e pesadas, construção de barcos, 
fabricação de laminados, chapas de fibras, de partículas e para a produção de polpas de fibras longas, entre outros usos. Este Pinus é, adicionalmente, bom produtor de resina, CARPANEZZI et al. (1986).

Segundo BERTOLANI (1978), a variedade em questão é intermediária entre Pinus caribaea var. caribaea e Pinus caribaea var. hondurensis, tanto em forma como em crescimento.

\subsubsection{Pinus caribaea var. hondurensis}

Ocorre naturalmente na costa atlântica da América Central, de Belize até Nicarágua, em latitudes compreendidas entre 12 e $18^{\circ} \mathrm{N}$ e altitudes entre 0 e 1000 metros. $\mathrm{O}$ regime de chuvas é periódico, podendo ocorrer, em alguns locais, períodos secos com duração de até seis meses. A temperatura média anual varia de 21 a $27^{\circ} \mathrm{C}$, a média das máximas do mês mais quente entre 19 e $34{ }^{\circ} \mathrm{C}$ e a média das mínimas do mês frio, entre 15 e $23{ }^{\circ} \mathrm{C}$. Os solos são bem drenados, de textura leve a média, neutros e ácidos, podendo, ocasionalmente, suportar curtos períodos de alagamento. A madeira, com densidade entre 0,35 a $0,50 \mathrm{~g} / \mathrm{cm}^{3}$, a $12 \%$ de umidade, pode ser empregada para construções leves e pesadas, construção de barcos, fabricação de laminados, chapas de fibras, de partículas e para a produção de celulose de fibras longas, entre outros usos. Adicionalmente, esta variedade é tida como produtora de resina.

Por outro lado, entre as variedades da espécie, Pinus caribaea var. hondurensis é a de maior crescimento, BERTOLANI (1978).

\subsubsection{Pinus oocarpa}

Tem uma ampla área de ocorrência, desde o norte do México $\left(28^{\circ}\right.$ de latitude), até o norte da Nicarágua $\left(13^{\circ}\right)$. Vive em áreas de colina, planalto e montanhas entre 500 e 2600 metros de altitude, GOLFARI et al. (1978). 
A precipitação varia entre 750 e $1500 \mathrm{~mm}$, com períodos secos. A temperatura média anual varia entre 13 e $21{ }^{\circ} \mathrm{C}$, a média das máximas do mês mais quente entre 20 e $30^{\circ} \mathrm{C}$ e a média das mínimas do mês frio, entre 8 e $16^{\circ} \mathrm{C}$. Os solos em que ocorre naturalmente possuem textura que varia de leve a pesada, $\mathrm{pH}$ neutro a ácido e drenagem livre. A espécie tolera solos rasos e, entre os Pinus tropicais, é a que apresenta maior tolerância ao frio. É, contudo, susceptível aos ventos fortes, CARPANEZZI et al. (1986).

De acordo com BERTOLANI (1978), o crescimento da espécie é idêntico ao de Pinus caribaea var. caribaea, porém, os galhos mais finos, a maior altura e a precocidade, geram madeira de maior densidade, podendo atingir no final de uma rotação de 30-35 anos, padrões de qualidade semelhantes ao de Araucária angustifolia. Segundo o mesmo autor, a espécie é altamente resistente ao fogo.

A madeira, cuja densidade varia entre 0,45 e $0,60 \mathrm{~g} / \mathrm{cm}^{3}$, a $12 \%$ de umidade, pode ser utilizada para construções leves, fabricação de laminados, chapas de fibras, de partículas e para produção de celulose de fibras longas. A espécie não é considerada boa produtora de resina, CARPANEZZI et al. (1986).

\subsubsection{Pinus taeda}

É natural das regiões Leste e Sudeste dos Estados Unidos e tem uma área de ocorrência extensa e descontínua, o que proporcionou o surgimento de vários ecótipos ou raças geográficas. Ocorre entre 28 e $39^{\circ} \mathrm{N}, 75$ e $97^{\circ} \mathrm{W}$ e altitudes compreendidas entre 0 e 2400 metros. A precipitação média anual varia entre 900 e $2200 \mathrm{~mm}$. O regime de chuvas pode ser periódico, com períodos de seca de até dois meses, ou de distribuição uniforme ao longo do ano. A temperatura média anual situase entre 13 e $19{ }^{\circ} \mathrm{C}$, a média das máximas do mês mais quente entre 20 e $25^{\circ} \mathrm{C}$ e a média das mínimas do mês frio, entre 4 e $18{ }^{\circ} \mathrm{C}$. Os solos são de textura leve a pesada, com pff geralmente ácido e drenagem média. Ocasionalmente, a espécie pøde ocorrer 
em solos sujeitos a alagamentos por um período curto de dias, CARPANEZZI et al. (1986).

Com densidade entre 0,47 e $0,51 \mathrm{~g} / \mathrm{cm}^{3}$, a madeira é usada em construções leves, na produção de laminados, compensados, chapas de fibras e de partículas e para produção de celulose de fibras longas. A espécie não é boa produtora de resina, CARPANEZZI et al. (1986).

\subsubsection{Pinus elliottii}

Sua área de ocorrência natural é menos ampla que a de Pinus taeda e, por vezes, ambas se confundem. Estendem-se através do Sudoeste dos Estados Unidos, em latitudes compreendidas entre 28 e $33^{\circ} \mathrm{N}$ e altitudes entre 0 e 2500 metros. A precipitação varia de 650 a $2500 \mathrm{~mm}$ e o regime de distribuição das chuvas é periódico, com dois a quatro meses secos. A temperatura média anual situa-se entre 15 e $24^{\circ} \mathrm{C}$, a média das máximas do mês mais quente, entre 23 e $32{ }^{\circ} \mathrm{C}$, e a média das mínimas do mês mais frio, entre 4 e $12{ }^{\circ} \mathrm{C}$. Os solos são de textura leve a pesada, geralmente ácidos e bem drenados. A espécie suporta alagamentos periódicos curtos e tolera solos rasos, CARPANEZZI et al. (1986).

Com densidade entre 0,50 e $0,56 \mathrm{~g} / \mathrm{cm}^{3}$, a $12 \%$ de umidade, em idades mais avançadas, sua madeira pode ser utilizada em construções leves ou pesadas, construção de barcos, na produção de laminados, compensados, chapas de fibras, de partículas e para produção de celulose de fibras longas. É considerada excelente para produção de resina, CARPANEZZI et al. (1986). 


\subsubsection{Propriedades físicas, de resistência e de elasticidade de espécies de Pinus}

O desenvolvimento de projetos estruturais requer o conhecimento prévio das propriedades fisicas, de resistência e de elasticidade do material estrutural a ser utilizado, qualquer que seja. Relativamente ao estudo aqui proposto, o mesmo sucede.

$\mathrm{Na}$ bibliografia consultada para elaboração deste trabalho, foram encontradas algumas referências significativas a respeito das propriedades fisicas, de resistência e de elasticidade do Pinus, que garantem a disponibilidade suficiente de informações para a elaboração dos projetos previstos.

\section{O INSTITUTO DE PESQUISAS TECNOLÓGICAS DO ESTADO DE} SÃO PAULO (1956) traz os valores de diversas propriedades de espécies de Pinus, determinadas através de ensaios de material retirado de apenas uma árvore por espécie. Apesar da restrita representatividade estatística, os resultados se constituem em interessantes indicadores do potencial do gênero.

Outro trabalho a referir é o apresentado por ROCCO LAHR (1992), que avaliou as propriedades físicas e mecânicas de espécies chamadas de "alternativas para aplicação na construção de estruturas", incluindo entre elas o Pinus elliottii. Ficou evidenciada a possibilidade de emprego estrutural da madeira da mencionada espécie, uma vez conduzidos adequadamente os cálculos estruturais, e garantindo o tratamento preservativo contra a demanda biológica do material a ser usado.

Mais recentemente, BORTOLETTO Jr. (1993), apresentou trabaho com intuito de indicar os empregos mais convenientes para diversas espécies e variedades de Pinus crescidos no Estado de São Paulo. Entre os empregos propostos, encontram-se diversos deles ligados à estruturas, podendo ser mencionados: pontaletes, formas, cimbramentos, divisórias, coberturas e vigas em geral. 


\subsubsection{Propriedades físicas}

As características físicas são conseqüências da estrutura anatômica e composição química da madeira. Como resultado, obteve-se um material higroscópico e poroso, de natureza anisotrópica.

Do ponto de vista construtivo, as características físicas mais importantes são: umidade, retratibilidade e massa específica aparente.

\section{$\rightarrow$ Umidade}

Trata-se de um parâmetro muito importante, por ter influência direta sobre todas as outras propriedades da madeira, sejam elas de resistência, de elasticidade e até mesmo sobre outras propriedades físicas. A umidade é definida como sendo a relação entre a massa de água existente na peça de madeira e a massa seca desta mesma peça. A água (seiva) existente no interior da madeira pode ocorrer em três situações distintas, ou seja, água livre, de embebição ou capilaridade; água de impregnação ou de adesão e água de constituição. A primeira está presente no interior das células (lúmen), nos espaços intercelulares, e sua perda se dá pela passagem das moléculas de uma célula a outra até a superficie através da ação da capilaridade. As moléculas de água de impregnação ou de adesão mantêm-se unidas às microfibrilas da parede celulósica dos elementos anatômicos (células dos vasos, traqueídes, fibras, parênquima axiais e raios medulares), e sua eliminação ocorre mais facilmente através da secagem artificial, pelo processo de difusão e, conseqüentemente, provocando redução volumétrica da peça de madeira. As moléculas de água de constituição encontram-se quimicamente unidas aos constituintes da parede celular e, quando eliminadas, provoca alterações na composição química da parede celular.

O limite entre a água livre e a água de impregnação foi definido como Ponto de Saturação das Fibras (PSF) e, dependendo da espécie, este valor se encontra na faixa de 22 a $30 \%$. 


\section{$\rightarrow$ Retratibilidade}

$\mathrm{O}$ fato da madeira ser um material altamente higroscópico, produz o fenômeno de retração e inchamento (variação da umidade da madeira em patamares inferiores a PSF), isto é, redução e aumento volumétrico. Segundo KARLSEN (1967), estas variações ocorrem de forma diferenciada em cada uma das três direções principais: axial (aproximdamente $0,1 \%$ ), radial ( 3 a $6 \%$ ) e tangencial ( 6 a 12\%), e é responsável ou explicam a maioria dos defeitos ocorridos durante a secagem. Este comportamento é conseqüência, principalmente, do ângulo fibrilar da camada " $\mathrm{S}_{2}$ " da parede secundária, pois, compõe aproximadamente $75 \%$ do volume da parede celular, TOMAZELLO (1996).

Segundo MOREY (1980), o ângulo das microfibrilas da camada " $\mathrm{S}_{2}$ " varia entre 10 e 30 graus. Portanto, o acréscimo da variação volumétrica esta diretamente relacionada com o aumento do ângulo fibrilar.

Geralmente, pode-se dizer que as folhosas (Angiospermas dicotiledôneas) são mais susceptíveis às variações volumétricas que as coníferas (Gimnospermas). Este fato pode ser entendido baseando-se em diferenças existentes na composição química da madeira. MOREY (1980), afirma que na maioria das vezes, a porcentagem de hemicelulose presente nas angiospermas é superior àquelas encontradas nas gimnospermas e, conseqüentemente, a porcentagem de lignina é menor.

De acordo com MOREY (1980), dentre os principais elementos químicos que compõem a parede celular, a hemicelulose é a mais higroscópica. Assim sendo, podese entender a causa das diferentes variações volumétricas entre as angiospermas e gimnospermas. 


\section{$\rightarrow$ Massa específica aparente e densidade básica}

De acordo com a literatura consultada, foi possível observar a unanimidade dos pesquisadores quanto a importância do conhecimento da massa específica aparente e densidade básica, principalmente, no que diz respeito a análise da qualidade das madeiras.

Tais propriedades, podem ser definidos da seguinte maneira:

$\Rightarrow$ Massa específica aparente: é a relação entre a massa de uma amostra e o seu volume, para um determinado teor de umidade;

$\Rightarrow$ Densidade Básica: é a relação entre a massa de uma amostra a $0 \%$ de umidade e o volume saturado.

Ambas as propriedades, dependem de vários fatores, entre eles, a espécie, o volume de poros, espessura da parede celular, rearranjo e tamanho das células, a quantidade de extrativos por unidade de volume, etc. Dentro de uma mesma árvore, podem existir variações destas propriedades, tanto no sentido base-topo como no sentido medula-casca.

No âmbito estrutural, a massa específica aparente é considerada a propriedade fisica mais significativa, pelo fato de estar intimamente relacionada com a resistência mecânica da madeira. De modo geral, pode-se dizer: quanto maior a massa específica aparente, maior será a resistência mecânica da madeira. Além disto, o peso próprio de quaisquer estruturas é calculado em função deste parâmetro.

\subsubsection{Propriedades de resistência e de elasticidade}

As características de resistência e de elasticidade são também den@minadas como características mecânicas. São definidas como sendo as característicąs da madeira submetidas a todos os tipos de solicitações oriundas de ações externas. Esstas 
características estão relacionadas com a composição química, propriedades físicas e anatômicas da madeira e são divididas da seguinte maneira:

$\Rightarrow$ Compressão paralela e normal às fibras;

$\Rightarrow$ Tração paralela e normal às fibras;

$\Rightarrow$ Cisalhamento paralelo às fibras;

$\Rightarrow$ Fendilhamento paralelo às fibras;

$\Rightarrow$ Dureza;

$\Rightarrow$ Flexão estática e Tenacidade (Flexão dinâmica).

Além das características mecânicas, o desempenho estrutural pode ser influenciado pela forma de crescimento de cada espécie, o método de desdobro, os subseqüentes tratamentos, a presença de defeitos (nós), bolsões de resina, extrativos, etc.

\subsubsection{Durabilidade natural}

Segundo o TRADA (1991), a durabilidade de uma peça de madeira em serviço depende da sua resistência natural e de um meio ambiente não propício a ataques de organismos xilófagos. A Durabilidade ou resistência natural é definido como a capacidade inerente a uma espécie de resistir à ação de agentes deterioradores, incluindo os agentes bióticos e abióticos, sem tratamento preservativo, BENEVENTE (1995).

Segundo TRADA (1991), a classificação da madeira quanto à durabilidade natural é dada em função do desempenho de seu cerne em contato direto com o solo, como mostrado na tabela abaixo: 
TABELA 1 - Classificação das madeiras segundo sua durabilidade natural.

\begin{tabular}{|c|c|}
\hline Grau de durabilidade & Vida média em contato com o solo \\
\hline muito durável & 25 anos \\
\hline durável & $15-20$ anos \\
\hline moderadamente durável & $10-15$ anos \\
\hline não durável & $5-10$ anos \\
\hline perecível & até 5 anos \\
\hline
\end{tabular}

Algumas propriedades quanto a durabilidade natural (resistência e permeabilidade) de espécies de Pinus são mostradas na tabela a seguir:

TABELA 2 - Resistência natural e permeabilidade em espécies de Pinus

\begin{tabular}{|c|c|c|c|}
\hline \multicolumn{5}{|c|}{ Durabilidade Natural } \\
\hline Espécies de Pinus & Fungos & Insetos & Permeabilidade \\
\hline Pinus caribea & 5 & 4 & 1 \\
\hline Pinus bahamensis & 5 & 4 & 1 \\
\hline Pinus hondurensis & 5 & 4 & 1 \\
\hline Pinus oocarpa & 5 & 3 & 1 \\
\hline Pinus elliottii & 5 & 4 & 1 \\
\hline Pinus taeda & 5 & 4 & 1 \\
\hline
\end{tabular}

Fonte: Revista Téchne - nov/dez - 1995 nº 19

\section{- Resistência a fungos}

1-muito durável; 2-durável a muito duravél; 3-durável; 4-med. durável; 5-pouco ou não durável.

\section{- Resistência a insetos}

1-muito resistente; 2-resistente;; 3-med. resistente; 4-não resistente.

\section{- Permeabilidade}

1-Impregnável; 2-med. impregnável; 3-pouco ou não impregnável. 


\subsection{Aspectos gerais da durabilidade natural da madeira e da demanda biológica}

\subsubsection{Introdução}

Um engenheiro projetista, que usa a madeira como material estrutural, espera dela algumas qualidades de fundamental importância, tais como:

$\Rightarrow$ durabilidade natural;

$\Rightarrow$ a manutenção das propriedades físicas e mecânicas com o decorrer do uso, etc.

Em decorrência do extrativismo descontrolado e sem planejamento, segundo FLORESTAR ESTATÍSTICO (1994/95), registra-se que, nos grandes centros consumidores do país (regiões Sul/Sudeste) ocorrem baixa disponibilidade de espécies de madeira de boa durabilidade natural. Este fato propicia a imigração de espécies nativas de outras regiões do pais, principalmente, regiões Norte/Centro-Oeste. Em conseqüência, obtém-se um custo relativamente alto, devido às dificuldades de exploração e transporte. Todavia, as regiões consumidoras já possuem áreas reflorestadas em condições de fornecer madeira para as aplicações necessárias.

É de conhecimento de todos os pesquisadores da área que espécies de reflorestamento, como as dos gêneros Eucalipto e Pinus, são altamente susceptíveis à ataques de organismos xilófagos, necessitando de alguns cuidados que previnam a demanda biológica.

Com o objetivo de evitar a deterioração e aumentar o tempo de vida útil das peças de madeira, sejam elas destinadas ou não às estruturas, algumas medidas de prevenção contra a demanda biológica podem ser adotadas, como por exemplo: época e idade do corte; método de secagem e de preservação; classificação; condições dos locais de armazenamento e disposições construtivas. 


\subsubsection{Deterioração da madeira}

Como qualquer outro material, a madeira está susceptível à deterioração, causadas principalmente por:
$\Rightarrow$ defeitos naturais;
$\Rightarrow$ agentes deterioradores.

\subsubsection{Defeitos naturais}

A deterioração oriunda dos defeitos naturais está diretamente relacionada com o tipo de espécie e também com a forma de crescimento. Alguns tipos de defeitos naturais:

$$
\begin{aligned}
& \Rightarrow \text { grã irregular; } \\
& \Rightarrow \text { presença de nós; } \\
& \Rightarrow \text { madeira de reação; } \\
& \Rightarrow \text { falso cerne; } \\
& \Rightarrow \text { fendas anelares; } \\
& \Rightarrow \text { bolsões de resinas. }
\end{aligned}
$$

\subsubsection{Agentes deterioradores}

Toda madeira em seu estado natural ou não está sujeita às ações de agentes deterioradores, sejam de origem biológica ou não. Segundo LEPAGE et al. (1986), tais agentes podem causar desde simples mudança de cor até redução das características fisico-mecânicas da madeira, podendo comprometer o desempenho arquitetônico e estrutural das peças de madeira.

De acordo com o mesmo autor, os agentes deterioradores da madeira são divididos em dois grupos: 
$\Rightarrow$ agentes abióticos;

$\Rightarrow$ agentes bióticos;

Além destes agentes, outros fatores podem comprometer a edificação como um todo, tais como: escolha do material, secagem incorreta, ausência de preservação, forma de armazenagem, processos construtivos, etc.

A pesquisa bibliográfica evidenciou uma certa uniformidade a respeito da divisão citada, ficando uma diferença em função da importância dada a um ou outro agente deteriorador.

\subsection{Agentes abióticos}

Os agentes abióticos podem ser divididos em: agentes físicos, mecânicos, químicos e climáticos.

JUNTA DEL ACUERdo DE CARTAGENA - JUNAC (1988), conhecendo as propriedades de retratibilidade da madeira, afirma: “...quando a madeira se encontra em condições de movimento, está exposta a deterioração por desgaste mecânicos". Segundo BENEVENTE (1995), a deterioração da madeira pela ação dos agentes mecânicos esta diretamente relacionada com a dureza da mesma. Os efeitos da abrasão combinados com os ataques de organismos xilófagos, principalmente os fungos apodrecedores, poderá causar deterioração do material, BENEVENTE (1995). Como prevenção, a JUNAC (1988) recomenda o uso de placas metálicas na região de contato entre ambas as superficies. A impregnação das faces com produtos óleo-solúveis e a utilização de pintura a óleo também são bastante eficazes contra o efeito abrasivo.

A respeito dos deterioradores físicos, o fogo é considerado o principal agente, JUNAC (1988). Tal assunto, é bastante abordado por BROCHARD (1969), KARLSEN (1967), LEPAGE et al. (1986) e AGUILLAR FILHO (1986). 
A madeira possui certa resistência aos agentes químicos, porém, o contato com algumas substâncias (ácidos e bases fortes, óxido de ferro, dióxido de enxofre, sais de sódio) podem proporcionar algumas transformações e reduzir os valores de suas propriedades físicos-mecânicas, BENEVENTE (1995). Este tipo de deterioração é facilmente encontrada nos pisos de fábricas de produtos químicos, nas peças de madeira em contato com ferragens, por exemplo.

Segundo LEPAGE et al. (1986), a madeira possui resistência considerável às soluções neutras, ácidas ou básicas fracas. Assim sendo, usa-se muito na construção de diversos equipamentos, tais como: tanques, filtros-prensas, tonéis, dutos de tiragem de gases e outros, sem que ocorra a deterioração do material. $\mathrm{O}$ mesmo autor afirma que, pode ser encontrado ataques químicos em estruturas de cobertura, principalmente, quando o substrato esta exposto à ambientes propícios, por exemplo, atmosfera que contenha fumos ácidos ou exposição à fumos quentes. Por outro lado, os custos inerentes às medidas tomadas contra estes tipos de ataques, demonstrou a viabilidade econômica do emprego da madeira.

Os agentes abióticos de origem natural capazes de deteriorar a madeira podem ser classificados como agentes climáticos, BENEVENTE (1995). Entre eles, destacam-se: umidade, temperatura, radiação solar e ventos. Segundo LEPAGE et al. (1986), a ação conjunta de todos estes efeitos pode ser resumida por "WEATHERING".

Além destes, os poluentes contidos na atmosfera também podem causar tal dano nas peças de madeira.

Tais agentes - umidade e temperatura -, quando combinados, podem tornar o ambiente propício a ataques de microorganismos, principalmente os fungos apodrecedores. A oscilação freqüente destes agentes podem causar variações dimensionais, provocar rachaduras, empenamentos, fendilhamentos, principalmente 
nas extremidades das peças, onde a absorção e a perda de umidade se verificam com maior rapidez.

Segundo LEPAGE et al. (1986), a degradação fotoquímica ocasionada pela radiação ultra-violeta altera a cor da madeira, dando-se o nome de envelhecimento natural.

Este fenômeno agindo conjuntamente com as intempéries (águas da chuva, ventos, etc), poderá provocar a deterioração das peças de madeira.

\subsection{Agentes bióticos}

Segundo CAVALCANTE (1982), os agentes biológicos são considerados os principais deterioradores da madeira.

Segundo a RAIMBAULT (1983) e LEPAGE et al(1986), dividem-se os organismos que atacam a madeira da seguinte maneira:

$\Rightarrow$ Microorganismos: fungos (apodrecedores, manchadores e emboloradores) e bactérias;

$\Rightarrow$ Insetos: coleóptera (brocas e besouros) e isóptera (cupins);

$\Rightarrow$ Perfuradores marinhos: moluscos e crustáceos.

O processo de deterioração provocado por estes organismos, é tido como biodeterioração.

É oportuno e conveniente registrar apenas os tipos de organismos xilófagos (fungos apodrecedores, isópteros e coleópteros) que possam vir a provocar danos à resistência mecânica da madeira e, assim, por exemplo, às estruturas treliçadas para cobertura. 


\subsubsection{2.a Microorganismos}

\section{$\rightarrow$ Fungos apodrecedores}

De acordo com CAVALCANTE (1982) e LEPAGE et al. (1986), os fungos apodecedrores atacam as paredes celulares, alterando as propiedades físicas e químicas das mesmas. Estas alterações são irreversíveis e comprometem as propriedades fisico-mecânicas da madeira. Segundo KÄÄRIK apud LEPAGE et al. (1986), devido as suas atividades enzimáticas, os fungos apodrecedores são convenientemente divididos em:

$\Rightarrow$ capacidade limitada de deterioração (podridão mole);

$\Rightarrow$ alta capacidade de deterioração (podridão branca e parda).

Tanto nas folhosas como das coníferas o ataque se dá preferencialmente no alburno, devido a maior presença de nutrientes.

Para que estes tipos de microorganismos possam se desenvolver, devem ocorrer condições ideais, isto é, teor de umidade adequado, temperatura, $\mathrm{pH}$, oxigênio, ausência de substâncias tóxicas e outras.

De acordo com CAVALCANTE (1982), peças de madeira que apresentam umidade acima de $20 \%$, estão sujeitas à proliferação de fungos. Segundo o mesmo autor, a umidade ideal para o desenvolvimento de tais organismos, deverá ser acima do ponto de saturação das fibras (PSF), ou seja, aproximadamente $30 \%$. O valor máximo depende da espécie da madeira, mas deverá ser sempre inferior à umidade de saturação. A temperatura ideal para a proliferação de fungos está em torno de 25 graus. Quanto ao $\mathrm{pH}$, a faixa para seu desenvolvimento varia entre 2 e 7, porém, ótimos valores se encontram em torno de 5 . 
Os fungos causadores da podridão parda atacam predominantemente a celulose e hemicelulose, CAVALCANTE (1982). Todavia, os fungos causadores da podridão branca atacam tanto a celulose, a hemicelulose quanto a lignina, com predominância para a última, LEPAGE et al. (1986). Segundo CAVALCANTE (1982) \& LEPAGE et al. (1986), ambos podem atacar porções profundas da madeira, já o fungos causadores da podridão mole ataca somente a superfície da madeira, não atingindo profundidas maiores que 20 milímetros.

Estes ataques provocam algumas transformações à nível estrutural, ou seja:

$\Rightarrow$ perda de massa;

$\Rightarrow$ redução da massa específica aparente;

$\Rightarrow$ diminuição da resistência mecânica.

Do ponto de vista estético, as conseqüências estão voltadas para a mudança na coloração e aparecimento de manchas na superficie das peças de madeira.

\subsubsection{2.b Isóptera}

\section{$\rightarrow$ Cupins ou Térmitas}

Alguns tipos de cupins (também conhecidos como térmitas) utilizam a madeira como alimento e outros, como meio físico de hospedagem, mas em quaisquer situações causarão prejuizo. Dentre os organismos da Classe Insecta, os cupins são os insetos que mais causam dano à madeira, CAVALCANTE (1982). A extensão destes danos é diretamente proporcional às condições de uso, o tipo de inseto e da espécie da madeira.

Segundo LELIS (1975/76), os cupins podem ser divididos em duas grandes categorias: 
a) Cupins que vivem no solo ou em contato com o solo: esta categoria vive no solo ou em contato com o mesmo, de onde retira umidade necessária para sua sobrevivência. Estes insetos chegam a atingir peças de madeira a grandes distâncias do solo. De acordo com a bibliografia, alguns autores dividem esta categoria da seguinte maneira: subterrâneos, epígeos (murunduns) e arbóreos. Em função da intensidade de seus ataques, podem vir a causar problemas estruturais em quaisquer edificações.

b) Cupins que vivem na madeira: neste caso, a madeira é útil para os insetos tanto para abrigo como alimentação. Em função da umidade, existe uma divisão: cupim de madeira seca e cupim de madeira úmida. Os cupins de madeira seca tem na madeira seu habitat e, somente a umidade da madeira e do ar é suficiente para sua sobrevivência. Os ataques nas peças de madeira se desenvolvem lentamente, porém, são freqüentes, podendo provocar sérios danos. Geralmente, são detectados quando a parte interna da peça está parcial ou totalmente destruída. Na maioria das vezes, estes insetos são detectados pela presença de grânulos (fezes) próximo à peça atacada. No segundo caso, atacam exclusivamente peças de madeira com teor de umidade mais alto, se comparado com os cupins de madeira seca. Não há registro deste tipo de ataque às construções no Brasil.

\subsubsection{2.c Coleóptera}

\section{$\rightarrow$ Besouros}

Esta ordem é a maior da Classe Insecta, correspondendo a aproximadamente $40 \%$ do total, LEPAGE et al. (1986).

Segundo CAVALCANTE (1982), “...depois dos cupins, os insetos que maiores danos causam às madeiras pertencem à Ordem Coleótera". Entre as famílias existentes na Ordem Coleóptera, algumas usam a madeira como fonte de alimentação - desde a árvore viva até bem seca -, num gradiente decrescente de umidade, 
LEPAGE et al. (1986). Segundo o mesmo autor, as brocas atacam mecanicamente as paredes celulares (possuem mandíbulas fortes e robustas), podendo digerir a celulose, a hemicelulose e o conteúdo de algumas celulas parenquimáticas.

\subsubsection{Secagem da madeira}

Durante o ciclo de vida, as árvores absorvem do solo uma solução diluída de água e sais minerais, conhecida como seiva bruta, que é transportada por capilaridade até as folhas, pelos traqueídeos (coníferas) ou vasos (folhosas) localizados na camada periférica do lenho (alburno). Ao atingir os componentes do vegetal que possuem clorofila, são transformados pelo processo de fotossíntese em seiva elaborada, que através do floema (casca interna) - via pressão osmótica do protoplasma (elemento do núcleo celular) -, desce ao longo do tronco da árvore, nutrindo-a. A contínua repetição deste processo pode ser considerada como sendo a essência da sobrevivência do vegetal.

$\mathrm{Na}$ árvore viva, a umidade pode variar desde 35 até mais de $200 \%$, alcançando em alguns casos 400\%, como é o caso do Pau-de-balsa, BORTOLETTO (1993).

Antes da madeira ser processada, ou seja, transformada nos produtos finais, deve ser submetida ao processo de secagem. Esta atividade apresenta uma série de importantes vantagens, tais como as destacadas à seguir:

$\Rightarrow$ redução no peso próprio, barateando o custo de transporte;

$\Rightarrow$ aumento da resistência mecânica da madeira;

$\Rightarrow$ torna o ambiente não propício a ataques de organismos xilófagos;

$\Rightarrow$ o processo de secagem, quando bem conduzido, pode evitar defeitos, tais como fendilhamento, empenamento, trincas;

$\Rightarrow$ comportamento dimensional mais estável das peças de madeira; 
$\Rightarrow$ a resistência das ligações executadas com pinos metálicos (pregos e parafusos) é maior em madeira seca;

$\Rightarrow$ a madeira úmida não é adequada para colagem ou tratamento preservativo, etc.

Especificamente para o gênero Pinus, há duas vantagens, as quais podem ser consideradas como fundamentais, são elas:

$\Rightarrow$ madeira de secagem rápida favorecendo um giro bastante rápido de capital;

$\Rightarrow$ apresenta poucos defeitos decorrentes da secagem, tendo assim um aproveitamento maior das peças desdobradas.

Segundo PONCE (1985), a Tabela 3 indica os teores de umidade para certos tipos de uso. Esta tabela é baseada em uma temperatura ambiente em torno de 20 graus e umidade relativa do ar por volta de $65 \%$, ou seja, os teores de umidade adequados dependerão da região onde será exposta a peça de madeira.

TABELA 3 - Teor de umidade final recomendado para certos produtos da madeira

\begin{tabular}{|l|c|l|c|}
\hline \multicolumn{1}{|c|}{ Produtos } & $\%$ & \multicolumn{1}{c|}{ Produtos } & $\%$ \\
\hline Madeira serrada comercial & $16-20$ & Brinquedos para exteriores & $10-15$ \\
\hline Madeira para construção externa & $12-18$ & Equipamentos elétricos & $5-8$ \\
\hline Madeira para construção interna & $8-11$ & Embalagens(caixas) & $12-16$ \\
\hline Painéis & $6-8$ & Fôrmas para calçados & $6-9$ \\
\hline Piso e lambris & $6-11$ & Coronhas de espingarda & $7-12$ \\
\hline Móveis para interiores & $6-10$ & Instrumentos musicais & $5-8$ \\
\hline Móveis para exteriores & $12-16$ & Implementos agricolas & $12-18$ \\
\hline Equipamentos esportivos & $8-12$ & Barcos & $12-16$ \\
\hline Brinquedos para interiores & $6-10$ & Aviões & $6-10$ \\
\hline
\end{tabular}

Para promover a secagem pode-se adotar vários processos e, entre os mostrados à seguir, a secagem ao ar livre e a secagem em estufa convencional são os mais usados universalmente e, portanto, os mais importantes do ponto de vista da prática industrial. Os tipos de processos de secagem são os seguintes: 
$\Rightarrow$ Secagem ao ar livre;

$\Rightarrow$ Secagem em estufas convencionais;

$\Rightarrow$ Secagem por ventilação forçada;

$\Rightarrow$ Secagem solar;

$\Rightarrow$ Secagem por condensação e desumificação a baixa temperatura;

$\Rightarrow$ Secagem a alta temperatura;

$\Rightarrow$ Secagem por fervura em líqüidos oleosos;

$\Rightarrow$ Secagem a vapor;

$\Rightarrow$ Secagem a vácuo;

$\Rightarrow$ Secagem por alta freqüência.

Todos os processos de secagem acima mencionados, são detalhadamente apresentados por PONCE (1985).

Dentre os atualmente conhecidos, não existe um processo que possa ser indicado para todas as condições, devendo ser considerados aspectos como o tamanho da indústria, o tipo de madeira, a quantidade de madeira a ser seca, o tempo disponível para secagem, a localização da operação, etc.

Os principais defeitos decorrentes do processo de secagem que podem causar danos estruturais, podem ter origem nas contrações, nas infecções por fungos apodrecedores e nos cupins de madeira e de solo. Os defeitos causados pelos fungos apodrecedores e cupins (madeira e de solo) podem levar à perda total ou parcial da peça de madeira.

As diferenças das contrações radiais e tangenciais, características intrínsicas da madeira, são causadoras das distorções das seções transversais das peças de madeira serrada. Estes defeitos são denominados empenamentos, e podem ser classificados como: abaulamento, arqueamento, encurvamento, torcimento e encurvamento completo. 


\subsubsection{Preservação da madeira}

\subsubsection{Os tratamentos preservativos}

Os tratamentos preservativos, têm como objetivo principal proteger quaisquer peças de madeira contra possíveis ações deterioradoras, sejam elas oriundas de defeitos naturais ou devido a agentes deterioradores. Esses tratamentos aumentam a vida útil da madeira como material de construção.

O processso de preservação das peças de madeira pode vir a causar impacto ambiental, mas cabe ressaltar a especial atenção desprendida atualmente pelas indústrias de preservação com relação ao meio ambiente, isto é, tomando as devidas precauções quanto ao emprego de preservativos. Segundo LEPAGE et al. (1986), os órgãos responsáveis pela aprovação ao uso de pesticidas vêm abrindo exceções para as indústrias de preservativos de madeira, principalmente por estarem convencidos da capacidade efetiva de controle deste tipo de poluição.

Atualmente, a preservação de madeira não pode ser considerada como custo adicional, mas como um investimento indispensável que traz beneficios, proporcionando à madeira condições de durabilidade para competir no mercado consumidor com os demais materiais.

MONTANA QUÍMICA (1991), para prevenir a proliferação de organismos xilófagos, pode-se resumir e mostrar algumas técnicas existentes de preservação de madeiras. São elas:

a) Preservação Natural: esta técnica é direcionada a detalhes construtivos, ou seja, é utilizada em locais onde a madeira estiver protegida contra ação de agentes deterioradores. 
b) Preservação Indireta: conhecida como "tratamento de solo", este procedimento é executado para prevenção ou controle de ataques por cupins de solo, evitando assim o acesso destes organismos xilófagos às peças de madeira em serviço.

c) Preservação Biológica: trata-se de um processo de inserção de fungos não xilófagos na peça de madeira já contaminada, com o objetivo de combater os fungos xilófagos.

d) Preservação Química: dentre todas as técnicas, é a mais conhecida e usada no campo da tecnologia da madeira e, direciona-se principalmente para o combate das ações dos agentes biodeterioradores. Este trabalho irá retratar exclusivamente preservação química da madeira devido a sua importância. Esta técnica de preservação pode ser entendida como sendo a incorporação de produtos químicos no interior de quaisquer peças de madeira, com a finalidade de retardar ou prevenir o ataque de organismos xilófagos. Este tratamento serve como obstáculo tóxico à fonte de alimentos dos fungos, isto é, provoca o envenenamento dos nutrientes celulares, prevenindo a deterioração ou evitando que ela se alastre.

O tratamento preservativo ( preservação química) das peças de madeira, pode ser feito de duas maneiras:

$\Rightarrow$ Tratamento preventivo;

$\Rightarrow$ Tratamento curativo.

\subsection{Tratamento preventivo}

O tratamento preventivo tem como objetivo principal preservar peças de madeira antes da sua utilização, prevenindo a deterioração das mesmas em serviço.

Atualmente, os métodos preventivos mais utilizados para tratamento de peças de madeira através da preservação química, podem ser divididos em: processos de 
aplicação sem pressão ou processos caseiros, e os processos industriais ou processos à vácu@ e pressão, geralmente utilizando autoclaves.

\subsubsection{1.a Processo à vácuo e pressão}

Segundo CAVALCANTE (1982), RAIMBAULT (1983) e LEPAGE et al. (1986), este processo é o mais eficiente, tendo como base os seguintes fatores:

$\Rightarrow$ tratar grandes quantidades de madeira em curto intervalo de tempo;

$\Rightarrow$ tratamento mais eficiente devido a uma distribuição mais uniforme;

$\Rightarrow$ melhor controle de qualidade durante a aplicação, controle na retenção e penetração na madeira e controle do tempo de aplicação.

Este processo apresenta algumas desvantagens, tais como o custo do equipamentos e de sua manutenção, mão-de-obra mais especializada e o transporte até a usina de tratamento.

Segundo LEPAGE et al. (1986), o processo convencional de impregnação à vácuo e pressão, são os seguintes:

a) Processo da Célula Cheia:

$\Rightarrow$ Processo de Bethell;

$\Rightarrow$ Processo de Burnett;

$\Rightarrow$ Processo de Boulton;

$\Rightarrow$ Processo de Cellon e Dow.

b) Processo da Célula Vazia:

$\Rightarrow$ Processo Rüeping;

$\Rightarrow$ Processo Lowry. 
O mesmo autor, cita outros processos de tratamento preventido menos empregados, são eles:

$$
\begin{aligned}
& \Rightarrow \text { Processo de alta pressão; } \\
& \Rightarrow \text { Processo de duplo vácuo; } \\
& \Rightarrow \text { Processo OPM (Oscilant Pression Method); } \\
& \Rightarrow \text { Processo MSU ( Mississipi State University); } \\
& \Rightarrow \text { Processo com jato de alta energia; } \\
& \Rightarrow \text { Processo “Q". }
\end{aligned}
$$

Os processos citados acima é apresentado com detalhes por LEPAGE et al. (1986).

De modo a comprovar a eficiência do tratamento preservativo via processos industriais, o químico industrial e supervisor técnico do departamento de preservação e tratamento de madeiras da Sayerlack, J. A. Campos, em entrevista cedida à Revista Téchne nov/dez - $1995 \mathrm{~N}^{\mathrm{0}}$ 19, afirma que " o processo em autoclave permite garantir por vinte e cinco anos madeiras que não durariam mais que três anos sem tratamento".

\subsubsection{1.b Processo de aplicação sem pressão}

Este processo também é conhecido como processo caseiro, sendo de grande utilidade para pequenos e médios proprietários rurais. Tem um desempenho inferior aos processos descritos no ítem 2.3.4.1.1.a deste capítulo, e não consegue uma impregnação profunda dos produtos químicos nas peças de madeira.

Este processo apresenta algumas vantagens consideráveis, tais como:

$\Rightarrow$ não há necessidade do emprego de equipamentos sofisticados;

$\Rightarrow$ pode ser executado em qualquer local e não necessita de mão-de-obra especializada;

$\Rightarrow$ é menos onerosos. 
Os processos de preservação caseiros são:

$\Rightarrow$ Pincelamento ou pulverização;

$\Rightarrow$ Imersão;

$\Rightarrow$ Banho quente-frio;

$\Rightarrow$ Difusão;

$\Rightarrow$ Capilaridade ou Substituição de seiva;

$\Rightarrow$ Processo de Boucherie.

CAVALCANTE (1982), LEPAGE et al. (1986) e MONTANA QUÍMICA (1991), apresenta detalhadamente cada um dos processos citados acima.

Segundo GALVÃo (1975), dentre os processos caseiros de tratamento preventivo, os mais viáveis são: substituição de seiva e banho quente-frio. Este mesmo autor, relata resumidamente cada processo e cita a proporção adequada de produtos químicos para cada caso.

Quanto ao processo de preservação, é inegável a superioridade dos processos de impregnação com pressão, se comparado com os processos caseiros, principalmente, se houver comparação em termos de qualidade e eficiência do tratamento.

Entre os processos de impregnação sem pressão, o único que oferece alguma importância industrial no Brasil é o banho quente-frio, RAIMBAULT (1983). Classicamente, este processo só é aplicado com preservativos óleo-solúveis.

\subsection{Tratamento curativo}

Estas medidas serão aplicadas quando a infestação já estiver instalada. De acordo com LEPAGE et al. (1986) e MONTANA QUÍMICA (1991), os processos de tratamento curativo podem se dar da seguinte maneira: 
$\Rightarrow$ Fumigação ou Expurgo;

$\Rightarrow$ Métodos de pasta e Bandagem.

Os mesmos autores descrevem com detalhes os processos de tratamento preventivos mencionados acima.

\subsubsection{Classificação dos preservativos}

De acordo com RAIMBAULT (1983), o decreto 58.016 de 18/03/66 que regulamenta a lei 4797 de 20/10/65, prescreve para um preservativo as seguintes características:

$$
\begin{aligned}
& \Rightarrow \text { alta toxidez aos organismos xilófagos; } \\
& \Rightarrow \text { alto grau de retenção na madeira; } \\
& \Rightarrow \text { alta difusibilidade na madeira; } \\
& \Rightarrow \text { não corroer metais e nem a própria madeira; } \\
& \Rightarrow \text { oferecer segurança aos usuários; } \\
& \Rightarrow \text { não deve alterar a resistência mecânica da madeira; } \\
& \Rightarrow \text { deve ser inodoro; } \\
& \Rightarrow \text { ser econômico e disponível no mercado. }
\end{aligned}
$$

Embora todos os biocidas devessem apresentar as propriedades citadas, podese exigir de um produto ou processo preservativo apenas as características necessárias para cada caso específico.

Os preservativos destinados à proteção de peças estruturais podem ser classificados em função do solvente adotado para possibilitar a penetração no elemento a ser preservado, isto é:

$$
\begin{aligned}
& \Rightarrow \text { hidrossolúveis: onde o solvente(transporte) é a água, } \\
& \Rightarrow \text { óleo-solúveis : meio de transporte utilizado é o óleo. }
\end{aligned}
$$


Em geral, os preservativos hidrossolúveis possuem ação fungicida e inseticida, podendo ser aplicados à temperatura ambiente.

\subsubsection{Especificação do tratamento de uma estrutura}

De acordo com RAIMBAULT (1983), para que o tratamento das peças de madeira que compõem uma estrutura sejam especificadas adequadamente e sejam obtidos resultados satisfatórios, é necessário analisar alguns pontos principais, tais como:

$$
\begin{aligned}
& \Rightarrow \text { utilidade da madeira; } \\
& \Rightarrow \text { ambiente em que a madeira ficará exposta; } \\
& \Rightarrow \text { tipo de tratamento e o tipo de preservativo utilizado; } \\
& \Rightarrow \text { grau de retenção e penetração do preservativo. }
\end{aligned}
$$

Alguns exemplos de especificações para tratamento são mencionados pelo mesmo autor:

$\Rightarrow$ em estrutura em contato com água salgada, não se deve usar o Pentaclorofenol. O cloreto de sódio provoca sua solubilização alterando-o quimicamente;

$\Rightarrow$ preservação em madeira que terá contato direto com alimentos, deve-se empregar preservativo de baixa toxidade;

$\Rightarrow$ para construção e acabamento, onde há muito contato com ser humano, deve-se usar produtos preservativos que não sofram o processo de exudação e nem exalem odores desagradáveis. Como exemplo, deve-se evitar o creosoto e alguns veículos utilizados com o Pentaclorofenol.

Do ponto de vista estrutural, algumas áreas exigem proteção mais atenciosa, tais como: 
$\Rightarrow$ elementos estruturais dos pisos térreos das edificações;

$\Rightarrow$ peças de telhado, próximas a rufos e calhas;

$\Rightarrow$ elementos estruturais em contato com o solo ou elemento concretado;

$\Rightarrow$ topos das peças de madeira, pois absorvem umidade mais rapidamente;

$\Rightarrow$ fendas, juntas e áreas próximas aos elementos de ligação, etc.

\subsubsection{Controle de qualidade do tratamento de uma estrutura}

Segundo RAIMBAULT (1983), para controlar a qualidade da preservação, algumas medidas devem ser tomadas:

$\Rightarrow$ teor de umidade da peça a ser tratada deve ser inferior a $35 \%$ quando o tratamento se der com preservativos hidrossolúveis e não superior a 30\% para preservativos óleo-solúveis;

$\Rightarrow$ a penetração e a retenção de preservativo no alburno deve ser total em espécies que tenham cerne bem definidos, e no mínimo de $85 \%$ nas espécies em que o cerne não seja bem definido,como no gênero Pinus;

$\Rightarrow$ controlar a intensidade e o tempo de vácuo e pressão, concentração da solução de tratamento e solução preservativa;

$\Rightarrow$ para madeiras cuja trabalhabilidade não se conhece, devem ser feitos testes para se obterem parâmetros de tratamento. 


\subsection{Classificação da madeira}

\subsubsection{Introdução}

Baseado na filosofia de segurança das estruturas e para atender as exigências do mercado consumidor, há necessidade de um conhecimento maior do material à ser empregado, e poder aplicá-lo com maior eficácia. Mas, segundo o enfoque de segurança estrutural, o emprego de quaisquer materiais sem que haja classificação ou controle tecnológico, é inadmissível.

Existem alguns materiais de fácil controle tecnológico, dentre eles, o aço e o concreto, mas, a madeira por ser de origem natural, carrega consigo todas as características inerentes à sua origem, causando uma dificuldade maior para serem classificadas.

De maneira geral, sabe-se que, quão mais eficientes os métodos adotados para a classificação do material, maior segurança e economia haverá na edificação.

De acordo com a literatura internacional, tem-se dois processos clássicos para classificar estruturalmente a madeira:

$\Rightarrow$ Classificação Visual

$\Rightarrow$ Classificação Mecânica.

A madeira, devido às características intrínsecas, é susceptível a defeitos na secagem (fendilhamento, rachaduras, empenamentos, etc.), bem como os defeitos naturais (nós, fibras revessas, etc.); defeitos de dificil eliminação. Sabendo-se que estes defeitos podem causar um decréscimo na resistência da madeira, há a necessidade de classifica-las quando utilizadas estruturalmente.

A "Classificação Visual" foi o primeiro método a ser utilizado na classificação de peças de madeira e fundamenta-se nas características de crescimento da árvore, ou 
seja, nas orientações das fibras, número de nós, fendas e de anéis anuais de crescimento. Em resumo, a classificação visual avalia a presença de defeitos através de inspeção visual e, em seguida, classifica-se a madeira de acordo com regras normalizadas.

A partir do decreto $30 / 835$ de $21 / 12 / 1951$, há no Brasil uma norma que regulariza a classificação visual, e esta, é voltada apenas à exportação do Pinho do Paraná (Araucária angustifolia). Todavia, os órgãos competentes que regulam metas para o uso da madeira em estruturas, recomendam a adoção do "Boletim 185 do Forest Products Laboratory". Atualmente, o método de avaliação visual está em desuso, pelos seguintes motivos:

$\Rightarrow$ intuitivamente é possível identificar peças de madeira de boa qualidade visual com facilidade e rapidez;

$\Rightarrow$ para peças de aparência semelhante, a impossibilidade de definição quanto à resistência;

$\Rightarrow$ custo e o tempo necessário para aplicação desta classificação, desestimulam seu uso.

FURIATI (1983), baseado na resistência efetiva da madeira, propõe um processo de selecionamento, definindo-o como "Classificação Estrutural".

O objetivo principal é a determinação no local da obra do módulo de elasticidade longitudinal através da realização do ensaio de flexão estática não destrutivo para as peças de madeira que compõem um determinado lote.

Segundo o mesmo autor, este processo de classificação têm algumas vantagens, tais como:

$\Rightarrow$ tempo de execução do ensaio é de aproximadamente 2 (dois) minutos;

$\Rightarrow$ baixo custo de equipamentos e de mão-de-obra. 
Como resultado final, comparou-se os dados da classificação normalizada - via norma brasileira NBR 7190/96 - Anexo "B" - com os resultados da classificação proposta por FURIATI (1983) e, obteve-se uma variação de aproximadamente 6\% para o módulo de elasticidade longitudinal.

A grande vantagem deste processo, é a possibilidade de classificação das peças estruturais no local da obra, dando condições de utilização dos melhores elementos nas condições mais críticas, ou seja, nas regiões mais solicitadas.

A determinação do módulo de elasticidade longitudinal segundo a "Classificação Mecânica", é feita em diferentes tipos de máquinas atualmente comercializadas e, como resultado, consegue-se separar as peças de melhor qualidade. Sabe-se que a eficiência deste processo é maior, se comparada com a classificação visual, mas, apesar das vantagens, é pouco utilizado no Brasil. O desuso deste método esta diretamente relacionado custo do investimento inicial em equipamentos e mãode-obra. Outro fator a ser considerado diz respeito à importância dada às madeiras e às estruturas de madeira.

Atualmente, pensando-se em divulgar o material e, em particular, as espécies do gênero Pinus voltadas às estruturas de coberturas, deve ser realizada obrigatoriamente uma classificação. Sugere-se primeiramente a adoção da classificação visual, onde o objetivo principal seria a classificação qualitativa, visando eliminar ao máximo os defeitos naturais e, posteriormente, dentre as peças selecionadas, faz-se o "Ensaio de Campo", classificando-as em função das características elásticas.

A realização da classificação visual seguida da estrutural seria de grande valia, pois, é facilmente acoplado aos sistemas construtivos usados atualmente, além do baixo custo referente à mão-de-obra e aos equipamentos. 


\subsection{Sistemas construtivos}

\subsubsection{Introdução}

Segundo a literatura, as estruturas de coberturas e os sistemas construtivos evoluíram ao longo do tempo, de acordo com as necessidades e costumes de cada civilização.

Quanto ao nível de tecnologia, os sistemas construtivos voltados às estruturas podem ser classificados de duas maneiras:

$\Rightarrow$ Sistema Construtivo Convencional (Artesanal);

$\Rightarrow$ Sistema Construtivo Industrializado (Pré-fabricação).

A priori, para tornar viável o estudo das estruturas industrializadas para cobertura, é necessário analisar e ter conhecimento da importância de alguns parâmetros triviais no comportamento das estruturas executadas segundo o sistema construtivo convencional, como por exemplo, as ligações e os sistemas de contraventamentos. Somente desta maneira é possível fazer algumas avaliações dos processos e, conseqüentemente, utilizá-los com maior eficácia.

\subsubsection{Sistema construtivo convencional (artesanal)}

O sistema construtivo artesanal é considerado o processo pioneiro nas construções de madeira.

Segundo o histórico bibliográfico, houve a evolução gradativa deste sistema construtivo; evolução calcada em suas próprias necessidades e, principalmente, devido ao advento de alguns materiais, como por exemplo, o ferro, muito utilizado 
como parte integrante das ferramentas de auxílio na construção, bem como, na própria estrutura.

Dentre as formas estruturais comumente utilizadas ao longo da história, podese dizer que, principalmente em estruturas treliçadas para cobertura, o sistema construtivo artesanal se destacou, ou seja, onde a qualidade da mão-de-obra pôde ser colocada à prova $\mathrm{e}$, conseqüentemente, ser reconhecida.

Da forma como se caracteriza este sistema construtivo, permite-se quaisquer tipos de variações, seja na geometria da estrutura, nos tipos de ligações entre elementos estruturais ou na forma e dimensão da seção transversal. Atualmente, a definição da geometria das estruturas depende, dos tipos de elementos de coberturas, dos carregamentos e do comportamento estrutural e, também, da mão-de-obra disponível no local.

Quanto aos tipos de ligações mais convenientes para o sistema em questão, pode-se citar os pinos metálicos (pregos, parafusos), os conectores metálicos (anéis), e os pinos de madeira (cavilhas).

As seções tranversais são classificadas de acordo com as sua forma geométrica:

$\Rightarrow$ Simples: formadas por apenas uma peça, podendo ser retangular, quadrada ou circular.

$\Rightarrow$ Composta: formadas por duas, três ou quatro peças, ligadas entre si por meio de pregos, parafusos ou cola. Quanto à sua forma geométrica, podem ser denominadas por seção "I", “T", "H" ou caixão.

$\Rightarrow$ Múltipla: formadas por mais de uma peça, na maioria das vezes retangulares. Estas peças são ligadas entre si através de enrijecedores descontínuos dispostos perpendicularmente ao eixo axial das peças. 
Para executar uma estrutura qualquer através do sistema construtivo artesanal, deve-se ter conhecimento dos tipos de ligações a das formas geométricas das seções transversais. Assim sendo, define-se a estrutura de acordo com alguns parâmetros, tais como:

$\Rightarrow$ funcionalidade da edificação;

$\Rightarrow$ ordem de grandeza dos carregamentos;

$\Rightarrow$ grau de agressividade do ambiente em que a estrutura será submetida;

$\Rightarrow$ disponibilidade comercial do elemento de ligação à ser adotado;

$\Rightarrow$ disponibilidade de mão-de-obra capacitada e outros.

Pode-se afirmar que o sistema construtivo artesanal ainda é o mais divulgado e utilizado em todo o Brasil.

\subsubsection{Sistema construtivo industrializado (pré-fabricação)}

Mundialmente, o processo evolutivo gerou um mercado consumidor muito exigente, propiciando o surgimento de sistemas produtivos, visando obter produtos finais de boa qualidade com baixo custo.

Com base nesta tendência mundial e levando-se em consideração a crescente e programada extração de madeira de reflorestamento, propôs-se a industrialização de estruturas, com objetivo de recolocar a madeira ao nível competitivo com os demais materiais usados na construção civil. Desta forma, pode-se dizer que os objetivos principais da industrialização vão de encontro com o emprego racional da madeira.

Os sistemas industrializados são destinados, na maioria das vezes, à produção de estruturas treliçadas para coberturas, e consistem basicamente na sobreposição dos conectores metálicos (chapas com dentes estampados) nas extremidades dos elementos estruturais que se pretendem unir. Tais estruturas são executadas na sua 
quase totalidade em indústrias, respeitando uma linha de produção. Mas, mesmo assim, alguns componentes são executados "in loco", como as emendas responsáveis pela integralização da estrutura, as terças e o sistema de contraventamento.

Em função da geometria das estruturas, poderá haver a necessidade do seu desmembramento, em duas ou mais partes, com a finalidade de facilitar e tornar viável o transporte.

Segundo BARROS Jr. (1989), este sistema é indicado para espécies que tenham massa específica aparente entre 450 e $750 \mathrm{Kg} / \mathrm{m}^{3}$, devido a facilidade de fixação das chapas com dentes estampados e, conseqüentemente, garantir a efetividade da união. Entre estas espécies, encontram-se as coníferas de reflorestamento. Tal sistema, também pode ser utilizado com espécies que tenham maior massa específica, porém, deve-se ter maiores cuidados com a fixação dos dispositivos de ligação, BARALDI (1996).

As uniões das estruturas pré-fabricadas são executadas necessariamente através de chapas com dentes estampados e, não é permitida a utilização de elementos estruturais com seções transversais múltiplas. Portanto, o emprego das demais formas de seções tranversais pode ocorrer, exceto nas regiões de posicionamento dos dispositivos de ligação, devendo-se então, empregar seção transversal simples. A variação da seção tranversal dos elementos estruturais, deverá ocorrer quando houver a necessidade de resistir aos esforços solicitantes ou para propiciar maior rigidez do plano da estrutura. Estas iniciativas têm por finalidade proporcionar maior segurança do ponto de vista estrutural.

Independente dos sistemas construtivos a serem adotados, existe a necessidade da adoção de alguns procedimentos básicos para propiciar à madeira uma vida útil mais longa. Tais procedimentos, como a classificação, a forma de armazenamento, o controle de umidade, desdobramento e cortes das pranchas e o tratamento preservativo, devem ser rigorosamente considerados durante a fase de 
processamento das peças de madeira, visando minorar os defeitos de secagem e armazenamento (empenamentos, rachaduras, fendilhamento), defeitos naturais (presença de nós, bolsões de resina, fibras reversas, etc) e defeitos causados pelos ataques de organismos xilófagos.

De Acordo com BARROS Jr. (1989), o sistema industrializado possue algumas vantagens e limitações em relação ao sistema convencional, são eles:

$\diamond$ Vantagens:

$\Rightarrow$ estruturas construídas na sua maior parte em local separado da obra, evitando possíveis incovenientes quanto ao andamento de outras atividades;

$\Rightarrow$ exigência de número reduzido de pessoal, porém especializado, e não há necessidade de deslocamento da mão-de-obra;

$\Rightarrow$ estruturas relativamente leves, possibilitando o seu transporte e manuseio;

$\Rightarrow$ produção em indústria, ou seja, de forma centralizada, facilitando o uso de melhores equipamentos e, conseqüentemente, permitindo a obtenção de estruturas com melhor controle de qualidade;

$\Rightarrow$ possibilidade de variações na forma geométrica, sem que haja variações consideráveis no custo;

$\Rightarrow$ entrega quase imediata, evitando perda e roubo de material;

^ Limitações:

$\Rightarrow$ resistência inicial das empresas, companhias de habitação e dos próprios usuários quanto à nova tecnologia;

$\Rightarrow$ necessidade de estabelecer limitação do raio econômico para transporte;

$\Rightarrow$ falta de conhecimento técnico da parte dos profissionais da construção civil e dos projetistas;

$\Rightarrow$ para obras mal executadas, as estruturas pré-fabricadas podem não se encaixar de forma satisfatória nos dispositivos de fixação; 
$\Rightarrow$ este sistema não permite alterações de projeto durante a execução das obras;

$\Rightarrow$ devido a possibilidade da deterioração dos conectores metálicos, não é indicado para construções expostas à ambientes agressivos, ou seja, ambiente marinho ou indústrias que manipulam produtos químicos. 


\section{METODOLOGIA}

\subsection{Introdução}

Entre todas as formas de utilização estrutural da madeira na construção civil, a estrutura de sustentação de coberturas é a mais difundida.

A utilização em grande escala da madeira em estruturas de telhados no país, foi conseqüência de alguns fatores, tais como:

$\Rightarrow$ grande quantidade de matéria-prima disponível nas florestas nativas;

$\Rightarrow$ relativa proximidade entre as matas nativas e os grandes centros consumidores;

$\Rightarrow$ baixo custo final da madeira processada.

Tais fatores, levaram ao extrativismo exagerado provocando redução e escassez das espécies nativas. De algum modo, este fato permitiu a implantação de áreas de reflorestamento.

À vista do exposto, pode-se considerar que o emprego da madeira em telhados, ocorreu, numa primeira fase, através da utilização da madeira retirada de árvores das florestas nativas. Na segunda fase - bem recente no Brasil - teve início a exploração das áreas de reflorestamento, que fornecem material compatível para a pré-fabricação de estruturas treliçadas, à produção de peças de madeira laminadacolada e de chapas de madeira reconstituída. 
Diante dos fatos, e sabendo que, atualmente no Brasil as estruturas destinadas a coberturas estão muito aquém, no que diz respeito as etapas projetual e construtiva, optou-se pelo desenvolvimento de um trabalho teórico embasado na elaboração de vários projetos.

$\mathrm{O}$ descaso à respeito das etapas citadas, pode ser explicado por alguns fatores, entre eles:

$\Rightarrow$ falta de concientização dos usuários e proprietários, que não valorizão os projetos elaborados de acordo com as normas de segurança e qualidade;

$\Rightarrow$ falta de conhecimento do material por parte de alguns profissionais (engenheiros e arquitetos);

$\Rightarrow$ falta de uma política de incentivo à utilização adequada e racional da madeira;

$\Rightarrow \mathrm{o}$ avanço tecnológico de alguns materiais, concomitantemente à produção artesanal das estruturas de madeira, levou a diminuição do emprego das mesmas.

Desta maneira, torna-se evidente a necessidade de racionalização do projeto e da produção, levando-se em conta a possível utilização de espécies de reflorestamento. De acordo com esta idéia e com o objetivo citado no Ítem 1.3, foram elaborados numerosos projetos utilizando-se procedimentos condizentes ao contexto da engenharia civil. Para isto, foi necessária a adoção de algumas diretrizes, como explicitado a seguir:

a) Elaboração de projetos à luz dos conceitos do Método das Tensões Admissíveis (MTA): treliças tipo "Howe" e "Fink", vãos teóricos variando entre 6 e 12 metros, telhas de fibro-cimento e aço, ligação entre elementos estruturais através de parafusos de aço;

b) Elaboração de projetos à luz dos conceitos do Método dos Estados Limites (MEL): treliças tipo "Howe" e "Fink", vãos teóricos variando entre 6 e 12 metros, 
telhas de fibro-cimento e aço, ligação entre elementos estruturais através de parafusos de aço;

c) Elaboração de projetos à luz dos conceitos do Método das Tensões Admissíveis (MTA): treliças "PRATT" e "FINK", vãos teóricos variando entre 6 e 12 metros, telhas de fibro-cimento e aço, ligação entre elementos estruturais através de chapas com dentes estampados (CDE);

Considerada a expressiva probabilidade de ocorrerem defeitos em peças de madeira de diversas espécies de reflorestamento, em particular nos Pinus elliottii e taeda, aqui estudados, optou-se pela adoção de elementos estruturais com seções transversais simples e compostas, porém, com peças de seção transversal menores que as comumente usadas nas construções pelo sistema artesanal.

Em alguns casos, por exemplo, os montantes das treliças tipo "Howe" e "Pratt", foram utilizadas peças com espessura inferior à mínima preconizada pela atual Norma Brasileira NBR 7190/82 - "Cálculo e Execução de Estruturas de Madeira" e também pelo Projeto da Norma Brasileira PNBR 7190/96 - "Projetos de Estruturas de Madeira".

Tratando de peças estruturais de espécies de coníferas e considerando a necessidade de ser efetuada a sua classificação, admitiu-se que a qualidade final dos elementos classificados seria suficientemente aceitável, a ponto de não comprometer o desempenho estrutural.

Este procedimento favorece a classificação visual, pois, a menor espessura da peça permite controlar melhor os defeitos de origem natural.

A opção pela utilização de peças estruturais mais esbeltas, trouxe consigo uma redução no consumo e, obviamente, obteve-se estruturas mais leves, menos onerosa e, sobretudo, com a segurança exigida pelos orgãos competentes. 


\subsection{Dispositivos de ligação}

\subsubsection{Introdução}

Um dos aspectos que mais ocupa a atenção dos projetistas de estruturas de madeira é o da ligação entre elementos estruturais, pois trata-se de um dos pontos de partida na concepção da geometria da estrutura.

Neste trabalho, foram adotados os parafusos de aço e as CDE como os elementos de ligação entre as barras da estrutura.

\subsubsection{Parafusos de aço}

Atualmente, no Brasil, o método de cálculo normalizado para ligações parafusadas exige seções transversais mais robustas para os elementos estruturais, de modo a permitir a locação dos parafusos. Este fator é o grande responsável pelas limitações deste tipo de ligação, fazendo com que esta se torne o ponto crítico das estruturas, algumas vezes reduzindo a probabilidade do emprego da madeira de forma competitiva.

Ainda hoje, a maioria das estruturas treliçadas destinadas às coberturas são executadas usando ligações parafusadas

\subsubsection{Chapas com dentes estampados (CDE)}

Com o intuito de diminuir ou eliminar os problemas oriundos das ligações executadas com parafusos, foi desenvolvido outro tipo de conector; que não somente substituisse os existentes, mas, que também garantisse a integridade das estruturas. 
De acordo com as expectativas do mercado consumidor, a solução alternativa mais adequada para inovar as ligações estruturais, foram as CDE.

Do ponto de vista projetual, tais chapas possibilitam a adoção de seções transversais mais leves, em alguns casos até inferiores às seções mínimas exigidas pela NBR 7190/82 e pelo PNBR 7190/96.

O dimensionamento dos dispositivos de ligação foi feito segundo os padrões da Gang-Nail do Brasil Ltda, apresentados por UJVARI (1983).

A nível construtivo, este tipo de ligação facilita a montagem e possibilita a préfabricação de estruturas de madeira.

Tais chapas, atualmente, são muito empregadas e consagradas em quaisquer tipos de estruturas treliçadas para cobertura, em particular nos países da Europa, na América do Norte e na Austrália. No Brasil, devido à falta de divulgação das mesmas, sua utilização ainda não atingiu os mesmos níveis dos parafusos de aço.

\subsection{Sistemas estruturais}

Para o cálculo dos esforços solicitantes nos elementos estruturais estudados, foram adotadas as hipóteses a seguir mencionadas.

\subsubsection{Estrutura secundária (terça): viga maciça}

As vigas podem ser consideradas como o sistema estrutural precursor na engenharia de estruturas de madeira.

Neste trabalho em específico, este elemento será denominado "Estrutura Secundária" ou "Terça" e, são solicitadas por flexão oblíqua composta. 
Alguns parâmetros foram adotados de modo a permitir o desenvolvimento do projeto:

$\Rightarrow$ seção transversal e vão teórico compatíveis com as condições de projeto;

$\Rightarrow$ esquema estático: bi-apoiada em relação ao eixo maior inércia, tendo como apoio os nós do banzo superior das treliças; para o eixo de menor inércia, as vigas são consideradas tendo dois tramos, sendo o apoio interno proporcionado por uma estrutura de travamento (barra de aço rosqueada) interceptando perpendicularmente o ponto médio do eixo axial da mesma.

\subsubsection{Estrutura principal (treliça): viga treliçada}

Esta forma estrutural é utilizada em grande escala, principalmente, nas estruturas destinadas às coberturas. As hipóteses básicas do cálculo estrutural são:

$\Rightarrow$ estrutura isostática internamente;

$\Rightarrow$ os nós são considerados rótulas ideais;

$\Rightarrow$ os carregamentos externos são transferidos para a estrutura na forma de cargas concentradas aplicadas nos nós;

Com base nas hipóteses citadas e de acordo com o objetivo da pesquisa, foram adotadas alguns parâmetros para as vigas treliçadas:

$\Rightarrow$ esquema estático:

* internamente: estrutura isostática;

* externamente: estrutura isostática, tendo um apoio rotulado fixo e um apoio rotulado móvel;

$\Rightarrow$ inclinação do banzo superior em relação à horizontal: 15 graus; 
$\Rightarrow$ admite-se que todas as cargas estão aplicadas sobre os nós do banzo superior;

$\Rightarrow$ tipos de dispositivos de ligação adotados:

* parafusos de aço;

* chapas com dentes estampados.

$\Rightarrow$ Seções transversais definidas de acordo com os projetos.

A definição das formas geométricas adotadas, deu-se após uma prévia avaliação do comportamento estrutural das treliças existentes, e de posse dos resultados, priorizou-se as geometrias usadas freqüentemente, ou seja:

$\Rightarrow$ Treliça tipo "Howe";

$\Rightarrow$ Treliça tipo "Pratt";

$\Rightarrow$ Treliça tipo "Fink".

\subsubsection{Treliça tipo "Howe"}

De acordo com MOLITERNO (1981), também conhecida como Treliça Inglesa e, dentre todas as formas geométricas existentes, é a que se destaca no Brasil quanto sua utilização.

Para carregamentos permanentes, esta geometria possue características próprias, ou seja, as diagonais são solicitadas por compressão, enquanto os montantes são tracionados. Para carregamento, cuja combinação de ações, resultem em sucção do telhado, os esforços internos são invertidos em relação ao carregamento permanente.

O emprego desta configuração é conveniente quando tem-se diagonais com secão transversal suficientemente rígida, de modo a evitar a perda da estabilidade fora do plano da treliça. $\mathrm{O}$ uso desta geometria é freqüente em estruturas de coberturas destinadas a residências, galpões industriais e comerciais de pequeno e médio portes, construções rurais, entre outros. 


\subsubsection{Treliça tipo "Pratt"}

Em relação à "Howe", esta possue diagonais invertidas e, sob as ações permanentes, terá os montantes comprimidos e as diagonais tracionadas. A utilização desta forma geométrica é justificada quando os carregamentos permanentes são preponderantes sobre os demais, pois, os elementos internos mais longos serão tracionados e não terão problemas de instabilidade local. Sabendo-se que a resistência da madeira é maior à tração, poderá haver uma redução das seções tranversais, levando a um consumo menor de material. A grande limitação desta geometria, refere-se ao nó da cumeeira, no que diz respeito ao posicionamento dos dispositivos de ligação, quando estes forem parafusos de aço, pois, haverá a convergêrncia de 5 (cinco) elementos estruturais neste nó.

O emprego desta forma geométrica está voltada principalmente para estruturas de coberturas de grandes vãos, como por exemplo, galpões industriais ou similares.

\subsubsection{Treliça tipo "Fink"}

É muito difundida na América do Norte, parte da Europa e Austrália, principalmente no caso de estruturas industrializadas, onde a ligação é feita por chapas com dentes estampados. No Brasil, seu emprego ainda é relativamente pequeno.

A utilização da treliça tipo "Fink" é voltada para residências, galpões industriais e comerciais e outros.

O comportamento estrutural é semelhante às treliças tipo "Howe" $\mathrm{e}$ "Pratt". 


\subsubsection{Estrutura de Contraventamento}

As vigas treliçadas e os elementos que as compõem estão sujeitos à perda da estabilidade global e local, respectivamente, tanto no plano da estrutura como fora dele.

Para evitar a ocorrência da instabilidade fora do próprio plano, adota-se o sistema de contraventamento, ou seja, estruturas dispostas com seu plano de maior rigidez na direção perpendicular ao sistema principal, com finalidade de impedir os deslocamentos transversais da estrutura principal, bem como dos elementos estruturais que as compõem.

O sistema de contraventamento adotado para as estruturas citadas nos Ítens 3.3.2.1 a 3.3.2.3 deste capítulo, será constituído de treliças dispostas no plano horizontal e no plano da cobertura, ambos ortogonais à estrutura principal, contendo o banzo inferior e superior, respectivamente.

As treliças que irão compor o sistema de contraventamento no plano do banzo superior terão as terças e os tirantes metálicos (aço) como elementos principais. Tais terças, são elementos estruturais indispensáveis no sistema de cobertura. Assim serão aproveitadas como parte integrante da estrutura de contraventamento. Devido à sua rigidez, terão como função principal a absorção dos esforços de compressão.

De acordo com a geometria adotada, as barras metálicas (barras de aço rosqueadas) terão baixa rigidez à compressão, sendo dimensionadas para absorver apenas esforços de tração.

O plano horizontal que contém os banzos inferiores, terá o sistema de contraventamento composto somente por barras de aço. 
A transferência de esforços entre os sistemas de contraventamentos adjacentes será dada pelas terças no plano da cobertura e por barras metálicas no plano horizontal.

Sabendo-se que não há estudos definitivos que estabeleçam as distâncias ideais entre estruturas de contraventamento adjacentes, estas serão adotadas com base em dados empíricos, ou seja, espaçamentos máximos entre três treliças (estruturas principais).

Desta forma, adotar-se-á os seguintes espaçamentos:

$\Rightarrow$ para as treliças que tenham ligações parafusadas: espaçamento entre 6,5 e 10 metros;

$\Rightarrow$ para as treliças que tenham ligações com chapas com dentes estampados: espaçamento de 2 metros.

As estruturas de contraventamento terão as seguintes configurações:

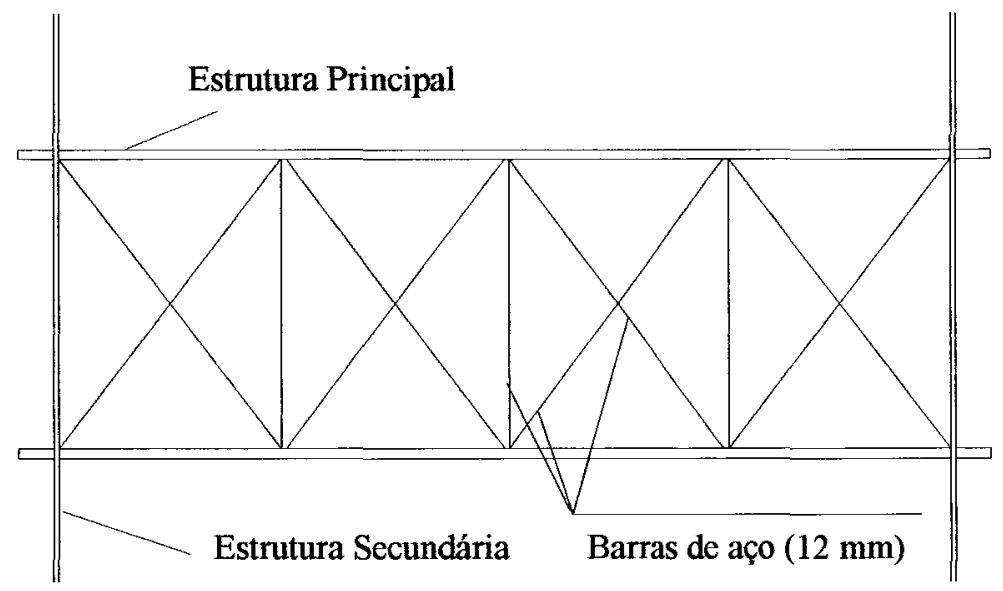

FIGURA 8 - Esquema geral da estrutura de contraventamento do banzo inferior 
Capitulo 3: Metodologia

68

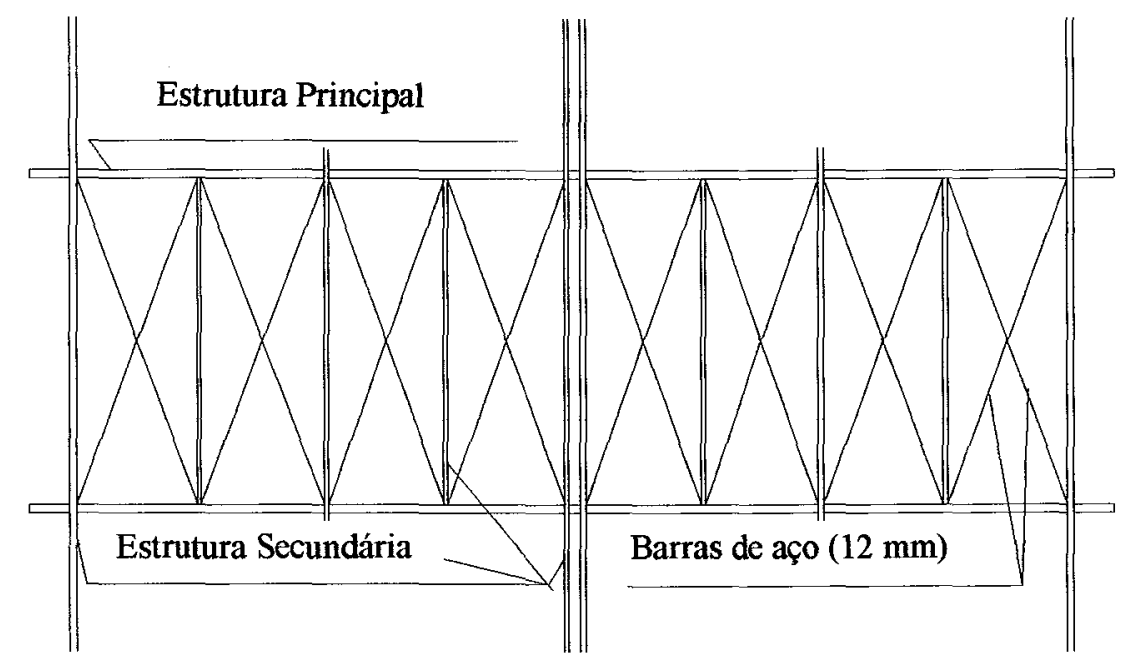

FIGURA 9 - Esquema geral da estrutura de contraventamento do banzo superior 


\section{DIMENSIONAMENTO DOS ELEMENTOS ESTRUTURAIS}

\subsection{Introdução}

Com o intuito de alcançar o objetivo inicialmente proposto e para atingir a faixa de mercado destinada aos usos mais freqüentes (estruturas de cobertura para construções rurais, galpões industriais e comerciais, depósitos, etc), optou-se pela elaboração de vários projetos.

Para ilustrar os procedimentos utilizados visando a obtenção dos resultados desejados, é apresentado, a seguir, um exemplo de cálculo, para o qual foram adotados:

$\Rightarrow$ estrutura principal: treliça tipo "Howe";

$\Rightarrow$ estrutura secundária: viga maciça (terça);

$\Rightarrow$ estrutura de contraventamento: viga maciça (terça) e barras de aço rosqueadas;

$\Rightarrow$ estrutura de travamento: barras de aço rosqueadas;

$\Rightarrow$ telha de fibro-cimento (6 milímetros);

$\Rightarrow$ ligações através de parafusos passantes;

$\Rightarrow$ planta da edificação: 12 metros de largura por 30 metros de comprimento;

$\Rightarrow$ telhado com duas águas;

$\Rightarrow$ inclinação do banzo superior: 15 graus;

$\Rightarrow$ aberturas laterais: oito janelas por face, medindo 2 metros de comprimento por 0,75 metro de altura cada uma; 
$\Rightarrow$ abertura (frente): um portão medindo 5 metros de largura por 3,8 metros de altura;

$\Rightarrow$ abertura (fundo): três janelas medindo 2 metros de comprimento por 0,75 metro de altura cada uma.

$\Rightarrow$ altura da edificação: 4 a 5 metros

Estas características são representadas a seguir:

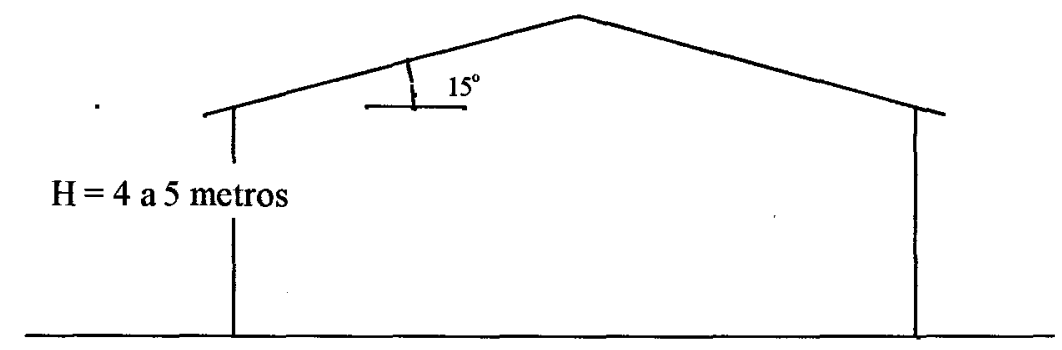

Vão - 12 metros

FIGURA 10 - Esquema da elevação da edificação

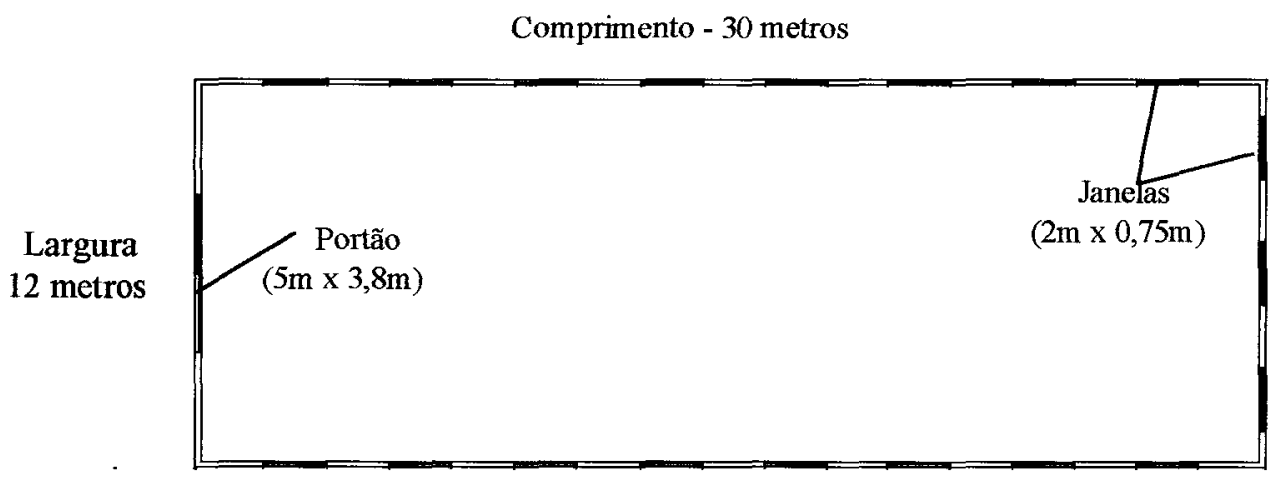

FIGURA 11 - Esquema da planta da edificação

Para efeito de dimensionamento, são considerados como elementos estruturais as barras da treliça (estrutura principal), as terças (estrutura secundária) e a estrutura de contraventamento.

Para a resolução deste exemplo e para a elaboração segura e econômica de quaisquer projetos de estruturas de cobertura, há a necessidade do uso dos 
documentos normativos pertinentes. Assim sendo, utilizou-se como respaldo alguns documentos:

$\Rightarrow$ NBR 7190/96 - "Projeto de Estruturas de Madeira";

$\Rightarrow$ NBR 7190/82 - "Cálculo e Execução de Estruturas de Madeira";

$\Rightarrow$ NBR 6120/82 - "Cargas para o Cálculo de Estruturas de Edificações";

$\Rightarrow$ NBR 6123/88 - "Forças Devidas ao Vento em Edificações";

$\Rightarrow$ NBR 8681/84 - "Ações e Segurança nas Estruturas";

$\Rightarrow$ NBR 8800/86 - "Projeto e Execução de Estruturas de Aço de Edificios".

Dentre as ações com maiores probabilidades de ocorrência durante as fases construtiva e de utilização, destacam-se:

$\Rightarrow$ ação permanente;

$\Rightarrow$ ação variável (vento de sobrepressão, vento de sucção e acidental);

Para as ações citadas, têm-se os seguintes carregamentos:

$1^{\underline{0}}$ - ação permanente;

$2^{\circ}$ - ação permanente combinada com ação variável (Vento de sobrepressão);

$3^{\underline{0}}$ - ação permanente combinada com ação variável (Vento de sucção);

$4^{0}$ - ação permanente combinada com ação da carga acidental.

$5^{0}$ - ação permanente combinada com ação da carga acidental e ação variável (Vento de sobrepressão).

\subsection{Estrutura secundária (terça)}

\subsubsection{Introdução}

Este elemento estrutural tem como função principal transferir para a treliça as ações (permanentes e variáveis) oriundas da cobertura. Neste caso, também é parte 
integrante do sistema de contraventamento no plano que contém o banzo superior. Desta forma, seria necessário dimensioná-la à flexão composta oblíqua. Mas, com base na NBR 7190/96 - Ítem 6.6, constata-se que o esforço normal é muito pequeno e, conseqüentemente, o valor da tensão normal proveniente da compressão é pequena se comparada com o valor da tensão normal originada na flexão. Deste modo, o dimensionamento será feito considerando-se a ocorrência de flexão oblíqua.

As hipóteses básicas de cálculo são as seguintes:

$\Rightarrow$ material trabalhando na fase elástica, ou seja, na faixa de validade da Lei de Hooke;

$\Rightarrow$ módulo elasticidade longitudinal (E) constante para toda a peça;

$\Rightarrow$ para a verificação dos deslocamentos nas direções principais, admite-se viga bi-apoiada;

$\Rightarrow$ para o cálculo das tensões em relação ao "eixo z", admite-se viga isostática bi-apoiada;

$\Rightarrow$ no cálculo das tensões em relação ao "eixo y", considera-se viga contínua com dois tramos, sendo o apoio intermediário proporcionado por uma estrutura de travamento (linha de corrente).

Para as terças, serão feitas apenas as verificações de resistência e de deslocamento para o caso mais crítico, ou seja, quando se tem a atuação das ações permanentes combinadas com a ação da carga acidental.

\subsubsection{Dimensionamento}

De modo a tornar possível o dimensionamento, foi necessário adotar alguns parâmetros geométricos. A escolha de tais parâmetros, baseou-se em experiências profissionais anteriores. Portanto:

$\Rightarrow$ seção transversal: $6 \mathrm{~cm} \times 16 \mathrm{~cm}$; 
$\Rightarrow$ inclinação $(\alpha)$ : 15 graus.

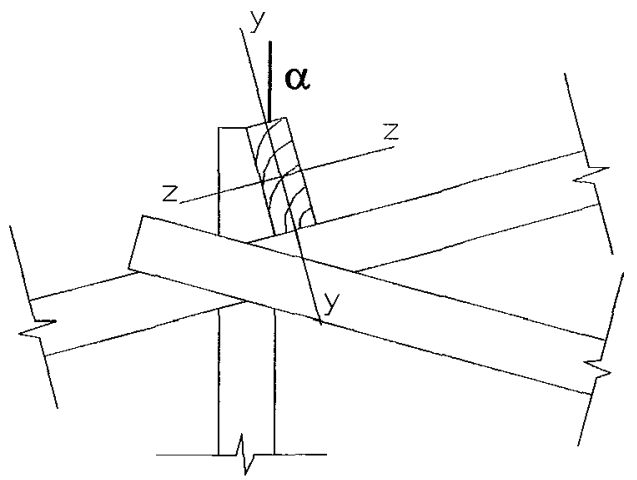

FIGURA 12 - Sistemas de eixos

$\Rightarrow$ vão teórico:

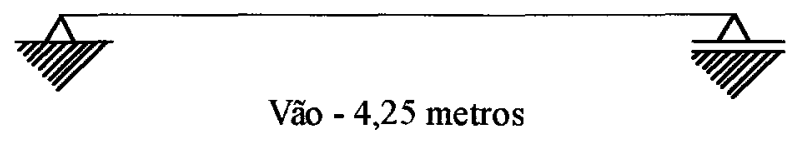

FIGURA 13 - Vão teórico em relação ao eixo "z"

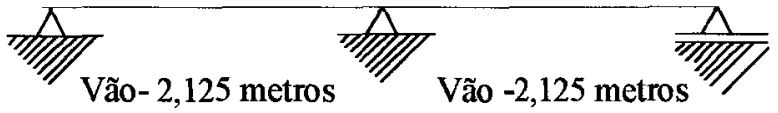

FIGURA 14 - Vão teórico em relação ao eixo "y"

\subsubsection{Cálculo das grandezas geométricas}

$\diamond$ Momento de Inércia e Área da Seção Transversal

$\rightarrow \mathrm{I}_{\mathrm{z}}=2048 \mathrm{~cm}^{4}$

$\rightarrow \mathrm{I}_{\mathrm{y}}=288 \mathrm{~cm}^{4}$

$\rightarrow \mathrm{A}=96 \mathrm{~cm}^{4}$ 


\subsubsection{Determinação das ações}

\subsection{Permanente}

Segundo a NBR 7190/96 - Ítem 4.5 .2 e, de acordo com os catálogos dos fabricantes de telha de fibro-cimento e de barras de aço, obtêm-se os seguintes valores:

$\boldsymbol{\lambda}$ peso próprio da terça: $\mathrm{g}=5,4 \mathrm{daN} / \mathrm{m}$;

$\boldsymbol{7}$ peso próprio da telha: $\mathrm{g}_{\mathrm{t}}=30,6 \mathrm{daN} / \mathrm{m}$;

$\boldsymbol{\lambda}$ peso próprio do sistema de contraventamento e de travamento: $\mathrm{g}_{\mathrm{c}}=2$ $\mathrm{daN} / \mathrm{m}$.

ação total permanente $\Rightarrow p=g+g_{t}+g_{c} \Rightarrow p=38 d a N / m$

\subsection{Variável (acidental)}

Segundo a NBR 6120 - Ítem 2.2.1.4, deve-se considerar uma carga concentrada de $1 \mathrm{KN}$ aplicada na posição mais desfavorável da peça em estudo. Portanto:

$\rightarrow$ carga variável (acidental): $\mathrm{Q}=100 \mathrm{daN}$.

\subsubsection{Verificação dos deslocamentos e cálculo dos esforços internos}

Para o cálculo dos esforços internos e na verificação dos deslocamentos, desconsiderou-se o "efeito grelha" proporcionado pela estrutura de travamento (ligação entre a terça e a linha de corrente - barra de aço rosqueada).

No dimensionamento segundo o MEL., foram adotadas as indicações propostas no texto da NBR 7190/96, como segue: 
1) Coeficiente de Ponderação das Ações

1.1) Estados Limites Últimos

1.1.a) Ações Permanentes - Ítem 4.6.4.b (Tabela 4)

* efeito desfavorável $\Rightarrow \gamma_{G}=1,4$

* efeito favorável $\Rightarrow \gamma_{\mathrm{G}}=0,9$

1.1.b) Ações Variáveis - Ítem 4.6.5 (Tabela 6)

* efeito de ações em geral $\Rightarrow \gamma_{Q}=1,4$

1.2) Estados Limites de Utilização

1.2.a) Ítem 4.6 .3

$* \gamma_{\mathrm{f}}=1$

2) Fator de Combinação

2.1) Estados Limites Últimos

Considerando apenas a carga acidental como ação variável (Ítem 4.4.4) e de acordo com as combinações últimas normais (Ítem 4.7.1), definiu-se que:

$$
* \Psi_{0}=0(\text { Zero })
$$

3) Fator de Utilização

3.1) Estados Limites de Utilização

De acordo com os Ítens 4.4.5, 4.4.6 (Tabela 2) e 4.8.1, as ações variáveis atuam com seus valores correspondentes à classe de carregamento de longa duração. Por isso definiu-se:

$$
\begin{aligned}
& * \Psi_{1}=0(\text { Zero }) \\
& * \Psi_{2}=0,2
\end{aligned}
$$

4) Classe de Resistência

As propriedades físico-mecânicas foram adotadas de acordo com o Ítem 5.3.5 (Tabela 8) - Classe 30. 
5) Coeficiente de Modificação

Segundo o Ítem 5.4.4, definiu-se:

$\Rightarrow$ Coeficiente Parcial de Modificação " 1 ” $\left(K_{\bmod 1}=0,7\right)$ : considera a classe de carregamento e o tipo de material empregado, é dado na Tabela 10.

$\Rightarrow$ Coeficiente Parcial de Modificação " 2 ” $\left(K_{\bmod 2}=1\right)$ : considera a classe de umidade e o tipo de material empregado, é dado na Tabela 11.

$\Rightarrow$ Coeficiente Parcial de Modificação “ 3 ” $\left(\mathrm{K}_{\mathrm{mod} 3}=0,8\right)$ : considera a categoria do material empregado.

Portanto:

$\rightarrow \mathrm{K}_{\mathrm{mod}}=\mathrm{K}_{\mathrm{mod} 1} * \mathrm{~K}_{\mathrm{mod} 2} * \mathrm{~K}_{\mathrm{mod} 3} \Rightarrow \mathrm{K}_{\mathrm{mod}}=0,56$

6) Coeficiente de Ponderação das Resistências

6.1) Estados Limites Últimos- Ítem 5.4.5

6.1.a) Tração Paralela às Fibras $\Rightarrow \gamma_{\mathrm{k}}=1,8$

6.1.b) Compressão Paralela às Fibras $\Rightarrow \gamma_{\mathrm{wc}}=1,4$

6.1.c) Cisalhamento Paralelo às Fibras $\Rightarrow \gamma_{\mathrm{wv}}=1,8$

6.2) Estados Limites de Utilização - Ítem 5.4.6

6.2.a) Valor básico $\Rightarrow \gamma_{w}=1$

\subsection{Verificação dos deslocamentos}

O deslocamento é calculado de acordo como a NBR 7190/96 - Ítem 4.8.1, como mostrado a seguir:

४ Seção crítica considerada para deslocamento em relação ao eixo "z":

a $212,5 \mathrm{~cm}$ do apoio de extremidade.

$$
\mathrm{V}_{\mathrm{z}}^{\mathrm{uti}}=\left(5^{*} \mathrm{p} * \cos (\alpha) * \mathrm{~L}^{4}\right) /\left(384 * \mathrm{E}_{\mathrm{co,ef}} * \mathrm{I}_{\mathrm{z}}\right)+\Psi_{2} *\left(\mathrm{Q}^{*} \cos (\alpha) * \mathrm{~L}^{3}\right) /\left(48 * \mathrm{E}_{\mathrm{co}, \mathrm{ef}} * \mathrm{I}_{\mathrm{z}}\right)
$$


Portanto, na eq. (1):

$\rightarrow \mathrm{v}_{\mathrm{z}}^{\mathrm{uti}} \cong 1,1 \mathrm{~cm}$

Seção crítica considerada para deslocamento em relação ao eixo " $y$ ":

a $106 \mathrm{~cm}$ do apoio de extremidade.

$$
v_{y}^{\text {uti }}=\left(5 * p * \operatorname{sen}(\alpha) * L^{4}\right) /\left(384 * E_{c o, e f} * I_{y}\right)+\Psi_{2} *\left(Q * \operatorname{sen}(\alpha) * L^{3}\right) /\left(48 * E_{c o, e f} * I_{y}\right)
$$

Portanto, na eq. (2):

$\rightarrow \mathrm{v}_{\mathbf{y}}{ }^{\mathrm{uti}} \cong 0,2 \mathrm{~cm}$

Onde:

$$
E_{c o, e f}=K_{\text {mod }} * E_{c o, m} \Rightarrow E_{c o, e f}=81200 \mathrm{daN} / \mathrm{cm}^{2}
$$

Observação: os demais dados já foram registrados anteriormente.

Segundo o PNBR 7190/96 - Ítem 8.2.1, a flecha total não deve superar os seguintes valores:

$\rightarrow \mathrm{V}_{\mathrm{z}}^{\text {lim. }}=\mathrm{L}_{\mathrm{z}} / 300 \Rightarrow \mathrm{v}_{\mathrm{z}}{ }^{\lim } \cong 1,4 \mathrm{~cm}$

$\rightarrow \mathrm{v}_{\mathrm{y}}^{\text {lim. }}=\mathrm{L}_{\mathrm{y}} / 300 \Rightarrow \mathrm{v}_{\mathrm{y}}^{\text {lim }} \cong 0,7 \mathrm{~cm}$

Portanto:

$$
\mathrm{v}_{\mathbf{z}}{ }^{\mathrm{uti}}<\mathrm{v}_{\mathrm{z}}^{\text {lim. }} \text { e } \mathrm{v}_{\mathbf{y}}^{\mathrm{uti}}<\mathrm{v}_{\mathbf{y}}^{\text {lim. }}
$$

\subsection{Cálculo dos esforços Internos}

Os esforços internos mostrados a seguir são referentes às seções mais solicitadas, e foram calculados de acordo com a NBR 7190/96 - Ítem 4.7.1. 


\subsubsection{2.a Cálculo do momento fletor máximo}

De acordo com o esquema estático mostrado abaixo, foram calculados os momentos fletores na seção crítica (meio do vão).

$\rightarrow \mathrm{M}_{\mathrm{z}, \mathrm{d}}=25970 \mathrm{daN}{ }^{*} \mathrm{~cm}$ (momento positivo);

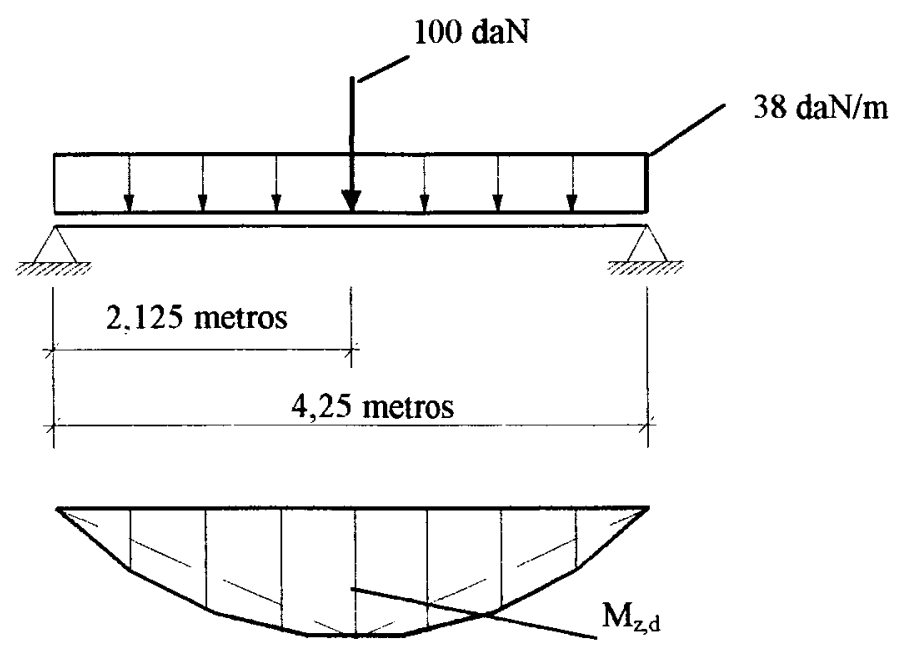

FIGURA 15 - Esquema estático e diagrama de momento fletor em relação ao eixo " $z$ "

$\mathrm{M}_{\mathrm{y}, \mathrm{d}}=777 \mathrm{daN}^{*} \mathrm{~cm}$ (momento negativo devido ao apoio interno proporcionado pela linha de corrente).
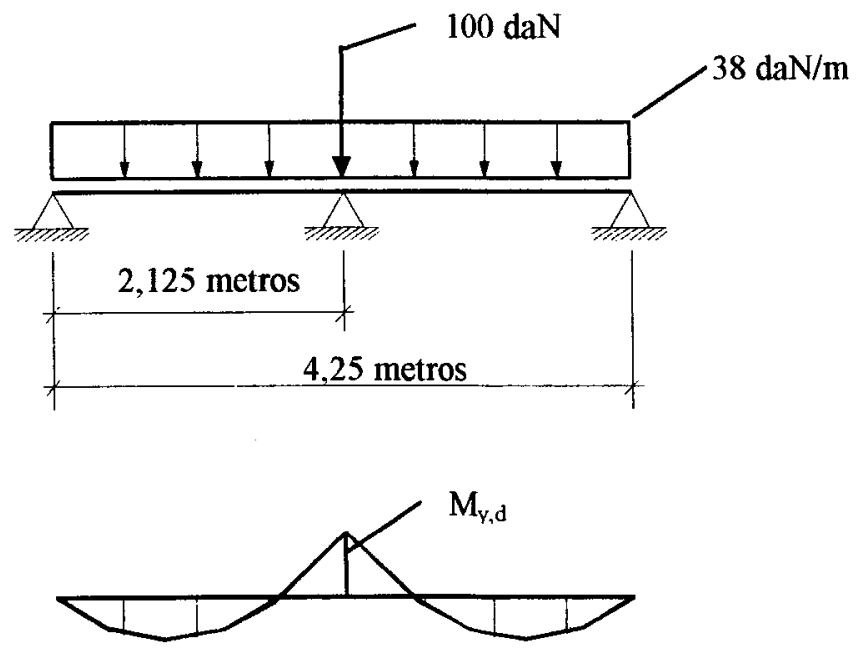

FIGURA 16 - Esquema estático e diagrama de momento fletor em relação ao eixo "y" 


\subsubsection{2.b Cálculo do esforço cortante máximo}

Para o esquema de carregamento ilustrado abaixo e de acordo com a NBR 7190/96 - Ítem 6.4.2, calculou-se o esforço cortante máximo para a seção transversal que dista $32 \mathrm{~cm}$ (duas vezes a altura da peça considerada) do apoio de extremidade.

$\rightarrow \mathrm{V}_{z, \mathrm{~d}}=196 \mathrm{daN}$

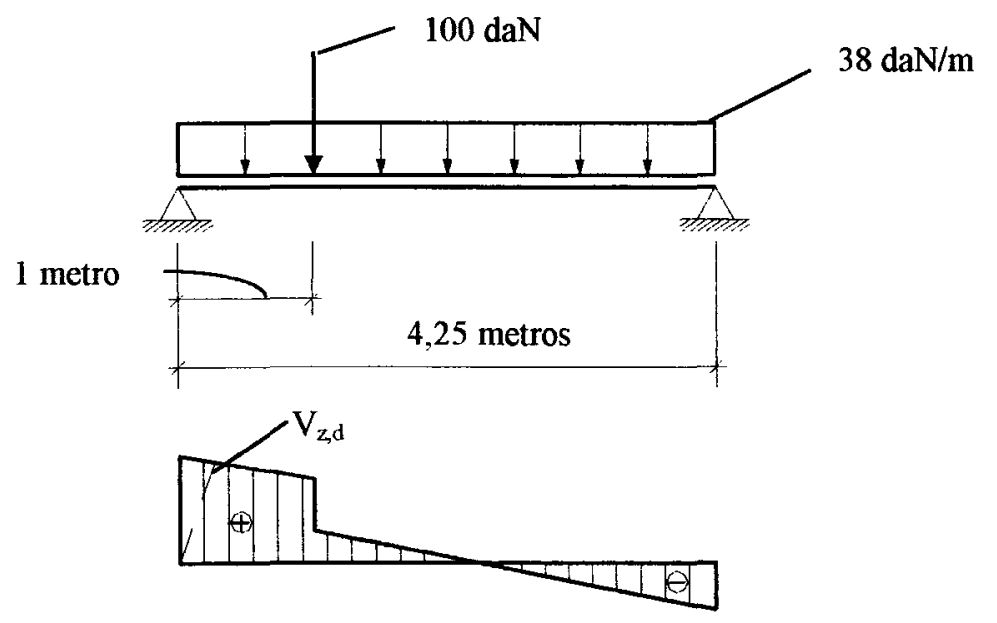

FIGURA 17 - Esquema estático e diag. de esforço cortante em relação ao eixo "z"

\subsubsection{Cálculo das tensões}

\subsection{Tensão Normal}

As tensões normais atuantes máximas têm os seguintes valores:

$\rightarrow \sigma_{\mathrm{Mz}, \mathrm{d}}=101,5 \mathrm{daN} / \mathrm{cm}^{2}$

$\rightarrow \sigma_{\mathrm{My}, \mathrm{d}}=8 \mathrm{daN} / \mathrm{cm}^{2}$

As resistências de projeto são calculadas de acordo com o PNBR 7190/96 Ítens 6.2.6 e 6.2.7. Portanto:

$$
\begin{aligned}
& \Rightarrow \mathrm{f}_{\mathrm{co}, \mathrm{d}}=120 \mathrm{daN} / \mathrm{cm}^{2} \\
& \Rightarrow \mathrm{f}_{\mathrm{to}, \mathrm{d}}=120 \mathrm{daN} / \mathrm{cm}^{2} \\
& \Rightarrow \mathrm{f}_{\mathrm{vo}, \mathrm{d}}=14,4 \mathrm{daN} / \mathrm{cm}^{2}
\end{aligned}
$$


Segundo a NBR 7190/96 - Ítem 6.3.4, a condição de segurança para tensão normal oriunda da flexão simples oblíqua é expressa pela mais rigorosa das duas equações, tanto em relação às tensões de tração quanto às de compressão. Portanto:

$$
\begin{aligned}
& \left(\sigma_{M z, d} / f_{w d}\right)+K_{M} *\left(\sigma_{M y, d} / f_{w d}\right) \leq 1 \\
& K_{M} *\left(\sigma_{M z, d} / f_{w d}\right)+\left(\sigma_{M y, d} / f_{w d}\right) \leq 1
\end{aligned}
$$

Onde:

$$
\Rightarrow K_{M}=0,5 \text { (Coeficiente de Correção) }
$$

Observação: Com base no comportamento elástico do material (válida a Lei de Hooke) e devido à bi-simetria da seção transversal, as tensões atuantes máximas de compressão e tração paralela às fibras têm mesmo valor.

Assim sendo, faz-se a verificação das eq. (3) e (4):

\section{Borda comprimida e tracionada}

Eq. (1) $\Rightarrow 0,88<1$

$\rightarrow$ Eq. (2) $\Rightarrow 0,49<1$

Portanto, ambas as equações foram satisfeitas.

\subsection{Tensão tangencial}

Segundo a NBR 7190/96 - Ítem 6.4.1, a condição de segurança em relação às tensões cisalhantes é :

$$
\tau_{\mathrm{d}} \leq \mathrm{f}_{\mathrm{vo}, \mathrm{d}}
$$


A tensão cisalhante máxima atuante tem o seguinte valor:

$\rightarrow \tau_{\mathrm{d}}=(3 / 2) *\left[\mathrm{~V}_{\mathrm{zd}} /(\mathrm{b} * \mathrm{~h})\right] \Rightarrow \tau_{\mathrm{d}}=3 \mathrm{daN} / \mathrm{cm}^{2}$

Verificando a eq. (5), tem-se:

$$
\Rightarrow 3 \leq 14,4 \mathrm{daN} / \mathrm{cm}^{2}
$$

\subsubsection{Verificação da estabilidade lateral}

A verificação da estabilidade lateral é feita com base na NBR 7190/96 - Ítem 6.5.6. De acordo com este ítem, tem-se:

“... para as peças em que

$$
\rightarrow\left(\mathrm{L}_{1} / \mathrm{b}\right)>\mathrm{E}_{\mathrm{co}, \mathrm{ef}} /\left(\beta_{\mathrm{M}} * \mathrm{f}_{\mathrm{co}, \mathrm{d}}\right) \Rightarrow 70,8>62,5
$$

também se dispensa a verificação da segurança em relação ao estado limite último de instabilidade lateral, desde que sejam satisfeitas as exigências de 6.3.3, com

$$
\sigma_{\mathrm{cld}} \leq \mathrm{E}_{\mathrm{co}, \mathrm{ef}} /\left[\left(\mathrm{L}_{1} / \mathrm{b}\right) * \beta_{\mathrm{M}}\right]
$$

Onde:

$\rightarrow \sigma_{\mathrm{cld}}=\sigma_{\mathrm{Mz}, \mathrm{d}}=101,5 \mathrm{daN} / \mathrm{cm}^{2}$

Assim sendo, na eq. (6):

$$
101,5 \mathrm{daN} / \mathrm{cm}^{2}<107,4 \mathrm{daN} / \mathrm{cm}^{2}
$$

Desta maneira, para o vão teórico considerado, não haverá perda de estabilidade lateral e, conseqüentemente, não haverá necessidade de travamento intermediário. 


\subsection{Estrutura principal (treliça)}

As estruturas de cobertura têm como função principal dar sustentação aos elementos integrantes do telhado, ou seja, às próprias telhas, às terças, aos sistemas de contraventamento e outros.

As estruturas treliçadas são vigas dispostas de tal modo que, em função da geometria e da forma de carregamento, é possível assumir que, ao longo das barras, ocorrem somente esforços internos axiais, ou seja, tração e compressão paralela às fibras.

As hipóteses básicas de cálculo para o dimensionamento dos elementos estruturais que compõem as treliças, são as seguintes:

$\Rightarrow$ material trabalhando na fase elástica, ou seja, na faixa de validade da Lei de Hooke;

$\Rightarrow$ módulo elasticidade longitudinal (E) constante para toda a peça;

$\Rightarrow$ consideração apenas de esforços axiais (tração e compressão);

$\Rightarrow$ peso próprio de cada elemento estrutural concentrado em sua extremidade, evitando assim o efeito da flexão e do cisalhamento ao longo da peça.

\subsubsection{Ações, carregamentos e esforços internos}

\subsubsection{Ação variável}

\subsection{Vento}

Segundo a NBR 6123/88 - Ítem 4.2.1, o coeficiente de pressão é dado pela soma entre os coeficientes de pressão interna e externa. As combinações mais críticas são mostradas a seguir: 
a) Sucção no Telhado (Vento a $90^{\circ}$ )

Combinação entre sucção externa e sobrepressão interna:

* face de barlavento : $\mathrm{C}_{\mathrm{p}}=1,1$.

* face de sotavento: $\mathrm{C}_{\mathrm{p}}=0,5$.

b) Sobrepressão no Telhado (Vento a $0^{\circ}$ )

Combinação entre sucção externa (face de sotavento) e sucção interna:

$$
* \mathrm{C}_{\mathrm{p}}=0,3
$$

A força devida ao vento atua perpendicularmente à superfície do telhado. A ação externa proveniente da ação do vento é transferido para a estrutura principal (treliça) por meio de cargas concentradas aplicadas pelas estruturas secundárias (terças). De acordo com a NBR 6123/88 - Ítem 4.2, calcula-se a força em cada nó da seguinte maneira:

$$
\mathrm{F}=\mathrm{C}_{\mathrm{p}} * \mathrm{q} * \mathrm{~A}_{\mathrm{inf}}
$$

A representação numérica deste valor dar-se-á da seguinte maneira:

Sobrepressão Simétrica (devido ao vento $0^{0}$ )

* face de barlavento e sotavento $\Rightarrow P_{v}=13,3 \mathrm{daN} / \mathrm{m}^{2}$

Sucção Assimétrica (devido ao vento $90^{\circ}$ )

* face de barlavento $\Rightarrow P_{v}=48,6 \mathrm{daN} / \mathrm{m}^{2}$

* face de sotavento $\Rightarrow P_{v}=22,1 \mathrm{daN} / \mathrm{m}^{2}$ 


\subsubsection{Ação permanente}

\subsection{Estrutural}

7 estrutura principal $-2,8 \mathrm{daN} / \mathrm{m}^{2}$

$$
\begin{aligned}
& \diamond \text { banzo superior : } 2 \text { peças } 2,5 \mathrm{~cm} \times 12 \mathrm{~cm} \\
& \diamond \text { banzo inferior : } 2 \text { peças } 2,5 \mathrm{~cm} \times 12 \mathrm{~cm} \\
& \diamond \text { diagonal : } 2 \text { peças. } 2,5 \mathrm{~cm} \times 9 \mathrm{~cm} \\
& \diamond \text { montante : } 1 \text { peça } 5 \mathrm{~cm} \times 8 \mathrm{~cm}
\end{aligned}
$$

$\boldsymbol{\eta}$ elementos de ligação (Parafusos) - 0,1 daN $/ \mathrm{m}^{2}$

7 elementos de contraventamento (Barras de aço- $\phi 12 \mathrm{~mm}$ ) - 2,0 daN $/ \mathrm{m}^{2}$

$\eta$ terças $(6 \mathrm{~cm} \times 16 \mathrm{~cm})-4,8 \mathrm{daN} / \mathrm{m}^{2}$

* ação permanente estrutural $\Rightarrow \mathbf{P}_{\mathrm{e}}=9,7 \mathrm{daN} / \mathrm{m}^{2}$

As ações permanentes oriundas do peso próprio da madeira e dos elementos de ligação foram obtidas de acordo a Norma Brasileira NBR 7190/96 - Ítem 4.5.2. As demais ações foram adotadas em função de dados dos próprios fabricantes.

\subsection{Não-estrutural}

7 dispositivos de fixação para as barras de aço $-0,8 \mathrm{daN} / \mathrm{m}^{2}$

$\boldsymbol{\gamma}$ telha para cobertura (fibro-cimento) $-18 \mathrm{daN} / \mathrm{m}^{2}$

* ação permanente não estrutural $\Rightarrow P_{n e}=18,8 \mathrm{daN} / \mathrm{m}^{2}$

Portanto:

ação permanente total $\Rightarrow \mathrm{P}_{\mathrm{p}}=28,5 \mathrm{daN} / \mathrm{m}^{2}$

As ações de origem não estrutural foram obtidas de catálogos dos próprios fabricantes. 
Na estrutura em estudo não ocorrerão ações acidentais significativas, tais como pontes rolantes e monovias, portanto consideram-se críticos os seguintes carregamentos:

$\Rightarrow$ ação permanente combinada com ação variável (vento de sucção assimétrico);

$\Rightarrow$ ação permanente combinada com ação variável (vento de sobrepressão simétrico);

Os esforços internos e os deslocamentos são obtidos com auxílio do software SAP90.

Para o dimensionamento, foram adotados os seguintes coeficientes:

1) Coeficiente de Ponderação das Ações

1.1) Estados Limites Últimos

1.1.a) Ações Permanentes - Ítem 4.6.4.b - Tabela 4

* efeito favorável $\quad \Rightarrow \gamma_{\mathrm{G}}=1,4$

* efeito desfavorável $\Rightarrow \gamma_{\mathrm{G}}=0,9$

1.1.b) Ações Variáveis - Ítem 4.6.5 - Tabela 6

$*$ efeito favorável e desfavorável $\Rightarrow \gamma_{\mathrm{Q}}=1,4$

1.2) Estados Limites de Utilização

1.2.a) Ítem 4.6 .3

$* \gamma_{\mathrm{f}}=1$

2) Fator de Combinação

2.1) Estados Limites Últimos

Considerando apenas o vento como ação variável, com base no Ítem 4.4.4, definiu-se que:

$$
* \Psi_{\mathrm{O}}=0 \text { (Zero) }
$$


3) Fator de Utilização

3.1) Estados Limites de Utilização

Para os carregamentos considerados e de acordo com os Ítens $4.4 .5,4.4 .6 \mathrm{e}$ 4.8.1, as ações variáveis atuam com seus valores correspondentes à classe de carregamento de longa duração. Assim:

$$
* \Psi_{1} \text { e } \Psi_{2}=0 \text { (Zero) }
$$

4) Classe de Resistência

As propriedades físico-mecânicas foram adotadas de acordo com o Ítem 5.3.5 (Tabela 8) - Classe 30.

5) Coeficientes de Modificação

Segundo o Ítens 5.4.4., definiu-se:

* Coeficiente Parcial de Modificação "1" $\left(\mathrm{K}_{\bmod 1}=0,7\right)$ : considera a classe de carregamento e o tipo de material empregado, é dado na Tabela 10.

* Coeficiente Parcial de Modificação " 2 " $\left(K_{\bmod 2}=1\right)$ : considera a classe de umidade e o tipo de material empregado, é dado na Tabela 11.

* Coeficiente Parcial de Modificação “3” $\left(K_{\bmod 3}=0,8\right)$ : considera a categoria do material empregado.

6) Coeficiente de Ponderação das Resistências

6.1) Estados Limites Últimos- Ítem 5.4 .5

6.1.a) Tração Paralela às Fibras $\Rightarrow \gamma_{\mathrm{wt}}=1,8$

6.1.b) Compressão Paralela às Fibras $\Rightarrow \gamma_{\mathrm{wc}}=1,4$

6.1.c) Cisalhamento Paralelo às Fibras $\Rightarrow \gamma_{w v}=1,8$

6.2) Estados Limites de Utilização - Ítem 5.4.6

6.2.a) Valor básico $\Rightarrow \gamma_{\mathrm{w}}=1$

Com base no Ítem 4.5.8 do mesmo projeto de norma, tem-se: “...para se levar em conta a maior resistência da madeira sob ação de cargas de curta duração, na verificação da segurança em relação a estados limites últimos, apenas na combinação 
de ações de longa duração em que o vento representa a ação variável principal, as solicitações nas peças de madeira devidas à ação do vento serão multiplicadas por 0,75 ."

\subsubsection{Dimensionamento}

Alguns parâmetros geométricos são definidos inicialmente:

$\Rightarrow$ seções transversais:

* banzo superior e inferior: 2 peças de $2,5 \mathrm{~cm} \times 13 \mathrm{~cm}$ :

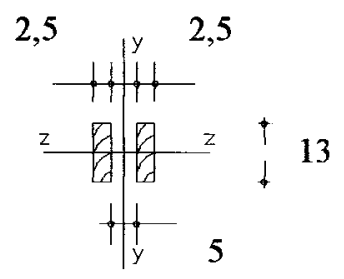

FIGURA 18 - Seção transversal das barras do banzo superior e inferior

* diagonais: 2 peças de $2,5 \mathrm{~cm} \times 9 \mathrm{~cm}$ :

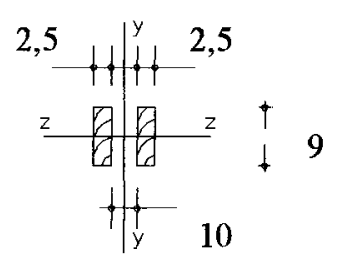

FIGURA 19 - Seção transversal das barras das diagonais

* montante central: 1 peça de $5 \mathrm{~cm} \times 12 \mathrm{~cm}$ :

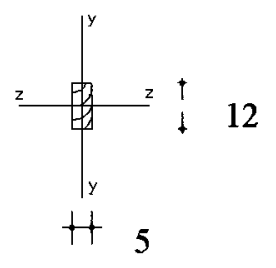

FIGURA 20 - Seção transversal da barra do montante central 
* demais montantes: 1 peça de $5 \mathrm{~cm} \mathrm{x} 6 \mathrm{~cm}$ :

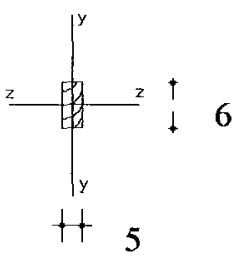

FIGURA 21 - Seção transversal das barras dos demais montantes

$\Rightarrow$ inclinação do banzo superior em relação à horizontal: 15 graus;

$\Rightarrow$ vão teórico: 12 metros;

$\Rightarrow$ disposição geométrica das barras:

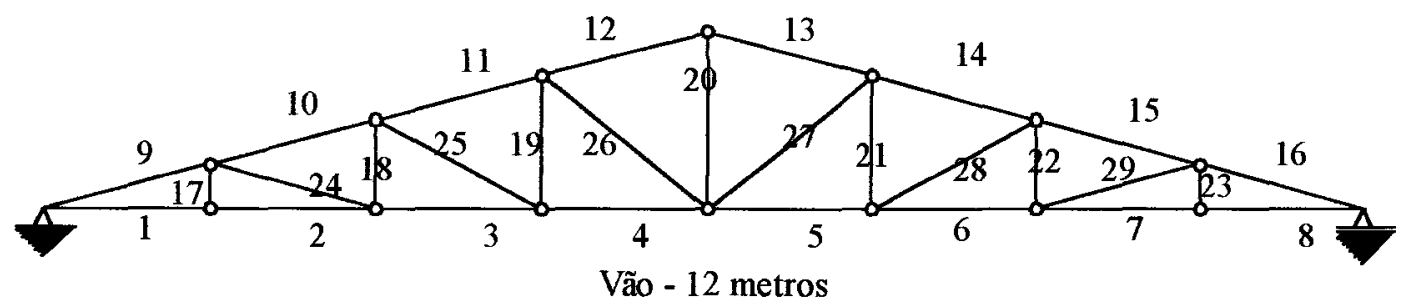

FIGURA 22 - Elevação da estrutura principal (treliça)

\subsubsection{Cálculo das grandezas geométricas}

\subsection{Referentes ao banzo superior e inferior}

$\diamond$ Momentos de Inércia e Área da Seção Transversal

$\rightarrow \mathrm{I}_{\mathrm{z}}=915 \mathrm{~cm}^{4}$

$\rightarrow \mathrm{I}_{\mathrm{y}}=948 \mathrm{~cm}^{4}$

$\rightarrow \mathrm{A}=65 \mathrm{~cm}^{2}$

\subsection{Referentes às diagonais}

$\diamond$ Momentos de Inércia e Área da Seção Transversal

$\rightarrow \mathrm{I}_{\mathrm{z}}=304 \mathrm{~cm}^{4}$

$\Rightarrow I_{y}=1781 \mathrm{~cm}^{4}$

$\rightarrow \mathrm{A}=45 \mathrm{~cm}^{2}$ 


\subsection{Referentes ao montante central}

$\diamond$ Momentos de Inércia e Área da Seção Transversal

$\rightarrow \mathrm{I}_{\mathrm{z}}=720 \mathrm{~cm}^{4}$

$\rightarrow \mathrm{I}_{\mathrm{y}}=125 \mathrm{~cm}^{4}$

$\rightarrow \mathrm{A}=60 \mathrm{~cm}^{2}$

\subsection{Referentes aos demais montantes}

$\diamond$ Momentos de Inércia e Área da Seção Transversal

$\rightarrow \mathrm{I}_{\mathrm{z}}=90 \mathrm{~cm}^{4}$

$\rightarrow \mathrm{I}_{\mathrm{y}}=62,5 \mathrm{~cm}^{4}$

$A=30 \mathrm{~cm}^{2}$

\subsubsection{Verificação das tensões normais}

As resistências de projeto são calculadas de acordo com Ítens 6.2.6 e 6.2.7. Tem-se:

$$
\begin{aligned}
& \Rightarrow \mathrm{f}_{\mathrm{co}, \mathrm{d}}=120 \mathrm{daN} / \mathrm{cm}^{2} \\
& \Rightarrow \mathrm{f}_{\mathrm{to}, \mathrm{d}}=120 \mathrm{daN} / \mathrm{cm}^{2}
\end{aligned}
$$

Para as verificações das tensões normais nos elementos estruturais da treliça, baseou-se nos esforços internos mostrados na tabela abaixo:

TABELA 4 - Esforços internos - dimensionamento dos elementos estruturais.

\begin{tabular}{|c|c|c|}
\hline $\begin{array}{c}\text { Elemento } \\
\text { Estrutural }\end{array}$ & Barra & $\begin{array}{c}\text { Esforço Critico } \\
\text { (DaN) }\end{array}$ \\
\hline \multirow{5}{*}{ B. Inferior } & 1 & 4434 \\
\cline { 2 - 3 } & 2 & 4434 \\
\cline { 2 - 3 } & 3 & 3640 \\
\cline { 2 - 3 } & 4 & 2955 \\
\cline { 2 - 3 } & 5 & 2955 \\
\cline { 2 - 3 } & 6 & 3640 \\
\cline { 2 - 3 } & 7 & 4434 \\
\hline \multirow{5}{*}{ Montante } & 8 & 4434 \\
\hline & 17 & 0 \\
\hline & 18 & 131 \\
\hline & 19 & 297 \\
\hline & 20 & $915(-218)$ \\
\cline { 2 - 3 } & 21 & 297 \\
\cline { 2 - 3 } & 22 & 131 \\
\hline & 23 & 0 \\
\hline
\end{tabular}

\begin{tabular}{|c|c|c|}
\hline $\begin{array}{c}\text { Elemento } \\
\text { Estrutural }\end{array}$ & Barra & $\begin{array}{c}\text { Esforço Crítico } \\
\text { (DaN) }\end{array}$ \\
\hline \multirow{5}{*}{ B. Superior } & 9 & -4603 \\
\cline { 2 - 3 } & 10 & -3805 \\
\cline { 2 - 3 } & 11 & -3119 \\
\cline { 2 - 3 } & 12 & -2427 \\
\cline { 2 - 3 } & 13 & -2427 \\
\cline { 2 - 3 } & 14 & -3119 \\
\cline { 2 - 3 } & 15 & -3805 \\
\cline { 2 - 3 } & 16 & -4603 \\
\hline \multirow{5}{*}{ Diagonal } & 24 & -805 \\
\cline { 2 - 3 } & 25 & -747 \\
\cline { 2 - 3 } & 26 & -829 \\
\cline { 2 - 3 } & 27 & -829 \\
\cline { 2 - 3 } & 28 & -747 \\
\cline { 2 - 3 } & 29 & -805 \\
\hline
\end{tabular}




\subsection{Tração paralela às fibras}

Segundo o Ítem 6.3.1, as condições de segurança para as barras solicitadas à tração paralelas às fibras serão satisfeitas quando a tensão atuante máxima não superar a resistência da peça, ou seja:

$$
\sigma_{\mathrm{td}} \leq \mathrm{f}_{\mathrm{to}, \mathrm{d}}
$$

\subsubsection{1.a Verificação para o banzo inferior}

ঔ Esforço máximo de tração

$\rightarrow \mathrm{F}_{\mathrm{td}}=4434 \mathrm{daN}\left(\right.$ Barra $^{\mathrm{o}}$ 1)

$\rightarrow \mathrm{A}^{\text {útil }}=2 *\left\{2,5^{*}[13-(2 * \phi)]\right\}$, para $\phi=10 \mathrm{~mm}$ (diâmetro do parafuso)

Então:

$\rightarrow \mathrm{A}^{\mathrm{u} t \mathrm{il}}=55 \mathrm{~cm}^{2}$

§Tensão máxima de tração

$\rightarrow \sigma_{\mathrm{td}}=80,6 \mathrm{daN} / \mathrm{cm}^{2}$

Portanto, satisfeita a eq. (8), ou seja,

$$
80,6 \mathrm{daN} / \mathrm{cm}^{2}<120 \mathrm{daN} / \mathrm{cm}^{2}
$$

\subsubsection{1.b Verificação para o banzo superior}

Considerando os esforços atuantes de tração paralela às fibras nas barras $n^{\mathfrak{Q}} 9$ e $\mathrm{n}^{\mathrm{o}} 16$ e procedendo de maneira análoga ao Ítem 4.3.2.2.1.a deste capítulo, verificouse a eq. (8): 


\subsubsection{1.c Verificação para as diagonais}

Considerando os esforços atuantes de tração paralela às fibras nas barras $\mathrm{n}^{\mathbf{0}} 26$ e no 27 e procedendo de maneira análoga ao Ítem 4.3.2.2.1.a deste capítulo, verificouse a eq. (8):

$$
11,2 \mathrm{daN} / \mathrm{cm}^{2}<120 \mathrm{daN} / \mathrm{cm}^{2}
$$

\subsubsection{1.d Verificação para o montante central}

Considerando os esforços atuantes de tração paralela às fibras na barra $\mathrm{n}^{\mathrm{o}} 20 \mathrm{e}$ procedendo de maneira análoga ao Ítem 4.3.2.2.1.a deste capítulo, verificou-se a eq. (8):

$$
22,9 \mathrm{daN} / \mathrm{cm}^{2}<120 \mathrm{daN} / \mathrm{cm}^{2}
$$

\subsubsection{1.e Verificação para os demais montantes}

Considerando os esforços atuantes de tração paralela às fibras nas barras $n^{\mathbf{0}} 19$ e $\mathrm{n}^{\mathrm{o}} 21$ e procedendo de maneira análoga ao Ítem 4.3.2.2.1.a deste capítulo, verificouse a eq. (8):

$$
14,9 \mathrm{daN} / \mathrm{cm}^{2}<120 \mathrm{daN} / \mathrm{cm}^{2}
$$

\subsection{Compressão paralela às fibras e estabilidade local}

\subsubsection{2.a Verificação para o banzo superior}

Segundo o Ítem 6.5.1, foi calculado o índice de esbeltez: 
$\rightarrow \mathrm{L}_{0}=169 \mathrm{~cm}\left(\right.$ Barras no $^{-} 10$ e $\left.\mathrm{n}^{-0} 15\right)$

Tem-se:

$\rightarrow \mathrm{i}_{\text {min }}=3,75 \mathrm{~cm}$

$\rightarrow \lambda=45$

Então:

$$
40<\lambda<80 \text { (peça medianamente esbelta) }
$$

Segundo o Ítens 6.5 .4 e 6.8.2, as condições de segurança relativas ao estado limite de instabilidade serão verificadas, se no ponto de maior compressão for atendida a seguinte expressão:

$$
\left(N_{d} / A\right)+\left[\left(M_{d} * I_{2}\right) /\left(I_{y, e f} * W_{2}\right)\right]+\left(M_{d} /\left(2 * a_{1} * A_{1}\right)\right) *\left(1-\left(n * I_{2} / I_{y, e f}\right)\right) \leq f_{c o, d}
$$

\section{$\diamond$ Esforços internos críticos}

O cálculo do momento fletor oriundo das excentricidades é calculado pela seguinte expressão:

$$
\mathrm{M}_{\mathrm{d}}=\mathrm{N}_{\mathrm{d}} * \mathrm{e}_{\mathrm{d}}
$$

Para:

$\rightarrow \mathrm{N}_{\mathrm{d}}=\mathbf{3 8 0 5 \mathrm { daN }}$

Sendo:

$$
\begin{gathered}
\mathrm{e}_{\mathrm{d}}=\mathrm{e}_{1} *\left(\left(\mathrm{~F}_{\mathrm{E}} /\left(\mathrm{F}_{\mathrm{E}}-\mathrm{N}_{\mathrm{d}}\right)\right)\right. \\
\mathrm{F}_{\mathrm{E}}=\pi^{2} * \mathrm{E}_{\mathrm{co,ef}} * \mathrm{I} / \mathrm{L}^{2}{ }_{0} \\
\mathrm{e}_{1}=\mathrm{e}_{\mathrm{i}}+\mathrm{e}_{\mathrm{a}}
\end{gathered}
$$

Na eq. (10.2), determina-se: 
$\rightarrow \mathrm{F}_{\mathrm{E}}=25675 \mathrm{daN}$

Tem-se:

$\rightarrow \mathrm{e}_{\mathrm{i}}=\mathrm{M}_{\mathrm{ld}} / \mathrm{N}_{\mathrm{d}}$, sendo $\mathrm{M}_{1 \mathrm{~d}}=0$ (zero) - momento na extremidade da barra $\Rightarrow \mathrm{e}_{\mathrm{i}}=0$ (zero)

$\rightarrow \mathrm{e}_{\mathrm{a}}=\mathrm{L}_{0} / 300 \Rightarrow \mathrm{e}_{\mathrm{a}}=0,56 \mathrm{~cm}$.

Portanto, na eq. (10.3):

$\rightarrow \mathrm{e}_{1}=0,56 \mathrm{~cm}$.

Desta maneira, com auxílio da eq. (10.3):

$\rightarrow \mathrm{e}_{\mathrm{d}}=0,66 \mathrm{~cm}$.

Com base na eq. (10)

$\rightarrow \mathrm{M}_{\mathrm{d}}=2511 \mathrm{daN}^{*} \mathrm{~cm}$

Assim sendo, faz-se a verificação da eq. (9):

$$
94,7 \mathrm{daN} / \mathrm{cm}^{2}<120 \mathrm{daN} / \mathrm{cm}^{2}
$$

Obs.: para todas as peças do banzo superior, adotar no mínimo 2 (dois) espaçadores (enrijecedor disposto entre os elementos estruturais de seção transversal múltipla).

\subsubsection{2.b Verificação para o banzo inferior}

Considerando os esforços atuantes nas barras $n^{\circ} 2$ e $n^{0} 7$ e procedendo de maneira análoga ao Ítem 4.3.2.2.2.a deste capítulo, verificou-se a eq. (9):

$$
35,2 \mathrm{daN} / \mathrm{cm}^{2}<120 \mathrm{daN} / \mathrm{cm}^{2}
$$

Obs.: Para todas as peças do banzo inferior, adotar no mínimo 2 (dois) espaçadores (enrijecedor disposto entre os elementos estruturais de seção transversal múltipla). 


\subsubsection{2.c Verificação para as diagonais}

Considerando os esforços atuantes nas barras $n^{0} 26$ e $n^{0} 27$ e procedendo de maneira análoga ao Ítem 4.3.2.2.2. a deste capítulo, verificou-se a eq. (9):

$$
44,2 \mathrm{daN} / \mathrm{cm}^{2}<120 \mathrm{daN} / \mathrm{cm}^{2}
$$

Obs.: Para todas as diagonais, adotar no mínimo 2 (dois) espaçadores (enrijecedor disposto entre os elementos estruturais de seção transversal múltipla).

\subsubsection{2.d Verificação para o montante central}

Segundo o Ítem 6.5.1, foi calculado o índice de esbeltez:

$\rightarrow \mathrm{L}_{0}=161 \mathrm{~cm}\left(\right.$ Barra $\left.\mathrm{n}^{\mathrm{o}} 20\right)$

Tem-se:

$\rightarrow \mathrm{i}_{\min }=1,4 \mathrm{~cm}$

$\rightarrow \lambda=111$

Então:

$$
80<\lambda<140 \text { (peça esbelta) }
$$

Segundo o Ítem 6.5.5, a verificação será atendida se no ponto de maior compressão for respeitada a seguinte expressão:

$$
\left(\sigma_{N d} / f_{c o, d}\right)+\left(\sigma_{M d} / f_{c o, d}\right) \leq 1
$$

$\diamond$ Esforço crítico de compressão

O cálculo do momento fletor oriundo das excentricidades é calculado pela seguinte expressão: 


$$
M_{d}=N_{d} * e_{1, \text { ef }} *\left(\left(F_{E} /\left(F_{E}-N_{d}\right)\right)\right.
$$

Onde:

$\rightarrow \mathrm{N}_{\mathrm{d}}=218 \mathrm{daN}$

$\rightarrow \mathrm{A}^{\text {útil }}=5 * 12=60 \mathrm{~cm}^{2}$

Segundo a eq. (10.2), determina-se:

$\rightarrow \mathrm{F}_{\mathrm{E}}=3865 \mathrm{daN}$

Sendo:

$$
\mathrm{e}_{1, \mathrm{ef}}=\mathrm{e}_{\mathrm{i}}+\mathrm{e}_{\mathrm{a}}+\mathrm{e}_{\mathrm{c}}
$$

Tem-se:

$\rightarrow e_{i}=M_{1 d} / N_{d}$, sendo $M_{1 d}=0$ (zero) - momento na extremidade da barra $\Rightarrow e_{i}=0$ (zero)

$\rightarrow \mathrm{e}_{\mathrm{a}}=\mathrm{L}_{0} / 300 \Rightarrow \mathrm{e}_{\mathrm{a}}=0,54 \mathrm{~cm}$.

O cálculo da excentricidade suplementar de $1^{\mathbf{a}}$ ordem que representa a fluência da madeira é feito pela seguinte equação:

$$
\mathrm{e}_{\mathrm{c}}=\left(\mathrm{e}_{\mathrm{ig}}+\mathrm{e}_{\mathrm{a}}\right) * \exp ^{\mathrm{K}}
$$

Onde:

$$
\begin{gathered}
\mathrm{K}=\left\{\phi^{*}\left[\mathrm{~N}_{\mathrm{gk}}+\left(\Psi_{1}+\Psi_{2}\right) * \mathrm{~N}_{\mathrm{qk}}\right] /\left[\mathrm{F}_{\mathrm{E}}-\left(\mathrm{N}_{\mathrm{gk}}+\left(\Psi_{1}+\Psi_{2}\right) * \mathrm{~N}_{\mathrm{qk}}\right)\right]\right\}-1(12.1 .1 .1) \\
\operatorname{com}\left(\Psi_{1}+\Psi_{2}\right) \leq 1 \mathrm{e} \phi=0,8
\end{gathered}
$$

De acordo com a eq. (12.1.1.1), obteve-se:

$\rightarrow \mathrm{K}=-0,919$

De acordo com Ítem 4.4.6 - Tabela 2, tem-se:

$$
\Psi_{1}=0,2 \text { e } \Psi_{2}=0 \text { (zero) }
$$


Portanto, na eq. (12.1.1):

$\rightarrow \mathrm{e}_{\mathrm{c}}=0,22 \mathrm{~cm}$.

Desta maneira, com a eq. (12.1):

$\rightarrow \mathrm{e}_{1, \mathrm{ef}}=0,76 \mathrm{~cm}$.

Com base na eq. (12):

$\rightarrow \mathrm{M}_{\mathrm{d}}=176 \mathrm{daN}^{*} \mathrm{~cm}$

$\diamond$ Tensão crítica de compressão

As tensões normais atuantes têm os seguintes valores:

$\rightarrow \sigma_{\mathrm{Nd}}=3,6 \mathrm{daN} / \mathrm{cm}^{2}$ (originada do esforço normal de compressão)

$\rightarrow \sigma_{\mathrm{Md}}=3,5 \mathrm{daN} / \mathrm{cm}^{2}$ (originada do momento fletor)

Assim sendo, faz-se a verificação da eq. (11):

$$
0,06 \leq 1
$$

\subsubsection{2.e Verificação para os demais montantes}

Considerando os esforços atuantes nos demais montantes, verificou-se que não ocorrem esforços de compressão.

\subsubsection{Estabilidade global}

De acordo com Ítem 6.6.4 e após as verificações feitas no Ítem 4.3.2.2 deste capítulo, considera-se garantida a estabilidade global das estruturas principais (treliças). 


\subsubsection{Verificação do deslocamento}

De acordo com o Ítem 4.8.1 e com auxílio do software SAP90, obteve-se o deslocamento vertical no meio do vão.

$\rightarrow \mathrm{v}^{\mathrm{uti}}=1,8 \mathrm{~cm}$

Segundo o Ítem 8.2.1, a flecha total não deve superar o seguinte valor:

$\rightarrow \mathrm{v}^{\lim }=\mathrm{L} / 300 \Rightarrow \mathrm{v}^{\lim }=4 \mathrm{~cm}$

Desta maneira, verifica-se que:

$$
\mathrm{v}^{\mathrm{uti}}<\mathrm{v}^{\lim }
$$

\subsubsection{Dimensionamento das ligações}

De acordo com os critérios de dimensionamento e com o objetivo de reduzir ao máximo o consumo de material, foram adotados parafusos com diâmetro de 10 milímetros.

\subsection{Resistência de cálculo de um pino}

\subsubsection{1.a Embutimento na madeira}

De acordo com o Ítem 6.2.5, calculou-se a resistência ao embutimento paralelo e normal às fibras da madeira.

\section{Embutimento paralelo às fibras da madeira}

Banzo Superior, Banzo Inferior, Montante, e Diagonal:

$\rightarrow \mathrm{f}_{\mathrm{eo}, \mathrm{d}}=120 \mathrm{daN} / \mathrm{cm}^{2}$ 


\section{Embutimento normal às fibras da madeira}

Banzo Superior, Banzo Inferior, Montante, e Diagonal:

$\rightarrow \mathrm{f}_{\mathrm{e} 90, \mathrm{~d}}=58,5 \mathrm{daN} / \mathrm{cm}^{2}$

Para o cálculo da resistência ao embutimento inclinado em relação às fibras da madeira - inclinação maior que $6^{\circ}$ - adotou-se a expressão de Hankinson; dada no Ítem 6.2.9.

De acordo com o Ítem 7.3 e com o auxílio do Ítem 4.3.2.5.1.a deste capítulo, determinou-se o valor de cálculo $R_{\mathrm{vd}, 1}$ da resistência de um pino, correspondente a uma única seção de corte, referente ao embutimento na madeira. Veja:

$$
\mathrm{R}_{\mathrm{vd}, 1}=0,4 *\left(\mathrm{t}^{2} / \beta\right) * \mathrm{f}_{\mathrm{e} \theta, \mathrm{d}}
$$

\subsubsection{1.b Flexão no pino}

De acordo com o Ítem 7.3, determinou-se o valor de cálculo $R_{v d, 1}$ da resistência de um pino, correspondente a uma única seção de corte, referente à flexão no pino. Tem-se:

$$
\begin{aligned}
& \mathbf{R}_{v d, 1}=0,625 *\left(d^{2} / \beta_{\text {lim }}\right) * f_{y d} \\
& \operatorname{para}\left(\beta=\beta_{\text {lim }}\right) \text { e } f_{y, d}=f_{y, k} / \gamma_{s}, \text { sendo } \gamma_{s}=1,1
\end{aligned}
$$

A resistência de um pino, correspondente a uma seção de corte qualquer, é determinada como sendo o menor valor entre o embutimento na madeira e a flexão no pino (Ítem 7.3). 


\subsection{Cálculo do número de parafusos}

Para o dimensionamento dos dispositivos de ligação utilizados na treliça, baseou-se nos esforços internos mostrados na tabela abaixo:

TABELA 5 - Esforços internos - dimensionamento dos parafusos.

\begin{tabular}{|c|c|c|}
\hline $\begin{array}{c}\text { Elemento } \\
\text { Estrutural }\end{array}$ & Barra & Esforço Crítico (DaN) \\
\hline \multirow{5}{*}{ B. Inferior } & 1 & 4805 \\
\cline { 2 - 3 } & 2 & 4805 \\
\cline { 2 - 3 } & 3 & 3940 \\
\cline { 2 - 3 } & 4 & 3194 \\
\cline { 2 - 3 } & 5 & 3194 \\
\hline \multirow{5}{*}{ Montante } & 6 & 3940 \\
\hline & 7 & 4805 \\
\hline & 8 & 4805 \\
\hline & 17 & 0 \\
\cline { 2 - 3 } & 18 & 143 \\
\cline { 2 - 3 } & 19 & 324 \\
\cline { 2 - 3 } & 20 & 996 \\
\hline & 21 & 324 \\
\hline & 22 & 143 \\
\hline
\end{tabular}

\begin{tabular}{|c|c|c|}
\hline $\begin{array}{c}\text { Elemento } \\
\text { Estrutural }\end{array}$ & Barra & $\begin{array}{c}\text { Esforço Crítico } \\
\text { (DaN) }\end{array}$ \\
\hline \multirow{5}{*}{ B. Superior } & 9 & -4990 \\
\cline { 2 - 3 } & 10 & $-4127(2032)$ \\
\cline { 2 - 3 } & 11 & -3387 \\
\cline { 2 - 3 } & 12 & -2640 \\
\cline { 2 - 3 } & 13 & -2640 \\
\cline { 2 - 3 } & 14 & -3387 \\
\hline \multirow{5}{*}{ Diagonal } & 15 & $-4127(2032)$ \\
\hline & 16 & -4990 \\
\hline & 24 & -878 \\
\hline & 25 & -814 \\
\hline & 26 & $-902(683)$ \\
\hline & 27 & $-902(683)$ \\
\hline & 28 & -814 \\
\hline & 29 & -878 \\
\hline
\end{tabular}

\subsubsection{2.a Ligação entre banzo superior $e$ inferior}

Tem-se:

$\rightarrow \mathrm{N}_{\mathrm{d}}=4990$ daN (Esforço crítico - compressão) - (Barras $\mathrm{n}^{\circ} 9$ e $\left.\mathrm{n}^{\mathbf{o}} 16\right)$

$\rightarrow \mathrm{f}_{\mathrm{e} \theta \mathrm{d}}=112 \mathrm{daN} / \mathrm{cm}^{2}, \operatorname{para} \theta=15^{\circ}$

Portanto, de acordo com as eq. (13) e (14) respectivamente, tem-se:

$\rightarrow \mathrm{R}_{\mathrm{vd}, 1}=224 \mathrm{daN}$, para 4 (quatro) seções de corte (embutimento na madeira)

$\rightarrow \mathrm{R}_{\mathrm{vd}, 1}=943 \mathrm{daN}$, para 4 (quatro) seções de corte (flexão no pino)

Então:

$\rightarrow \mathrm{N}_{\mathrm{p}}=\mathrm{N}_{\mathrm{d}} / \mathrm{R}_{\mathrm{vd}, 1} \Rightarrow \mathrm{N}_{\mathrm{p}}=23$ parafusos (diâmetro $-10 \mathrm{~mm}$ ) 


\subsubsection{2.b Ligação do nó central (banzo inferior)}

\section{$\boldsymbol{\lambda}$ Referente ao montante}

Tem-se:

$\rightarrow \mathrm{N}_{\mathrm{d}}=996$ daN (Esforço crítico - tração) - (Barra n⿳0 20)

$\rightarrow \mathrm{f}_{\mathrm{e} \theta, \mathrm{d}}=58,5 \mathrm{daN} / \mathrm{cm}^{2}, \operatorname{para} \theta=90^{\circ}$

Portanto, de acordo com as eq. (13) e (14) respectivamente, tem-se:

$\rightarrow \mathrm{R}_{\mathrm{vd}, 1}=117 \mathrm{daN}$, para 2 (duas) seções de corte (embutimento na madeira)

$\rightarrow \mathrm{R}_{\mathrm{vd}, 1}=341 \mathrm{daN}$, para 2 (duas) seções de corte (flexão no pino)

Então:

$\rightarrow N_{p}=N_{d} / R_{v d, 1} \Rightarrow N_{p}=8$ parafusos (diâmetro $-10 \mathrm{~mm}$ )

\section{Referente à diagonal}

Tem-se:

$\rightarrow \mathrm{N}_{\mathrm{d}}=683 \mathrm{daN}$ (Esforço crítico - tração) - (Barras n⿳0 26 e n⿳0 27)

$\rightarrow \mathrm{f}_{\mathrm{e} \theta, \mathrm{d}}=90,9 \mathrm{daN} / \mathrm{cm}^{2}, \operatorname{para} \theta=33,5^{\circ}$

Portanto, de acordo com as eq. (13) e (14) respectivamente, tem-se:

$\rightarrow \mathrm{R}_{\mathrm{vd}, 1}=182 \mathrm{daN}$, para 2 (duas) seções de corte (embutimento na madeira)

$\rightarrow \mathrm{R}_{\mathrm{vd}, 1}=425 \mathrm{daN}$, para 2 (duas) seções de corte (flexão no pino)

Então:

$\rightarrow N_{p}=N_{d} / R_{v d, 1} \Rightarrow N_{p}=4$ parafusos (diâmetro - $10 \mathrm{~mm}$ )

Sabendo-se que as diagonais estão de topo entre si, verificou-se então a tensão normal de compressão inclinada às fibras, devida ao esforço atuante de compressão. Para isto, foram tomados por base os Ítens 6.2.9 e 6.3.2. 
Portanto:

$$
\sigma_{\mathrm{cd}} \leq \mathrm{f}_{\mathrm{c} \theta}
$$

$\rightarrow \mathrm{N}_{\mathrm{d}}=902 \mathrm{daN}$ (Esforço crítico - compressão)

$\rightarrow A^{\text {tutil }}=2 *(2,5 * 9)=45 \mathrm{~cm}^{2}$

A tensão normal atuante tem o seguinte valor:

$\rightarrow \sigma_{\mathrm{cd}}=16,7 \mathrm{daN} / \mathrm{cm}^{2}$

Assim sendo, na eq. (15):

$$
16,7 \mathrm{daN} / \mathrm{cm}^{2}<62,7 \mathrm{daN} / \mathrm{cm}^{2}
$$

Em resumo, esta ligação terá 4 parafusos (diâmetro - $10 \mathrm{~mm}$ para cada diagonal) e 8 parafusos (diâmetro - $10 \mathrm{~mm}$ para o montante).

\subsubsection{2.c Ligação do montante e diagonal com o banzo inferior}

\section{Referente ao montante}

Tem-se:

$\rightarrow \mathrm{N}_{\mathrm{d}}=324 \mathrm{daN}$ (Esforço crítico - tração) - $\left(\right.$ Barra $\mathrm{n}^{\circ} 19$ e $\left.\mathrm{n}^{\circ} 21\right)$

$\rightarrow \mathrm{f}_{\mathrm{e} \theta \mathrm{d}}=58,5 \mathrm{daN} / \mathrm{cm}^{2}, \operatorname{para} \theta=90^{\circ}$

Portanto, de acordo com as eq. (13) e (14) respectivamente, tem-se:

$\rightarrow \mathrm{R}_{\mathrm{vd}, 1}=117 \mathrm{daN}$, para 2 (duas) seções de corte (embutimento na madeira)

$\rightarrow \mathrm{R}_{\mathrm{vd}, 1}=341 \mathrm{daN}$, para 2 (duas) seções de corte (flexão no pino)

Então:

$\rightarrow \mathrm{N}_{\mathrm{p}}=\mathrm{N}_{\mathrm{d}} / \mathrm{R}_{\mathrm{vd}, 1} \Rightarrow \mathrm{N}_{\mathrm{p}}=3$ parafusos (diâmetro $-10 \mathrm{~mm}$ ). 


\section{Referente à diagonal}

Tem-se:

$\rightarrow \mathrm{N}_{\mathrm{d}}=814 \mathrm{daN}$ (Esforço crítico - compressão) - (Barras $\mathrm{n}^{\circ} 25$ e $\left.\mathrm{n}^{\circ} 28\right)$

$\rightarrow \mathrm{f}_{\mathrm{e} \theta, \mathrm{d}}=102,9 \mathrm{daN} / \mathrm{cm}^{2}, \operatorname{para} \theta=23,4^{\circ}$

Portanto, de acordo com as eq. (13) e (14) respectivamente, tem-se:

$\rightarrow \mathrm{R}_{\mathrm{vd}, 1}=206 \mathrm{daN}$, para 2 (duas) seções de corte (embutimento na madeira)

$\rightarrow \mathrm{R}_{\mathrm{vd}, 1}=452 \mathrm{daN}$, para 2 (duas) seções de corte (flexão no pino)

Então:

$\rightarrow \mathrm{N}_{\mathrm{p}}=\mathrm{N}_{\mathrm{d}} / \mathrm{R}_{\mathrm{vd}, 1} \Rightarrow \mathrm{N}_{\mathrm{p}}=4$ parafusos (diâmetro $-10 \mathrm{~mm}$ )

Em resumo, esta ligação terá 6 parafusos (diâmetro - $10 \mathrm{~mm}$.)

\subsubsection{2.d Ligação do montante e diagonal com o banzo superior}

\section{Referente ao montante}

Tem-se:

$\rightarrow \mathrm{N}_{\mathrm{d}}=324 \mathrm{daN}$ (Esforço crítico - tração) - (Barras n⿳0 19 e n⿳⺈ 21)

$\rightarrow \mathrm{f}_{\mathrm{e} \theta, \mathrm{d}}=60,5 \mathrm{daN} / \mathrm{cm}^{2}$, para $\theta=75^{\circ}$

Portanto, de acordo com as eq. (13) e (14) respectivamente, tem-se:

$\rightarrow \mathrm{R}_{\mathrm{vd}, 1}=121 \mathrm{daN}$, para 2 (duas) seções de corte (embutimento na madeira)

$\rightarrow \mathrm{R}_{\mathrm{vd}, 1}=346 \mathrm{daN}$, para 2 (duas) seções de corte (flexão no pino)

Então:

$\rightarrow \mathrm{N}_{\mathrm{p}}=\mathrm{N}_{\mathrm{d}} / \mathrm{R}_{\mathrm{vd}, 1} \Rightarrow \mathrm{N}_{\mathrm{p}}=3$ parafusos (diâmetro $-10 \mathrm{~mm}$ ) 


\section{Referente à diagonal}

Tem-se:

$\mathrm{N}_{\mathrm{d}}=902 \mathrm{daN}$ (Esforço crítico - compressão) - (Barras $\mathrm{n}^{-} 26$ e n⿳0 $\left.^{0} 27\right)$

$\rightarrow \mathrm{f}_{\mathrm{e} \theta, \mathrm{d}}=75,5 \mathrm{daN} / \mathrm{cm}^{2}$, para $\theta=48,5^{\circ}$

Portanto, de acordo com as eq. (13) e (14) respectivamente, tem-se:

$\rightarrow \mathrm{R}_{\mathrm{vd}, 1}=151 \mathrm{daN}$, para 2 (duas) seções de corte (embutimento na madeira)

$\rightarrow \mathrm{R}_{\mathrm{vd}, 1}=387$ daN, para 2 (duas) seções de corte (flexão no pino)

Então:

$\rightarrow N_{p}=N_{d} / R_{v d, 1} \Rightarrow N_{p}=6$ parafusos (diâmetro $-10 \mathrm{~mm}$ )

Em resumo, esta ligação terá 6 parafusos (diâmetro - $10 \mathrm{~mm}$ )

\subsubsection{2.e Ligação do nó central (banzo superior)}

\section{$\lambda$ Referente ao banzo superior}

Tem-se:

$\rightarrow \mathrm{N}_{\mathrm{d}}=1121$ daN (Esforço crítico - tração) - (Barras no 12 e $\mathrm{n}^{\mathrm{o}} 13$ )

$\rightarrow \mathrm{f}_{\mathrm{e \theta ,d}}=112 \mathrm{daN} / \mathrm{cm}^{2}$, para $\theta=15^{\circ}$ (em relação à cobrejunta)

Portanto, de acordo com as eq. (13) e (14) respectivamente, tem-se:

$\rightarrow \mathrm{R}_{\mathrm{vd}, 1}=224 \mathrm{daN}$, para 2 (duas) seções de corte (embutimento na madeira)

$\rightarrow \mathrm{R}_{\mathrm{vd}, 1}=470 \mathrm{daN}$, para 2 (duas) seções de corte (flexão no pino)

Então:

$N_{p}=N_{d} / R_{v d, 1} \Rightarrow N_{p}=5$ parafusos (diâmetro $-10 \mathrm{~mm}$ ) 
Sabendo-se que as barras dos banzos estão de topo entre si, verificou-se então a tensão normal de compressão inclinada às fibras, devida ao esforço atuante de compressão. Para isto, tomou-se por base os Ítens 6.2.9 e 6.3.2.

Tem-se:

$\rightarrow \mathrm{N}_{\mathrm{d}}=2639 \mathrm{daN}$ (Esforço crítico - compressão)

$\rightarrow \mathrm{A}^{\text {útil }}=2 *(2,5 * 12)=60 \mathrm{~cm}^{2}$

A tensão normal atuante tem o seguinte valor:

$\rightarrow \sigma_{\mathrm{cd}}=39,4 \mathrm{daN} / \mathrm{cm}^{2}$

De acordo com a eq. (15), verificou-se:

$$
39,4 \mathrm{daN} / \mathrm{cm}^{2}<100 \mathrm{daN} / \mathrm{cm}^{2}
$$

\section{Referente ao montante}

Tem-se:

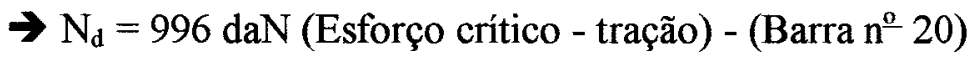

$\mathrm{f}_{\mathrm{e} \theta, \mathrm{d}}=58,5 \mathrm{daN} / \mathrm{cm}^{2}, \operatorname{para} \theta=90^{\circ}$

Portanto, de acordo com as eq. (13) e (14) respectivamente, tem-se:

$\mathrm{R}_{\mathrm{vd}, 1}=117 \mathrm{daN}$, para 2 (duas) seções de corte (embutimento na madeira)

$\rightarrow \mathrm{R}_{\mathrm{vd}, 1}=346 \mathrm{daN}$, para 2 (duas) seções de corte (flexão no pino)

Então:

$\rightarrow \mathrm{N}_{\mathrm{p}}=\mathrm{N}_{\mathrm{d}} / \mathrm{R}_{\mathrm{vd}, 1} \Rightarrow \mathrm{N}_{\mathrm{p}}=8$ parafusos (diâmetro $-10 \mathrm{~mm}$ )

Em resumo, esta ligação terá 10 parafusos (diâmetro - $10 \mathrm{~mm}$ para cada barra do banzo) e 8 parafusos (diâmetro - $10 \mathrm{~mm}$ para o montante). 


\subsubsection{2.f Emendas}

A escolha das barras para efetuar as emendas dos banzos deu-se com base na ordem de grandeza dos esforços solicitantes.

\section{$\nexists$ Referente ao banzo superior}

Tem-se:

$\rightarrow \mathrm{N}_{\mathrm{d}}=2032 \mathrm{daN}$ (Esforço crítico - tração) - (Barras n⿳o 10 e n⿳o 15)

$\rightarrow \mathrm{f}_{\mathrm{e} \theta, \mathrm{d}}=120 \mathrm{daN} / \mathrm{cm}^{2}, \operatorname{para} \theta=0^{\circ}$

Portanto, de acordo com as eq. (13) e (14) respectivamente, tem-se:

$\rightarrow \mathrm{R}_{\mathrm{vd}, 1}=240 \mathrm{daN}$, para 4 (quatro) seções de corte (embutimento na madeira)

$\rightarrow \mathbf{R}_{\mathrm{vd}, 1}=975 \mathrm{daN}$, para 4 (quatro) seções de corte (flexão no pino)

Então:

$\rightarrow N_{p}=N_{d} / R_{v d, 1} \Rightarrow N_{p}=9$ parafusos (diâmetro $-10 \mathrm{~mm}$ )

Sabendo que as peças do banzo a serem emendadas estão de topo entre si, verificou-se então a tensão normal de compressão paralela às fibras, devida ao esforço atuante de compressão. Para isto, tomou-se por base os Ítens 6.2.9 e 6.3.2.

Tem-se:

$\rightarrow \mathrm{N}_{\mathrm{d}}=4127$ daN (Esforço crítico - compressão)

$\rightarrow \mathrm{A}^{\text {útil }}=2 *(2,5 * 12)=60 \mathrm{~cm}^{2}$

A tensão normal atuante tem o seguinte valor:

$\rightarrow \sigma_{\mathrm{cd}}=68,8 \mathrm{daN} / \mathrm{cm}^{2}$

De acordo com a eq. (15), verificou-se:

$$
68,8 \mathrm{daN} / \mathrm{cm}^{2}<120 \mathrm{daN} / \mathrm{cm}^{2}
$$

Em resumo, esta ligação terá 9 parafusos (diâmetro - $10 \mathrm{~mm}$ para cada barra do banzo). 


\section{$\boldsymbol{7}$ Referente ao banzo inferior}

Tem-se:

$\rightarrow \mathrm{N}_{\mathrm{d}}=3194 \mathrm{daN}$ (Esforço crítico - tração) - (Barras n $\mathrm{n}^{-} 4 \mathrm{e} \mathrm{n}^{\circ}$ 5)

$\rightarrow \mathrm{f}_{\mathrm{e} \theta, \mathrm{d}}=120 \mathrm{daN} / \mathrm{cm}^{2}, \operatorname{para} \theta=0^{\circ}$

Portanto, de acordo com as eq. (13) e (14) respectivamente, tem-se:

$\rightarrow \mathrm{R}_{\mathrm{vd}, 1}=240$ daN, para 4 (quatro) seções de corte (embutimento na madeira)

$\rightarrow \mathrm{R}_{\mathrm{vd}, 1}=975 \mathrm{daN}$, para 4 (quatro) seções de corte (flexão no pino)

Então:

$\rightarrow N_{p}=N_{d} / R_{v d, 1} \Rightarrow N_{p}=14$ parafusos (diâmetro $-10 \mathrm{~mm}$ )

Em resumo, esta ligação terá 14 parafusos (diâmetro - $10 \mathrm{~mm}$ para cada barra do banzo)

\subsection{Espaçamentos dos parafusos}

A distribuição dos parafusos em cada ligação será feita de acordo com o Ítem 7.6.1.

O Ítem 4.5.2 afirma “...o peso próprio real, avaliado depois do dimensionamento final da estrutura, não deve diferir de mais de $10 \%$ do peso próprio inicialmente admitido no cálculo". Portanto, fazendo-se os cálculos correspondentes, chega-se a:

$$
\Delta=4,6 \%<10 \%
$$

Ao final do dimensionamento das ligações, verificou-se um consumo de 264 (duzentos e sessenta e quatro) parafusos (diâmetro - $10 \mathrm{~mm}$ ) com aproximadamente 18 centímetros de comprimento. De acordo com as características intrínsicas do material dos parafusos (aço), admite-se com razoável precisão a seguinte proporção:

$\Rightarrow 7$ (sete) parafusos com porcas e arruelas por unidade de massa (1 kilograma). 
Portanto, obteve-se o peso total referente aos dispositivos de ligação igual a aproximadamente 38 (trinta e oito) daN por treliça. $\mathrm{O}$ consumo de madeira da treliça e das terças corresponde ao peso próprio de aproximadamente 395 (trezentos e noventa e cinco) daN. Assim sendo, tem-se a seguinte proporção entre dispositivos de ligação (parafusos) e volume de madeira consumido:

$$
38 / 395 \cong 0,095(9,5 \%)
$$

Verificou-se que este valor é bem superior ao valor recomendado pela PNBR $7190 / 96$ - Ítem 4.5.2, que registra "...nas estruturas pregadas ou parafusadas, o peso próprio das peças metálicas de união pode ser estimado em $3 \%$ do peso próprio da madeira". 


\section{RESULTADOS E DISCUSSÕES}

De acordo com os documentos normativos citados no Ítem 4.1 - Capítulo 4, foram obtidas através do dimensionamento e das demais verificações pertinentes, as seções transversais dos elementos que compõem as estruturas principais (treliças), estruturas secundárias (terças), estruturas de contraventamento e de travamento.

\subsection{Dimensões finais das estruturas principais (treliças)}

A geometria dos elementos das estruturas principais é mostrada no Anexo"A".

\subsection{Dimensões finais das estruturas de contraventamento}

As barras de aço rosqueadas que compõem as estruturas de contraventamento e de travamento têm diâmetro de 12 milímetros, conforme Ítem 7.3.2.2 da NBR $8800 / 86$

\subsection{Dimensões finais das estruturas secundárias (terças)}

No desenvolvimento de todos os projetos, admitiu-se comprimento máximo de 5 (cinco) metros para as vigas $(6 \mathrm{~cm} \times 12 \mathrm{~cm}$ e $6 \mathrm{~cm} \times 16 \mathrm{~cm})$. Para as estruturas secundárias (terças), foram obtidas as seguintes dimensões: 


\section{Cálculo através do Método das Tensões Admissíveis (MTA)}

\ Estrutura tipo "Howe" e "Fink", telha de fibro-cimento e ligações através de parafusos passantes:

Vão teórico: 10 a 12 metros

$\Rightarrow 10$ peças de $6 \mathrm{~cm} \times 16 \mathrm{~cm} \times 325 \mathrm{~cm}$

> Vão teórico: 7 a 9 metros

$\Rightarrow 8$ peças de $6 \mathrm{~cm} \times 16 \mathrm{~cm} \times 325 \mathrm{~cm}$

४ Vão teórico: 6 metros

$\Rightarrow 6$ peças de $6 \mathrm{~cm} \times 16 \mathrm{~cm} \times 325 \mathrm{~cm}$

$\eta$ Estrutura tipo "Howe" e "Fink", telha de aço e ligações através de parafusos passantes:

$\diamond$ Vão teórico: 11 e 12 metros

$\Rightarrow 8$ peças de $6 \mathrm{~cm} \times 16 \mathrm{~cm} \times 375 \mathrm{~cm}$

\& Vão teórico: 6 a 10 metros

$\Rightarrow 6$ peças de $6 \mathrm{~cm} \times 16 \mathrm{~cm} \times 375 \mathrm{~cm}$

7 Estrutura tipo "Pratt" e "Fink", telha de fibro-cimento e ligações através de CDE:

O vão teórico adotado é conseqüência da tecnologia adotada, ou seja, devido ao sistema construtivo industrializado (pré-fabricado).

今 Vão teórico: 10 a 12 metros

$\Rightarrow 10$ peças de $3,5 \mathrm{~cm} \times 7 \mathrm{~cm} \times 100 \mathrm{~cm}$

Vão teórico: 7 a 9 metros

$\Rightarrow 8$ peças de $3,5 \mathrm{~cm} \times 7 \mathrm{~cm} \times 100 \mathrm{~cm}$

$\diamond$ Vão teórico: 6 metros

$\Rightarrow 6$ peças de $3,5 \mathrm{~cm} \times 7 \mathrm{~cm} \times 100 \mathrm{~cm}$

Observação: estas estruturas foram calculadas admitindo-se uma carga concentrada de 60 daN aplicada no ponto mais desfavorável (meio do vão). 
7 Estrutura tipo "Pratt" e "Fink", telha de aço e ligações através de CDE:

\& Vão teórico: 10 a 12 metros

$\Rightarrow 8$ peças de $2,5 \mathrm{~cm} \times 5 \mathrm{~cm} \times 100 \mathrm{~cm}$

$\diamond$ Vão teórico: 6 a 9 metros

$\Rightarrow 6$ peças de $2,5 \mathrm{~cm} \times 5 \mathrm{~cm} \times 100 \mathrm{~cm}$

Observação: estas estruturas foram calculadas admitindo-se uma carga concentrada de 20 daN aplicada no ponto mais desfavorável (meio do vão).

\section{$\rightarrow$ Cálculo através do Método dos Estados Limites (MEL)}

П Estrutura tipo "Howe" e "Fink", telha de fibro-cimento e ligações através de parafusos passantes:

^ Vão teórico: 10 a 12 metros

$\Rightarrow 10$ peças de $6 \mathrm{~cm} \times 16 \mathrm{~cm} \times 425 \mathrm{~cm}$

Vão teórico: 7 a 9 metros

$\Rightarrow 8$ peças de $6 \mathrm{~cm} \times 16 \mathrm{~cm} \times 425 \mathrm{~cm}$

$\diamond$ Vão teórico: 6 metros

$\Rightarrow 6$ peças de $6 \mathrm{~cm} \times 16 \mathrm{~cm} \times 425 \mathrm{~cm}$

7 Estrutura tipo "Howe" e "Fink", telha de aço e ligações através de parafusos passantes:

Para os vãos teóricos de 11 e 12 metros, propõem-se com base no consumo, duas alternativas:

a) Opção I

$\diamond$ Vão teórico: 11 e 12 metros

$\Rightarrow 8$ peças de $6 \mathrm{~cm} \times 16 \mathrm{~cm} \times 500 \mathrm{~cm}$

b) Opção II

$\diamond$ Vão teórico: 11 e 12 metros

$\Rightarrow 8$ peças de $6 \mathrm{~cm} \times 12 \mathrm{~cm} \times 425 \mathrm{~cm}$ 
Comparando ambas as opções, verificou-se que a segunda proporciona uma redução do consumo total (treliça e terça) - relação entre metros cúbicos de madeira $\mathrm{e}$ área coberta - em torno de 7 (sete) \%. Portanto, para a mesma área coberta, necessita-se de maior número de treliças e estruturas de apoio (pilares). Os valores apresentados nas tabelas A7 a A12 referem-se ao ítem "a" (Opção I).

Para os demais vãos, obteve-se os seguintes valores:

Vão teórico: 9 e 10 metros

$\Rightarrow 6$ peças de $6 \mathrm{~cm} \times 16 \mathrm{~cm} \times 500 \mathrm{~cm}$

Vão teórico: 6 a 8 metros

$\Rightarrow 6$ peças de $6 \mathrm{~cm} \times 12 \mathrm{~cm} \times 425 \mathrm{~cm}$

\subsection{Consumo final de material}

Com a finalização de todos os projetos, são apresentados os resultados priorizando a abordagem referente aos seguintes tópicos:

$\Rightarrow$ consumo de madeira por unidade de área construída;

$\Rightarrow$ número de parafusos por unidade de volume;

$\Rightarrow$ massa de CDE por unidade de volume;

$\Rightarrow$ massa de estruturas de contraventamento (barras de aço rosqueadas diâmetro $12 \mathrm{~mm}$ ) por unidade de volume;

$\Rightarrow$ proporção entre o peso próprio dos parafusos e o peso próprio total da cobertura, obtida segundo o Método dos Estados Limites.

Tais valores são mostrados a seguir. 


\subsubsection{Consumo de material das estruturas principais e secundárias.}

\section{A) Consumo de madeira}

\section{$\boldsymbol{n}$ Telhas de Fibro-cimento}

O gráfico apresentado na Figura 23 é originado das Tabelas A1 a A6. Tais valores, foram obtidos tomando como referência o tipo de telha (telha de fibrocimento).

Considerando o mesmo dispositivo de ligação e o mesmo método de cálculo, observou-se que, para cada vão teórico e independentemente da forma geométrica das estruturas principais (treliças), os consumos se equivalem.

Tomando os parafusos como base, pode-se afirmar que ao longo dos vãos considerados, o consumo de madeira obtido segundo o MEL é em média $6 \%$ menor se comparado com o MTA.

De acordo com o MTA, verificou-se que ocorrem menores consumos em estruturas cujos dispositivos de ligação são as CDE. Em estruturas com vãos de $11 \mathrm{e}$ 12 metros, a redução é de aproximadamente $20 \%$, sendo a máxima diferença em torno de $30 \%$ nas estruturas com 7 metros. Nos demais vãos, a diferença é de $25 \%$ em média.

Comparando os resultados obtidos de acordo com o MTA (estruturas com CDE) e o MEL (estruturas parafusadas), notou-se que o consumo de madeira relativo ao primeiro caso é sempre menor. Tais reduções são mostradas abaixo:

$\Rightarrow$ vãos de 7 a 8 metros: aproximadamente $25 \%$;

$\Rightarrow$ vãos de 11 a 12 metros: aproximadamente $15 \%$;

$\Rightarrow$ demais vãos: aproximadamente $20 \%$. 
Os valores extremos de consumo registrados para os vãos de 7 e 10 metros, são conseqüências do aumento do número de terças. Este fato é facilmente entendido observando-se o Ítem 5.3 deste capítulo e o Anexo "A".

TABELA A1 - MTA - Estrutura tipo "Howe" - Parafusos passantes.

\begin{tabular}{|c|c|c|c|c|}
\hline $\begin{array}{c}\text { Vão } \\
(\mathrm{m})\end{array}$ & $\begin{array}{c}\text { Volume } \\
\mathrm{da} \text { Treliça } \\
\left(\mathrm{m}^{3}\right)\end{array}$ & $\begin{array}{c}\text { Volume } \\
\mathrm{da} \text { Terça } \\
\left(\mathrm{m}^{3}\right)\end{array}$ & $\begin{array}{c}\text { Vol. Total } \\
\text { de Madeira } \\
\left(\mathrm{m}^{3}\right)\end{array}$ & $\begin{array}{c}\text { Consumo de } \\
\text { Madeira } \\
\left(\mathrm{m}^{3} / \mathrm{m}^{2}\right)\end{array}$ \\
\hline 6 & 0,098 & 0,187 & 0,285 & 0,015 \\
\hline 7 & 0,128 & 0,250 & 0,378 & 0,017 \\
\hline 8 & 0,148 & 0,250 & 0,398 & 0,015 \\
\hline 9 & 0,180 & 0,250 & 0,430 & 0,015 \\
\hline 10 & 0,213 & 0,312 & 0,525 & 0,016 \\
\hline 11 & 0,237 & 0,312 & 0,549 & 0,015 \\
\hline 12 & 0,26 & 0,312 & 0,572 & 0,015 \\
\hline
\end{tabular}

TABELA A2 - MTA - Estrutura tipo "Fink" - Parafusos passantes.

\begin{tabular}{|c|c|c|c|c|}
\hline $\begin{array}{c}\text { Vão } \\
(\mathbf{m})\end{array}$ & $\begin{array}{c}\text { Volume } \\
\text { da } \\
\text { Treliça } \\
\left(\mathrm{m}^{3}\right)\end{array}$ & $\begin{array}{c}\text { Volume } \\
\text { da Terça } \\
\left(\mathrm{m}^{3}\right)\end{array}$ & $\begin{array}{c}\text { Vol. Total } \\
\text { de Madeira } \\
\left(\mathrm{m}^{3}\right)\end{array}$ & $\begin{array}{c}\text { Consumo de } \\
\text { Madeira } \\
\left(\mathrm{m}^{3} / \mathrm{m}^{2}\right)\end{array}$ \\
\hline 6 & 0,097 & 0,187 & 0,284 & 0,015 \\
\hline 7 & 0,128 & 0,250 & 0,378 & 0,017 \\
\hline 8 & 0,147 & 0,250 & 0,397 & 0,015 \\
\hline 9 & 0,174 & 0,250 & 0,424 & 0,015 \\
\hline 10 & 0,207 & 0,312 & 0,519 & 0,016 \\
\hline 11 & 0,231 & 0,312 & 0,543 & 0,015 \\
\hline 12 & 0,249 & 0,312 & 0,561 & 0,014 \\
\hline
\end{tabular}

TABELA A3 - MTA - Estrutura tipo "Fink" - CDE

\begin{tabular}{|c|c|c|c|c|}
\hline $\begin{array}{c}\text { Vão } \\
(\mathrm{m})\end{array}$ & $\begin{array}{c}\text { Volume } \\
\text { da Treliça } \\
\left(\mathrm{m}^{3}\right)\end{array}$ & $\begin{array}{c}\text { Volume } \\
\text { da Terça } \\
\left(\mathrm{m}^{3}\right)\end{array}$ & $\begin{array}{c}\text { Vol. Total } \\
\text { de Madeira } \\
\left(\mathrm{m}^{3}\right)\end{array}$ & $\begin{array}{c}\text { Consumo de } \\
\text { Madeira } \\
\left(\mathrm{m}^{3} / \mathrm{m}^{2}\right)\end{array}$ \\
\hline 6 & 0,052 & 0,015 & 0,067 & 0,011 \\
\hline 7 & 0,067 & 0,020 & 0,087 & 0,012 \\
\hline 8 & 0,075 & 0,020 & 0,095 & 0,011 \\
\hline 9 & 0,085 & 0,020 & 0,105 & 0,011 \\
\hline 10 & 0,100 & 0,025 & 0,125 & 0,012 \\
\hline 11 & 0,108 & 0,025 & 0,133 & 0,012 \\
\hline 12 & 0,117 & 0,025 & 0,142 & 0,012 \\
\hline
\end{tabular}


TABELA A4 - MTA - Estrutura tipo "Pratt" - CDE.

\begin{tabular}{|c|c|c|c|c|}
\hline $\begin{array}{c}\text { Vão } \\
(\mathrm{m})\end{array}$ & $\begin{array}{c}\text { Volume da } \\
\text { Treliça } \\
\left(\mathbf{m}^{3}\right)\end{array}$ & $\begin{array}{c}\text { Volume } \\
\text { da Terça } \\
\left(\mathrm{m}^{3}\right)\end{array}$ & $\begin{array}{c}\text { Vol. Total } \\
\text { de Madeira } \\
\left(\mathrm{m}^{3}\right)\end{array}$ & $\begin{array}{c}\text { Consumo de } \\
\text { Madeira } \\
\left(\mathrm{m}^{3} / \mathrm{m}^{2}\right)\end{array}$ \\
\hline 6 & 0,054 & 0,015 & 0,069 & 0,011 \\
\hline 7 & 0,067 & 0,020 & 0,087 & 0,012 \\
\hline 8 & 0,075 & 0,020 & 0,095 & 0,011 \\
\hline 9 & 0,086 & 0,020 & 0,106 & 0,011 \\
\hline 10 & 0,101 & 0,025 & 0,126 & 0,013 \\
\hline 11 & 0,111 & 0,025 & 0,136 & 0,012 \\
\hline 12 & 0,121 & 0,025 & 0,146 & 0,012 \\
\hline
\end{tabular}

TABELA A5 - MEL - Estrutura tipo "Howe" - Parafusos passantes.

\begin{tabular}{|c|c|c|c|c|}
\hline $\begin{array}{c}\text { Vão } \\
(\mathrm{m})\end{array}$ & $\begin{array}{c}\text { Volume da } \\
\text { Treliça } \\
\left(\mathrm{m}^{3}\right)\end{array}$ & $\begin{array}{c}\text { Volume da } \\
\text { Terça } \\
\left(\mathrm{m}^{3}\right)\end{array}$ & $\begin{array}{c}\text { Vol. Total } \\
\text { de Madeira } \\
\left(\mathrm{m}^{3}\right)\end{array}$ & $\begin{array}{c}\text { Consumo de } \\
\text { Madeira } \\
\left(\mathrm{m}^{3} / \mathrm{m}^{2}\right)\end{array}$ \\
\hline 6 & 0,111 & 0,245 & 0,356 & 0,014 \\
\hline 7 & 0,146 & 0,326 & 0,472 & 0,016 \\
\hline 8 & 0,174 & 0,326 & 0,500 & 0,015 \\
\hline 9 & 0,192 & 0,326 & 0,518 & 0,014 \\
\hline 10 & 0,238 & 0,408 & 0,646 & 0,015 \\
\hline 11 & 0,259 & 0,408 & 0,667 & 0,014 \\
\hline 12 & 0,297 & 0,408 & 0,705 & 0,014 \\
\hline
\end{tabular}

TABELA A6 - MEL - Estrutura tipo "Fink" - Parafusos passantes.

\begin{tabular}{|c|c|c|c|c|}
\hline $\begin{array}{c}\text { Vão } \\
(\mathrm{m})\end{array}$ & $\begin{array}{c}\text { Volume da } \\
\text { Treliça } \\
\left(\mathrm{m}^{3}\right)\end{array}$ & $\begin{array}{c}\text { Volume } \\
\mathrm{da} \mathrm{Terca} \\
\left(\mathrm{m}^{3}\right)\end{array}$ & $\begin{array}{c}\text { Vol. Total } \\
\text { de Madeira } \\
\left(\mathrm{m}^{3}\right)\end{array}$ & $\begin{array}{c}\text { Consumo de } \\
\text { Madeira } \\
\left(\mathrm{m}^{3} / \mathrm{m}^{2}\right)\end{array}$ \\
\hline 6 & 0,107 & 0,245 & 0,352 & 0,014 \\
\hline 7 & 0,147 & 0,326 & 0,473 & 0,016 \\
\hline 8 & 0,175 & 0,326 & 0,501 & 0,015 \\
\hline 9 & 0,197 & 0,326 & 0,523 & 0,014 \\
\hline 10 & 0,246 & 0,408 & 0,654 & 0,015 \\
\hline 11 & 0,265 & 0,408 & 0,673 & 0,014 \\
\hline 12 & 0,309 & 0,408 & 0,717 & 0,014 \\
\hline
\end{tabular}

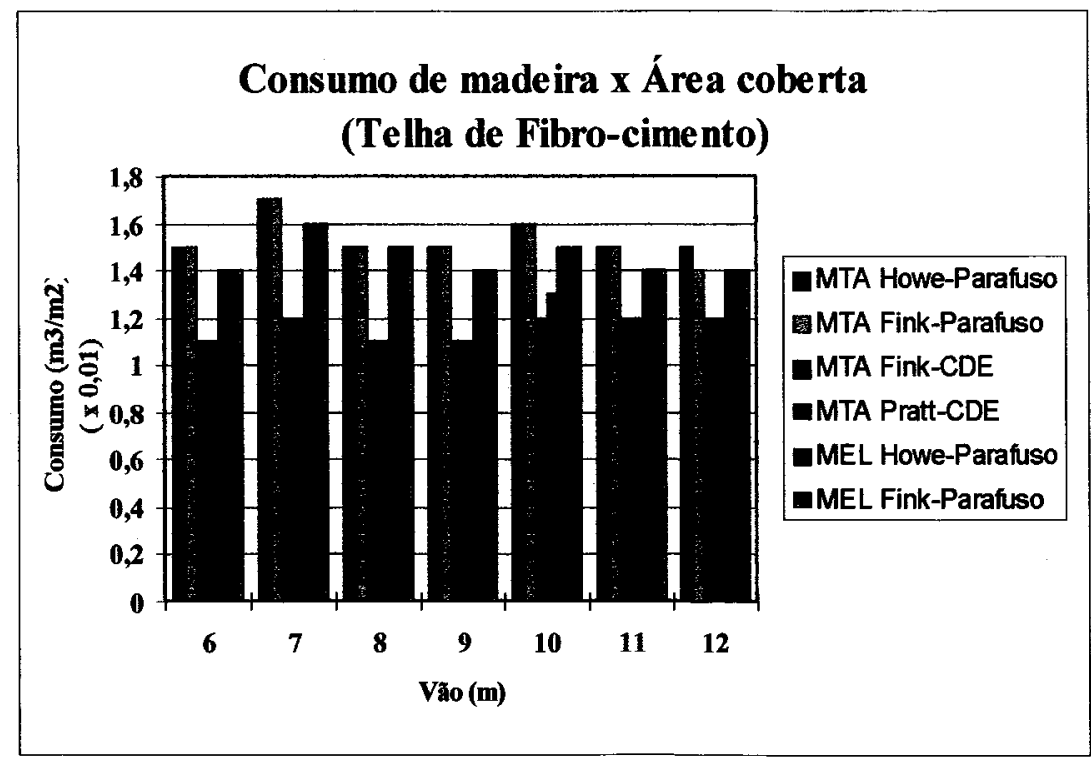

FIGURA 23 - Consumo de madeira x Área coberta (Telha de Fibro-cimento) 


\section{$\boldsymbol{\pi}$ Telhas de Aço}

O gráfico apresentado na Figura 24 é originado das Tabelas A7 a A12. Estes valores foram obtidos tomando como referência as estruturas, cujo elemento de cobertura utilizado foi a telha de aço.

Considerando ambos os métodos de cálculo e os parafusos como dispositivos de ligação, observou-se que, para cada vão teórico e independentemente da geometria das estruturas principais (treliças), os consumos se equivalem.

Tomando os parafusos como referência, pode-se afirmar que ao longo dos vãos considerados, o consumo de madeira obtido segundo o MEL é sempre menor se comparado com o MTA. Para os vãos de 6 a 7 e 8 metros, a diferença é em torno de $22 \%$ e $17 \%$, respectivamente. Para os demais vãos, este valor decresce até aproximadamente $10 \%$.

Notou-se que, nas estruturas parafusadas os picos das diferenças entre o MTA e o MEL, referem-se aos vãos de 6 e 11 metros. Isto ocorreu devido ao acréscimo do número de terças, principalmente nas estruturas com 11 metros. Quanto às treliças de 6 metros, deve-se à relação entre o volume de madeira e a área de influência das mesmas. Este fato é facilmente entendido observando-se o Anexo "A" e o Ítem 5.3 deste capítulo.

Nas estruturas tipo "Pratt" com CDE, pode-se afirmar que as estruturas com vãos de 10 a 12 metros, apresentam consumos de madeira superiores aos demais vãos e, este valor gira em torno de $10 \%$. Verificou-se que, independentemente do vão considerado, os consumos da citada estrutura é aproximadamente $10 \%$ superior se comparado às estruturas tipo "Fink".

De acordo com o MTA, verificou-se que as maiores diferenças entre consumos ocorrem em estruturas com vãos de 6 a 8 metros e CDE como dispositivo 
de ligação. Nestes vãos, têm-se diferenças em torno de $30 \%$ a $15 \%$, respectivamente. Nos demais, os valores se equivalem.

Comparando os resultados obtidos de acordo com o MTA (estruturas tipo "Fink" com CDE) e o MEL (estruturas parafusadas), notou-se que o consumo de madeira é praticamente igual. Referente às estruturas tipo "Pratt", verificou-se um consumo em torno de $10 \%$ maior se comparado com o MEL. Tal fato é justificado, observando-se o exposto no Ítem 5.3 deste capítulo e no Anexo "A".

TABELA A7 - MTA - Estrutura tipo "Howe" - Parafusos passantes.

\begin{tabular}{|c|c|c|c|c|}
\hline $\begin{array}{c}\text { Vão } \\
(\mathrm{m})\end{array}$ & $\begin{array}{c}\text { Volume } \\
\mathrm{da} \text { Treliça } \\
\left(\mathrm{m}^{3}\right)\end{array}$ & $\begin{array}{c}\text { Volume } \\
\text { da Terça } \\
\left(\mathrm{m}^{3}\right)\end{array}$ & $\begin{array}{c}\text { Vol. Total } \\
\text { de Madeira } \\
\left(\mathrm{m}^{3}\right)\end{array}$ & $\begin{array}{c}\text { Consumo de } \\
\text { Madeira } \\
\left(\mathrm{m}^{3} / \mathrm{m}^{2}\right)\end{array}$ \\
\hline 6 & 0,090 & 0,187 & 0,277 & 0,014 \\
\hline 7 & 0,107 & 0,187 & 0,294 & 0,012 \\
\hline 8 & 0,121 & 0,187 & 0,308 & 0,011 \\
\hline 9 & 0,144 & 0,187 & 0,331 & 0,011 \\
\hline 10 & 0,181 & 0,187 & 0,368 & 0,011 \\
\hline 11 & 0,192 & 0,250 & 0,442 & 0,012 \\
\hline 12 & 0,205 & 0,250 & 0,455 & 0,011 \\
\hline
\end{tabular}

TABELA A8 - MTA - Estrutura tipo "Fink" - Parafusos passantes.

\begin{tabular}{|c|c|c|c|c|}
\hline $\begin{array}{c}\text { Vão } \\
(\mathrm{m})\end{array}$ & $\begin{array}{c}\text { Volume } \\
\text { da Treliça } \\
\left(\mathrm{m}^{3}\right)\end{array}$ & $\begin{array}{c}\text { Volume } \\
\text { da Terça } \\
\left(\mathbf{m}^{3}\right)\end{array}$ & $\begin{array}{c}\text { Vol. Total } \\
\text { de Madeira } \\
\left(\mathbf{m}^{3}\right)\end{array}$ & $\begin{array}{c}\text { Consumo de } \\
\text { Madeira } \\
\left(\mathrm{m}^{3} / \mathrm{m}^{2}\right)\end{array}$ \\
\hline 6 & 0,088 & 0,187 & 0,275 & 0,014 \\
\hline 7 & 0,103 & 0,187 & 0,290 & 0,012 \\
\hline 8 & 0,119 & 0,187 & 0,306 & 0,011 \\
\hline 9 & 0,139 & 0,187 & 0,326 & 0,011 \\
\hline 10 & 0,174 & 0,187 & 0,361 & 0,011 \\
\hline 11 & 0,187 & 0,250 & 0,437 & 0,012 \\
\hline 12 & 0,201 & 0,250 & 0,451 & 0,011 \\
\hline
\end{tabular}

TABELA A9 - MTA - Estrutura tipo "Fink" - CDE.

\begin{tabular}{|c|c|c|c|c|}
\hline $\begin{array}{c}\text { Vão } \\
(\mathrm{m})\end{array}$ & $\begin{array}{c}\text { Volume } \\
\text { da Treliça } \\
\left(\mathrm{m}^{3}\right)\end{array}$ & $\begin{array}{c}\text { Volume } \\
\text { da Terça } \\
\left(\mathrm{m}^{3}\right)\end{array}$ & $\begin{array}{c}\text { Vol. Total } \\
\text { de Madeira } \\
\left(\mathrm{m}^{3}\right)\end{array}$ & $\begin{array}{c}\text { Consumo de } \\
\text { Madeira } \\
\left(\mathrm{m}^{3} / \mathrm{m}^{2}\right)\end{array}$ \\
\hline 6 & 0,052 & 0,008 & 0,060 & 0,010 \\
\hline 7 & 0,064 & 0,008 & 0,072 & 0,010 \\
\hline 8 & 0,076 & 0,008 & 0,084 & 0,010 \\
\hline 9 & 0,085 & 0,008 & 0,093 & 0,010 \\
\hline 10 & 0,103 & 0,010 & 0,113 & 0,011 \\
\hline 11 & 0,117 & 0,010 & 0,127 & 0,011 \\
\hline 12 & 0,127 & 0,010 & 0,137 & 0,011 \\
\hline
\end{tabular}


TABELA A10 - MTA - Estrutura tipo "Pratt" - CDE.

\begin{tabular}{|c|c|c|c|c|}
\hline $\begin{array}{c}\text { Vão } \\
(\mathrm{m})\end{array}$ & $\begin{array}{c}\text { Volume da } \\
\text { Treliça } \\
\left(\mathrm{m}^{3}\right)\end{array}$ & $\begin{array}{c}\text { Volume } \\
\mathrm{da} \mathrm{Terça} \\
\left(\mathrm{m}^{3}\right)\end{array}$ & $\begin{array}{c}\text { Vol. Total } \\
\text { de Madeira } \\
\left(\mathrm{m}^{3}\right)\end{array}$ & $\begin{array}{c}\text { Consumo de } \\
\text { Madeira } \\
\left(\mathrm{m}^{3} / \mathrm{m}^{2}\right)\end{array}$ \\
\hline 6 & 0,060 & 0,008 & 0,068 & 0,011 \\
\hline 7 & 0,070 & 0,008 & 0,078 & 0,011 \\
\hline 8 & 0,079 & 0,008 & 0,087 & 0,011 \\
\hline 9 & 0,089 & 0,008 & 0,097 & 0,011 \\
\hline 10 & 0,113 & 0,010 & 0,123 & 0,012 \\
\hline 11 & 0,122 & 0,010 & 0,132 & 0,012 \\
\hline 12 & 0,131 & 0,010 & 0,141 & 0,012 \\
\hline
\end{tabular}

TABELA A11 - MEL - Estrutura tipo "Howe" - Parafusos passantes.

\begin{tabular}{|c|c|c|c|c|}
\hline $\begin{array}{c}\text { Vão } \\
(\mathrm{m})\end{array}$ & $\begin{array}{c}\text { Volume da } \\
\text { Treliça } \\
\left(\mathrm{m}^{3}\right)\end{array}$ & $\begin{array}{c}\text { Volume } \\
\text { da Teŗa } \\
\left(\mathrm{m}^{3}\right)\end{array}$ & $\begin{array}{c}\text { Vol. Total } \\
\text { de Madeira } \\
\left(\mathrm{m}^{3}\right)\end{array}$ & $\begin{array}{c}\text { Consumo de } \\
\text { Madeira } \\
\left(\mathrm{m}^{3} / \mathrm{m}^{2}\right)\end{array}$ \\
\hline 6 & 0,109 & 0,184 & 0,293 & 0,011 \\
\hline 7 & 0,124 & 0,184 & 0,308 & 0,010 \\
\hline 8 & 0,157 & 0,184 & 0,341 & 0,010 \\
\hline 9 & 0,173 & 0,288 & 0,461 & 0,010 \\
\hline 10 & 0,219 & 0,288 & 0,507 & 0,010 \\
\hline 11 & 0,231 & 0,384 & 0,615 & 0,010 \\
\hline 12 & 0,248 & 0,384 & 0,632 & 0,010 \\
\hline
\end{tabular}

TABELA A12 - MEL - Estrutura tipo "Fink" - Parafusos passantes.

\begin{tabular}{|c|c|c|c|c|}
\hline $\begin{array}{c}\text { Vão } \\
(\mathrm{m})\end{array}$ & $\begin{array}{c}\text { Volume da } \\
\text { Treliça } \\
\left(\mathrm{m}^{3}\right)\end{array}$ & $\begin{array}{c}\text { Volume } \\
\text { da Terça } \\
\left(\mathrm{m}^{3}\right)\end{array}$ & $\begin{array}{c}\text { Vol. Total } \\
\text { de Madeira } \\
\left(\mathrm{m}^{3}\right)\end{array}$ & $\begin{array}{c}\text { Consumo de } \\
\text { Madeira } \\
\left(\mathrm{m}^{3} / \mathrm{m}^{2}\right)\end{array}$ \\
\hline 6 & 0,101 & 0,184 & 0,285 & 0,011 \\
\hline 7 & 0,118 & 0,184 & 0,302 & 0,010 \\
\hline 8 & 0,161 & 0,184 & 0,345 & 0,010 \\
\hline 9 & 0,173 & 0,288 & 0,461 & 0,010 \\
\hline 10 & 0,227 & 0,288 & 0,515 & 0,010 \\
\hline 11 & 0,242 & 0,384 & 0,626 & 0,010 \\
\hline 12 & 0,259 & 0,384 & 0,643 & 0,010 \\
\hline
\end{tabular}

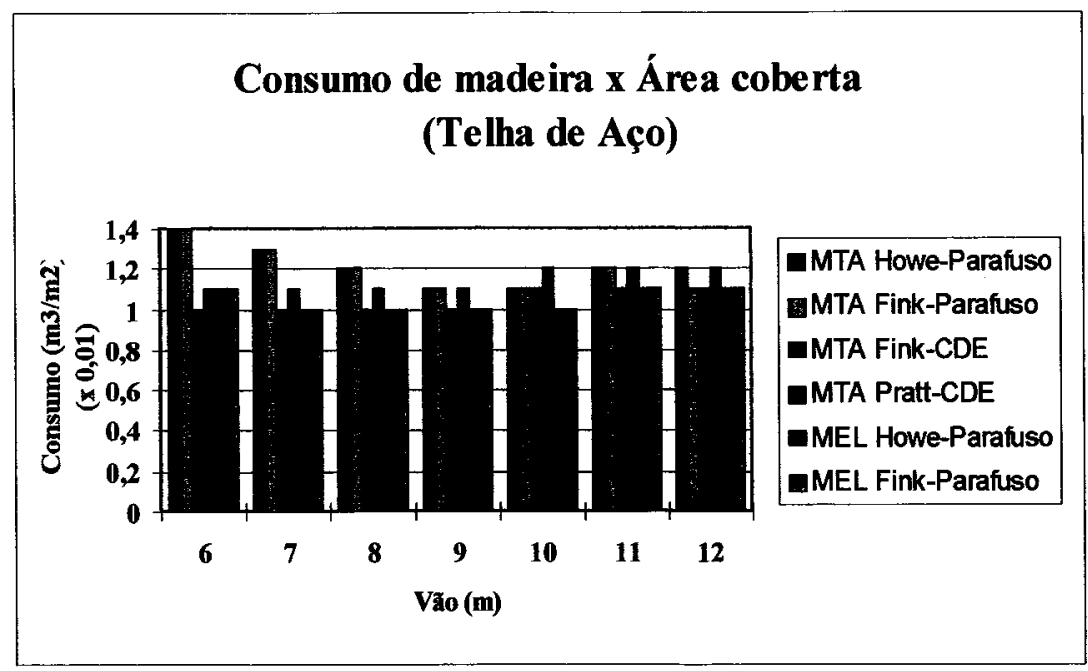

FIGURA 24 - Consumo de madeira x Área coberta (Telha de Aço) 


\section{B) Consumo de parafusos}

\section{$\boldsymbol{\lambda}$ Telhas de Fibro-cimento}

O gráfico da Figura 25 representa os valores apresentados nas Tabelas B1 a B4. Tais tabelas registram os consumos de parafusos em relação ao volume de madeira empregado nas estruturas em estudo, considerando as telhas de fibro-cimento como elemento de cobertura.

Segundo os resultados obtidos através do MTA e o MEL, constatou-se que as estruturas tipo "Howe" levam a maiores consumos de parafusos. Com auxílio do Anexo " $\mathrm{A}$ ", verificou-se que a maior diferença de consumo entre ambos os métodos de cálculos ocorre nas estruturas com 10 metros de vão. Tal fato está diretamente relacionado com as emendas entre elementos estruturais do banzo inferior e nas quantidades de nós existentes.

Tomando como referência o MTA, observou-se o decréscimo do consumo nas estruturas principais com 7 metros. Isto aconteceu devido ao acréscimo do volume das estruturas secundárias (terças). Em relação ao MEL, observou-se também o aumento do volume de madeira e do número de parafusos em relação ao volume da mesma.

De acordo com os dois métodos de cálculo, constatou-se que os acréscimos de consumo referentes às estruturas de 11 e 12 metros são bastante significativos. A explicação do ocorrido deve-se às emendas dos elementos estruturais do banzo superior.

De acordo com a Figura 25, pode-se afirmar que o consumo de parafusos segundo o MEL é mais elevado. Isto ocorreu em razão da abordagem dada pela NBR 7190/96 - no que se refere aos coeficientes de ponderações de ações -, o qual proporcionou esforços internos consideravelmente elevados. 
TABELA B1- MTA - Estrutura tipo "Howe".

\begin{tabular}{|c|c|c|}
\hline $\begin{array}{c}\text { Vão } \\
(\mathrm{m})\end{array}$ & $\begin{array}{c}\text { Número } \\
\text { de Parafusos }\end{array}$ & $\begin{array}{c}\text { Consumo de Parafusos } \\
\left(\text { Unid } / \mathrm{m}^{3} \text { ) }\right.\end{array}$ \\
\hline 6 & 63 & 221 \\
\hline 7 & 77 & 204 \\
\hline 8 & 88 & 222 \\
\hline 9 & 102 & 237 \\
\hline 10 & 132 & 252 \\
\hline 11 & 158 & 288 \\
\hline 12 & 168 & 294 \\
\hline
\end{tabular}

TABELA B2- MTA - Estrutura tipo "Fink".

\begin{tabular}{|c|c|c|}
\hline $\begin{array}{c}\text { Vão } \\
(\mathrm{m})\end{array}$ & $\begin{array}{c}\text { Número } \\
\text { de Parafusos }\end{array}$ & $\begin{array}{c}\text { Consumo de Parafusos } \\
\left(\text { Unid/m } / \mathrm{m}^{3}\right)\end{array}$ \\
\hline 6 & 54 & 191 \\
\hline 7 & 68 & 180 \\
\hline 8 & 80 & 202 \\
\hline 9 & 92 & 217 \\
\hline 10 & 112 & 216 \\
\hline 11 & 156 & 288 \\
\hline 12 & 166 & 296 \\
\hline
\end{tabular}

TABELA B3 - MEL - Estrutura tipo "Howe".

\begin{tabular}{|c|c|c|}
\hline $\begin{array}{c}\text { Vão } \\
(\mathrm{m})\end{array}$ & $\begin{array}{c}\text { Número } \\
\text { de Parafusos }\end{array}$ & $\begin{array}{c}\text { Consumo de Parafusos } \\
\left(\text { Unid } / \mathrm{m}^{3} \text { ) }\right.\end{array}$ \\
\hline 6 & 86 & 242 \\
\hline 7 & 116 & 246 \\
\hline 8 & 128 & 256 \\
\hline 9 & 144 & 278 \\
\hline 10 & 200 & 310 \\
\hline 11 & 244 & 365 \\
\hline 12 & 264 & 375 \\
\hline
\end{tabular}

TABELA B4 - MEL - Estrutura tipo "Fink".

\begin{tabular}{|c|c|c|}
\hline $\begin{array}{c}\text { Vão } \\
(\mathbf{m})\end{array}$ & $\begin{array}{c}\text { Número } \\
\text { de Parafusos }\end{array}$ & $\begin{array}{c}\text { Consumo de Parafusos } \\
\left(\text { Unid } / \mathrm{m}^{3}\right)\end{array}$ \\
\hline 6 & 76 & 209 \\
\hline 7 & 108 & 225 \\
\hline 8 & 122 & 244 \\
\hline 9 & 136 & 260 \\
\hline 10 & 164 & 251 \\
\hline 11 & 238 & 354 \\
\hline 12 & 254 & 355 \\
\hline
\end{tabular}


Consumo de parafuso $x$ Volume da madeira

(Telha de Fibro-cimento)

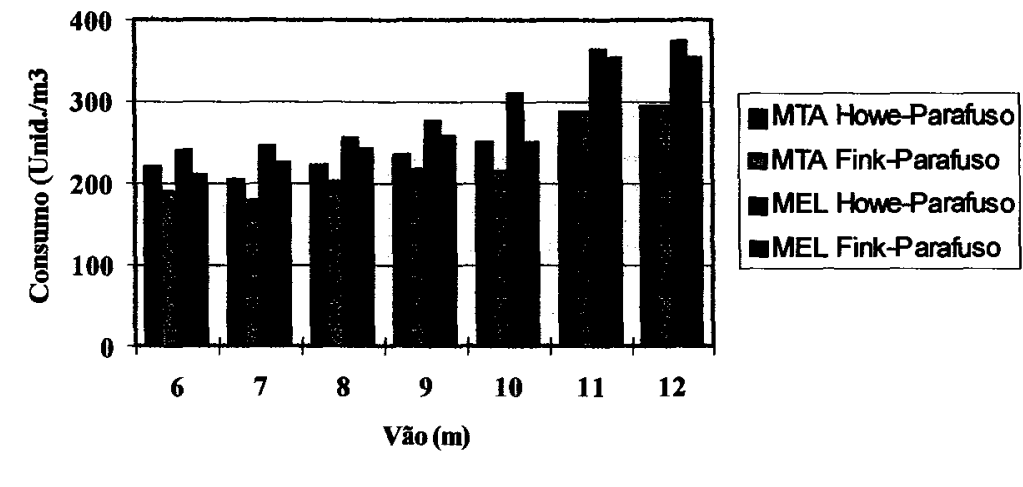

FIGURA 25 - Consumo de parafuso x Volume de madeira (Telha de Fibro-cimento)

\section{$\boldsymbol{x}$ Telhas de Aço}

O gráfico da Figura 26 representa os valores apresentados nas Tabelas B5 a B8. Estas tabelas registram os consumos de parafusos em relação ao volume de madeira empregado, considerando estruturas com telhas de aço.

Segundo os resultados obtidos de acordo com o MTA e o MEL, constatou-se que, na maioria das vezes, as estruturas tipo "Howe" levam a maiores consumos de parafusos. Com auxílio do Anexo "A", verificou-se que a maior diferença de consumo entre ambos os métodos de cálculos ocorre nas estruturas com 10 metros de vão. Tal fato está diretamente relacionado com as emendas entre elementos estruturais do banzo inferior e na mudança da forma geométrica das estruturas.

Tomando como referência o MEL, observou-se o decréscimo do consumo nas estruturas com 9 metros de vão. Isto aconteceu devido ao maior acréscimo do volume de madeira - principalmente das estruturas secundárias (terças)- em relação ao número de parafusos. Para o MTA, houve também o aumento do volume de madeira e do número de parafusos, porém, o consumo de parafusos permaneceu praticamente 
constante para ambos os tipos de estruturas. Estes fatos são facilmente entendidos observando-se o Anexo "A" e o Ítem 5.3 deste capítulo.

De acordo com o MEL, constatou-se que os acréscimos de consumo referentes às estruturas de 11 e 12 metros são bastante significativos. Devem-se ao aumento do número de parafusos das emendas dos elementos estruturais do banzo superior. Tal fato é decorrência dos elevados valores de tração nos elementos do banzo superior.

Pode-se afirmar que o consumo de parafusos segundo o MEL é superior ao do MTA, exceto em estruturas com 9 metros de vão. Cabem aqui, as mesmas justificativas abordadas para as estruturas, cujo elemento de cobertura considerado é de telha fibro-cimento.

TABELA B5 - MTA - Estrutura tipo "Howe".

\begin{tabular}{|c|c|c|}
\hline $\begin{array}{c}\text { Vão } \\
(\mathrm{m})\end{array}$ & $\begin{array}{c}\text { Número } \\
\text { de Parafusos }\end{array}$ & $\begin{array}{c}\text { Consumo de Parafusos } \\
\left(\mathrm{Unid} / \mathrm{m}^{3}\right)\end{array}$ \\
\hline 6 & 57 & 206 \\
\hline 7 & 63 & 215 \\
\hline 8 & 70 & 228 \\
\hline 9 & 76 & 230 \\
\hline 10 & 110 & 299 \\
\hline 11 & 136 & 308 \\
\hline 12 & 144 & 317 \\
\hline
\end{tabular}

TABELA B6 - MTA - Estrutura tipo "Fink".

\begin{tabular}{|c|c|c|}
\hline $\begin{array}{c}\text { Vão } \\
(\mathrm{m})\end{array}$ & $\begin{array}{c}\text { Número } \\
\text { de Parafusos }\end{array}$ & $\begin{array}{c}\text { Consumo de Parafusos } \\
\left(\mathrm{Unid} / \mathrm{m}^{3}\right)\end{array}$ \\
\hline 6 & 50 & 182 \\
\hline 7 & 54 & 187 \\
\hline 8 & 62 & 203 \\
\hline 9 & 66 & 203 \\
\hline 10 & 96 & 266 \\
\hline 11 & 132 & 303 \\
\hline 12 & 144 & 320 \\
\hline
\end{tabular}


TABELA B7 - MEL - Estrutura tipo "Howe".

\begin{tabular}{|c|c|c|}
\hline $\begin{array}{c}\text { Vão } \\
(\mathbf{m})\end{array}$ & $\begin{array}{c}\text { Número } \\
\text { de Parafusos }\end{array}$ & $\begin{array}{c}\text { Consumo de Parafusos } \\
\left(\text { Unid/m } \mathbf{m}^{3}\right)\end{array}$ \\
\hline 6 & 72 & 246 \\
\hline 7 & 84 & 273 \\
\hline 8 & 92 & 270 \\
\hline 9 & 100 & 217 \\
\hline 10 & 152 & 300 \\
\hline 11 & 212 & 345 \\
\hline 12 & 230 & 364 \\
\hline
\end{tabular}

TABELA B8 - MEL - Estrutura tipo "Fink".

\begin{tabular}{|c|c|c|}
\hline $\begin{array}{c}\text { Vão } \\
(\mathrm{m})\end{array}$ & $\begin{array}{c}\text { Número } \\
\text { de Parafusos }\end{array}$ & $\begin{array}{c}\text { Consumo de Parafusos } \\
\left(\mathrm{Unid} / \mathrm{m}^{3} \text { ) }\right.\end{array}$ \\
\hline 6 & 64 & 224 \\
\hline 7 & 72 & 238 \\
\hline 8 & 78 & 226 \\
\hline 9 & 86 & 187 \\
\hline 10 & 114 & 222 \\
\hline 11 & 202 & 323 \\
\hline 12 & 218 & 340 \\
\hline
\end{tabular}

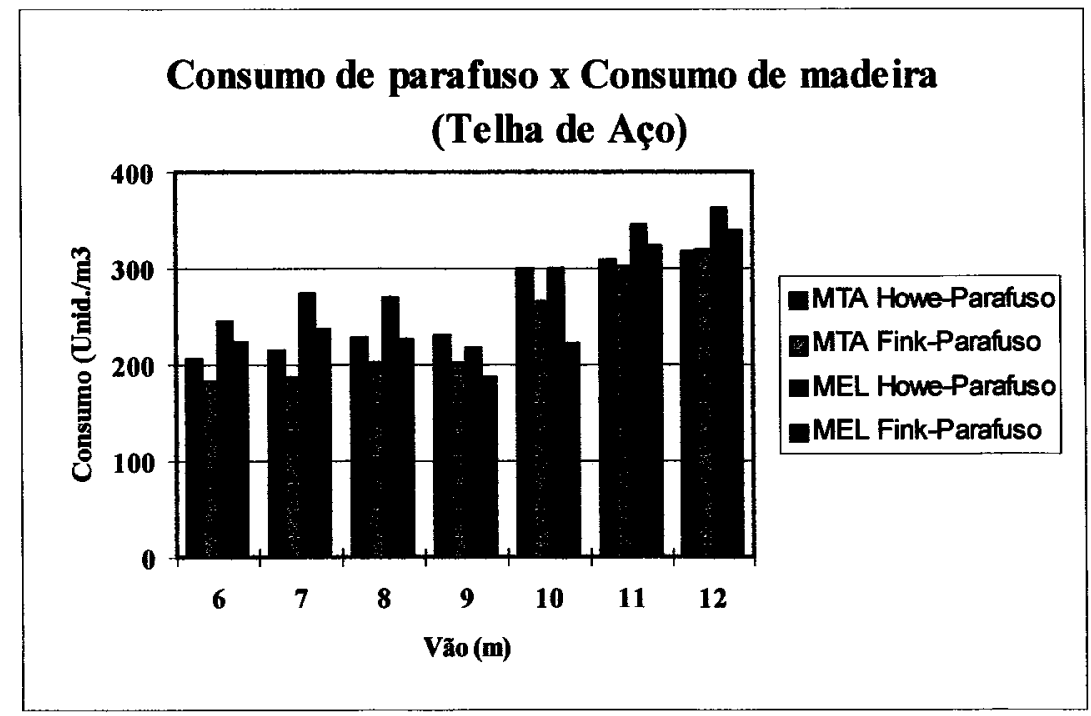

FIGURA 26 - Consumo de parafuso x Volume de madeira (Telha de Aço) 


\section{C) Consumo de CDE}

O gráfico da Figura 27 abaixo mencionado, registra os resultados explicitados nas Tabelas $\mathrm{C} 1$ a $\mathrm{C} 4$. Tais resultados são conseqüência da avaliação do consumo de $\mathrm{CDE}$ em relação ao volume de madeira empregado.

Observou-se o maior consumo de $\mathrm{CDE}$ referente às estruturas com telhas de fibro-cimento, exceto nas estruturas com 6 metros. Este fato deve-se a mesma massa de $\mathrm{CDE}$ e ao maior volume de madeira empregado pelas mesmas.

Com base nas estruturas tipo "Pratt"e "Fink", ambas com telhas de fibrocimento, verificou-se que em cada vão o consumo de $\mathrm{CDE}$ é praticamente igual. $\mathrm{O}$ mesmo pode ser afirmado para as estruturas de cobertura com telhas de aço, porém, com valores inferiores ao primeiro.

Foi observado o aumento abrupto do consumo de CDE referentes às estruturas de 7 e 10 metros de vão com telhas de fibro-cimento. Tal fato deve-se, principalmente, às variações geométricas sofridas pelas estruturas. Estas variações proporcionaram maior número de nós e, conseqüentemente, maior volume de madeira e maior massa de CDE. Entretanto, o aumento desta em relação ao acréscimo de volume de madeira, resultou num aumento do consumo de CDE. Verificou-se, também, que as estruturas com 11 metros têm consumo superior às demais. Este acréscimo deve-se à introdução de dispositivos de ligação nas emendas de elementos estruturais do banzo superior das mesmas. Tais comentários servem também para as estruturas com telhas de aço e vãos de 10 e 11 metros, respectivamente.

Para cada vão, verificou-se que, em estruturas com telhas de aço e fibrocimento com ligações através de $\mathrm{CDE}$, o consumo independe da forma geométrica das mesmas. 
TABELA C1 - MTA - Estrutura tipo "Fink", telha de fibro-cimento.

\begin{tabular}{|c|c|c|}
\hline $\begin{array}{c}\text { Vão } \\
(\mathrm{m})\end{array}$ & $\begin{array}{c}\text { Massa de CDE } \\
(\mathrm{Kg})\end{array}$ & $\begin{array}{c}\text { Consumo de CDE } \\
\left(\mathrm{Kg} / \mathrm{m}^{3}\right)\end{array}$ \\
\hline 6 & 1,27 & 19,0 \\
\hline 7 & 1,98 & 22,8 \\
\hline 8 & 2,12 & 22,3 \\
\hline 9 & 2,12 & 20,2 \\
\hline 10 & 3,17 & 25,4 \\
\hline 11 & 3,52 & 26,5 \\
\hline 12 & 3,57 & 25,1 \\
\hline
\end{tabular}

TABELA C2 - MTA - Estrutura tipo "Pratt", telha de fibro-cimento.

\begin{tabular}{|c|c|c|}
\hline $\begin{array}{c}\text { Vão } \\
(\mathrm{m})\end{array}$ & $\begin{array}{c}\text { Massa de CDE } \\
(\mathrm{Kg})\end{array}$ & $\begin{array}{c}\text { Consumo de CDE } \\
\left(\mathrm{Kg} / \mathrm{m}^{3}\right)\end{array}$ \\
\hline 6 & 1,32 & 19,1 \\
\hline 7 & 2,03 & 23,3 \\
\hline 8 & 2,18 & 22,9 \\
\hline 9 & 2,18 & 20,6 \\
\hline 10 & 3,25 & 25,8 \\
\hline 11 & 3,60 & 26,5 \\
\hline 12 & 3,63 & 24,9 \\
\hline
\end{tabular}

TABELA C3 - MTA - Estrutura tipo "Fink", telha de aço.

\begin{tabular}{|c|c|c|}
\hline $\begin{array}{c}\text { Vão } \\
(\mathrm{m})\end{array}$ & $\begin{array}{c}\text { Massa de CDE } \\
(\mathrm{Kg})\end{array}$ & $\begin{array}{c}\text { Consumo de CDE } \\
\left(\mathrm{Kg} / \mathrm{m}^{3}\right)\end{array}$ \\
\hline 6 & 1,27 & 21,2 \\
\hline 7 & 1,27 & 18,7 \\
\hline 8 & 1,27 & 16,7 \\
\hline 9 & 1,27 & 15,1 \\
\hline 10 & 1,97 & 18,9 \\
\hline 11 & 2,33 & 20,6 \\
\hline 12 & 2,33 & 19,1 \\
\hline
\end{tabular}

TABELA C4 - Estrutura tipo "Pratt", telha de aço.

\begin{tabular}{|c|c|c|}
\hline $\begin{array}{c}\text { Vão } \\
(\mathrm{m})\end{array}$ & $\begin{array}{c}\text { Massa de CDE } \\
(\mathrm{Kg})\end{array}$ & $\begin{array}{c}\text { Consumo de CDE } \\
\left(\mathrm{Kg} / \mathrm{m}^{3}\right)\end{array}$ \\
\hline 6 & 1,32 & 21,3 \\
\hline 7 & 1,32 & 18,6 \\
\hline 8 & 1,32 & 16,5 \\
\hline 9 & 1,32 & 14,8 \\
\hline 10 & 2,03 & 18,5 \\
\hline 11 & 2,38 & 20,2 \\
\hline 12 & 2,38 & 18,9 \\
\hline
\end{tabular}




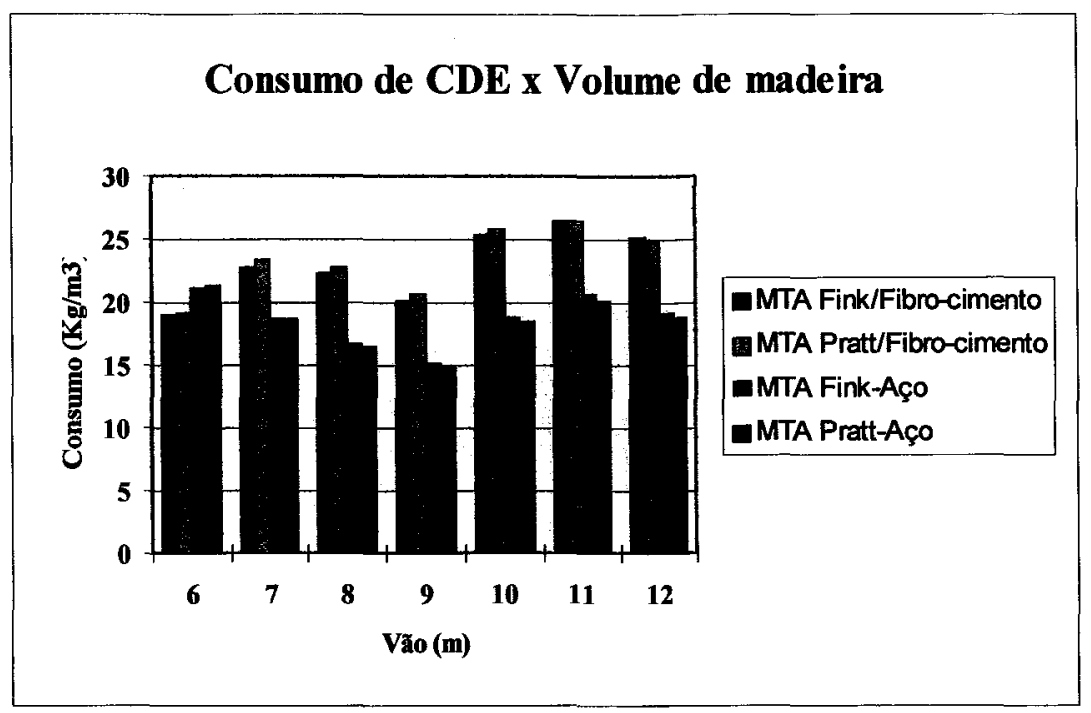

FIGURA 27 - Consumo de CDE x Volume de madeira

\subsubsection{Consumo de material das estruturas de contraventamento}

D) Consumo de barras de aco rosqueadas.

Os valores apresentados na última coluna (Consumo $\mathrm{x}$ Volume de madeira) das tabelas D1 a D12, relacionam a massa de barras de aço rosqueadas com o volume de madeira contidos em 3 (três) estruturas. Tal fato, é conseqüência dos espaçamentos adotados para as estruturas de contraventamento.

$\boldsymbol{7}$ Telhas de Fibro-cimento

TABELA D1 - MTA - Estrutura tipo "Howe" - Parafusos passantes.

\begin{tabular}{|c|c|c|c|c|}
\hline $\begin{array}{c}\text { Vão } \\
(\mathrm{m})\end{array}$ & $\begin{array}{c}\text { Comprimento } \\
\text { Total das barras } \\
(\mathrm{m})\end{array}$ & $\begin{array}{c}\text { Diâmetro } \\
\text { das Barras } \\
(\mathrm{mm})\end{array}$ & $\begin{array}{c}\text { Massa } \\
\text { Linear } \\
(\mathrm{Kg} / \mathrm{m})\end{array}$ & $\begin{array}{c}\text { Consumo por Volume de } \\
\text { Madeira } \\
\left(\mathrm{Kg} / \mathrm{m}^{3}\right)\end{array}$ \\
\hline 6 & 110 & & & 129 \\
\hline 7 & 140 & & & 124 \\
\hline 8 & 153 & \multirow{3}{*}{12} & \multirow{2}{*}{1} & 128 \\
\hline 9 & 166 & & & 129 \\
\hline 10 & 199 & & & 126 \\
\hline 11 & 212 & & & 129 \\
\hline 12 & 225 & & & 131 \\
\hline
\end{tabular}


TABELA D2 - MTA - Estrutura tipo "Fink" - Parafusos passantes.

\begin{tabular}{|c|c|c|c|c|}
\hline $\begin{array}{c}\text { Vão } \\
(\mathrm{m})\end{array}$ & $\begin{array}{c}\text { Comprimento } \\
\text { Total das barras } \\
(\mathrm{m})\end{array}$ & $\begin{array}{c}\text { Diâmetro } \\
\text { das Barras } \\
(\mathrm{mm})\end{array}$ & $\begin{array}{c}\text { Massa } \\
\text { Linear } \\
(\mathrm{Kg} / \mathrm{m})\end{array}$ & $\begin{array}{c}\text { Consumo por Volume de } \\
\text { Madeira } \\
\left(\mathrm{Kg} / \mathrm{m}^{3}\right)\end{array}$ \\
\hline 6 & 100 & & & 117 \\
\hline 7 & 125 & & & 110 \\
\hline 8 & 137 & \multirow{3}{*}{12} & 1 & 115 \\
\hline 9 & 149 & & & 117 \\
\hline 10 & 182 & & & 117 \\
\hline 11 & 194 & & & 119 \\
\hline 12 & 208 & & & 123 \\
\hline
\end{tabular}

TABELA D3 - MTA - Estrutura tipo "Fink" - CDE.

\begin{tabular}{|c|c|c|c|c|}
\hline $\begin{array}{c}\text { Vão } \\
(\mathrm{m})\end{array}$ & $\begin{array}{c}\text { Comprimento } \\
\text { Total das barras } \\
(\mathrm{m})\end{array}$ & $\begin{array}{c}\text { Diâmetro } \\
\text { das Barras } \\
(\mathrm{mm})\end{array}$ & $\begin{array}{c}\text { Massa } \\
\text { Linear } \\
(\mathrm{Kg} / \mathrm{m})\end{array}$ & $\begin{array}{c}\text { Consumo por Volume de } \\
\text { Madeira } \\
\left(\mathrm{Kg} / \mathrm{m}^{3}\right)\end{array}$ \\
\hline 6 & 36 & & & 179 \\
\hline 7 & 45 & & & 172 \\
\hline 8 & 50 & \multirow{2}{*}{12} & 1 & 175 \\
\hline 9 & 54 & & & 171 \\
\hline 10 & 67 & & & 179 \\
\hline 11 & 72 & & & 181 \\
\hline 12 & 76 & & & \\
\hline
\end{tabular}

TABELA D4 - MTA - Estrutura tipo "Pratt" - CDE.

\begin{tabular}{|c|c|c|c|c|}
\hline $\begin{array}{l}\text { Vão } \\
\text { (m) }\end{array}$ & $\begin{array}{l}\text { Comprimento } \\
\text { Total das barras } \\
(\mathrm{m})\end{array}$ & $\begin{array}{c}\text { Diâmetro } \\
\text { das Barras } \\
(\mathbf{m m})\end{array}$ & $\begin{array}{c}\text { Massa } \\
\text { Linear } \\
(\mathrm{Kg} / \mathrm{m})\end{array}$ & $\begin{array}{c}\text { Consumo por Volume de } \\
\text { Madeira } \\
\left(\mathrm{Kg} / \mathrm{m}^{3}\right)\end{array}$ \\
\hline 6 & 41 & \multirow{7}{*}{12} & \multirow{7}{*}{1} & 198 \\
\hline 7 & 50 & & & 192 \\
\hline 8 & 55 & & & 193 \\
\hline 9 & 59 & & & 186 \\
\hline 10 & 71 & & & 188 \\
\hline 11 & 76 & & & 186 \\
\hline 12 & 81 & & & 185 \\
\hline
\end{tabular}

TABELA D5 - MEL - Estrutura tipo "Howe" - Parafusos passantes.

\begin{tabular}{|c|c|c|c|c|}
\hline $\begin{array}{c}\text { Vâo } \\
(\mathrm{m})\end{array}$ & $\begin{array}{c}\text { Comprimento } \\
\text { Total das barras } \\
(\mathrm{m})\end{array}$ & $\begin{array}{c}\text { Diâmetro } \\
\text { das Barras } \\
(\mathrm{mm})\end{array}$ & $\begin{array}{c}\text { Massa } \\
\text { Linear } \\
(\mathrm{Kg} / \mathrm{m})\end{array}$ & $\begin{array}{c}\text { Consumo por Volume de } \\
\text { Madeira } \\
\left(\mathrm{Kg} / \mathrm{m}^{3}\right)\end{array}$ \\
\hline 6 & 134 & & & 126 \\
\hline 7 & 174 & & & 123 \\
\hline 8 & 189 & \multirow{2}{*}{12} & 1 & 126 \\
\hline 9 & 205 & & & 132 \\
\hline 10 & 246 & & & 127 \\
\hline 11 & 262 & & & 131 \\
\hline 12 & 277 & & & \\
\hline
\end{tabular}


TABELA D6 - MEL - Estrutura tipo "Fink" - Parafusos passantes.

\begin{tabular}{|c|c|c|c|c|}
\hline \multirow{2}{*}{$\begin{array}{c}\text { Vão } \\
(\mathrm{m})\end{array}$} & $\begin{array}{c}\text { Comprimento } \\
\text { Total das barras } \\
(\mathbf{m})\end{array}$ & $\begin{array}{c}\text { Diâmetro } \\
\text { das Barras } \\
(\mathrm{mm})\end{array}$ & $\begin{array}{c}\text { Massa } \\
\text { Linear } \\
(\mathrm{Kg} / \mathrm{m})\end{array}$ & $\begin{array}{c}\text { Consumo por Volume de } \\
\text { Madeira } \\
\left(\mathrm{Kg} / \mathbf{m}^{3}\right)\end{array}$ \\
\hline 6 & 112 & & & 102 \\
\hline 7 & 142 & & & 99 \\
\hline 8 & 157 & \multirow{2}{*}{12} & \multirow{2}{*}{1} & 105 \\
\hline 9 & 172 & & 110 \\
\hline 10 & 227 & & & 116 \\
\hline 11 & 242 & & & 120 \\
\hline 12 & 256 & & & 119 \\
\hline
\end{tabular}

$7 \underline{\text { Telhas de Aço }}$

TABELA D7 - MTA - Estrutura tipo "Howe" - Parafusos passantes.

\begin{tabular}{|c|c|c|c|c|}
\hline $\begin{array}{c}\text { Vão } \\
(\mathrm{m})\end{array}$ & $\begin{array}{c}\text { Comprimento } \\
\text { Total das barras } \\
(\mathrm{m})\end{array}$ & $\begin{array}{c}\text { Diâmetro } \\
\text { das Barras } \\
(\mathrm{mm})\end{array}$ & $\begin{array}{c}\text { Massa } \\
\text { Linear } \\
(\mathrm{Kg} / \mathrm{m})\end{array}$ & $\begin{array}{c}\text { Consumo por Volume de } \\
\text { Madeira } \\
\left(\mathrm{Kg} / \mathrm{m}^{3}\right)\end{array}$ \\
\hline 6 & 92 & & & 111 \\
\hline 7 & 102 & & & 116 \\
\hline 8 & 112 & \multirow{3}{*}{12} & \multirow{2}{*}{1} & 121 \\
\hline 9 & 121 & & 122 \\
\hline 10 & 130 & & & 118 \\
\hline 11 & 172 & & & 130 \\
\hline 12 & 183 & & & \\
\hline
\end{tabular}

TABELA D8 - MTA - Estrutura tipo "Fink" - Parafusos passantes.

\begin{tabular}{|c|c|c|c|c|}
\hline $\begin{array}{c}\text { Vão } \\
(\mathrm{m})\end{array}$ & $\begin{array}{c}\text { Comprimento } \\
\text { Total das barras } \\
(\mathrm{m})\end{array}$ & $\begin{array}{c}\text { Diâmetro } \\
\text { das Barras } \\
(\mathrm{mm})\end{array}$ & $\begin{array}{c}\text { Massa } \\
\text { Linear } \\
(\mathrm{Kg} / \mathrm{m})\end{array}$ & $\begin{array}{c}\text { Consumo por Volume de } \\
\text { Madeira } \\
\left(\mathrm{Kg} / \mathrm{m}^{3}\right)\end{array}$ \\
\hline 6 & 80 & & & 97 \\
\hline 7 & 89 & & & 102 \\
\hline 8 & 99 & \multirow{3}{*}{12} & \multirow{2}{*}{1} & 108 \\
\hline 9 & 107 & & 109 \\
\hline 10 & 114 & & & 105 \\
\hline 11 & 157 & & & 120 \\
\hline 12 & 167 & & & 123 \\
\hline
\end{tabular}

TABELA D9 - MTA - Estrutura tipo "Fink" - CDE.

\begin{tabular}{|c|c|c|c|c|}
\hline $\begin{array}{c}\text { Vão } \\
(\mathrm{m})\end{array}$ & $\begin{array}{c}\text { Comprimento } \\
\text { Total das barras } \\
(\mathrm{m})\end{array}$ & $\begin{array}{c}\text { Diâmetro } \\
\text { das Barras } \\
(\mathrm{mm})\end{array}$ & $\begin{array}{c}\text { Massa } \\
\text { Linear } \\
(\mathrm{Kg} / \mathrm{m})\end{array}$ & $\begin{array}{c}\text { Consumo por Volume de } \\
\text { Madeira } \\
\left(\mathrm{Kg} / \mathrm{m}^{3}\right)\end{array}$ \\
\hline 6 & 35 & & & 194 \\
\hline 7 & 39 & & & 191 \\
\hline 8 & 44 & \multirow{3}{*}{12} & 1 & 193 \\
\hline 9 & 49 & & & 194 \\
\hline 10 & 57 & & & 183 \\
\hline 11 & 61 & & & 180 \\
\hline 12 & 66 & & \\
\hline
\end{tabular}


TABELA D10 - MTA - Estrutura tipo "Pratt" - CDE.

\begin{tabular}{|c|c|c|c|c|}
\hline $\begin{array}{l}\text { Vão } \\
\text { (m) }\end{array}$ & $\begin{array}{l}\text { Comprimento } \\
\text { Total das } \\
\text { barras } \\
\text { (m) }\end{array}$ & $\begin{array}{c}\text { Diâmetro } \\
\text { das Barras } \\
(\mathrm{mm})\end{array}$ & $\begin{array}{l}\text { Massa } \\
\text { Linear } \\
(\mathrm{Kg} / \mathrm{m})\end{array}$ & $\begin{array}{c}\text { Consumo por Volume } \\
\text { de Madeira } \\
\left(\mathrm{Kg} / \mathrm{m}^{3}\right)\end{array}$ \\
\hline 6 & 39 & \multirow{7}{*}{12} & \multirow{7}{*}{1} & 210 \\
\hline 7 & 44 & & & 207 \\
\hline 8 & 48 & & & 200 \\
\hline 9 & 53 & & & 199 \\
\hline 10 & 59 & & & 179 \\
\hline 11 & 65 & & & 184 \\
\hline 12 & 69 & & & 183 \\
\hline
\end{tabular}

TABELA D11 - MEL - Estrutura tipo "Howe" - Parafusos passantes.

\begin{tabular}{|c|c|c|c|c|}
\hline $\begin{array}{l}\text { Vão } \\
\text { (m) }\end{array}$ & $\begin{array}{l}\text { Comprimento } \\
\text { Total das barras } \\
(\mathrm{m})\end{array}$ & $\begin{array}{c}\text { Diâmetro } \\
\text { das Barras } \\
(\mathrm{mm})\end{array}$ & $\begin{array}{l}\text { Massa } \\
\text { Linear } \\
(\mathrm{Kg} / \mathrm{m})\end{array}$ & $\begin{array}{c}\text { Consumo por Volume } \\
\text { de Madeira } \\
\left(\mathrm{Kg} / \mathrm{m}^{3}\right)\end{array}$ \\
\hline 6 & 115 & \multirow{7}{*}{12} & \multirow{7}{*}{1} & 131 \\
\hline 7 & 128 & & & 139 \\
\hline 8 & 140 & & & 137 \\
\hline 9 & 162 & & & 117 \\
\hline 10 & 169 & & & 111 \\
\hline 11 & 231 & & & 125 \\
\hline 12 & 245 & & & 130 \\
\hline
\end{tabular}

TABELA D12 - MEL - Estrutura tipo "Fink" - Parafusos passantes.

\begin{tabular}{|c|c|c|c|c|}
\hline $\begin{array}{l}\text { Vão } \\
\text { (m) }\end{array}$ & $\begin{array}{l}\text { Comprimento } \\
\text { Total das } \\
\text { barras } \\
\text { (m) }\end{array}$ & $\begin{array}{c}\text { Diâmetro } \\
\text { das Barras } \\
(\mathrm{mm})\end{array}$ & $\begin{array}{l}\text { Massa } \\
\text { Linear } \\
(\mathrm{Kg} / \mathrm{m})\end{array}$ & $\begin{array}{c}\text { Consumo por Volume } \\
\text { de Madeira } \\
\left(\mathrm{Kg} / \mathrm{m}^{3}\right)\end{array}$ \\
\hline 6 & 99 & \multirow{7}{*}{12} & \multirow{7}{*}{1} & 116 \\
\hline 7 & 111 & & & 123 \\
\hline 8 & 123 & & & 119 \\
\hline 9 & 138 & & & 100 \\
\hline 10 & 144 & & & 94 \\
\hline 11 & 208 & & & 111 \\
\hline 12 & 221 & & & 115 \\
\hline
\end{tabular}




\subsection{Relação entre o peso próprio de parafusos e o peso total da estrutura}

À vista do exposto nas Tabelas $6 \mathrm{e}$ 7, verificou-se que a relação entre o peso próprio dos parafusos e o peso total da estrutura varia de 1,7 a $2,6 \%$ nas estruturas tipo "Howe" e de 1,5 a 2,5\% nas estruturas tipo "Fink".

TABELA 6 - MEL - Estrutura tipo "Howe", telha de fibro-cimento.

\begin{tabular}{|c|c|c|c|c|c|c|}
\hline $\begin{array}{c}\text { Vão } \\
(\mathrm{m})\end{array}$ & $\begin{array}{c}\text { Vol. Total } \\
\text { de Madeira } \\
\left(\mathrm{m}^{3}\right)\end{array}$ & $\begin{array}{c}\text { Peso Próprio } \\
\text { de Madeira } \\
(\mathrm{daN})\end{array}$ & $\begin{array}{c}\text { Peso Próprio } \\
\text { Total da } \\
\text { Estrutura } \\
(\mathrm{daN})\end{array}$ & $\begin{array}{c}\text { Número de } \\
\text { Parafusos } \\
(\text { Unid. })\end{array}$ & $\begin{array}{c}\text { Peso Próprio } \\
\text { de Parafusos } \\
(\mathrm{daN})\end{array}$ & $\begin{array}{c}\text { Razão do Peso Próprio } \\
\text { dos Parafusos e } \\
\text { Estrutura } \\
(\%)\end{array}$ \\
\hline 6 & 0,356 & 199,4 & 729,8 & 86 & 12,3 & 1,7 \\
\hline 7 & 0,472 & 264,3 & 883,1 & 116 & 16,6 & 1,9 \\
\hline 8 & 0,500 & 280,0 & 987,2 & 128 & 18,3 & 1,9 \\
\hline 9 & 0,518 & 290,1 & 1085,7 & 144 & 20,6 & 1,9 \\
\hline 10 & 0,646 & 361,8 & 1245,8 & 200 & 28,6 & 2,3 \\
\hline 11 & 0,667 & 373,5 & 1345,9 & 236 & 33,7 & 2,5 \\
\hline 12 & 0,705 & 394,8 & 1455,6 & 264 & 37,7 & 2,6 \\
\hline
\end{tabular}

TABELA 7 - MEL - Estrutura tipo "Fink", telha de fibro-cimento.

\begin{tabular}{|c|c|c|c|c|c|c|}
\hline $\begin{array}{c}\text { Vão } \\
(\mathrm{m})\end{array}$ & $\begin{array}{c}\text { Vol. Total } \\
\text { de Madeira } \\
\left(\mathrm{m}^{3}\right)\end{array}$ & $\begin{array}{c}\text { Peso Próprio } \\
\text { de Madeira } \\
(\mathrm{daN})\end{array}$ & $\begin{array}{c}\text { Peso Próprio } \\
\text { Total da } \\
\text { Estrutura } \\
(\mathrm{daN})\end{array}$ & $\begin{array}{c}\text { Número de } \\
\text { Parafusos } \\
(\text { Unid. })\end{array}$ & $\begin{array}{c}\text { Peso Próprio } \\
\text { de Parafusos } \\
(\text { daN })\end{array}$ & $\begin{array}{c}\text { Razão do Peso Próprio } \\
\text { dos Parafusos e } \\
\text { Estrutura } \\
(\%)\end{array}$ \\
\hline 6 & 0,365 & 204,4 & 734,8 & 76 & 10,9 & 1,5 \\
\hline 7 & 0,480 & 268,8 & 887,6 & 108 & 15,4 & 1,7 \\
\hline 8 & 0,501 & 280,6 & 987,8 & 122 & 17,4 & 1,8 \\
\hline 9 & 0,523 & 292,9 & 1088,5 & 136 & 19,4 & 1,8 \\
\hline 10 & 0,654 & 366,2 & 1250,2 & 164 & 23,4 & 1,9 \\
\hline 11 & 0,673 & 376,9 & 1349,3 & 238 & 34,0 & 2,5 \\
\hline 12 & 0,717 & 401,5 & 1462,3 & 254 & 36,3 & 2,5 \\
\hline
\end{tabular}


A partir dos resultados apresentados nas Tabelas 8 e 9, verificou-se que a relação entre o peso próprio dos parafusos e o peso total da estrutura varia de 2 a $3,7 \%$ nas estruturas tipo "Howe" e de 1,8 a 3,4\% nas estruturas tipo "Fink".

TABELA 8 - MEL - Estrutura tipo "Howe", telha de aço.

\begin{tabular}{|c|c|c|c|c|c|c|}
\hline $\begin{array}{c}\text { Vão } \\
(\mathrm{m})\end{array}$ & $\begin{array}{c}\text { Vol. Total } \\
\text { de Madeira } \\
\left(\mathrm{m}^{3}\right)\end{array}$ & $\begin{array}{c}\text { Peso Próprio } \\
\text { de Madeira } \\
(\mathrm{daN})\end{array}$ & $\begin{array}{c}\text { Peso Próprio } \\
\text { Total da } \\
\text { Estrutura } \\
(\mathrm{daN})\end{array}$ & $\begin{array}{c}\text { Número de } \\
\text { Parafusos } \\
\text { (Unid.) }\end{array}$ & $\begin{array}{c}\text { Peso Próprio } \\
\text { de Parafusos } \\
(\mathrm{daN})\end{array}$ & $\begin{array}{c}\text { Razão do Peso Próprio } \\
\text { dos Parafusose Estrutura } \\
(\%)\end{array}$ \\
\hline 6 & 0,293 & 164,1 & 375,8 & 66 & 9,4 & 2,5 \\
\hline 7 & 0,308 & 172,5 & 419,4 & 76 & 10,9 & 2,5 \\
\hline 8 & 0,341 & 191,0 & 473,2 & 82 & 11,7 & 2,5 \\
\hline 9 & 0,461 & 258,2 & 631,7 & 90 & 12,9 & 2,0 \\
\hline 10 & 0,507 & 283,9 & 698,9 & 142 & 20,3 & 2,9 \\
\hline 11 & 0,615 & 344,4 & 800,9 & 196 & 28,0 & 3,5 \\
\hline 12 & 0,632 & 353,9 & 851,9 & 218 & 31,1 & 3,7 \\
\hline
\end{tabular}

TABELA 9 - MEL - Estrutura tipo "Fink", telha de aço.

\begin{tabular}{|c|c|c|c|c|c|c|}
\hline $\begin{array}{c}\text { Vão } \\
(\mathbf{m})\end{array}$ & $\begin{array}{c}\text { Vol. Total } \\
\text { de Madeira } \\
\left(\mathrm{m}^{3}\right)\end{array}$ & $\begin{array}{c}\text { Peso Próprio } \\
\text { de Madeira } \\
(\mathrm{daN})\end{array}$ & $\begin{array}{c}\text { Peso Próprio } \\
\text { Total da } \\
\text { Estrutura } \\
(\mathrm{daN})\end{array}$ & $\begin{array}{c}\text { Número de } \\
\text { Parafusos } \\
(\text { Unid. })\end{array}$ & $\begin{array}{c}\text { Peso Próprio } \\
\text { de Parafusos } \\
(\mathrm{daN})\end{array}$ & $\begin{array}{c}\text { Razão do Peso Próprio } \\
\text { dos Parafusose Estrutura } \\
(\%)\end{array}$ \\
\hline 6 & 0,285 & 159,6 & 371,3 & 58 & 8,3 & 2,2 \\
\hline 7 & 0,302 & 169,1 & 416,0 & 64 & 9,1 & 2,2 \\
\hline 8 & 0,345 & 193,2 & 475,4 & 70 & 10,0 & 2,1 \\
\hline 9 & 0,461 & 258,2 & 631,7 & 78 & 11,1 & 1,8 \\
\hline 10 & 0,515 & 288,4 & 703,4 & 104 & 14,9 & 2,1 \\
\hline 11 & 0,626 & 350,6 & 807,1 & 188 & 26,9 & 3,3 \\
\hline 12 & 0,643 & 360,1 & 858,1 & 204 & 29,1 & 3,4 \\
\hline
\end{tabular}




\section{CONCLUSÕES E SUGESTÕES}

O desenvolvimento do presente trabalho possibilitou as seguintes conclusões:

a) É viável a construção de estruturas de cobertura, utilizando a madeira do gênero Pinus, para vãos teóricos entre 6 e 12 metros. $O$ consumo varia de 0,011 a 0,017 e de 0,010 a 0,014 metros cúbicos de madeira por metro quadrado de área coberta, para as estruturas de cobertura com telha de fibro-cimento e aço, respectivamente. Estes valores são compatíveis com os consumos obtidos por PINHEIRO et al. (1993) para estruturas de cobertura construída a partir de espécies nativas.

As seções tranversais das estruturas de Pinus têm dimensões compatíveis com as disponiveis comercialmente, evidenciando ainda mais a viabilidade do seu emprego para a mencionada finalidade.

Em se tratando de espécies susceptíveis à demanda biológica, é imprescindível a preservação dos elementos estruturais. Dada a ocorrência de defeitos naturais, própria destas espécies de reflorestamento, é conveniente que se proceda a classificação prévia dos componentes estruturais das treliças.

b) O consumo de madeira por metro quadrado de área coberta, nas diferentes condições de projeto (forma geométrica, tipos de telhas, dispositivos de ligação) atinge os valores apresentados no Ítem 5.4.1.A do Capítulo 5.

c)A avaliação dos espaçamentos entre estruturas, fundamentada no cálculo das estruturas secundárias (terças), está apresentada no Ítem 5.3, Capítulo 5. Para as 
estruturas projetadas segundo o MTA, permite-se considerar que os valores obtidos estão dentro da faixa usualmente utilizada em construções desta natureza. De acordo com o MEL, foi possível alcançar valores superiores.

d) $\mathrm{O}$ consumo de dispositivos de ligação (parafusos passantes) obtido segundo o MEL foi superior ao do MTA. Este fato proporcionou um aumento do volume de madeira das treliças, em virtude da necessidade de maiores áreas para locação dos parafusos. Entretanto, com base no İtem 5.4.1.A do Capítulo 5, verificou-se que o consumo total de madeira ainda permaneceu inferior.

Com base no exposto neste trabalho, algumas sugestões são propostas:

$\Rightarrow$ reavaliação do valor recomendado pela NBR 7190/96 - Ítem 4.5.2, no que refere-se à relação entre o peso próprio de dispositivos de ligação e o peso próprio de madeira;

$\Rightarrow$ reavaliação dos critérios de dimensionamento das ligações com pinos metálicos (parafusos) recomendado pela NBR 7190/96;

$\Rightarrow$ reavaliação das recomendações da NBR 7190/96 referentes às seções transversais mínimas. 
ANEXO "A"

As geometrias adotadas em virtude do desenvolvimento do projeto de pesquisa em questão, estão apresentadas a seguir:

1) Método das Tensões Admissíveis - Parafusos Passantes

$\rightarrow \underline{\text { Seções Transversais }}$

Todas as dimensões estão em centímetros.
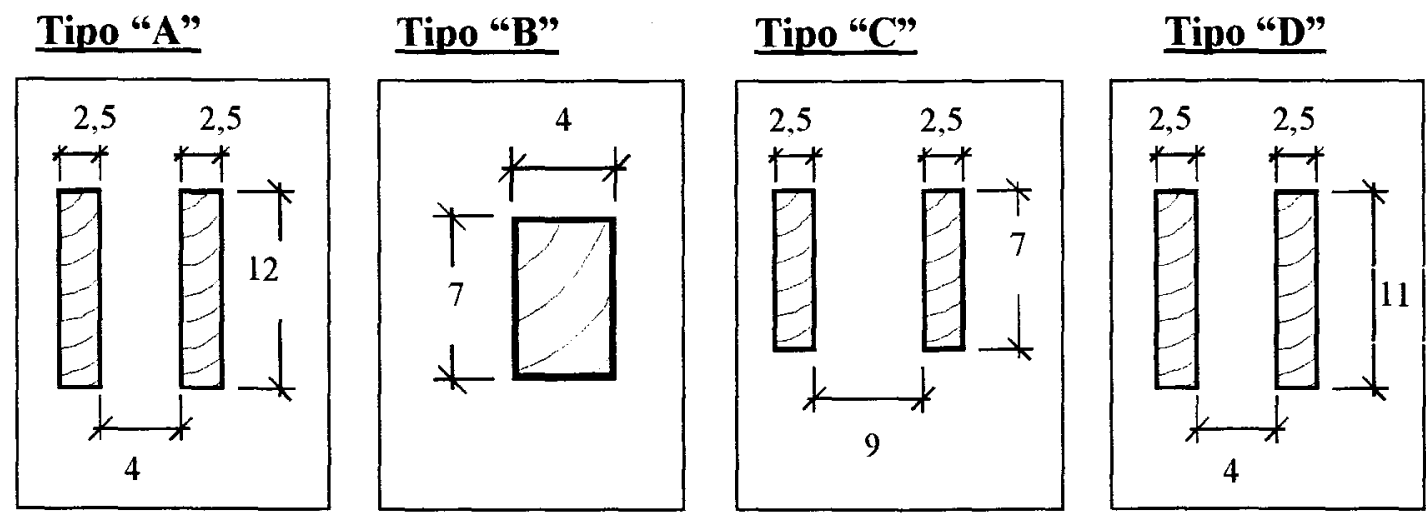

Tipo "E"

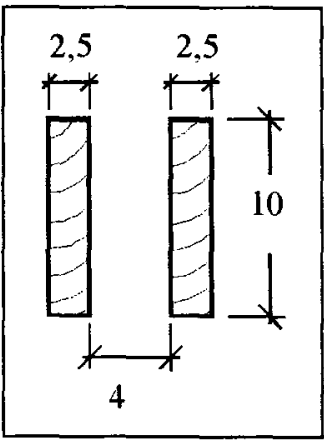

Tipo "F"

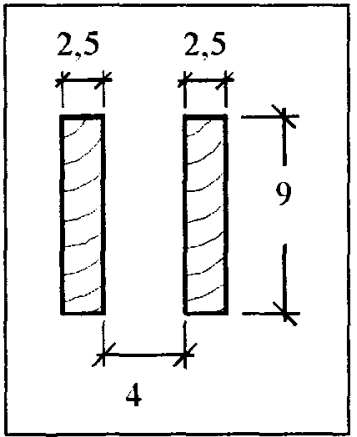

Tipo "G"

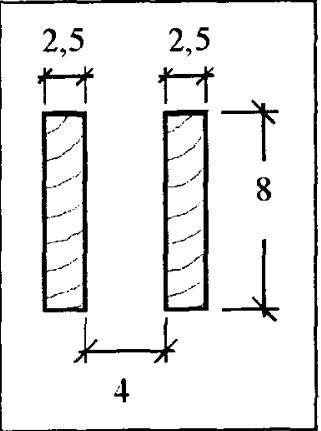




\section{Trelica "Howe" com telha de Fibro-cimento}

\section{Geometria}
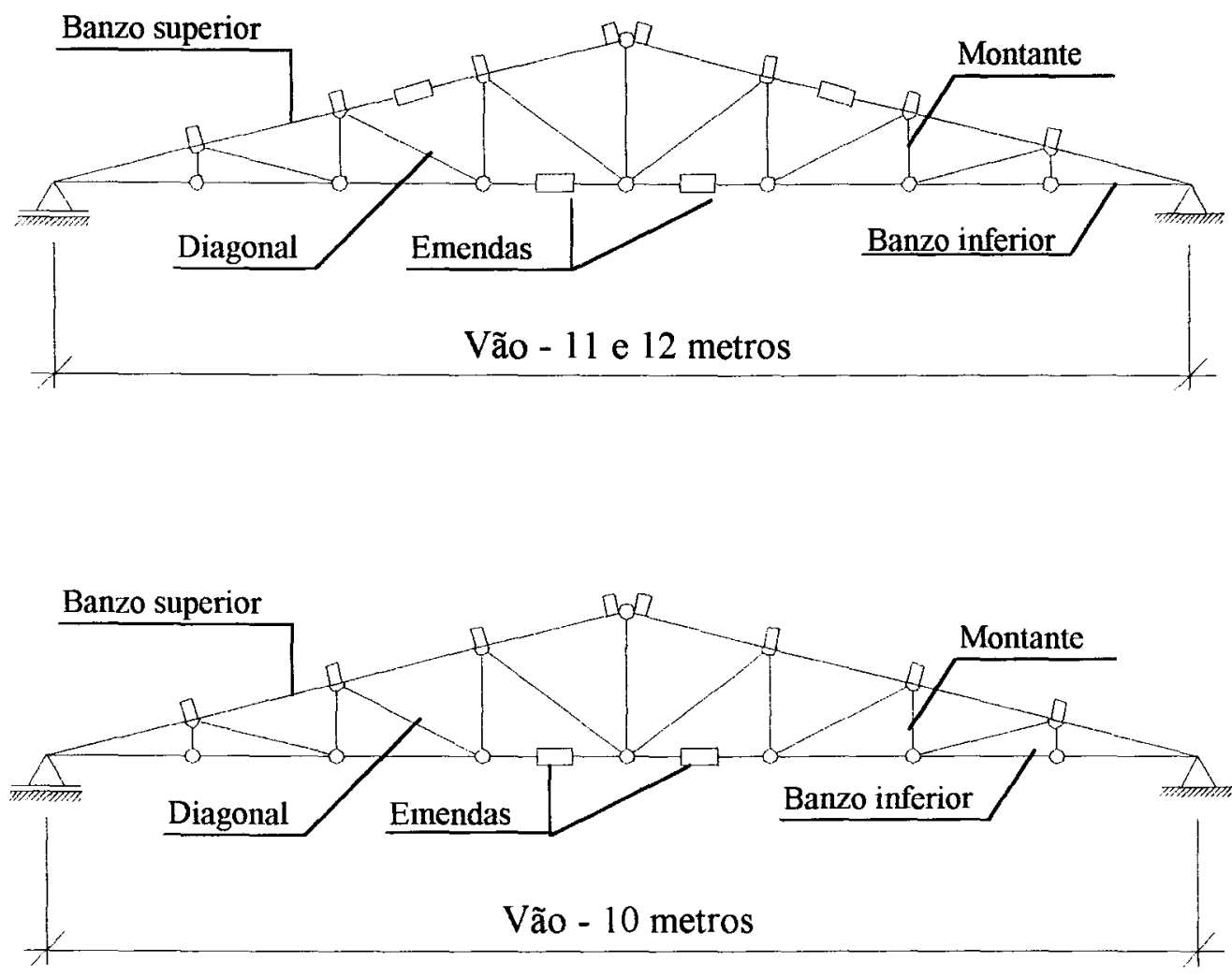

\begin{tabular}{|c|c|c|c|c|}
\hline Tipo de telha & $\begin{array}{l}\text { Vão teórico } \\
\text { (m) }\end{array}$ & Nomenclatura & Barras & $\begin{array}{c}\text { Seção transversal } \\
\left(\mathrm{cm}^{2}\right)\end{array}$ \\
\hline \multirow{4}{*}{ Fibro-cimento } & 10 & $\begin{array}{l}\text { B. superior e } \\
\text { B. inferior }\end{array}$ & \multirow{4}{*}{ todas } & Tipo "D" \\
\hline & 11 e 12 & $\begin{array}{l}\text { B. superior e } \\
\text { B. inferior }\end{array}$ & & Tipo "A" \\
\hline & \multirow[t]{2}{*}{10 a 12} & Diagonal & & Tipo "C" \\
\hline & & Montante & & Tipo "A" \\
\hline
\end{tabular}




\section{Geometria}

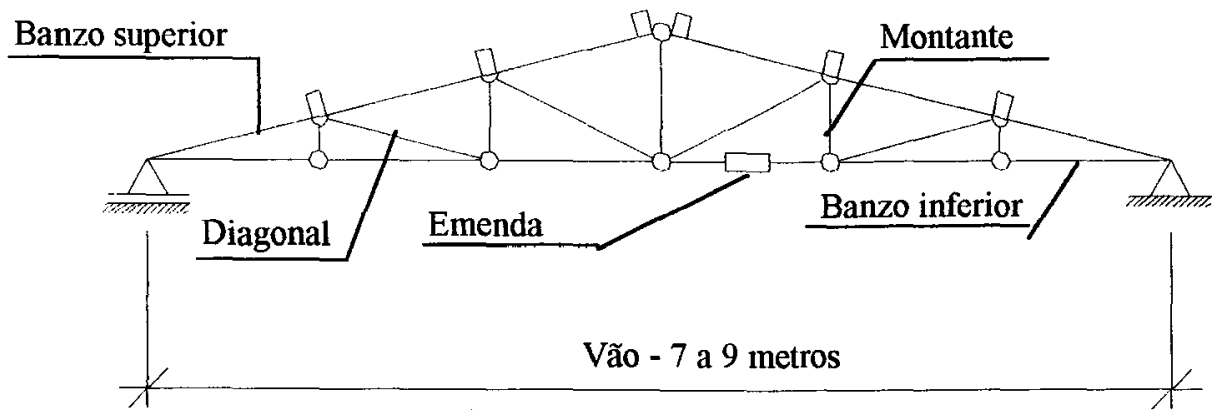

\begin{tabular}{|c|c|c|c|c|}
\hline Tipo de telha & $\begin{array}{c}\text { Vão teórico } \\
\text { (m) }\end{array}$ & Nomenclatura & Barras & $\begin{array}{c}\text { Seção transversal } \\
\left(\mathrm{cm}^{2}\right)\end{array}$ \\
\hline \multirow{7}{*}{ Fibro-cimento } & \multirow[t]{2}{*}{7} & B. superior & \multirow{7}{*}{ todas } & Tipo "G" \\
\hline & & B. inferior & & Tipo "D" \\
\hline & \multirow[t]{2}{*}{8} & B. superior & & Tipo "G" \\
\hline & & B. inferior & & Tipo "A" \\
\hline & 9 & $\begin{array}{l}\text { B. superior/ } \\
\text { B. inferior }\end{array}$ & & Tipo "D" \\
\hline & \multirow{2}{*}{7 a9 } & Diagonal & & Tipo "C" \\
\hline & & Montante & & Tipo "B" \\
\hline
\end{tabular}

\section{Geometria}

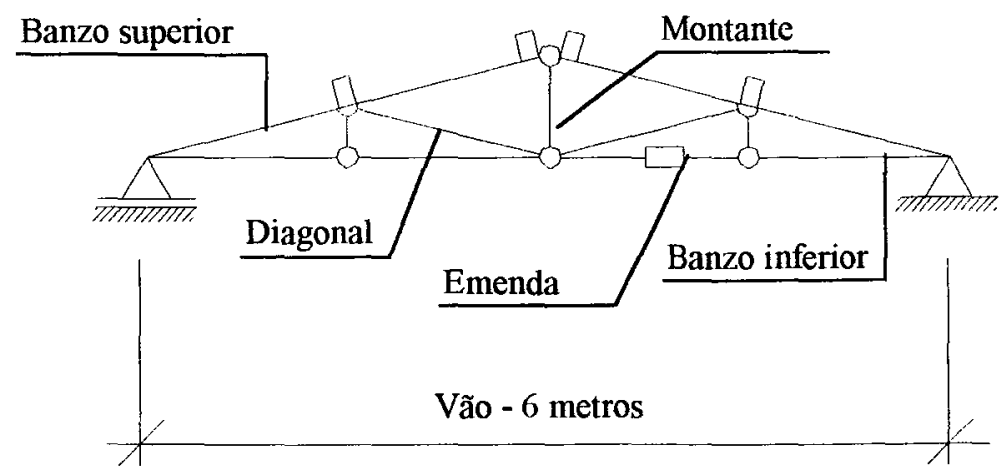

\begin{tabular}{|c|c|c|c|c|}
\hline Tipo de telha & $\begin{array}{c}\text { Vão teórico } \\
(\mathrm{m})\end{array}$ & Nomenclatura & Barras & $\begin{array}{c}\text { Seção transversal } \\
\left(\mathrm{cm}^{2}\right)\end{array}$ \\
\hline \multirow{3}{*}{ Fibro-cimento } & \multirow{3}{*}{6} & B. superior & \multirow{3}{*}{ todas } & Tipo "G" \\
& & B. inferior & Tipo "E" \\
& & Diagonal & & Tipo "C" \\
& & Montante & & Tipo "B" \\
\hline
\end{tabular}




\section{Trelica "Howe" com telha de Aco}

\section{Geometria}
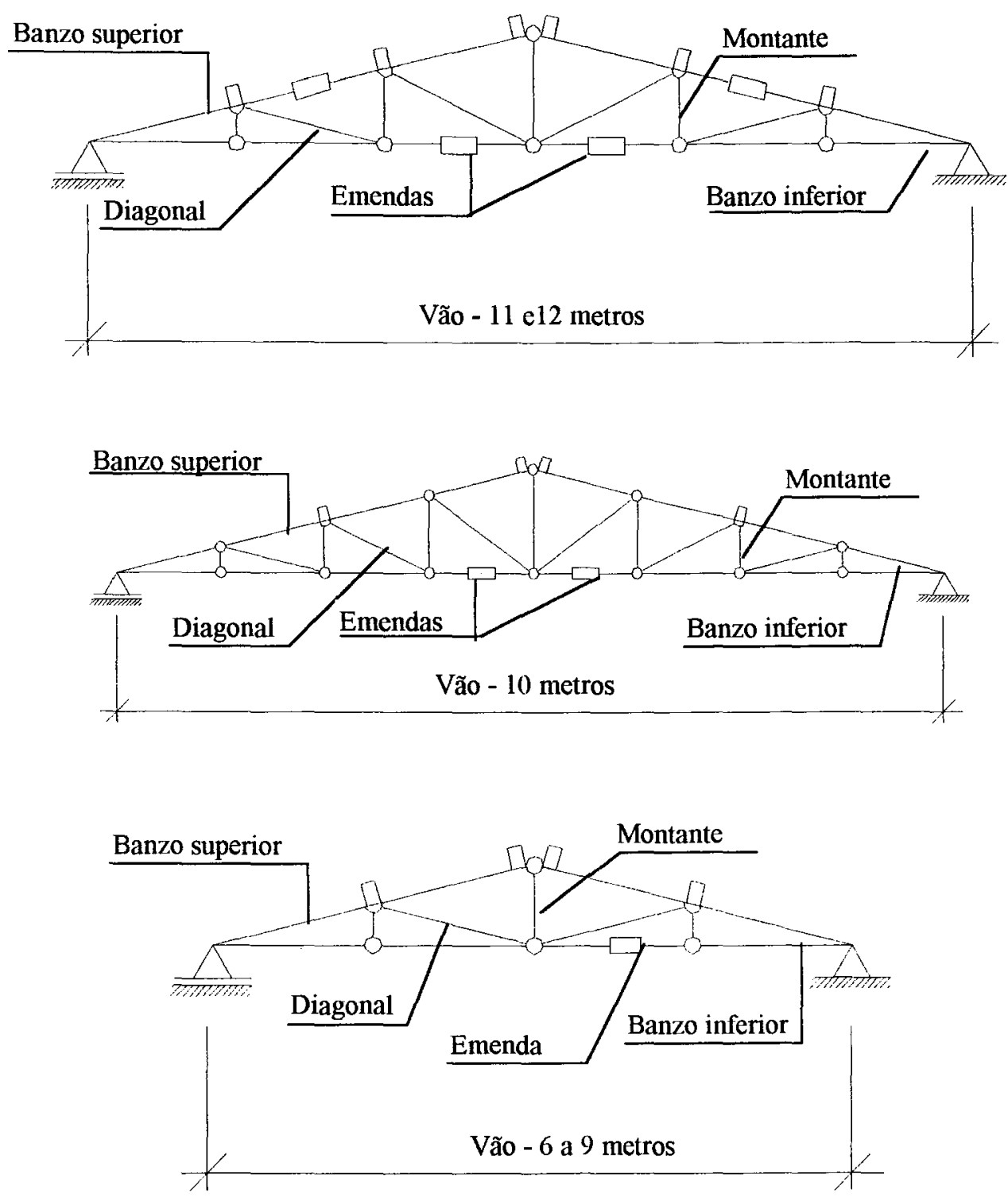

\begin{tabular}{|c|c|c|c|c|}
\hline Tipo de telha & $\begin{array}{l}\text { Vão teórico } \\
\text { (m) }\end{array}$ & Nomenclatura & Barras & $\begin{array}{l}\text { Seção transversal } \\
\left(\mathrm{cm}^{2}\right)\end{array}$ \\
\hline \multirow{6}{*}{ Aço } & \multirow{2}{*}{6 a 8} & B. inferior & \multirow{6}{*}{ todas } & Tipo "E" \\
\hline & & B. superior & & Tipo "G" \\
\hline & \multirow[t]{2}{*}{9 a 12} & B. inferior & & Tipo "D" \\
\hline & & B. superior & & Tipo "F" \\
\hline & \multirow[t]{2}{*}{6 a 12} & Diagonal & & Tipo "C" \\
\hline & & Montante & & Tipo "B" \\
\hline
\end{tabular}




\section{Trelica "Fink" com telha de Fibro-cimento}

$\rightarrow$ Geometria
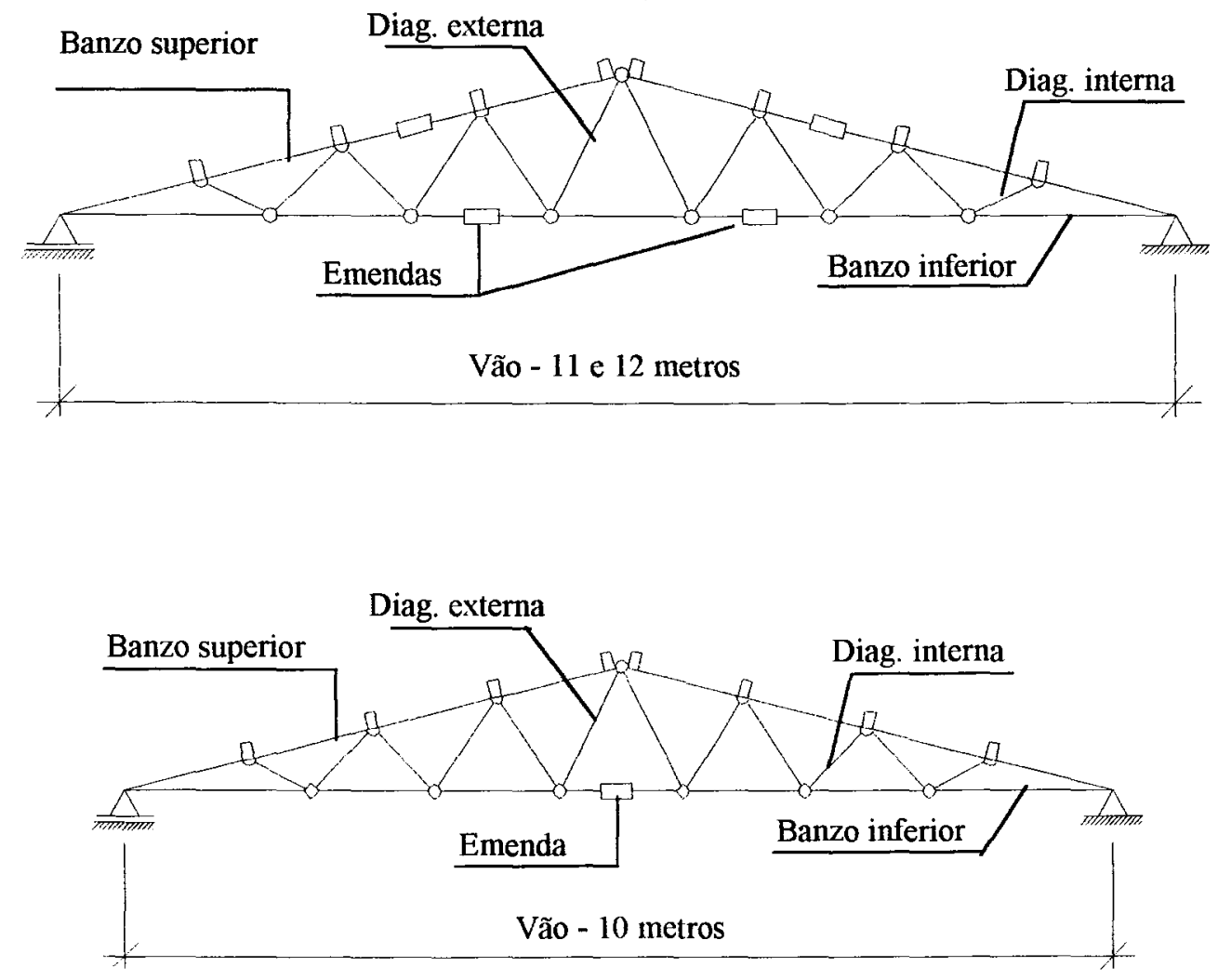

\begin{tabular}{|c|c|c|c|c|}
\hline Tipo de telha & $\begin{array}{c}\text { Vão teórico } \\
\text { (m) }\end{array}$ & Nomenclatura & Barras & $\begin{array}{c}\text { Seção transversal } \\
\left(\mathrm{cm}^{2}\right)\end{array}$ \\
\hline \multirow{4}{*}{ Fibro-cimento } & 10 & $\begin{array}{l}\text { B. superior/ } \\
\text { B. inferior }\end{array}$ & \multirow{4}{*}{ todas } & Tipo “D” \\
\hline & 11 e 12 & $\begin{array}{l}\text { B. superior e } \\
\text { B. inferior }\end{array}$ & & Tipo "A" \\
\hline & \multirow[t]{2}{*}{10 a 12} & Diagonal externa & & Tipo "C" \\
\hline & & Diagonal interna & & Tipo "B" \\
\hline
\end{tabular}




\section{Geometria}

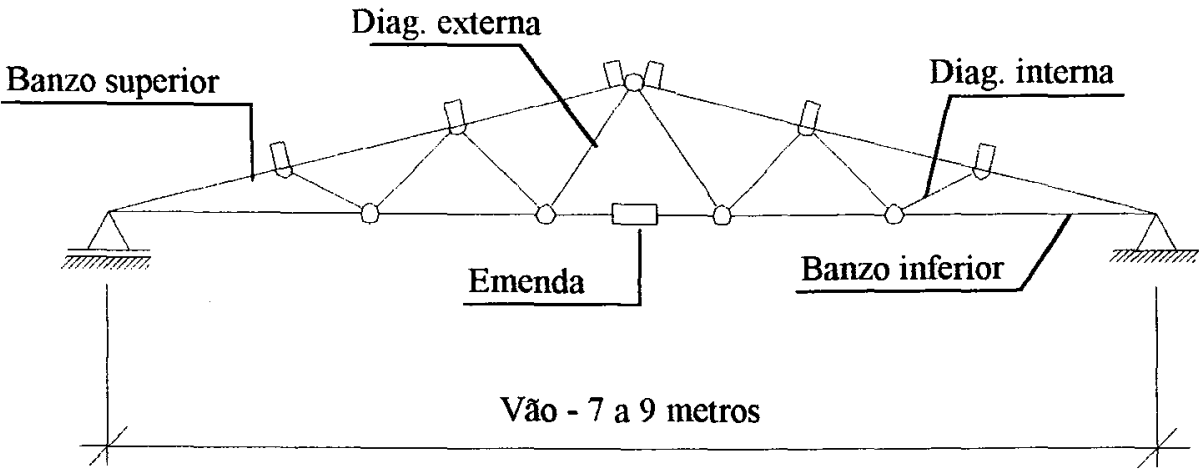

\begin{tabular}{|c|c|c|c|c|}
\hline Tipo de telha & $\begin{array}{c}\text { Vão teórico } \\
\text { (m) }\end{array}$ & Nomenclatura & Barras & $\begin{array}{c}\text { Seção transversal } \\
\left(\mathrm{cm}^{2}\right)\end{array}$ \\
\hline \multirow{7}{*}{ Fibro-cimento } & \multirow[t]{2}{*}{7} & B. superior & \multirow[t]{2}{*}{ todas } & Tipo " $G$ " \\
\hline & & B. inferior & & Tipo "D" \\
\hline & \multirow[t]{2}{*}{8} & B. superior & \multirow[t]{2}{*}{ todas } & Tipo "G" \\
\hline & & B. inferior & & Tipo "A" \\
\hline & 9 & $\begin{array}{l}\text { B. superior/ } \\
\text { B. inferior }\end{array}$ & todas & Tipo “D” \\
\hline & \multirow[t]{2}{*}{7 a 9} & Diagonal externa & & Tipo "C" \\
\hline & & Diagonal interna & & Tipo "B" \\
\hline
\end{tabular}

\section{Geometria}

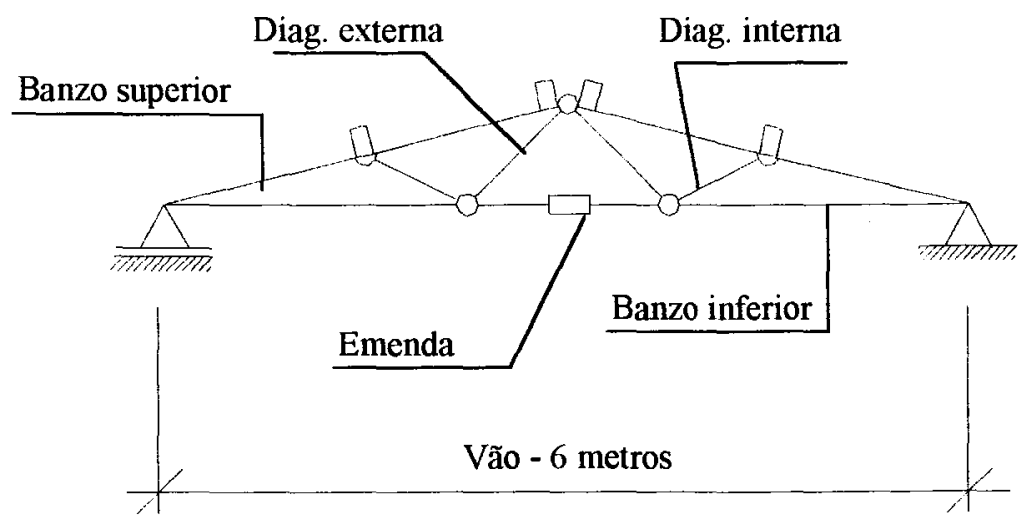

\begin{tabular}{|c|c|c|c|c|}
\hline \multirow{2}{*}{ Tipo de telha } & $\begin{array}{c}\text { Vão teórico } \\
(\mathrm{m})\end{array}$ & Nomenclatura & \multirow{3}{*}{ Barras } & $\begin{array}{c}\text { Seção transversal } \\
\left(\mathrm{cm}^{2}\right)\end{array}$ \\
\hline \multirow{3}{*}{ Fibro-cimento } & \multirow{3}{*}{6} & B. superior & \multirow{3}{*}{ todas } & Tipo "G" \\
& & B. inferior & Tipo "E" \\
& & Diagonal externa & Tipo "C" \\
& & Diagonal interna & Tipo "B" \\
\hline
\end{tabular}




\section{Trelica "Fink" com telha de Aco}

\section{Geometria}
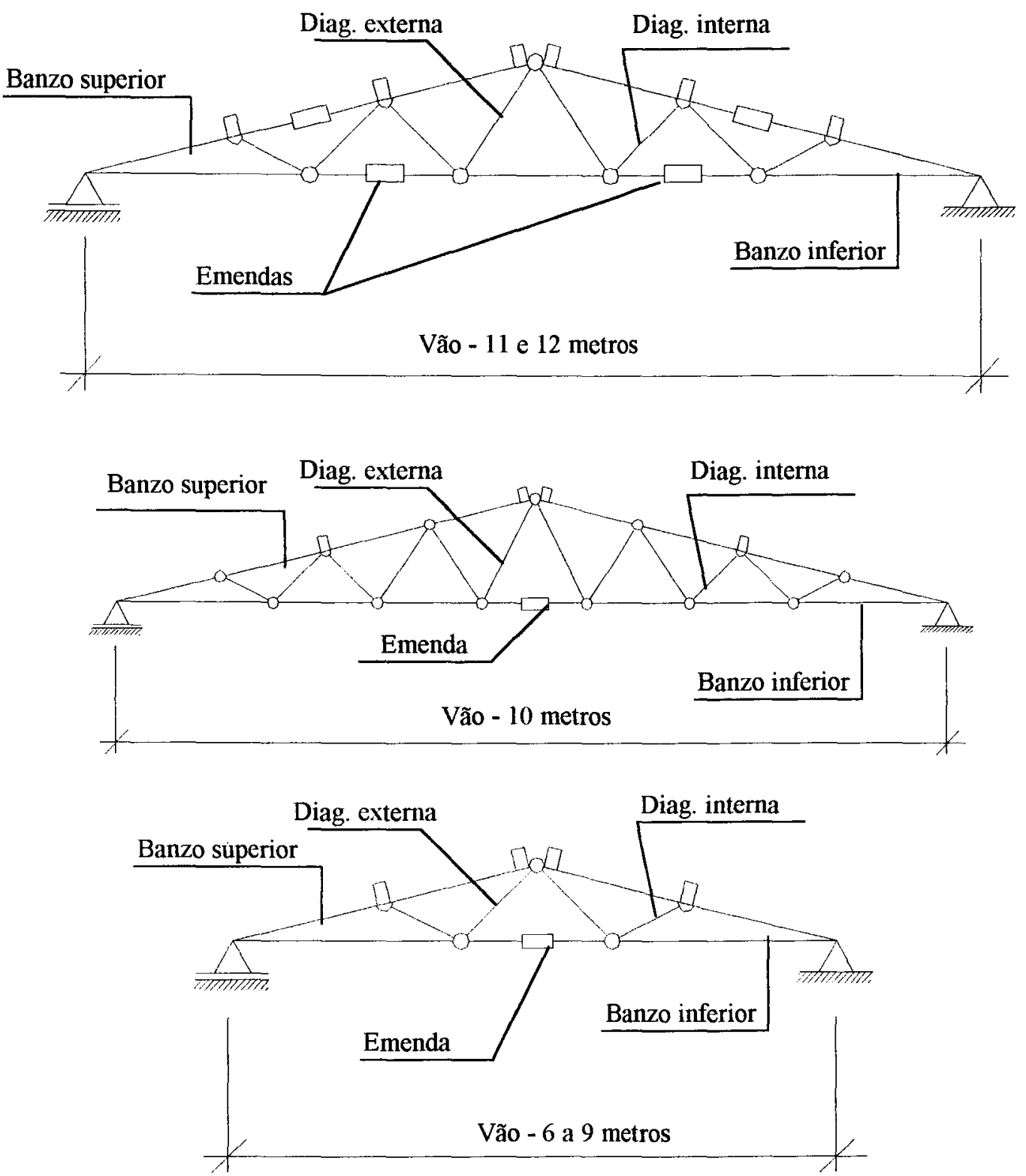

\begin{tabular}{|c|c|c|c|c|}
\hline Tipo de telha & $\begin{array}{l}\text { Vão teórico } \\
\text { (m) }\end{array}$ & Nomenclatura & Barras & $\begin{array}{l}\text { Seção transversal } \\
\left(\mathrm{cm}^{2}\right)\end{array}$ \\
\hline \multirow{6}{*}{ Aço } & \multirow[t]{2}{*}{6 a 8} & B. inferior & \multirow{6}{*}{ todas } & Tipo "E" \\
\hline & & B. superior & & Tipo "G" \\
\hline & \multirow[t]{2}{*}{9 a 12} & B. inferior & & Tipo "D" \\
\hline & & B. superior & & Tipo "F" \\
\hline & \multirow[t]{2}{*}{6 a 12} & Diagonal & & Tipo "C" \\
\hline & & Montante & & Tipo "B" \\
\hline
\end{tabular}


2) Método das Tensões Admissíveis - Chapas com Dentes Estampados

\section{Seções Transversais}

Todas as dimensões estão em centímetros.

\section{Tipo "H"}

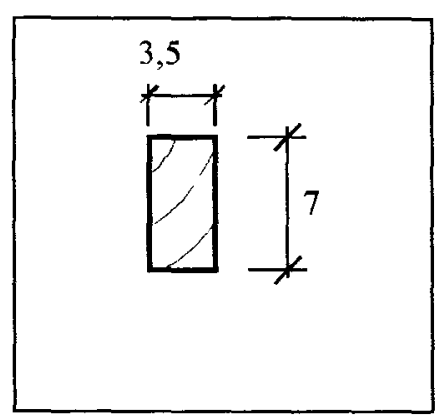

Tipo "I"

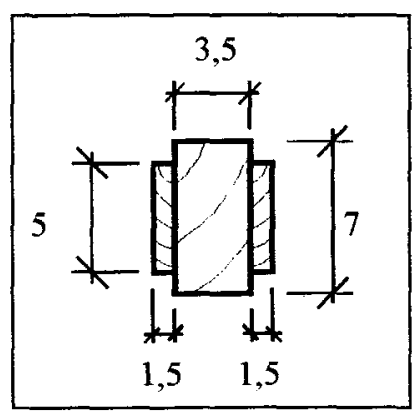

\section{Trelica "Pratt" com telha de Fibro-cimento}

\section{Geometria}

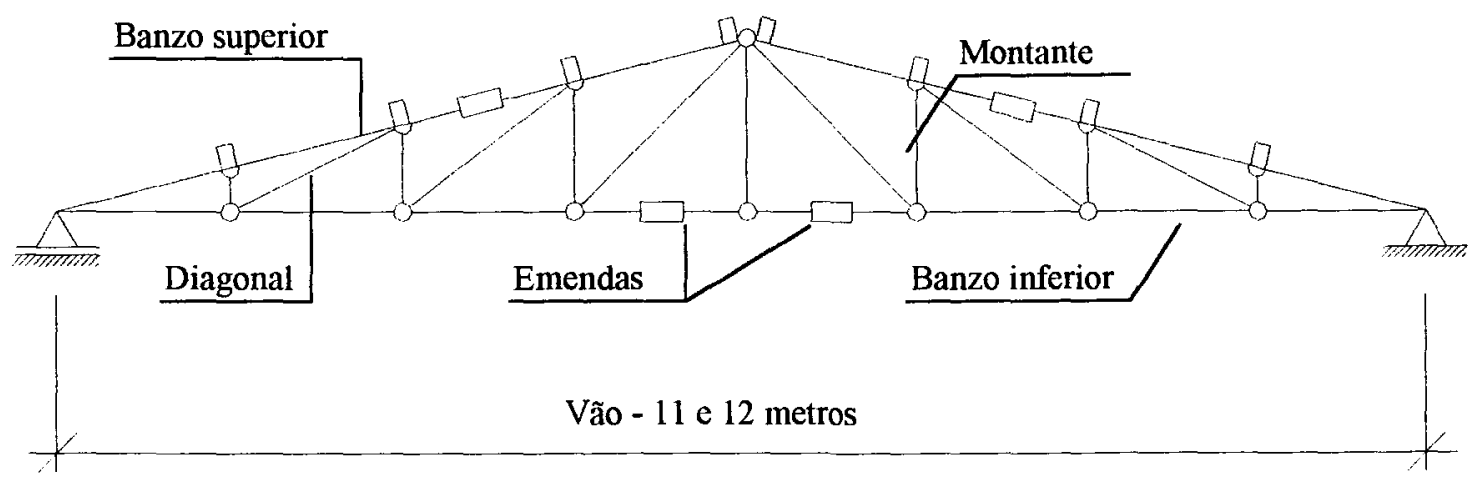



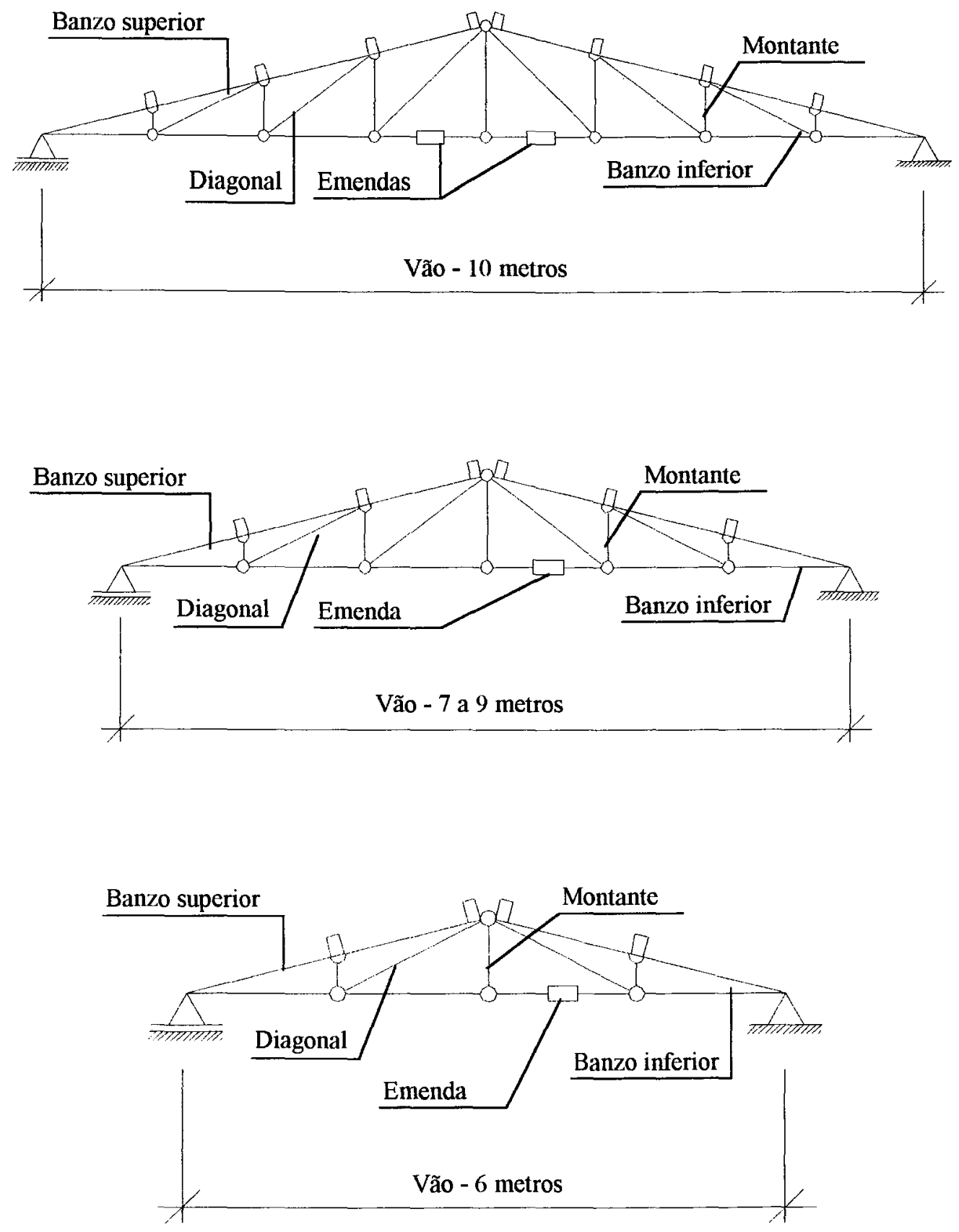

\begin{tabular}{|c|c|c|c|c|}
\hline Tipo de telha & $\begin{array}{c}\text { Vão teórico } \\
(\mathrm{m})\end{array}$ & Nomenclatura & Barras & $\begin{array}{c}\text { Seção transversal } \\
\left(\mathrm{cm}^{2}\right)\end{array}$ \\
\hline Fibro-cimento & 6 a 12 & B. superior/ & todas & Tipo "I" \\
\cline { 3 - 5 } & $\begin{array}{c}\text { B. inferior } \\
\text { Diagonal } \\
\text { Montante }\end{array}$ & todas & Tipo "H" \\
\hline
\end{tabular}




\section{Trelica "Pratt" com telha de Aco}

\section{Geometria}
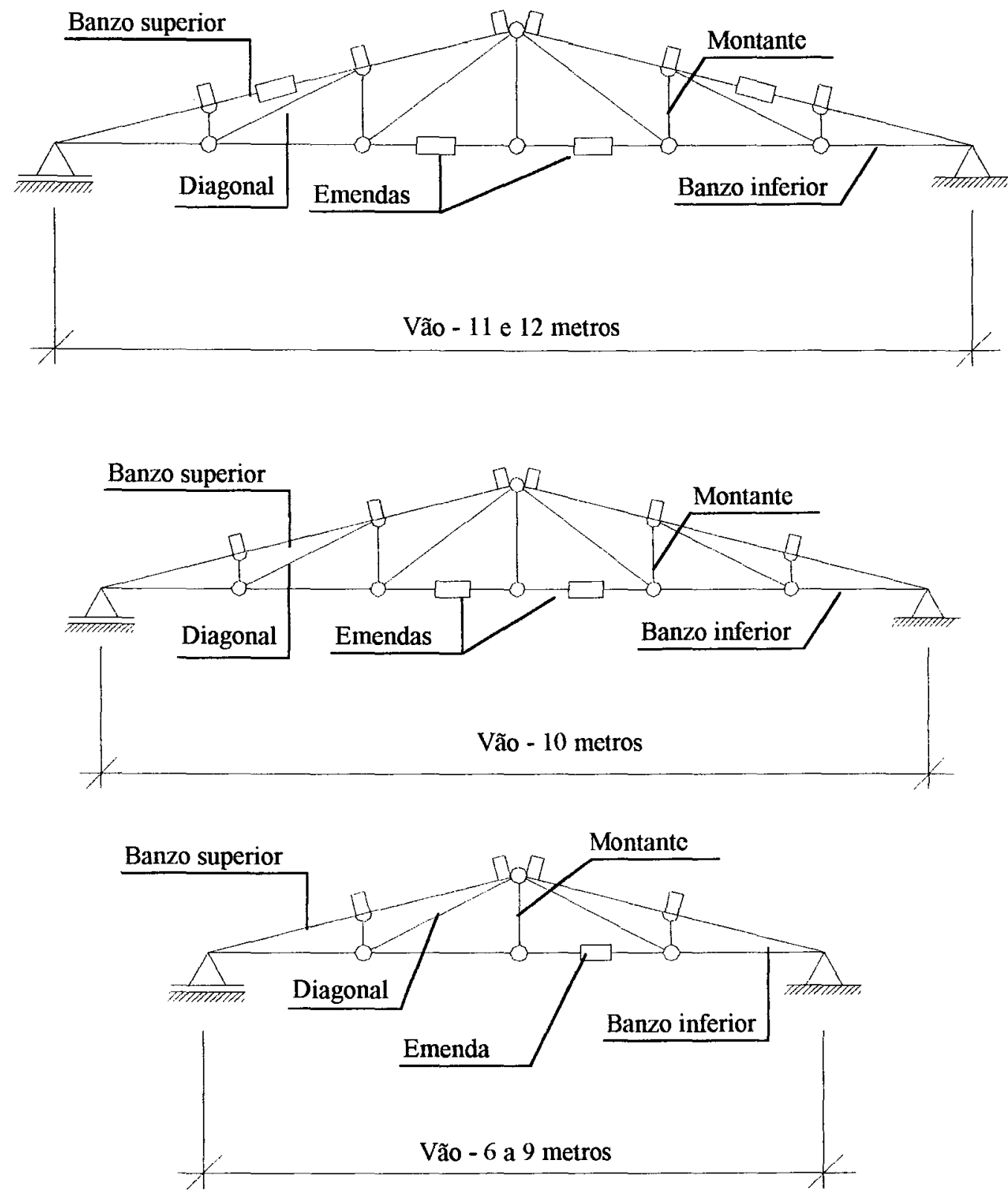

\begin{tabular}{|c|c|c|c|c|}
\hline Tipo de telha & $\begin{array}{c}\text { Vão teórico } \\
(\mathbf{m})\end{array}$ & Nomenclatura & Barras & $\begin{array}{c}\text { Seção transversal } \\
\left(\mathrm{cm}^{2}\right)\end{array}$ \\
\hline Aço & 6 a 12 & B. superior/ & todas & Tipo "I" \\
\cline { 3 - 5 } & $\begin{array}{c}\text { B. inferior } \\
\text { Diagonal } \\
\text { Montante }\end{array}$ & todas & Tipo "H" \\
\hline
\end{tabular}




\section{Trelica "Fink" com telha de Fibro-cimento}

\section{$\underline{\text { Geometria }}$}
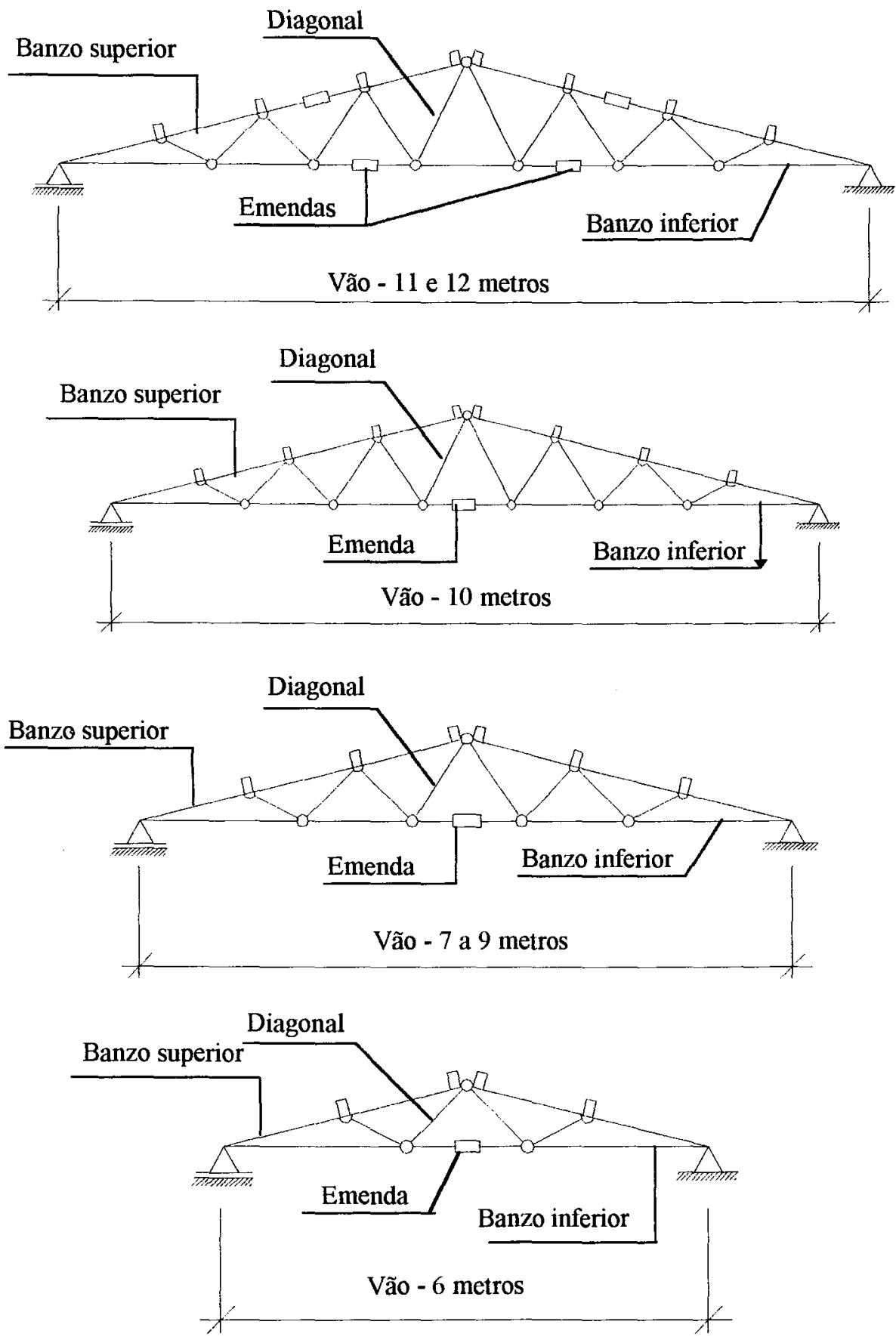

\begin{tabular}{|c|c|c|c|c|}
\hline Tipo de telha & $\begin{array}{c}\text { Vão teórico } \\
(\mathrm{m})\end{array}$ & Nomenclatura & Barras & $\begin{array}{c}\text { Seção transversal } \\
\left(\mathrm{cm}^{2}\right)\end{array}$ \\
\hline \multirow{2}{*}{ Fibro-cimento } & 6 a 12 & B. superior/ & todas & Tipo "I" \\
\cline { 3 - 5 } & $\begin{array}{c}\text { B. inferior } \\
\text { Diagonal }\end{array}$ & todas & Tipo "H" \\
\hline
\end{tabular}




\section{Trelica "Fink" com telha de Aco}

\section{Geometria}
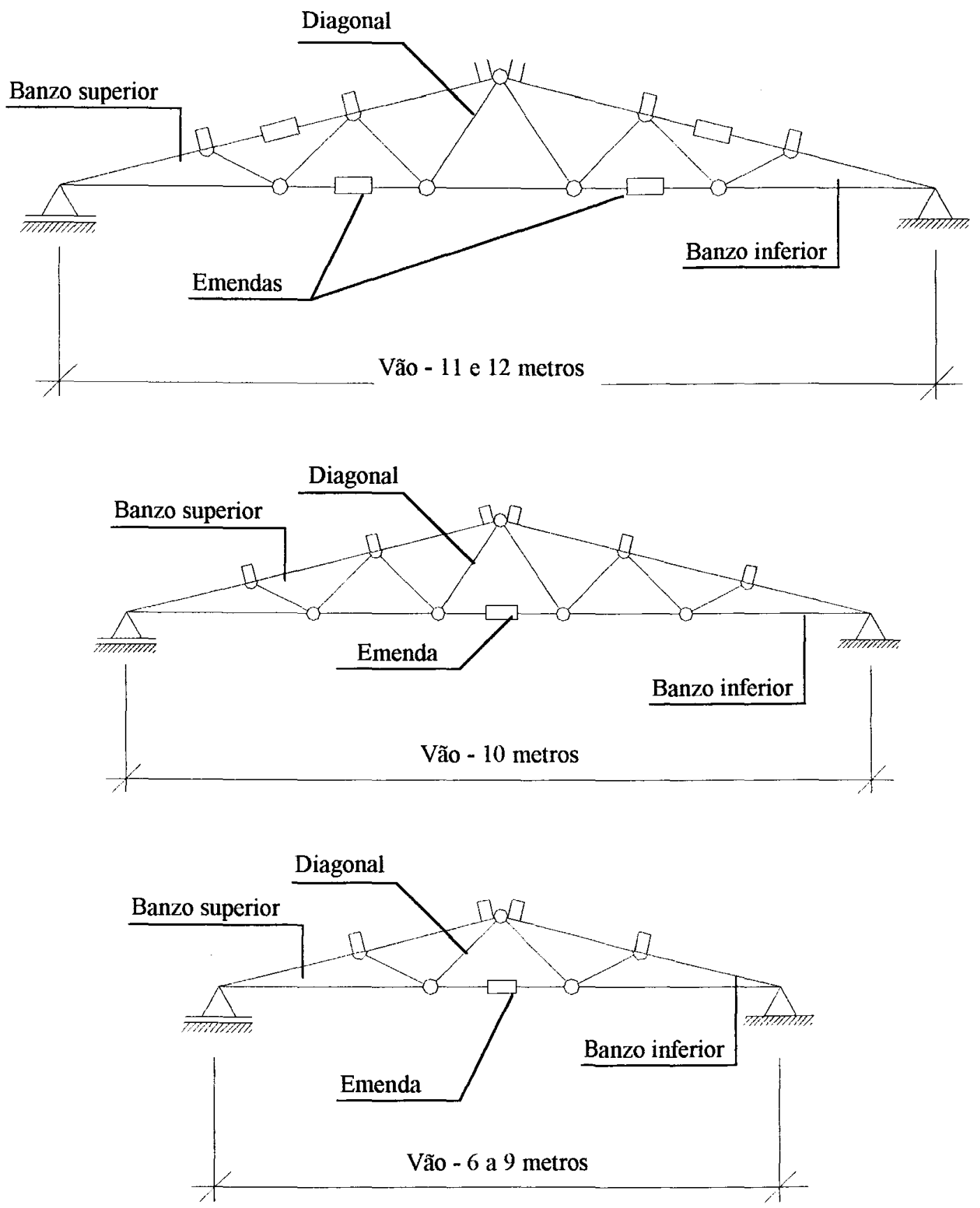

\begin{tabular}{|c|c|c|c|c|}
\hline Tipo de telha & $\begin{array}{l}\text { Vão teórico } \\
\text { (m) }\end{array}$ & Nomenclatura & Barras & $\begin{array}{c}\text { Seção transversal } \\
\left(\mathrm{cm}^{2}\right)\end{array}$ \\
\hline \multirow[b]{2}{*}{ Aço } & \multirow[b]{2}{*}{6 a 12} & B. superior/ & todas & Tipo "I" \\
\hline & & $\begin{array}{l}\text { B. inferior } \\
\text { Diagonal }\end{array}$ & todas & Tipo "H" \\
\hline
\end{tabular}


3) Método dos Estados Limites - Parafusos Passantes

\section{Seções Transversais}

Todas as dimensões estão em centímetros.
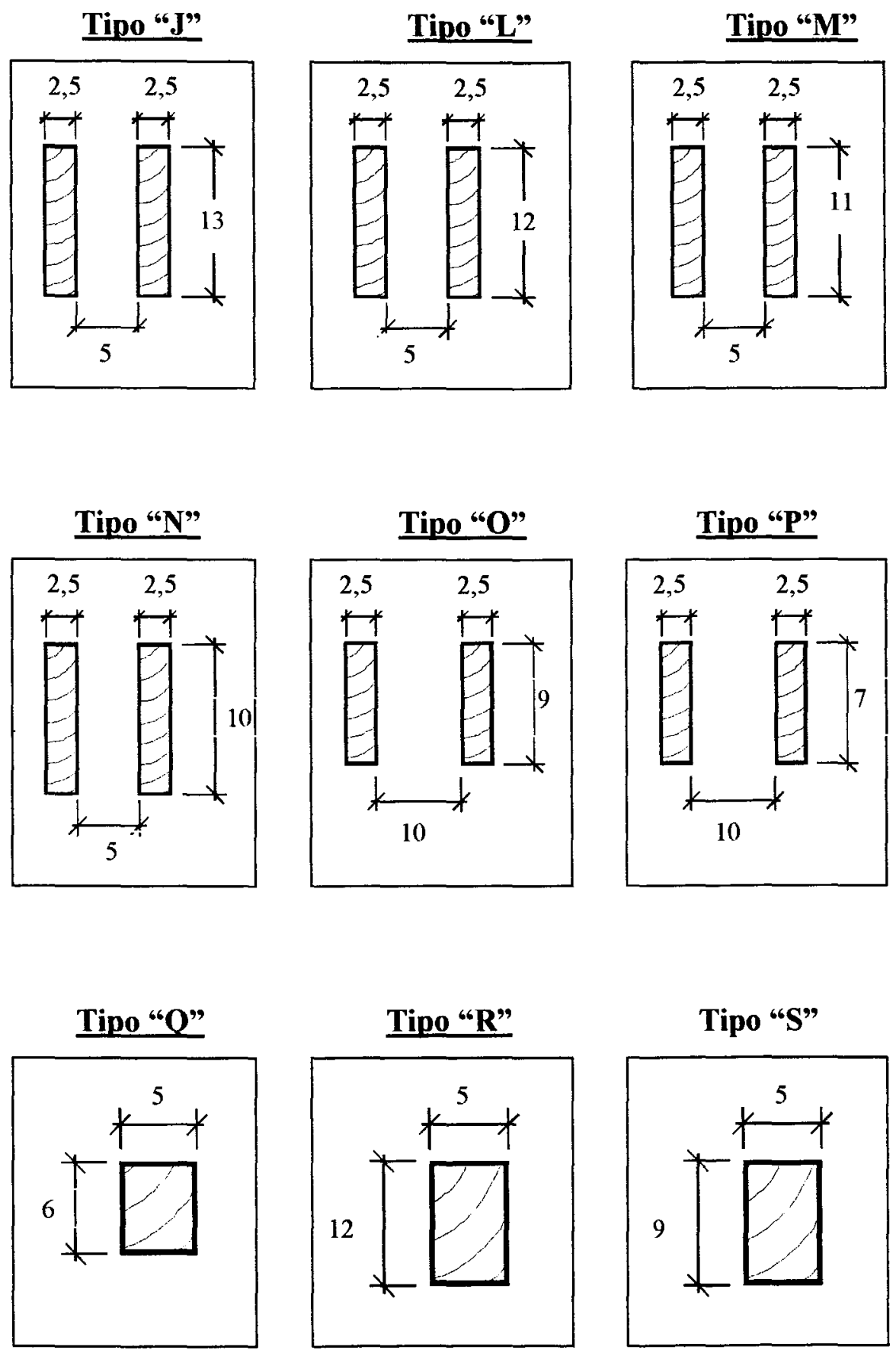


\section{Trelica "Howe" com telha de Fibro-cimento}

\section{Geometria}
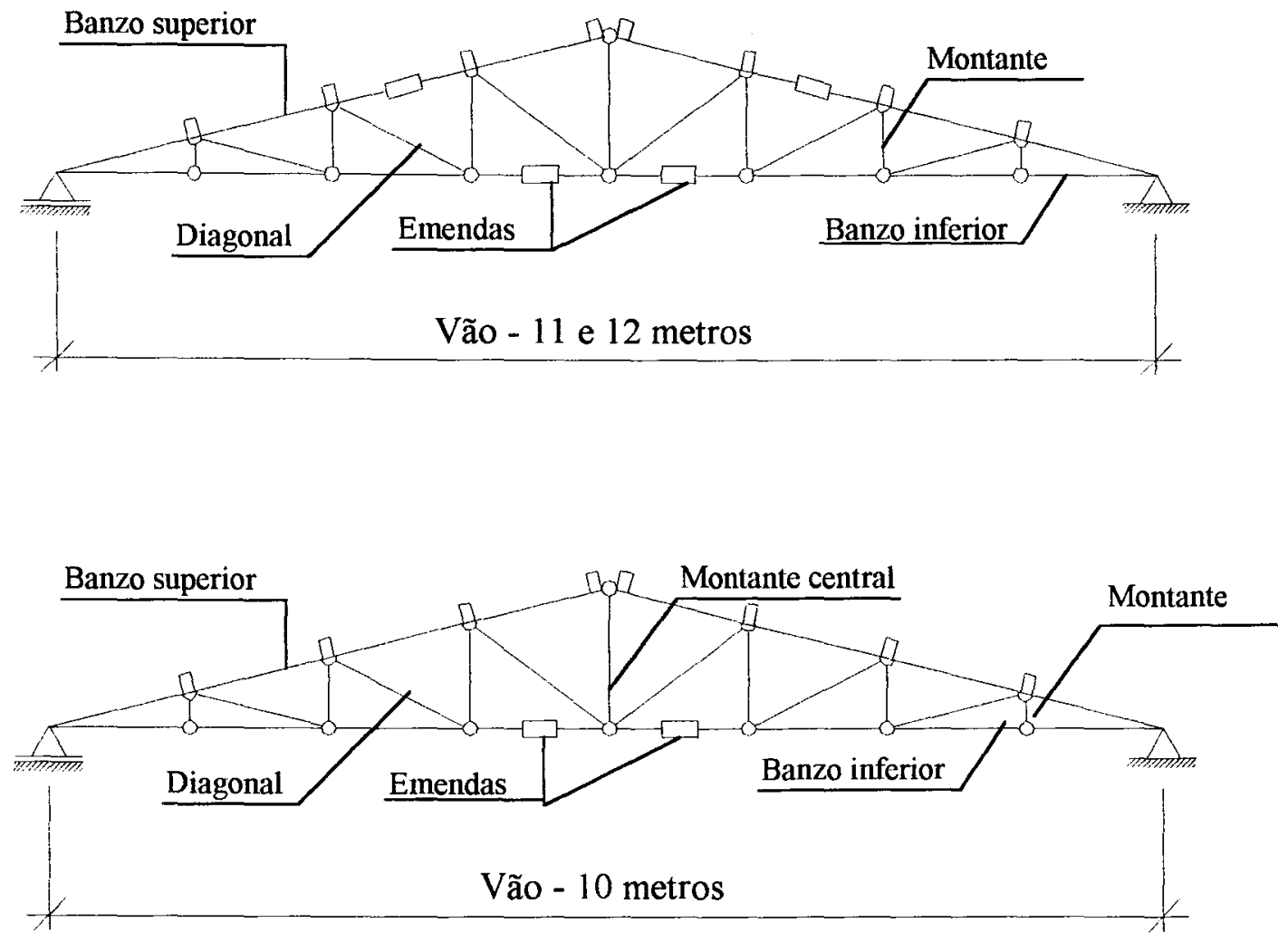

\begin{tabular}{|c|c|c|c|c|}
\hline Tipo de telha & $\begin{array}{c}\text { Vão teórico } \\
\text { (m) }\end{array}$ & Nomenclatura & Barras & $\begin{array}{c}\text { Seção transversal } \\
\left(\mathrm{cm}^{2}\right)\end{array}$ \\
\hline \multirow{5}{*}{ Fibro-cimento } & 10 e 11 & $\begin{array}{l}\text { B. superior e } \\
\text { B. inferior }\end{array}$ & \multirow{3}{*}{ todas } & Tipo "L" \\
\hline & 12 & $\begin{array}{l}\text { B. superior e } \\
\text { B. inferior }\end{array}$ & & Tipo "J" \\
\hline & \multirow{3}{*}{10 a 12} & Diagonal & & Tipo "O" \\
\hline & & Montante Central & $\ldots$ & Tipo "R" \\
\hline & & Demais montantes & --- & Tipo "Q" \\
\hline
\end{tabular}


$\underline{G e o m e t r i a}$

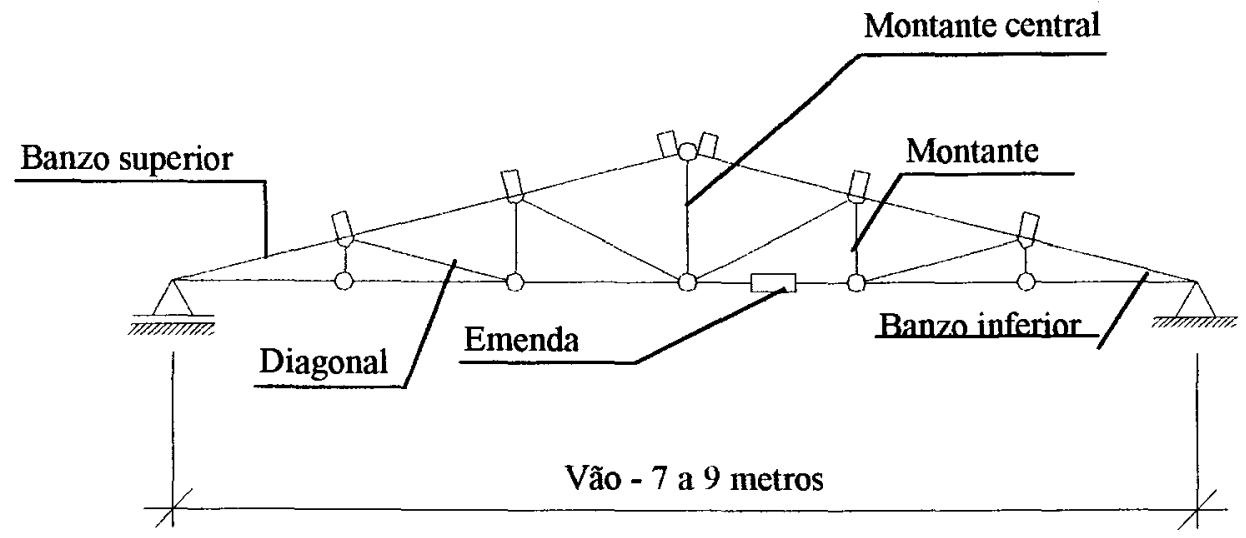

\begin{tabular}{|c|c|c|c|c|}
\hline Tipo de telha & $\begin{array}{l}\text { Vão teórico } \\
\text { (m) }\end{array}$ & Nomenclatura & Barras & $\begin{array}{c}\text { Seção transversal } \\
\left(\mathrm{cm}^{2}\right)\end{array}$ \\
\hline \multirow{5}{*}{ Fibro-cimento } & 7 & $\begin{array}{l}\text { B. superior e } \\
\text { B. inferior }\end{array}$ & \multirow{3}{*}{ todas } & Tipo "M" \\
\hline & 8 e 9 & $\begin{array}{l}\text { B. superior e } \\
\text { B. inferior }\end{array}$ & & Tipo "L" \\
\hline & \multirow{3}{*}{7 a 9} & Diagonal & & Tipo "P" \\
\hline & & Montante central & $-\cdots$ & Tipo "R" \\
\hline & & Demais montante & $-\cdots$ & Tipo "Q" \\
\hline
\end{tabular}

\section{Geometria}

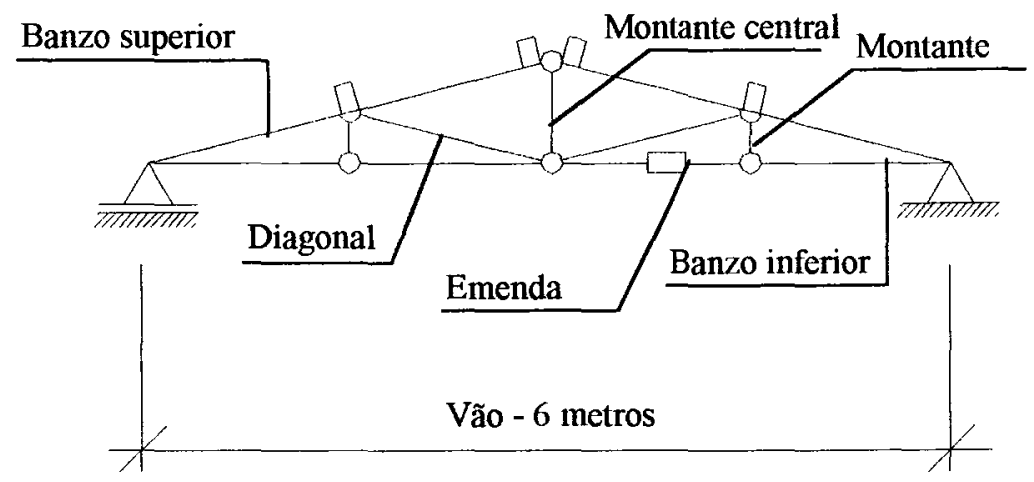

\begin{tabular}{|c|c|c|c|c|}
\hline Tipo de telha & $\begin{array}{c}\text { Vão teórico } \\
(\mathbf{m})\end{array}$ & Nomenclatura & Barras & $\begin{array}{c}\text { Seção transversal } \\
\left(\mathrm{cm}^{2}\right)\end{array}$ \\
\hline \multirow{2}{*}{ Fibro-cimento } & \multirow{2}{*}{6} & $\begin{array}{c}\text { B. superior } \mathrm{e} \\
\text { B. inferior }\end{array}$ & \multirow{3}{*}{ todas } & Tipo "N" \\
& & Diagonal & Tipo "P" \\
& & Montante & Tipo "Q" \\
\hline
\end{tabular}




\section{Trelica "Howe" com telha de Aco}

\section{Geometria}
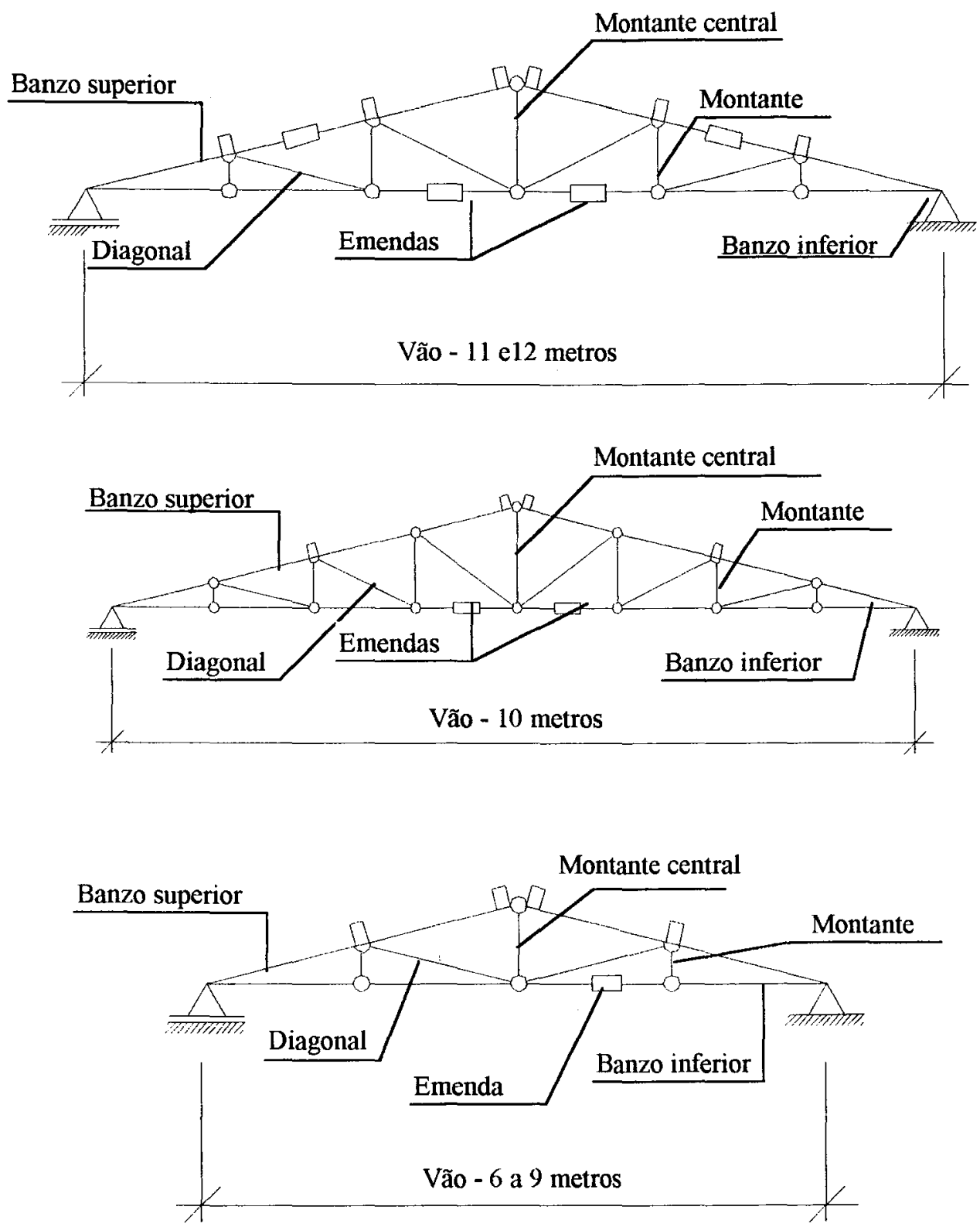

\begin{tabular}{|c|c|c|c|c|}
\hline Tipo de telha & $\begin{array}{c}\text { Vão teórico } \\
(\mathrm{m})\end{array}$ & Nomenclatura & Barras & $\begin{array}{c}\text { Seção transversal } \\
\left(\mathrm{cm}^{2}\right)\end{array}$ \\
\hline \multirow{4}{*}{ Aço } & $6 \mathrm{e} 7$ & $\begin{array}{c}\text { B. superior } \mathrm{e} \\
\text { B. inferior }\end{array}$ & \multirow{2}{*}{ todas } & Tipo "N" \\
\cline { 2 - 3 } & $\mathbf{8}$ a 12 & $\begin{array}{c}\text { B. superior e } \\
\text { B. inferior }\end{array}$ & & Tipo "L" \\
\cline { 2 - 5 } & \multirow{2}{*}{6 a 12} & Diagonal & todas & Tipo "O" \\
\cline { 2 - 5 } & Montante central & ---- & Tipo "S" \\
\cline { 2 - 5 } & Demais montante & ---- & Tipo "Q" \\
\hline
\end{tabular}




\section{Trelica "Fink" com telha de Fibro-cimento}

Geometria
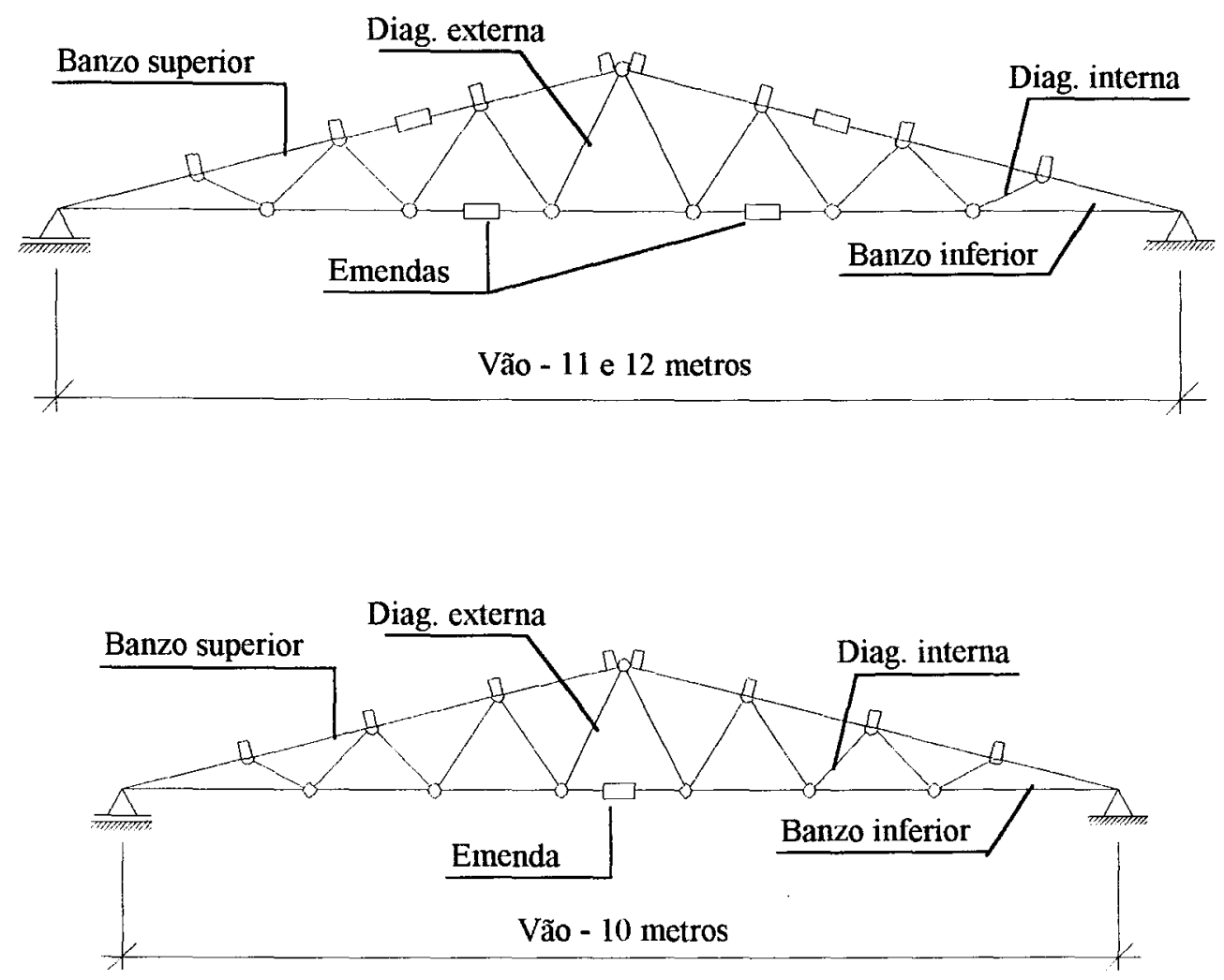

\begin{tabular}{|c|c|c|c|c|}
\hline Tipo de telha & $\begin{array}{c}\text { Vão teórico } \\
\text { (m) }\end{array}$ & Nomenclatura & Barras & $\begin{array}{c}\text { Seção transversal } \\
\left(\mathrm{cm}^{2}\right)\end{array}$ \\
\hline \multirow{4}{*}{ Fibro-cimento } & \multirow{2}{*}{$\begin{array}{c}10 \text { a } 11 \\
12\end{array}$} & $\begin{array}{l}\text { B. superior/ } \\
\text { B. inferior }\end{array}$ & \multirow{4}{*}{ todas } & Tipo "L" \\
\hline & & $\begin{array}{l}\text { B. superior/ } \\
\text { B. inferior }\end{array}$ & & Tipo "J" \\
\hline & \multirow[t]{2}{*}{10 a 12} & Diagonal externa & & Tipo "O" \\
\hline & & Diagonal interna & & Tipo "R" \\
\hline
\end{tabular}




\section{Geometria}

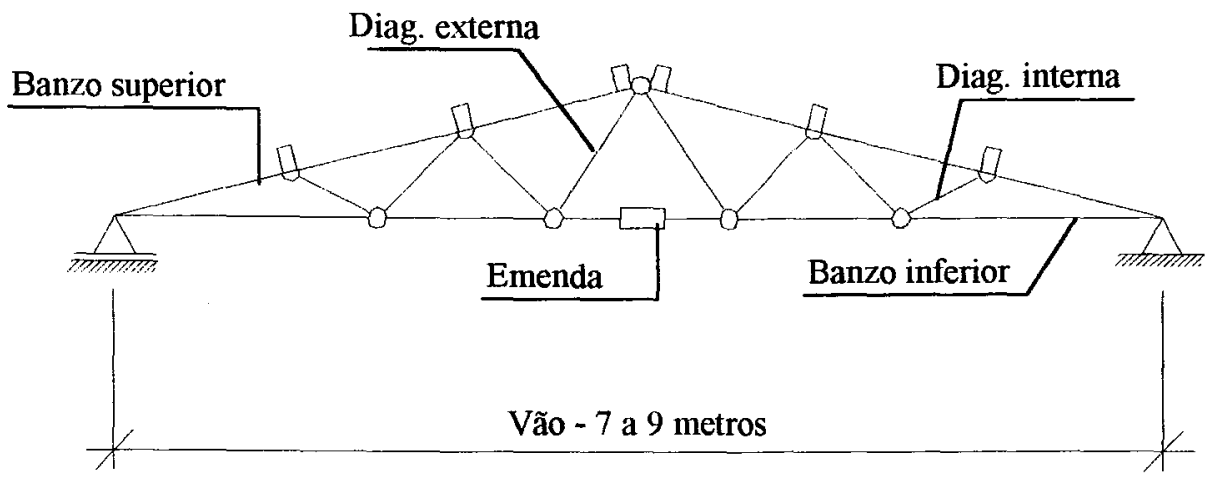

\begin{tabular}{|c|c|c|c|c|}
\hline Tipo de telha & $\begin{array}{l}\text { Vão teórico } \\
\text { (m) }\end{array}$ & Nomenclatura & Barras & $\begin{array}{c}\text { Seção transversal } \\
\left(\mathrm{cm}^{2}\right)\end{array}$ \\
\hline \multirow{4}{*}{ Fibro-cimento } & 7 & $\begin{array}{l}\text { B. superior e } \\
\text { B. inferior }\end{array}$ & \multirow{4}{*}{ todas } & Tipo "M" \\
\hline & 8 e 9 & $\begin{array}{l}\text { B. superior e } \\
\text { B. inferior }\end{array}$ & & Tipo “L” \\
\hline & \multirow[t]{2}{*}{7 a 9} & Diagonal externa & & Tipo "O" \\
\hline & & Diagonal interna & & Tipo "S" \\
\hline
\end{tabular}

\section{Geometria}

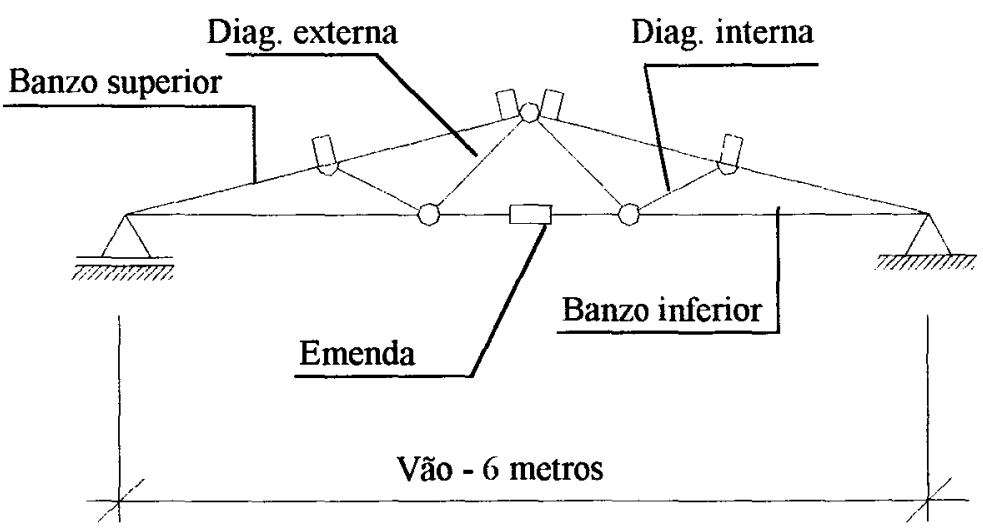

\begin{tabular}{|c|c|c|c|c|}
\hline \multirow{2}{*}{ Tipo de telha } & $\begin{array}{c}\text { Vão teórico } \\
(\mathbf{m})\end{array}$ & Nomenclatura & Barras & $\begin{array}{c}\text { Seção transversal } \\
\left(\mathrm{cm}^{2}\right)\end{array}$ \\
\hline \multirow{3}{*}{ Fibro-cimento } & \multirow{2}{*}{6} & $\begin{array}{c}\text { B. superior/ } \\
\text { B. inferior }\end{array}$ & \multirow{2}{*}{ todas } & Tipo "N \\
& & Diagonal externa & Tipo "O \\
& & Diagonal interna & Tipo "Q \\
\hline
\end{tabular}




\section{Trelica "Fink" com telha de Aco}

\section{Geometria}
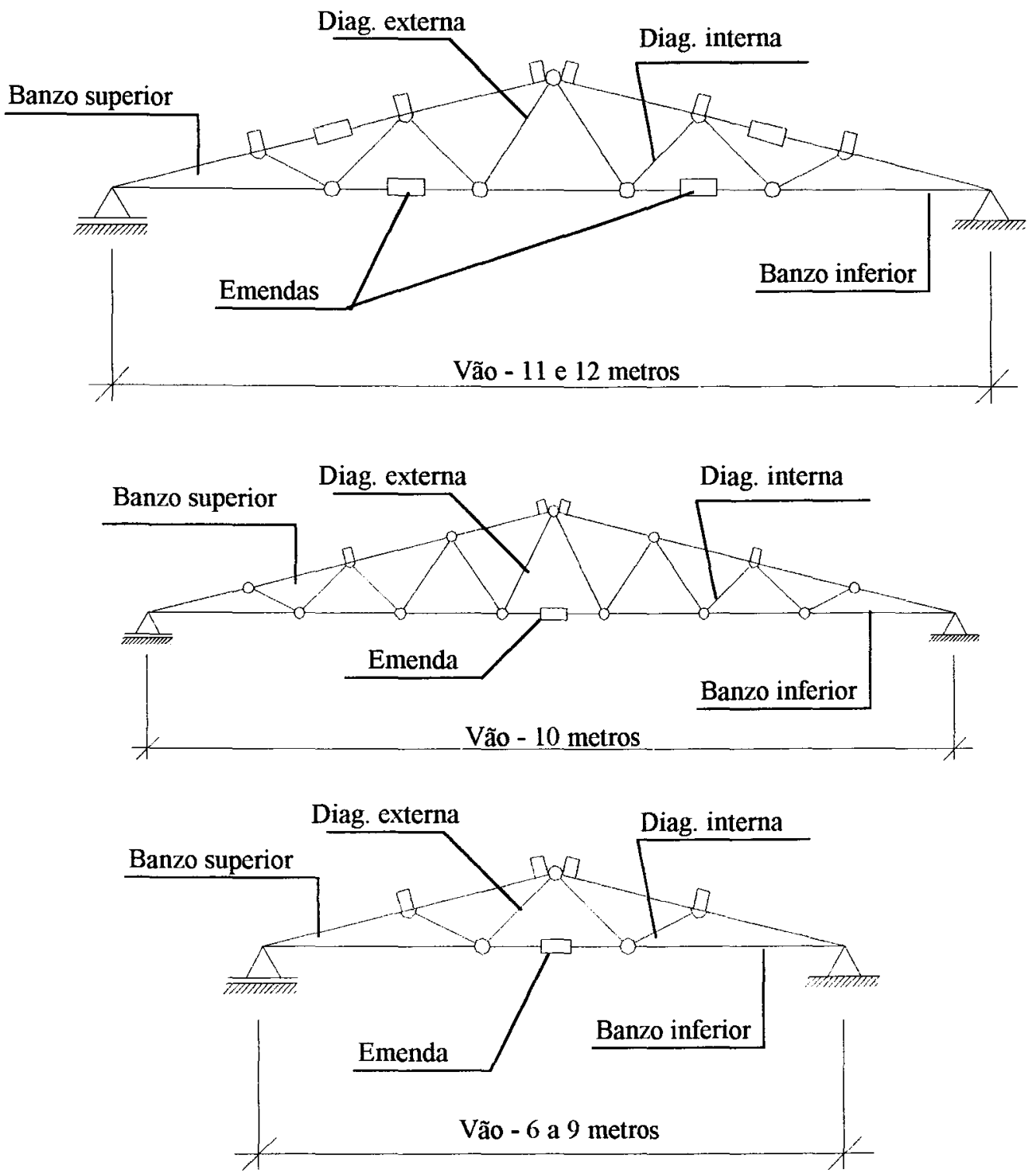

\begin{tabular}{|c|c|c|c|c|}
\hline Tipo de telha & $\begin{array}{c}\text { Vão teórico } \\
\text { (m) }\end{array}$ & Nomenclatura & Barras & $\begin{array}{c}\text { Seção transversal } \\
\left(\mathrm{cm}^{2}\right)\end{array}$ \\
\hline \multirow{6}{*}{ Aço } & \multirow{3}{*}{6 a 7} & $\begin{array}{l}\text { B. superior/ } \\
\text { B. inferior }\end{array}$ & \multirow{6}{*}{ todas } & Tipo "N" \\
\hline & & Diagonal externa & & Tipo "O" \\
\hline & & Diagonal interna & & Tipo "R" \\
\hline & \multirow{3}{*}{8 a 12} & $\begin{array}{l}\text { B. superior/ } \\
\text { B. inferior }\end{array}$ & & Tipo "L" \\
\hline & & Diagonal externa & & Tipo "P" \\
\hline & & Diagonal interna & & Tipo "S" \\
\hline
\end{tabular}




\section{REFERÊNCIAS BIBLIOGRÁFICAS}

AGUILLAR $\mathrm{F}^{\mathrm{O}}$, D. Combustibilidade e tratamento ignífugo da madeira. São Carlos, 1986. 99p. Dissertação (Mestrado) - Escola de Engenharia de São Carlos, Universidade de São Paulo.

ARRUDA VEIGA, A. Cultura de Pinus. São Paulo, Instituto Florestal, 1981. (Atualização do texto do Boletim Técnico nº 5).

ASSOCIAÇÃO BRASILEIRA DE NORMAS TÉCNICAS. (1982). NBR - 7190 Cálculo e execução de estruturas de madeira. Rio de Janeiro.

(1982).NBR 6120 -Cargas para o cálculo de estruturas de edificações.

Rio de Janeiro.

(1984). NBR 8681 - Ações e segurança nas estruturas. Rio de Janeiro.

(1986). NBR 8800 - Projeto e execução de estruturas de aço de edificios.

Rio de Janeiro.

(1988).NBR 6123 -Forças devidas ao vento em edificações. Rio de Janeiro.

(1996). PNBR 7190 - Projetos de estruturas de madeira. Rio de Janeiro.

BARROS Jr., O.; HELLMEISTER, J. C. Industrialização de estruturas de madeira para cobertura In: ENCONTRO BRASILEIRO DE MADEIRA E ESTRUTURAS DE MADEIRA, 3., São Carlos, 1989. Anais. São Carlos, Escola de Engenharia de São Carlos, Universidade de São Paulo, 1989. v.4, p.131-146. 
BENEVENTE, V. A. Durabilidade em construções de madeira - uma questão de projeto. São Carlos, 1995. 231p. Dissertação (Mestrado) - Escola de Engenharia de São Carlos, Universidade de São Paulo.

BERTOLANI, F. - As experiências com Pinus no Brasil. In: ENCONTRO NACIONAL DE REFLORESTADORES, 4., Campo Grande, 1978. Anais. São Paulo, UNIPRESS, 1978. p. 33-36.

BORTOLETTO Jr., G. Indicações para utilização da madeira de seis espécies e variedades de Pinus aplicada na construção civil. São Carlos, 1993. 119p. Dissertação (Mestrado) - Escola de Engenharia de São Carlos, Universidade de São Paulo.

BROCHARD, F. X. Bois et charpente en bois. Paris, Éditions Eyrolles, 1960.

CARPANEZZI, A. A. et al. Zoneamento ecológico para plantios florestais no Estado do Paraná. Brasília, EMBRAPA-DDT, 1986.

CAVAlCANTE, M. S. Deterioração biológica e preservação de madeiras. São Paulo, IPT, 1982. (Pesquisa \& Desenvolvimento).

FURIATI, M. - Engevix S.A. - Classificação estrutural de peças de madeira. In: ENCONTRO BRASILEIRO DE MADEIRA E ESTRUTURAS DE MADEIRA, 1., São Carlos, 1983. Anais. São Carlos, Escola de Engenharia de São Carlos, Universidade de São Paulo, 1983. Características, p.1-30.

FUSCO, P. B. Os caminhos da evolução da engenharia das madeiras. In: ENCONTRO BRASILEIRO DE MADEIRA E ESTRUTURAS DE MADEIRA, 3., São Carlos, 1989. Anais. São Carlos, Escola de Engenharia de São Carlos, Universidade de São Paulo, 1989. v.6, p.7-18. 
GALVÃO, A. P. M. - Processos práticos para preservar a madeira. Piracicaba, Escola Superior de Agricultura Luís de Queiróz, 1976.

GOLFARI, L. et al. Zoneamento ecológico esquemático para o reflorestamento no Brasil. Brasília, Ministério da Agricultura/PRODEPEF-PNDU/FAO/IBDF-45, 1978. (Série Técnica $n^{0} 11$ ).

INFORMATIVO QUADRIMESTRAL SOBRE O SETOR FLORESTAL PAULISTA. Florestar Estatístico, São Paulo, v.2, nº 6, nov-94/ fev.-95.

INSTITUTO DE PESQUISAS TECNOLÓGICAS DO ESTADO DE SÃO PAULO IPT. Madeiras nacionais - tabelas de resultados de ensaios físicos e mecânicos. São Paulo, IPT, 1956. (Boletim Técnico, nº 31).

JUNTA DEL ACUERDO DE CARTAGENA - JUNAC. Manual del grupo andino para la preservacion de maderas. Lima, PADT-REPORT-JUNAC, 1988.

KARLSEN, G. G. Wooden structures. Moscou, Mir Publishers, 1967.

LELIS, A. T. Cupins - prevenção e irradicação / Preservação de Madeiras. São Paulo, ABPM. p.51-58, 1975/76.

LEPAGE, E. S. et al. Manual de preservação de madeiras. v.1. São Paulo, IPT, 1986.

MOLITERNO, A. - Caderno de projetos de telhados em estruturas de madeira. São Paulo, Edgard Blücher Ltda, 1981.

MONTANA QUÍMICA S. A. Biodeterioração e preservação de madeiras. São Paulo, Montana Química S. A., 1991. 
MOREY, P. R. O crescimento das árvores. São Paulo, EPU/EDUSP, 1981.

PINHEIRO, R. V; ROCCO LAHR, F. A. Emprego de espécies de madeiras alternativas em estruturas de cobertura para construções rurais. In: II CONGRESO INTERNACIONAL/IV CONGRESO ARGENTINO DE INGENIERÍA RURAL, 4., Neuquem/Argentina, 1996. Anais. Neuquem/Argentina, Facultad de Ciencias Agrarias, Universidad Nacional del Camahue, 1996, (impress).

PINHEIRO, R. V et al. Espécies de madeiras alternativas para a construção de estruturas de cobertura. In: XXVI JORNADAS SUDAMERICANAS DE INGENIERÍA ESTRUCTURAL, 4., Montevideo/Uruguai, 1993. Anais. Montevideo/Uruguai, Facultad de Ingeniería, Instituto de Estructuras y Transporte, 1993. v.5,p. 313-84.

PONCE, E. S.; WATAI, L. T. Manual de secagem de madeiras. Brasília, STI/IPT, 1985.

RAIMBAULT, G.; CARLOS, V. J. - MONTANA QUÍMICA S.A. A preservação de madeira aplicada às estruturas. In: ENCONTRO BRASILEIRO DE MADEIRA E ESTRUTURAS DE MADEIRA, 1., São Carlos, 1983. Anais. São Carlos, Escola de Engenharia de São Carlos, Universidade de São Paulo, 1983. Tópicos Especiais, p.1-47.

ROCCO LAHR, F. A.; BARROS, O. Jr. Propriedades estruturais de três espécies alternativas de madeira - parte 1 In: ENCONTRO BRASILEIRO DE MADEIRA E ESTRUTURAS DE MADEIRA, 4., São Carlos, 1992. Anais. São Carlos, Escola de Engenharia de São Carlos, Universidade de São Paulo, 1992. v.5, p. $79-84$. 
ROCCO LAHR, F. A. Aspectos históricos do emprego das estruturas de madeira para coberturas. In: ENCONTRO BRASILEIRO DE MADEIRA E ESTRUTURAS DE MADEIRA, 1., São Carlos, 1983. Anais. São Carlos, Escola de Engenharia de São Carlos, Universidade de São Paulo, 1983. Telhados p.1-13.

TIMBER RESEARCH AND DEVELOPEMENT ASSOCIATION - TRADA. Timber - their properties and uses. London, TRADA, 1991. (Wood Information, Section 2/3 Sheet 10).

TOMAZELLO F $\mathrm{F}^{\mathrm{O}}$, M. - Formação e anatomia da madeira - exercícios práticos . Piracicaba, Escola Superior de Agricultura "Luiz de Queiróz", 1996.

UNIVERSIDADE DE SÃO PAULO.Escola de Engenharia de São Carlos (1993). Diretrizes para elaboração de dissertações e teses. São Carlos.

UJVARI, W. Z. Ligações em madeira, feitas com conectores dentados "Gang-Nail". In: ENCONTRO BRASILEIRO DE MADEIRA E ESTRUTURAS DE MADEIRA, 1., São Carlos, 1983. Anais. São Carlos, Escola de Engenharia de São Carlos, Universidade de São Paulo, 1983. Ligações p.01-25. 


\section{OBRAS CONSULTADAS}

ALBERTO, M. M. M.; TOMASELLI, I. - Efeito da temperatura de secagem na estabilidade dimensional da madeira de Pinus para uso externo. In: ENCONTRO BRASILEIRO DE MADEIRA E ESTRUTURAS DE MADEIRA, 4, São Carlos, 1992. Anais. São Carlos, Escola de Engenharia de São Carlos, Universidade de São Paulo, 1992. v.1, p.19-26.

ALMEIDA, P. A. O.; FUSCO, P. B. Dimensionamento das uniões pregadas e parafusadas baseado no método dos estados limites. In: ENCONTRO BRASILEIRO DE MADEIRA E ESTRUTURAS DE MADEIRA, 4., São Carlos, 1992,. Anais. São Carlos, Escola de Engenharia de São Carlos, Universidade de São Paulo, 1992. v.2, p.79-88.

ARANTES, E. M.; CHAHUD, E. Deformações normais e deslocamentos na flexão em vigas de madeira maciça pregada de seção "T". In: ENCONTRO REGIONAL DE MADEIRA E ESTRUTURAS DE MADEIRA, 1., São Paulo, 1993. Anais. São Paulo, Escola Politécnica, Universidade de São Paulo, 1993. v.2, p.9-20.

ASSOCIAÇÃO BRASILEIRA DE PRODUTORES DE MADEIRAS.. (1990) TB 397 - Madeira serrada de coniferas provenientes de reflorestamento, para uso geral - Terminilogia. São Paulo. 
(1990) NB 1381 - Madeira serrada de coniferas provenientes de reflorestamento, para uso geral - Medição e quantificação de defeitos. São Paulo.

(1990) PB 1560 - Madeira serrada de coniferas provenientes de reflorestamento, para uso geral - Dimensões e lotes. São Paulo.

(1990) CB 205 - Madeira serrada de coniferas provenientes de reflorestamento, para uso geral - Classificação. São Paulo.

(1990) EB 2169 - Madeira serrada de coniferas provenientes de reflorestamento, para uso geral - Especificação e recebimento. São Paulo.

BASTOS, J. L. - ETERNIT S.A. Ancoragem das coberturas. In: ENCONTRO BRASILEIRO DE MADEIRA E ESTRUTURAS DE MADEIRA, 2., São Carlos, 1986. Anais. São Carlos, Escola de Engenharia de São Carlos, Universidade de São Paulo, 1986. Telhados, p.53-76.

BREYER, D. E. Design of wood structures. Califórnia - U.S.A., Ed. McGraw-Hill, 1980.

CALIL Jr., C. Treliças de madeira para cobertura. São Carlos, Escola de Engenharia de São Carlos, 1994.

CORDOVIL, F. A. B. Projeto de cobertura com arco de madeira. In: ENCONTRO BRASILEIRO DE MADEIRA E ESTRUTURAS DE MADEIRA, 4., São Carlos, 1992. Anais. São Carlos, Escola de Engenharia de São Carlos, Universidade de São Paulo, 1992. v.3, p.33-44.

CORDOVIL, F. A. B.; LORIGGIO, D. D. Recuperação de uma estrutura de madeira. In: ENCONTRO BRASILEIRO DE MADEIRA E ESTRUTURAS DE MADEIRA, 4., São Carlos, 1992. Anais. São Carlos, Escola de Engenharia de São Carlos, Universidade de São Paulo, 1992. v.3, p.201-210. 
FUSCO, P. B. O estabelecimento de valores de cálculo para dimensionamento das estruturas de madeira pelo método dos estados limites. In: ENCONTRO BRASILEIRO DE MADEIRA E ESTRUTURAS DE MADEIRA, 4., São Carlos, 1992. Anais. São Carlos, Escola de Engenharia de São Carlos, Universidade de São Paulo, 1992. v.2, p.139-152.

GONÇALVES, R. M. et al. Ação do vento nas edificações. São Carlos, Escola de Engenharia de São Carlos, 1994.

HELLMEISTER, J. C. Madeiras e suas características. In: ENCONTRO BRASILEIRO DE MADEIRA E ESTRUTURAS DE MADEIRA, 1., São Carlos, 1983. Anais. São Carlos, Escola de Engenharia de São Carlos, Universidade de São Paulo, 1983. Características, p.1-37.

Sobre a determinação das características físicas da madeira. São Carlos, 1973. 119p. Tese (Doutorado) - Escola de Engenharia de São Carlos, Universidade de São Paulo

INSTITUTO DE PESQUISAS TECNOLÓGICAS DO ESTADO DE SÃO PAULO IPT. Cobertura com estrutura de madeira e telhados com telhas cerâmicas Material de Execução. São Paulo, IPT, 1988.

JESUS, L. L. H. Preservação da madeira de Pinus spp para a construção civil. São Carlos, 1987. 99p. Dissertação (Mestrado) - Escola de Engenharia de São Carlos, Universidade de São Paulo.

LISBOA, Carlos Roberto. Ligação de peças estruturais de madeira por parafusos. São Carlos, 1991. 106p. Dissertação (Mestrado) - Escola de Engenharia de São Carlos, Universidade de São Paulo. 
MALITE, M. et al. - Sistemas estruturais: elementos estruutrais. São Carlos, Escola de Engenharia de São Carlos, 1994.

MOLITERNO, A. - Estruturas de madeira para edificações. São Carlos, Escola de Engenharia de São Carlos, 1990.

MOODY, R. ; RITTER, M. - Structural wood products. In: SERVICEABILITY AND DURABILITY OF CONSTRUCTION MATERIALS - PROCEEDINGS OF THE FIRST MATERIALS ENGINEERING CONGRESS / PART 1, Denver - USA, 1990. Publ. by ASCE, Boston Society of Civil Engineers Sect., Boston MA, USA, 1990, p.41-52

OLIVEIRA, A. C.; BENEVENTE, V. A.; GALINDO, JAIME. Como se garante a durabilidade em uma construção de madeira através de disposições construtivas. In: ENCONTRO BRASILEIRO DE MADEIRA E ESTRUTURAS DE MADEIRA, 4., São Carlos, 1992. Anais. São Carlos, Escola de Engenharia de São Carlos, Universidade de São Paulo, 1992. v.3, p.189-200.

PARKER, H. . Diseño simplificado de estruturas de madeira. Limusa - Wiley México, 1972.

PASSOS, M. E. M. Vigas de seção composta "T", tendo o parafuso como elemento de solidarização. In: ENCONTRO BRASILEIRO DE MADEIRA E ESTRUTURAS DE MADEIRA, 4., São Carlos, 1992. Anais. São Carlos, Escola de Engenharia de São Carlos, Universidade de São Paulo, 1992. v.4, p.15-30.

PINHEIRO, R. V.; BARROS, O. Jr. ; LAHR, F. A. R. Arco treliçados com banzos paralelos em madeira de espécies alternativas. In: ENCONTRO REGIONAL DE MADEIRA E ESTRUTURAS DE MADEIRA, 1., São Paulo, 1993. Anais. São Paulo, Escola Politécnica, Universidade de São Paulo, 1993. v.1 p.25-26. 
Emprego da madeira de Pinus na construção de estruturas de coberturas.

In: ENCONTRO BRASILEIRO DE MADEIRA E ESTRUTURAS DE MADEIRA, 4., São Carlos, 1992. Anais. São Carlos, Escola de Engenharia de São Carlos, Universidade de São Paulo, 1992. v.3, p.229-234.

PLETS, E. O ensino de estruturas de madeira no curso de engenharia civil . In: ENCONTRO BRASILEIRO DE MADEIRA E ESTRUTURAS DE MADEIRA, 4., São Carlos, 1992. Anais. São Carlos, Escola de Engenharia de São Carlos, Universidade de São Paulo, 1992. v.1, p.207-214.

PLETS, E; CÉSAR, S. F. Recomendações para estruturas de madeira In: ENCONTRO BRASILEIRO DE MADEIRA E ESTRUTURAS DE MADEIRA, 2., São Carlos, 1986. Anais. São Carlos, Escola de Engenharia de São Carlos, Universidade de São Paulo, 1986. Telhados, p.33-52.

ROCCO LAHR, F. A; BARROS, O. Jr. Considerações sobre a utilização de madeiras na construção de estruturas de cobertura para conjuntos habitacionais. In: ENCONTRO BRASILEIRO DE MADEIRA E ESTRUTURAS DE MADEIRA, 4., São Carlos, 1992. Anais. São Carlos, Escola de Engenharia de São Carlos, Universidade de São Paulo, 1992. v.5, p.79-84.

ROCCO LAHR, F. A.; CALIL, C. Jr. EUROCODE $\mathrm{n}^{\circ}$ 5: algumas considerações. In: ENCONTRO BRASILEIRO DE MADEIRA E ESTRUTURAS DE MADEIRA, 3., São Carlos, 1989. Anais. São Carlos, Escola de Engenharia de São Carlos, Universidade de São Paulo, 1989. v.6, p.19-38.

ROCCO LAHR, F. A; HELLMEISTER, J. C. Projetos de tesouras de madeira. São Carlos, Escola de Engenharia de São Carlos, 1976. 
ROCCO LAHR, F. A. Propriedades físicas, de resistência e de elasticidade de espécies de madeira para emprego em estruturas. In: ENCONTRO BRASILEIRO DE MADEIRA E ESTRUTURAS DE MADEIRA, 3., São Carlos, 1989. Anais. São Carlos, Escola de Engenharia de São Carlos, Universidade de São Paulo, 1989. v.3, p.59-70.

Dimensionamento de peças de madeira à flexão estática. In: ENCONTRO BRASILEIRO DE MADEIRA E ESTRUTURAS DE MADEIRA, 2., São Carlos, 1986. Anais. São Carlos, Escola de Engenharia de São Carlos, Universidade de São Paulo, 1986. Dimensionamento, p.53-70.

.Estudos experimental de vigas de seção composta solidarizadas por pregos. In: ENCONTRO BRASILEIRO DE MADEIRA E ESTRUTURAS DE MADEIRA, 2., São Carlos, 1986. Anais. São Carlos, Escola de Engenharia de São Carlos, Universidade de São Paulo, 1986. Dimensionamento, p.72-96.

Arco treliçado de madeira - projeto e experimentação. In: ENCONTRO BRASILEIRO DE MADEIRA E ESTRUTURAS DE MADEIRA, 1., São Carlos, 1983. Anais. São Carlos, Escola de Engenharia de São Carlos, Universidade de São Paulo, 1983. Telhados p.65-78. Arco treliçado de madeira. São Carlos, 1978. 111p. Dissertação (Mestrado) - Escola de Engenharia de São Carlos, Universidade de São Paulo.

SALES, J .J et al. - Cobertura em arco metálico treliçado - exemplo de cálculo . São Carlos, Escola de Engenharia de São Carlos, 1994.

STAMATO, M. C. Deslocamento em estruturas lineares. São Carlos, Escola de Engenharia de São Carlos, 1970. 
SZUCS, C. P. Usando o Pinus: uma questão de desenho. In: ENCONTRO BRASILEIRO DE MADEIRA E ESTRUTURAS DE MADEIRA, 4., São Carlos, 1992. Anais. São Carlos, Escola de Engenharia de São Carlos, Universidade de São Paulo, 1992. v.2, p.177-186.

TIMOSHENKO, S. ; GERE, J. M. Theory of elastic stability. Tókio, $2^{\text {a. }}$ Edição, Ed. MacGraw-Hill Kogakusha Ltda, 1961.

TIMOSHENKO, S. Resistência dos materiais. Rio de Janeiro, $3^{\text {a. }}$ Edição, Ed. Ao Livro Técnico S.A., 1967.

VALENTIN, J. - ETERNIT S.A. - OSASCO S.P. Ação dos ventos nas edificações. In: ENCONTRO BRASILEIRO DE MADEIRA E ESTRUTURAS DE MADEIRA, 2., São Carlos, 1986. Anais. São Carlos, Escola de Engenharia de São Carlos, Universidade de São Paulo, 1986. Tópicos Especiais “B”, p.84-113. 